\title{
Evaluating Rainwater Harvesting Systems in Arid and Semi-Arid Regions
}




\section{Thesis committee}

\section{Promotor}

Prof. Dr C. J. Ritsema

Professor of Soil Physics and Land Management

Wageningen University \& Research

\section{Co-promotors}

Dr M.J.P.M. Riksen

Assistant professor, Soil Physics and Land Management Group

Wageningen University \& Research

Dr M. Ouessar

Associate professor

Institut des Régions Arides (IRA), Tunisia

\section{Other members}

Prof. Dr P. Hellegers, Wageningen University \& Research

Prof. Dr W. Cornelis, Ghent University, Belgium

Dr F. van Steenbergen, MetaMeta, the Netherlands

Dr S. Verzandvoort, Wageningen University \& Research

This research was conducted under the auspices of the Research School PE\&RC 


\title{
Evaluating Rainwater Harvesting Systems in Arid and Semi-Arid Regions
}

\author{
Ammar Adham Ali
}

Thesis

submitted in fulfilment of the requirements for the degree of doctor

at Wageningen University

by the authority of the Rector Magnificus,

Prof. Dr A.P.J. Mol,

in the presence of the

Thesis Committee appointed by the Academic Board

to be defended in public

on Monday 26 June 2017

at 11 a.m. in the Aula. 
Ammar Adham Ali

Evaluating Rainwater Harvesting Systems in Arid and Semi-Arid Regions, 207 pages.

PhD thesis, Wageningen University, Wageningen, the Netherlands (2017) With references, with summaries in English, Dutch and Arabic

ISBN: 978-94-6343-146-0

DOI http://dx.doi.org/10.18174/410534 


\section{Table of contents}

Chapter 1. General introduction ............................................................................ 7

Chapter 2. Identification of Suitable Sites for Rainwater Harvesting Structures in Arid and Semi-Arid Regions: A Review

Chapter 3. A GIS-Based Approach for Identifying Potential Sites for Harvesting Rainwater in the Western Desert of Iraq.

Chapter 4. A Methodology to Assess and Evaluate Rainwater Harvesting Techniques in (Semi-) Arid Regions

Chapter 5. A Microsoft Excel Application to Simulate and Optimise Water Harvesting in a Catchment.

Chapter 6. A Water Harvesting Model for Optimising Rainwater Harvesting in the Wadi Oum Zessar Watershed, Tunisia..... 109

Chapter 7. Assessing the Impact of Climate Change on Rainwater Harvesting in the Oum Zessar Watershed in Southeastern Tunisia.

Chapter 8. Synthesis 151

References. 167

English summary. 183

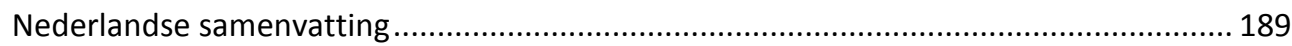

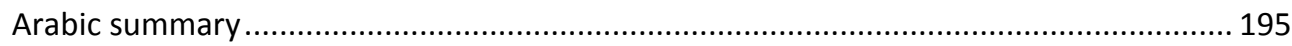

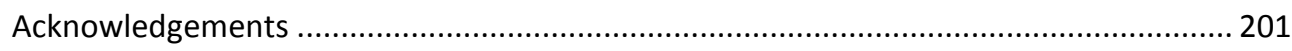

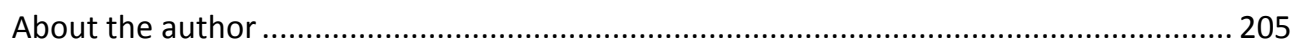





\section{General introduction}




\subsection{Background}

The earth's population has grown from about 2.5 billion in 1950 to 7.35 billion in 2015 (United Nations, 2015). Water is essential for human life, so the need for fresh water has also increased. About $10 \%$ of the global freshwater supplies are used for health and sanitation, whereas 70 and $20 \%$ are used for agriculture and industry, respectively (Machiwal and Jha, 2012). Arid and semi-arid regions (ASARs) cover $\geq 50$ million $\mathrm{km}^{2}$, representing $40 \%$ of the earth's land surface (Mekdaschi Studer and Liniger, 2013). ASARs are areas where the amount, distribution and/or unpredictability of rainfall is a problem (Hudson, 1987; Ibraimo, 2011). Arid regions receive about 150-350 mm of rain per year (Ouessar, 2007) and rainfall in semi-arid regions is also low, varying from 350 to 700 $\mathrm{mm} \mathrm{y}^{-1}$ (Oweis et al., 1998). The majority of the population in ASARs depends on rainfed agriculture and pastoralism for subsistence.

Increasing population, higher levels of human activities, continuous depletion of fresh surface and groundwater and climate change require that water resources be adequately managed for satisfying the current demands and to attain future sustainability, especially in ASARs (Mohammed, 2009). Using the limited amount of available rainfall as efficiently as possible is therefore very important. A large proportion of rainwater is often lost in peak flows to runoff to the outlets of catchments. Rainwater harvesting (RWH) is an important way to use this runoff. RWH is broadly defined as the collection and concentration of runoff for domestic water supply, productive purposes and livestock (Fentaw et al., 2002; Gould, 1999; Stott et al., 2001). Inhabitants of ASARs have endeavoured to increase water availability for domestic use, crop production and livestock grazing using a variety of traditional RWH techniques, but methods to quantitatively determine RWH efficiency and replacement strategies are lacking. Moreover, little is known about the degrees of their impacts on hydrological processes and their efficiencies in storing and conserving water. How these rainwater harvesting techniques and structures will perform under a changed climatological regime and whether the redesign of such structures will be required to adapt to future conditions, are also unknown. In the next sections, the developmental history of RWH, definitions and classifications of RWH and RWH in ASARs are discussed. Thenafter, a brief overview of hydrological models which are used for the evaluation of RWH systems is given. Finaly the RWH relevant climate change characteristics are presented.

\subsubsection{Historical development of RWH}

Humanity has struggled throughout history to survive in ASARs. Ancient evidence indicates that we have long devised ways and means of harvesting rainwater for purposes such as 
agricultural crops, livestock and human use (Prinz et al., 1998). RWH is an ancient traditional system that has been used for millennia in most drylands around the world. Many RWH techniques have been developed throughout history in several countries around the world, including Jordan, Palestine, Syria, Tunisia and Iraq (Al-Adamat, 2008). The earliest RWH structures are believed to have been constructed over 9000 years ago in the Edom Mountains in southern Jordan to supply drinking water for people and animals (Boers and Ben-Asher, 1982). Iraqis have built and practiced a simple form of water harvesting for domestic and agricultural use for over 6500 years (Oweis et al., 2012). Water harvesting was also used in India and China $\geq 4000$ years ago (Prinz, 1996). The meskat, check dams, jessour and tabias are still being used in southern Tunisia. So-called Lacs collinaires have been used in Algeria since ancient times. The ancient hafairs in Sudan are still in use for domestic and livestock purposes. Rock and earth bunds and stone terraces have been used in Niger and Burkina Faso to harvest water. West Africans often used zay (pitting) combined with bunds to collect water. Runoff farming systems were used in the Negev desert over 4000 years ago. These systems played an important role in the successful establishment of settlements in deserts (Oweis et al., 2012). Various RWH systems have been used in Yemen, Libya and Egypt, such as underground tanks, Khazzan, cisterns, terracing and wadi-beds. Several traditional systems of RWH have been identified in northern Mexico and southwestern USA. Ancient systems such as ponds, cisterns, small dams and diversion canals were often used for domestic and agricultural purposes (Oweis et al., 2012). Some of these techniques may have the same name in several regions but differ completely in practice. The same technique, though, may be known by several names (Oweis, 2004).

Interest in RWH has been renewed in recent decades, especially in ASARs, due to the growing demand for water for agricultural and urban development caused by higher population pressure and climate change. This interest has also led to increases in the understanding, implementation and management of rainwater harvesting systems (Ben Mechlia and Ouessar, 2004; Oweis et al., 2012)

\subsubsection{Definitions and classifications of RWH}

Definitions and classification systems of RWH techniques vary amongst regions. No standardised terminology at the regional or international levels has yet been established, causing different names to be used for the same process (Moges, 2009; Nasr, 1999). Geddes provided one of the earliest definitions of RWH, as quoted by Myers (1975): "The collection and storage of any farm waters, either runoff or creek flow, for irrigation use". Critchley et al. (1991) defined RWH as the collection of runoff for productive use. Oweis 
(2004) defined RWH as the concentration of rainwater in runoff into smaller target areas for beneficial use. Kahinda et al. (2008) saw RWH as "The collection, storage and use of rainwater for small-scale productive purposes". The World Overview of Conservation Approaches and Technologies (WOCAT) database (Mekdaschi Studer and Liniger, 2013) recently described RWH as: "The collection and management of floodwater or rainwater runoff to increase water availability for domestic and agricultural use as well as ecosystem sustenance". The main purpose of RWH is generally to increase the amount of available water by capturing rainwater for local use or for transfer to another area. RWH can be used to minimise water loss and augment water supplies in watersheds (Isioye et al., 2012).

All RWH systems consist of the following components (Oweis et al., 2012):

- A catchment: the part of an area from which some of the rainwater is harvested, also known as a runoff area. The size of this area can vary between a few square meters and several square kilometres. The catchment may be agricultural, rocky, a paved road, or a rooftop.

- A storage facility: the area that holds the harvested runoff water until it is used for people, crops, or animals. Water can be stored above ground (e.g. reservoirs or ponds), in the soil profil, or in underground storage containers (e.g. cisterns).

- A target: the endpoint of a rainwater harvesting system, the place where the harvested water is used for domestic use or crop production.

RWH systems have been variously classified, but the most commonly used classification system is based on the size of the catchment. Three categories of RWH systems are distinguished in this system (Mbilinyi et al., 2005; Oweis et al., 2012). The first category is in situ RWH, where the rainfall is captured, stored and used in the same area where it fell. This system is sometimes called water conservation by retaining rainwater and enhances the infiltration of rainwater into the soil. Examples of this system are deep tillage, ridges and borders, terraces and trash lines (Mbilinyi et al., 2005). The second category is called a micro-catchment system where the runoff and production area are adjacent to each other (Gowing et al., 2015). Some examples are contour bunds, semi-circular bunds and strip catchment tillage. The third category of RWH systems consists of macro-catchment systems. The runoff area in these systems is large and located outside the cultivated area. Examples are ndiva and dams.

The success of RWH systems depends heavily on the identification of suitable sites and their technical design (Al-Adamat, 2008). Proper implementation of RWH, including area selection and design, could therefore improve the performance of RWH systems. Field surveys are the most commonly used method for selecting suitable sites and RWH 
techniques for small areas. The selection of appropriate sites for different RWH technologies in larger areas is a great challenge, because the necessary hydrological and soil data are often lacking (Prinz et al., 1998).

\subsubsection{RWH in arid and semi-arid regions}

RWH is applied in ASARs where rainwater is not sufficient to supply all areas due to limited precipitation or unpredictable distribution. Ponds, check dams, terracing, percolation tanks and nala bunds are the most common types of RWH techniques used in ASARs.

Ponds are amongst the most reliable and economical sources of water in ASARs. Inhabitants have been using them for centuries in many parts of Jordan. The harvested water is used either for all or supplemental irrigation or for other purposes such as domestic use, watering livestock, controlling erosion and stabilising water channels. Farm ponds are the most suitable water harvesting structures for ASARs (Al-Adamat, 2008). Ponds are established on the higher parts of farms to block and store the runoff rainwater by constructing an embankment across a watercourse, excavating a pit or a combination of both (Fardous et al., 2004).

Check dams are small dams (impermeable structures) constructed across water courses in narrow wadis with gentle slopes. They are feasible both in hard-rock and alluvial formations (Arunima et al., 2015). These dams have the advantage of being cheap to construct, but the number of favourable sites available is usually limited. Check dams are a very popular type of RWH. They are of great importance because they can also control soil erosion (Arunima et al., 2015). Check dams can effectively harvest and store storm runoff from large catchments. They are a valuable source of supplementary water and can be designed and constructed using local materials and labour. They are a common feature of rural landscapes in many parts of the world such as Iraq, Tunisia, China and India (Johnson and Renwick, 1979).

Terraces function as systems of both soil and water conservation. They are constructed on steep slopes and are formed by small retaining walls. A variety of terracing systems are practiced in Arabic regions, such as weir terraces across narrow wadis, barrage terraces, linear dry-field terraces and stair terraces (Abdo and Eldaw, 2004). The terraces in Yemen are the most spectacular and oldest indigenous RWH systems. Rainwater is collected on the terraces and soaks into the shallow soil. The walls of the terraces are built of stone, and the spaces between the stones allow water to move down to successive terraces without eroding the soil. Terraces are designed and constructed in such a manner that the passage of runoff by sheet flow is allowed, thus preventing damage to the terraces from 
concentrated runoff at specific points (Bamatraf, 1994). This method is effective in mountains and locally available materials can be used for the construction.

The percolation tank is an artificially created surface water body, submerging a land area with adequate permeability to facilitate sufficient percolation of impounded surface runoff to recharge the groundwater (Johnson and Renwick, 1979). It is a multipurpose conservation structure, storing water for livestock and recharging the groundwater, depending on its location and size. A tank can be located either across small streams by creating low-elevation check dams or in uncultivated land adjoining streams by excavation and providing a delivery canal connecting the tank and stream (Johnson and Renwick, 1979). The percolation tank is similar to check dams with a large storage reservoir and is the most common RWH system in India. The catchment area should be sufficient to fill the tank in years with normal rainfall.

Nala bunds are embankments constructed across larger, second-order streams in areas with gentle slopes (Ghule et al., 2010). A nala bund acts like a mini percolation tank. The main objectives of nala bunding are to i) impound surface runoff from catchments, ii) stabilise stream grades to facilitate the percolation of stored water into the soil sub-strata for raising the groundwater level in the zone of influence of the nala bund and iii) trap the silt sediments that would otherwise reach the multipurpose reservoirs and reduce their storage capacity (Ghule et al., 2010).

\subsubsection{Iraq and Tunisia: examples of ASARs}

Iraq is a Middle-Eastern country. It covers over $430000 \mathrm{~km}^{2}$ of land and had a population >36 million in 2015 (United Nations, 2015). It has an arid climate with an average annual precipitation that ranges from $\leq 100 \mathrm{~mm}$ in the southeast to $\geq 400 \mathrm{~mm}$ in the northeast (Al-khateeb, 2013). Until the 1970s, Iraq was commonly considered to have rich water resources due to the Tigris and Euphrates Rivers. The impacts of RWH on domestic use, agricultural production and even small settlements have always been limited. No efficient management tools or procedures have been implemented for harvesting water in most of the country's catchments. Human settlements and agricultural activities in Iraq have always been concentrated on the Mesopotamian plain, where freshwater from the Tigris and Euphrates Rivers is accessible and can be used to irrigate the flat areas, fertile and deep soil (Adil, 2004). RWH has mainly been used to secure drinking water for the inhabitants of, and travellers in, some remote areas (Adil, 2004). Few RWH systems are used in Iraq. Saharij are the local name for caves in which runoff water is stored. The function of this system is simply to intercept wadi runoff water by directing it to a nearby cave (sihrij, singular of saharij), which acts as a holding tank. This system is still operational north of the city of Mosul. Kahariz is another ancient RWH technique and is still in 
operation. The oldest Kahariz originates from 1300-600 BC. This system can increase groundwater and is widespread in northern Iraq. The Kahariz are important because they can supply water continuously from groundwater storage without the use of a pump. The faydah system is another type of RWH that can be applied in the flat area of a wadi in which water collects. A faydah is in a favourable location for collecting floodwater, especially if the site is improved by excavation (Adil, 2004). Historical documents tell of the famous Zubaida pilgrimage road between Baghdad and Mecca, which was constructed during the early Abbasi dynasty (AD 750-1258). Ponds and wells were dug at selected sites along the pilgrimage road to collect runoff water from nearby wadis and waterways. Some important wadis in Iraqi deserts (such as the western desert) terminate at a faydah. Other ancient types of RWH such as khabrat, sidood, kharijah, jilban and hassy were used at different sites in Iraq. See Adil (2004) for more details.

The construction of dams in the upper reaches of the Tigris and Euphrates Rivers and their tributaries in Syria and Turkey caused major decreases in the flows of these rivers (AlAnsari et al., 2014). Al-Ansari et al. (2012) reported that the discharge from these two rivers would continue to decrease with time until they will be completely dried up by 2040. The amount of water available per person per year decreased from 5900 to $2400 \mathrm{~m}^{3}$ between 1977 and 2009 (Al-khateeb, 2013). The mismanagement of water resources and the effects of climate change are other main factors contributing to water shortages in Iraq. The continuing water crisis has directly contributed to the rising levels of food deprivation, displacement and poverty in Iraq. The people living in arid areas (e.g. Iraq's western desert) with highly variable rainfall and unforeseeable periods of drought and/or flooding especially often have insecure livelihoods. One solution for overcoming the water shortages is to expand the use of RWH systems. Planners of water resources are therefore considering RWH techniques as a promising means of increasing and conserving water resources in Iraq. The construction of dams on wadis for harvesting water from small watersheds for inducing artificial water recharge and supply water is becoming an acceptable practice in Iraq. This technique stores excess rainwater (runoff) in small reservoirs behind dams of different sizes.

Tunisia is one of the Mediterranean countries facing a scarcity of water that will worsen due to climate change, growing demands for water for agricultural and urban development and an expanding tourism industry (Ouessar et al., 2004). Tunisia is located in northern Africa. It has a total area of about $164000 \mathrm{~km}^{2}$ and had a population $>11$ million in 2015 (United Nations, 2015). The climate of Tunisia is Mediterranean but is influenced by the caprices of the Sahara climate. More than $2 / 3$ of the country has a semiarid, arid or desert climate. The precipitation is known for its unpredictability: it can be infrequent but intense and highly variable, both in time and space. The arid region in the 
south (not including the Sahara Desert) receives $\leq 200 \mathrm{~mm}$ of rain annually. This area covers $61 \%$ of the country but receives only $30 \%$ of the rainfall (Ouessar, 2007). A wide variety of small RWH systems have been introduced over many centuries to make the land productive, irrespective of its geographical location. Diverse indigenous practices involving the use of runoff water to supplement rainfall deficiencies are consistent with long-term climatological features. More sophisticated systems have been developed in arid areas. Inhabitants in the southeastern region have developed and implemented several types of RWH systems, such as meskat, jessour, tabias, cisterns, recharge wells and gabion check dams. Meskat is a very ancient technique for harvesting runoff water practiced in the Sahel region of Tunisia, where the landscape is dominated by a rolling topography (Ben Mechlia and Ouessar, 2004). The cultivated areas consist of one or several compartments bounded by earthen embankments. They are joined by spillways and still support millions of productive olive trees (Ben Mechlia and Ouessar, 2004). This technique efficiently controls erosion and enhances the supply of water to olive plantations (Ben Khlil, 1983). Jessour is an ancient technique for harvesting runoff water widely practiced in the arid highlands across wadis with steep slopes and dominated by calcareous outcrops and the deposition of quaternary calcareous silt (loess) (Ouessar, 2007). Each jessr (singular of jessour) consists of three parts: an impluvium or catchment area providing the runoff, a terrace or cultivated area where the runoff is collected and crops or trees are grown, and a dyke to retain the water and sediment. Each dyke has a spillway to regulate water flow between dykes. The main objectives of jessour are aquifer recharge, flood control, irrigation, domestic use and control of wind erosion. The tabia technique is similar to the jessour system but is used in the foothills and piedmont areas. It is considered to be a newer technique, developed by mountain dwellers who migrated to the plains. Tabias are usually installed on the piedmont, where slopes are $\leq 3 \%$ and where the soil is deep (Ouessar, 2007). In addition to their rainwater harvesting qualities, tabias have a positive effect on reducing soil erosion and recharging groundwater. Jessour and tabias are the most common RWH techniques in southeastern Tunisia and are used in our case study.

\subsection{Hydrological models for RWH}

In addition to field measurements, the effects of RWH can be evaluated by modelling the hydrological characteristics of RWH facilities (Ghisi et al., 2007). Fewkes (2000) addressed the need for a hydrological model for the analysis of RWH facilities. A hydrological analysis of RWH facilities is similar to a long-term rainfall-runoff analysis in a watershed, which generally assesses various components of hydrological circulation, such as precipitation, evapotranspiration, infiltration, percolation, groundwater and surface runoff (Kim and Yoo, 2009). Various detailed models capable of simulating RWH system design and/or 
performance have been developed and published (Ward et al., 2010). Dixon (2000) developed $D R H M$, a mass-balance model with stochastic elements for demand profiling, to simulate the quantity, quality and cost of RWH systems. Vaes and Berlamont (2001) developed the Rewaput model, which is a reservoir model with relationships among rainfall intensity, duration and frequency and with triangular distribution, which approximates the stochastic character of storage volume and water consumption (i.e. variation within a catchment). Fewkes (2004) developed the RCSM model that simulates RWH systems with a detailed analysis of time-interval variation and yield-before/afterspill. Kim and Han (2006) developed the RSR model and applied it in Korea. It optimises the tank size of an RWH system for storm water to reduce flooding. An Excel-based balance model (RainCycle) using a yield-after-spill algorithm and a whole life costing approach was developed in 2007 by Roebuck and Ashley (2007).

New discoveries in hydrological modelling emerged quickly with the digital revolution. Many improvements in hydrological modelling appeared, and a variety of physically based watershed hydrological models were developed, e.g. rainfall-runoff modelling systems. The method of the soil conservation service (SCS) is most widely used for estimating surface runoff from small catchments after a rain (De Winnaar et al., 2007). It assesses the relationship between land cover and the hydrological soil group, which together determine the curve number (CN) (De Winnaar et al., 2007). Several hydrological models incorporate the SCS-CN method for estimating storm runoff, e.g. TOPMODEL and SWAT (soil and water assessment tool) (Mbilinyi et al., 2007). The hydrologic modelling system (HEC-HMS), developed by the hydrological engineering centre of the US Army corps of engineers, is a set of mathematical models for simulating the routing of precipitation in dendritic systems of watersheds (Nasri et al., 2011).

The application of the water-balance equation is a good way to describe and understand the water regime of a specified area and to assess the availability of water at an RWH site. The water-balance equation represents the inflow, outflow and change in water storage for an area or water body (Tadesse et al., 2010a), i.e. the water balance is the application of the principle of conservation of mass in hydrology, often referred to as the continuity equation (Tadesse et al., 2010b). Water balance models are based on this equation and provide the most fundamental information about the hydrology of a catchment and can assess the performance of RWH techniques under current and future climatic conditions (Chauvin et al., 2011). The water balance model can be used to improve our understanding of the critical processes influencing the hydrological cycle and to extrapolate data from field or laboratory experiments to other sites and climates (Zhang et al., 2005). 
Essential issues for applying such models are whether they adequately represent the characteristics of rainfall and runoff of a watershed (e.g. topography, geology, soil and climate) and if the model parameters can be properly estimated using the available data (Kim and Yoo, 2009). The quality of the input data in any hydrological model strongly influences the accuracy of the results. The development of a simple RWH model based on the water balance equation in this study was therefore advantageous. The equation can hydrologically analyse RWH with only a few estimated parameters.

\subsection{Climate change}

Climate change is a very serious problem and has become a major global issue in recent years, especially in ASARs that are strongly affected by its impacts (Pun, 2013). Climate change refers to "any systematic change in the long-term statistics of climate elements (such as temperature, pressure, or winds) sustained over several decades or longer time periods" (Ghosh and Misra, 2010).

In terms of hydrology, climate change can have a large impact on water resources by affecting the components of the hydrological cycle (Hassan et al., 2014). For example, changes of temperature and precipitation can have direct impacts on evapotranspiration and the quantity and quality of runoff. The components of the water balance can consequently be strongly affected, which in turn influences sectors such as agriculture, industry and urban development (Mohammed, 2009).

The fifth assessment report (AR5) by the Intergovernmental Panel on Climate Change (IPCC) indicated an increase in global mean temperature between 1880 and 2012 of 0.85 ${ }^{\circ} \mathrm{C}$ (IPCC, 2013). This change in temperature has been accompanied by changes in precipitation in several regions, leading to frequent floods and droughts (Dai, 2013; Min et al., 2011). Many ASARs are likely to be highly vulnerable to climate change (Abouabdillah, 2010). ASARs are expected to suffer from increasing temperatures and intense heat waves (Al-Ansari et al., 2014). A higher temperature coupled with less frequent but more intense rain will accordingly likely cause more droughts and greater flooding. The droughts will affect water supplies and agricultural life (Al-Ansari et al., 2014). RWH can be a specific strategy to adapt to future climate change (Mukheibir, 2008; Pandey et al., 2003; Salas et al., 2009). Three main steps are involved in assessing the impacts of climate change on the performance of RWH (Ghosh and Misra, 2010): i) simulation of large-scale climatic variables (e.g. temperature, humidity, and mean atmospheric pressure at sea level) using general circulation models (GCMs), ii) downscaling large-scale variables (predictors) to local-scale meteorological variables (predictands) and iii) application of hydrological 
models to assess the performance of RWH systems under current and future climatic conditions by using the GCM outputs corresponding to a specific scenario of climate change.

It is important to note that the impact of climate change is forecasted at the global scale, and different regions of the globe are expected to respond differently. The type and magnitude of the impacts have not been well investigated at the catchment level in most regions around the world. The study of the impacts of climate change at catchment scales is therefore important, and quantifying the impacts on various aspects of water resources, such as precipitation, hydrological regimes, drought and RWH performance, is also essential.

\subsection{Objectives of this study}

This study contributes to the overall objective of improving RWH systems to eliminate water scarcity in ASARs by developing and testing a methodology to evaluate and optimise the performance of existing RWH techniques under various scenarios of design and management. Potential adaptive strategies for optimising RWH effectiveness to mitigate the impact of the predicted climate change were also investigated. The following research questions were addressed:

I. What are the common methodologies and criteria that have been applied to identify the suitable sites of RWH systems in arid and semi-arid regions?

II. What are the potential RWH sites in the wadi Horan watershed in the western desert of Iraq?

III. What is the most appropriate approach that includes engineering, biophysical and socioeconomic criteria for assessing the performance of RWH designs?

IV. How can the performance of an RWH system under various scenarios of design and management be evaluated and optimised?

V. What is the impact of climate change on the performance of RWH systems?

\subsection{Thesis outline}

The research objectives are addressed in Chapters 2-7. All chapters have been published in, or submitted to, international peer-reviewed journals, so they can be read independently. Figure 1.1 summarises the outline of this thesis, indicating the research topic(s) addressed in each chapter. 


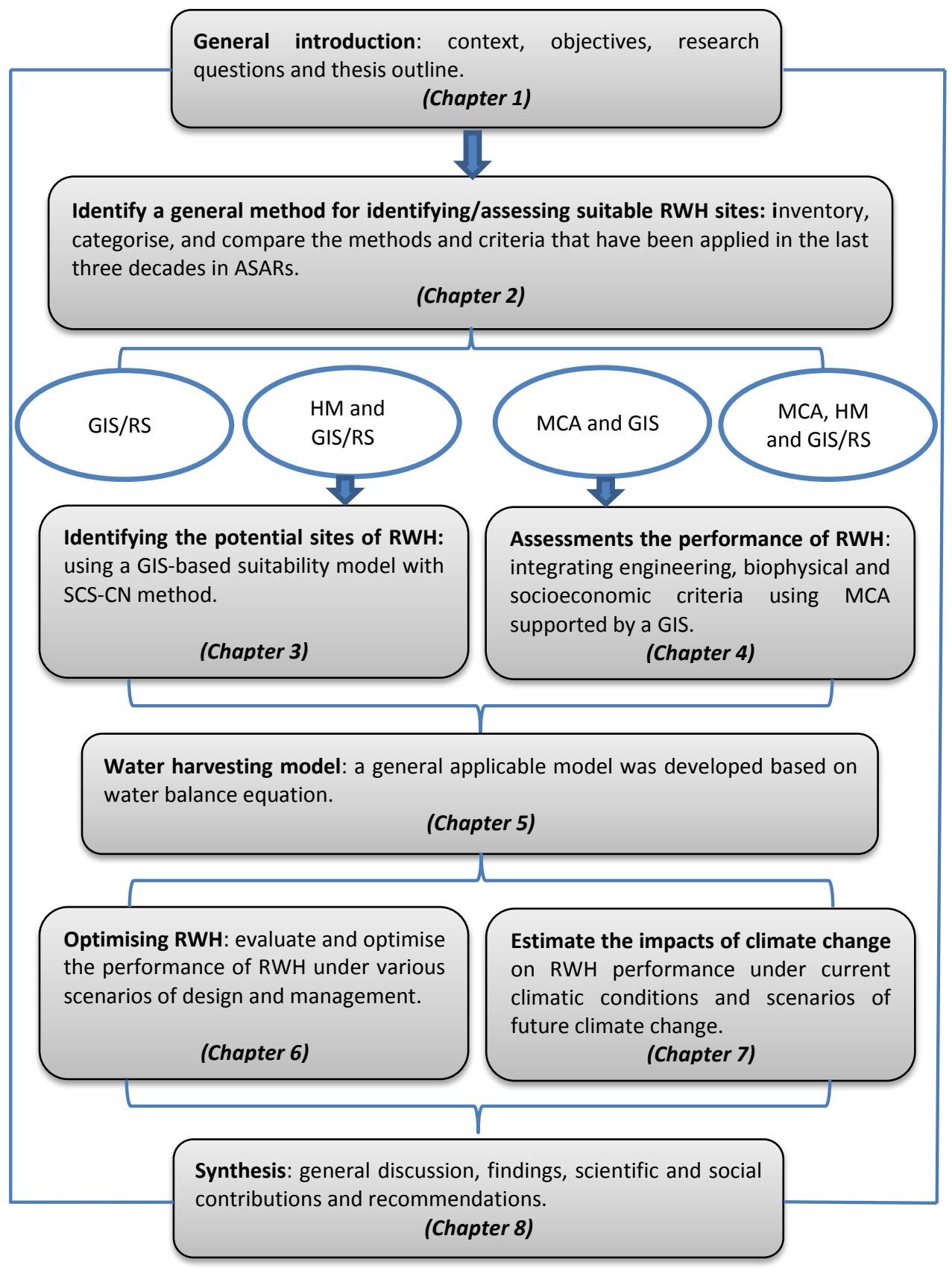

Figure 1.1 Thesis outline indicating the chapters in which the various topics are addressed and the relationships between them. 
Chapter 2 presents an overview of the various methodologies and criteria that have been applied for selecting sites suitable for RWH techniques in arid and semi-arid regions. This chapter enables the assessment of the best experience and most appropriate method for identifying suitable sites for RWH systems in arid and semi-arid regions.

Chapter 3 identifies potential RWH sites in wadi Horan in the western desert of Iraq using a GIS-based suitability model, created with ModelBuilder in ArcGIS 10.2. The suitability model combined biophysical criteria: slope, runoff depth, land use, soil texture and stream order. The analysis as presented, provides a first valuable screening of large areas and can be easily modified to incorporate other criteria or information with other spatial resolutions.

Chapter 4 presents a new methodology that has been developed to evaluate the performance of RWH techniques by integrating engineering, biophysical and socioeconomic criteria. The main criteria affecting the performance of RWH system design are identified and the weighted importance of each criterion associated with the main objective are determined. This integrated methodology, which is highly flexible, saves time and costs, is easy to adapt to different regions, and can support designers and decision makers in improving the performance of existing and new RWH sites.

Chapter 5 presents a simple but generally applicable water harvesting model (WHCatch) that was based on the water balance at a catchment level and that could be applied with minimum data for the analysis and optimisation of the performance of RWH systems.

Chapter 6 emphasises the advantages of simulating long-term water balances at the subcatchment level for improving the understanding of hydrological processes in an RWH system. It provides several solutions for optimising RWH performance under various scenarios. WHCatch was applied for 25 sub-catchments of the wadi Oum Zessar watershed (southeastern Tunisia). The results of the water harvesting model have practical importance, because lower parameterised models, which require less input data, are advocated for data-poor regions.

Chapter 7 addresses the performance of RWH systems under current and future scenarios of climate change. This study estimates the impact of climate change on water availability at the watershed level. Precipitation and temperature are downscaled from the GCMs using a statistical downscaling model. A water harvesting model was then applied to assess the performance of RWH techniques in the wadi Oum Zessar watershed under current climatic conditions and future scenarios of climate change. 
Finally, Chapter 8 synthesises the major findings of this study and their contributions to the scientific efforts for improving the performance of RWH design under current and future conditions of climate change. The implications and recommendations of this study are also presented. 


\section{Identification of Suitable Sites for Rainwater Harvesting Structures in Arid and Semi-Arid Regions: A Review}

Harvested rainwater is an alternative source of water in arid and semi-arid regions (ASARs) around the world. Many researchers have developed and applied various methodologies and criteria to identify suitable sites and techniques for rainwater harvesting (RWH). Determining the best method or guidelines for site selection, however, is difficult. The main objective of this study was to define a general method for selecting suitable RWH sites in ASARs by assembling an inventory of the main methods and criteria developed during the last three decades. We categorised and compared four main methodologies of site selection from 48 studies published in scientific journals, reports of international organisations, or sources of information obtained from practitioners. We then identified three main sets of criteria for selecting RWH locations and the main characteristics of the most common RWH techniques used in ASARs. The methods were diverse, ranging from those based only on biophysical criteria to more integrated approaches including socioeconomic criteria, especially after 2000. The most important criteria for the selection of suitable sites for RWH were slope, land use/cover, soil type, rainfall, distance to settlements/streams and cost. The success rate of RWH projects tended to increase when these criteria were considered, but an objective evaluation of these selection methods is still lacking. Most studies now select RHW sites using geographic information systems in combination with hydrological models and multi-criteria analysis.

This chapter is published as:

Ammar, A., Riksen, M., Ouessar, M. and Ritsema, C. (2016). Identification of suitable sites for rainwater harvesting structures in arid and semi-arid regions: A review. International Soil and Water Conservation Research, 4(2), 108-120. 


\subsection{Introduction}

Climate change and a growing demand for water and urban development are increasing the pressure on water resources. Between 75 and 250 million people in Africa are projected to be exposed to increased water stress by 2020 , yields from rainfed agriculture could be reduced by up to 50 percent in some regions, and agricultural production, including access to food, may be severely compromised (Field et al., 2014). The United Nations Environment Program estimates that more than two billion people will live under conditions of high water stress by 2050 , which would be a limiting factor for development in many countries around the world (Sekar and Randhir, 2007).

Arid and semi-arid regions (ASARs) around the world are already regularly facing problems of water scarcity, both for drinking water and for crops and other vegetation. ASARs represent $35 \%$ of Earth's land, about 50 million $\mathrm{km}^{2}$ (Ziadat et al., 2012). Rainfed agriculture is the predominant farming system in these areas, but aridity and climatic uncertainty are major challenges faced by farmers who rely on rainfed farming. To increase the availability of water for domestic use, crop and livestock production, inhabitants of dry areas have constructed and developed several techniques for harvesting rainwater.

Ponds and pans, dams, terracing, percolation tanks and nala bunds are the most common types of RWH techniques in ASARs (Oweis et al., 2012). Ancient evidence of the use of rainwater harvesting (RWH) techniques has been found in many countries around the world, including Jordan, Palestine, Syria, Tunisia and Iraq (Al-Adamat, 2008). The earliest signs of RWH are believed to have been constructed over 9000 years ago in the Edom Mountains in southern Jordan (Boers and Ben-Asher, 1982). RWH has several definitions and names. Geddes provided one of the earliest definitions of RWH, as quoted by Myers (1975): "The collection and storage of any farm waters, either runoff or creek flow, for irrigation use". Critchley et al. (1991) defined RWH as the collection of runoff for productive use. Gupta et al. (1997) defined RWH as a method for inducing, collecting, storing and conserving local surface runoff for agriculture in ASARs.

In this report, we use the definition in The World Overview of Conservation Approaches and Technologies (WOCAT) database (Mekdaschi Studer and Liniger, 2013): "The collection and management of floodwater or rainwater runoff to increase water availability for domestic and agricultural use as well as ecosystem sustenance". The main role of RWH is to increase the amount of available water by capturing rainwater in one area for local use or for transfer to another area. All water harvesting systems consist of the following components (Oweis et al., 2012): 
- A catchment: the part of an area from which some of the rainfall is harvested. It is also known as a runoff area. This area can be a few square meters to several square kilometres in size and may be rocky, a paved road, agricultural, or a rooftop.

- A storage facility: the area that holds the harvested runoff water until used for people, crops or animals. Water can be stored above ground (e.g. reservoirs or ponds), in the soil profile and in underground storage containers (e.g. cisterns).

- A target: the endpoint of a water harvesting system, where the harvested water is used for domestic use or crop production.

The success of RWH systems depends heavily on the identification of suitable sites and their technical design (Al-Adamat et al., 2012). Various methodologies have been developed for the selection of suitable sites and techniques for RWH (Ahmad, 2013; AlAdamat, 2008; De Winnaar et al., 2007). Field surveys are the most common method for selecting suitable sites and RWH techniques for small areas. The selection of appropriate sites for different RWH technologies in larger areas is a great challenge (Prinz et al., 1998).

Various factors such as rainfall, land cover/use, topography, soil texture/depth, hydrology, socioeconomics, ecology and environmental effects can be used for identifying suitable sites for RWH (Prinz and Singh, 2000). In practice, a high diversity of methodologies and criteria are used. Little attention, however, has been paid to the performance of these methods in selecting suitable sites. The main objective of this study was thus to define a general method for selecting suitable RWH sites in ASARs by comparing all methods and criteria developed in the last three decades. We collected and analysed 48 studies published in scientific journals, reports of international organisations, or sources of information obtained from practitioners. The tasks performed were:

- Identifying main sets of site-selection criteria;

- Categorising and comparing the main selection methodologies;

- Identifying the design criteria (quantitative/qualitative values) for the most commonly used RWH techniques in ASARs.

\subsection{Criteria and methods for RWH site selection in ASARs}

Water harvesting has been receiving renewed attention since 1980 . Developments in computer technology, geographic information systems (GISs) and remote sensing (RS) have made it possible to develop new procedures to identify suitable sites for RWH and have led to numerous publications focused on the selection of suitable RWH sites. A 
summary of the RWH types, authors, year, countries and selection criteria reported in our information source is presented for each method in section 2.2.2.

\subsubsection{Criteria used for selecting suitable RWH sites}

The selection of suitable sites for RWH depends on several criteria (Mahmoud and Alazba, 2014). Two main groups of criteria, biophysical and socioeconomic, have been defined. The criteria for the different RWH techniques that have been used in various methods are presented in the tables in the next section. Several of the studies in the 1990s (e.g. Gupta et al., 1997; Padmavathy et al., 1993; Prinz et al., 1998) focused primarily on biophysical criteria, such as rainfall, slope, soil type, drainage network and land use. Most of the studies after 2000 have tried to integrate socioeconomic parameters with the biophysical components as the main criteria for selecting suitable sites for RWH (e.g. De Winnaar et al., 2007; Senay and Verdin, 2004; Yusof et al., 2000). In 2003, the Food and Agriculture Organization of the United Nations (FAO), as cited by Kahinda et al., (2008), listed six main criteria for identifying RWH sites: climate, hydrology, topography, agronomy, soils and socioeconomics.

The most common biophysical criteria used in ASARs to identify suitable sites for RWH were (as a percentage of all studies reviewed): slope (83\%), land use/cover (75\%), soil type (75\%) and rainfall (56\%). The distance to settlements (25\%), distance to streams (15\%), distance to roads $(15 \%)$ and cost $(8 \%)$ were the most commonly applied socioeconomic criteria.

Table 2.1 The most common techniques and criteria and their values that have been used for RWH site selection in ASARs.

\begin{tabular}{|c|c|c|c|c|c|c|}
\hline $\begin{array}{l}\text { RWH } \\
\text { technique }\end{array}$ & $\begin{array}{l}\text { Rainfall } \\
\text { (mm) }\end{array}$ & $\begin{array}{l}\text { Slope } \\
\%\end{array}$ & Soil type & Land use/cover & $\begin{array}{l}\text { Catchment } \\
\text { area (ha) }\end{array}$ & $\begin{array}{l}\text { References as shown } \\
\text { in Tables 2.3- } 2.6\end{array}$ \\
\hline $\begin{array}{l}\text { Ponds and } \\
\text { pans }\end{array}$ & $>200$ & $<5$ & $\begin{array}{l}\text { Sandy clay loam } \\
\text { and silty loam }\end{array}$ & $\begin{array}{l}\text { Moderately } \\
\text { cultivated, } \\
\text { shrub land and } \\
\text { scrub land }\end{array}$ & $<2$ & $15,18,41,42,44,45$ \\
\hline Check dams & $<1000$ & $<15$ & Sandy clay loam & $\begin{array}{l}\text { Barren, shrub } \\
\text { and scrub land }\end{array}$ & $>25$ & $14,24,18,26,44$ \\
\hline Terracing & $\begin{array}{l}200- \\
1000\end{array}$ & $5-30$ & $\begin{array}{l}\text { Sandy clay, } \\
\text { clay loam and } \\
\text { sandy loam }\end{array}$ & $\begin{array}{l}\text { Bushland with } \\
\text { scattered trees } \\
\text { and shrub land }\end{array}$ & - & $17,33,30$ \\
\hline $\begin{array}{l}\text { Percolation } \\
\text { tank }\end{array}$ & $<1000$ & $<10$ & $\begin{array}{l}\text { Silt loam and } \\
\text { clay loam }\end{array}$ & $\begin{array}{l}\text { Barren or scrub } \\
\text { land }\end{array}$ & $>25$ & $3,18,44$ \\
\hline Nala bunds & $<1000$ & $<10$ & Silt loam & $\begin{array}{l}\text { Barren or scrub } \\
\text { land }\end{array}$ & $>40$ & $15,41,48$ \\
\hline
\end{tabular}


The most common techniques that have been developed and used in ASARs were (Table 2.1): ponds and pans, check dams, terracing, percolation tanks and Nala bunds. Table 2.1 also lists the most common biophysical criteria that have been applied in planning and implementing these techniques (based on this review). For example, all five techniques are all suitable in areas with rainfalls of $200-1000 \mathrm{~mm} \mathrm{y}^{-1}$, ponds are suitable for small flat areas with slopes $<5 \%$, percolation tanks and Nala bunds are suitable on moderate slopes of $5-10 \%$ and terracing is suitable for steeper slopes of $5-30 \%$. The most suitable soil type, land use/cover and catchment size for each RWH technique are also summarised in Table 2.1.

We identified three commonly prescribed sets of criteria (guidelines) for the selection of suitable RWH (Table 2.2). The first set was proposed by the integrated mission for sustainable development (IMSD, 1995) and included only biophysical criteria. The second set was proposed by Oweis (1998), who first included socioeconomic criteria. The third set was developed by the FAO (2003) and included more criteria in both domains. Most publications since 2000 followed or were derived from one of these sets of guidelines.

The various criteria were more flexible in the IMSD (1995) guidelines than other two guidelines. For example, different soil textures were given for different RWH types, such as percolation tanks suited to sandy soils and ponds suited to clay soils. Slopes $\leq 15 \%$ were considered suitable for some techniques. The land-use guidelines, however, were restrictive and were recommended for land-use classes such as barren, scrubland, or bare soil. These land-use classes are rarely used for agriculture, and RWH in these areas are small and should be close to cultivated areas. The IMSD guidelines thus include suitable sites far from where the water is needed (Durbude and Venkatesh, 2004; Kadam et al., 2012; Kumar et al., 2008). Moreover, the IMSD guidelines did not define socioeconomic criteria, which is a large limitation compared to the other two sets of guidelines.

The guidelines proposed by Oweis (1998) were more comprehensive than the IMSD guidelines. They considered RWH systems in difficult terrain and specified requirements specific to different types of agriculture, such as requirements for trees, field crops and rangeland. Moreover, criteria for the various types of RWH structures with values for each factor, such as soil texture, mean annual precipitation between $50-300 \mathrm{~mm} \mathrm{y}^{-1}$, soil depth $(<50 \mathrm{~cm})$, slope $(<4 \%)$ and vegetation have been determined (Al-Adamat, 2008; Bulcock and Jewitt, 2013; Ziadat et al., 2012). Socioeconomic criteria, however, were still limited and needed to be extended.

The FAO (2003) guidelines are presently the most comprehensive for the identification of potential RWH sites. They include more parameters and wider ranges relevant to RWH 
than the other guidelines and consider various socioeconomic criteria. In fact, the criteria for various RWH techniques have been determined, and the guidelines set suitable and ideal limits for factors such as water requirements for various crops, rainfall ranges, slope and soil depth/texture. For example, the FAO (2003) guidelines consider medium-textured loamy soil the most suitable for agriculture. Mean annual precipitation of $150-750 \mathrm{~mm} \mathrm{y}^{-1}$ is suitable for most RWH techniques. Slopes $<5 \%$ are suitable for ponds, slopes $<10 \%$ are suitable for percolation tanks and slopes $<15 \%$ are suitable for check dams (Krois and Schulte, 2014; Mati et al., 2006; Munyao, 2010; Ramakrishnan et al., 2009). These wide ranges and broad parameter definitions give more flexibility and reliability to the FAO guidelines for their accreditation by most researchers in ASARs.

Table 2.2 Commonly used guidelines to identify suitable sites for RWH in ASARs. Adapted from Bulcock and Jewitt (2013).

\begin{tabular}{|c|c|c|}
\hline IMSD (1995) & Oweis (1998) & FAO (2003) \\
\hline Not defined & Rainfall & Climate (Rainfall) \\
\hline Drainage system & Drainage system & Hydrology (rainfall-runoff relationship and intermittent watercourses) \\
\hline Slope & Slope & Slope \\
\hline Land use Land & LULC & Agronomy (crop characteristics) \\
\hline \multicolumn{3}{|l|}{ Cover (LULC) } \\
\hline Soil texture & Soil type & Soil (texture, structure and depth) \\
\hline Not defined & $\begin{array}{l}\text { Socioeconomic (land } \\
\text { tenure) }\end{array}$ & $\begin{array}{l}\text { Socioeconomic (population density, workforce, people's priority, } \\
\text { experience with RWH, land tenure, water laws, accessibility and } \\
\text { related cost) }\end{array}$ \\
\hline
\end{tabular}

\subsubsection{Methods and tools used for identifying suitable sites for RWH}

A variety of methods can be used to integrate the different criteria into a tool for the selection of suitable sites for RWH. We have categorised the methods/tools that have been applied to identify suitable sites in ASARs in the last three decades into four main groups: 1) GIS/RS (e.g. Al-Daghastani, 2010; Forzieri et al., 2008; Prinz et al., 1998), 2) hydrological modelling (HM) with GIS/RS (e.g. De Winnaar et al., 2007; Durbude and Venkatesh, 2004; Gupta et al., 1997), 3) multi-criteria analysis (MCA) integrated with HM and GIS/RS (e.g. Elewa et al., 2012; Sekar and Randhir, 2007; Weerasinghe et al., 2011), and 4) MCA integrated with a GIS (e.g. Al-Adamat et al., 2010; De-Pauw, 2008; Kahinda et al., 2008; Mahmoud and Alazba, 2014; Mbilinyi et al., 2007). These four groups were categorised based on how GIS/RS, MCA, and HM were applied in previous studies. Each group (method) therefore has its requirements with both pros and cons. Groups 3 and 4 are similar, but the main difference is the integration of HM in group 3. HM needs a lot of data and has requirements beyond the application of MCA with a GIS. The percentages of each group (method) that have been applied in the 48 articles were: $27 \%$ for group 1, $15 \%$ for group 2, 21\% for group 3 and $37 \%$ for group 4 . A description of each method, their 
specific requirements of data and systems, their applicability and limitations and examples of studies that have used these methods in ASARs are provided in the following sections.

\subsubsection{GIS/RS}

Computer technology has advanced greatly in recent decades, including GIS packages supported by RS that offer cost-effective and time-saving methods for identifying suitable sites for RWH. RS can be used to derive accurate information with high spatial and temporal resolution. For example, land-cover information and curve numbers (CNs), which are needed for runoff estimation, can easily be extracted in GIS environments. GISs are very useful tools, especially in areas where very little information is available, which is often the case in developing countries (Mahmoud, 2014). A GIS is a tool for collecting, storing and analysing spatial and non-spatial data (Mati et al., 2006). Various thematic layers can be generated by applying spatial analysis with GIS software. These layers can then be integrated for identifying suitable sites for RWH. The different sites identified by GISs in our sources of information were based on different guideline criteria, such as those by IMSD, (1995), Oweis, (1998) and FAO (2003) (Table2.2).

Ziadat et al. (2012) applied a GIS approach for identifying the suitability for RWH interventions in Jordan. They integrated biophysical criteria such as slope, vegetation cover, soil texture and soil depth with socioeconomic parameters such as land owner and then modified the criteria. Each criterion was assigned one of two ratings: best or second best. These ratings provided more flexibility for determining the suitability of an intervention. The data required for the biophysical criteria were obtained from various sources; contour lines extracted from topographic maps and slopes were derived from digital elevation models (DEMs) at 20-m resolution. ArcGIS was then used to derive a slope grid and the grid was converted into polygons for use as land-mapping units in the analysis. A field survey provided other data for the biophysical criteria, such as soil texture/depth and surface cover. The values for unmeasured locations were predicted using the inverse distance weight interpolator of ArcGIS 9.3 (Ziadat et al., 2012). Suitability maps were produced using two approaches for interpreting different layers of the biophysical parameters: a raster-based analysis assigned a suitability class for each pixel by comparing the RWH requirements with land characteristics using arithmetic map algebra and a polygon-based analysis assigned a suitability class for each slope-mapping unit. The final biophysical maps showed the number of RWHs suitable for each mapping unit or pixel. The suitability maps were overlaid with cadastral maps to apply farm-size criteria, the number of suitable sites was then reduced, and the final suitability map was integrated with socioeconomic parameters and local people discussions. A team visited the areas to validate the results in the field by comparison with the suitability maps. 


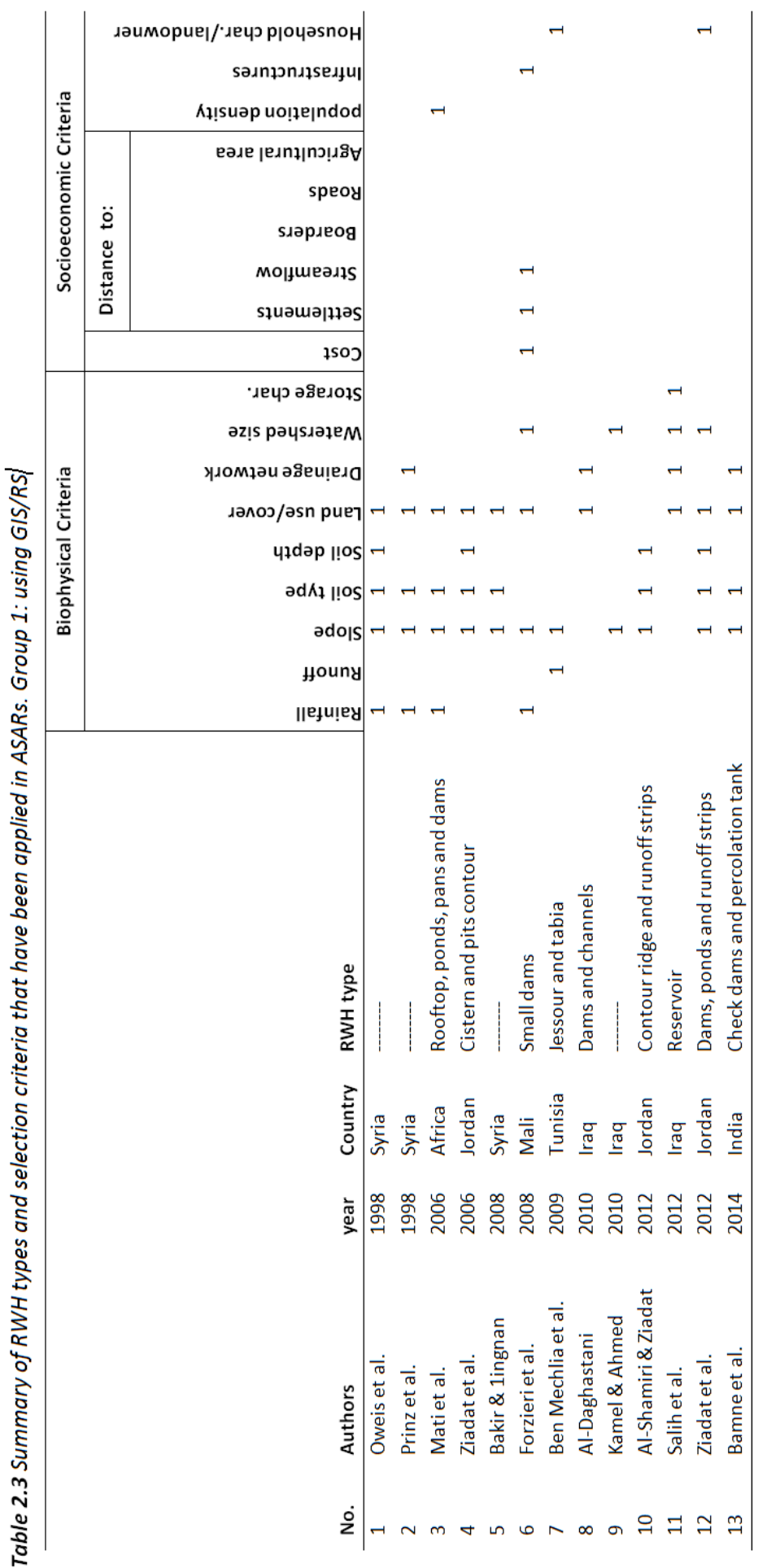


Suitability identified by both approaches indicated good coincidence with suitability on the ground.

The final suitability maps gave users the opportunity to state their needs, and users could access information for any location on the map to learn the suitable RWH option, landowner name, and area of the land parcel and could make enquiries based on the name of the owner.

The United Nations Environment Programme (UNEP, Mati et al., 2006) carried out a study to determine if RWH technologies could be mapped at continental and country scales by using RS and a GIS. The project developed a total of 73 thematic maps, 29 for RWH potential in Africa, and 44 for case studies covering Botswana, Ethiopia, Kenya, Malawi, Mozambique, Rwanda, Tanzania, Uganda, Zambia and Zimbabwe. The main criteria, largely governed by the FAO (2003) guidelines, were rainfall, population, land use, slope, soils and ephemeral streams. The study identified the most suitable sites for main RWH interventions as being (i) rooftop RWH, (ii) pans/ponds, (iii) sand/subsurface dams and (iv) in-situ systems for storing soil water. Digital GIS data was gathered from laboratories, and non-spatial data were gathered from libraries, local and international organisations, individuals and the internet. GPS (global positioning system) and satellite RS data were gathered in addition to data from cartographic surveys. A GIS database was developed using ArcGIS and ArcView software to identify potential RWH sites in Africa. The UNEP study produced baseline thematic maps for criteria such as rainfall and soils. Areas where RWH was not applicable or suitable were then eliminated by comparing two or more baseline maps. For example, areas with rainfall $>200 \mathrm{~mm}$ and a rainfall index $<60 \%$ were considered suitable for sand/subsurface dams. A lack of high-resolution input data and soil maps that did not cover the entire continent or had low resolution were some of the constraints faced in the continent-wide mapping of RWH potential in Africa. The resolution of the data could also differ between layers.

The products of the Africa-wide GIS database developed in the UNEP project are best viewed in soft formats; the user can zoom in, overlay different factors, update criteria and query for a specific question. The database will be quite useful in guiding users at subregional/national levels to target RWH projects, but the planning of the activities needs further detailed surveys and inputs of other socioeconomic criteria. 


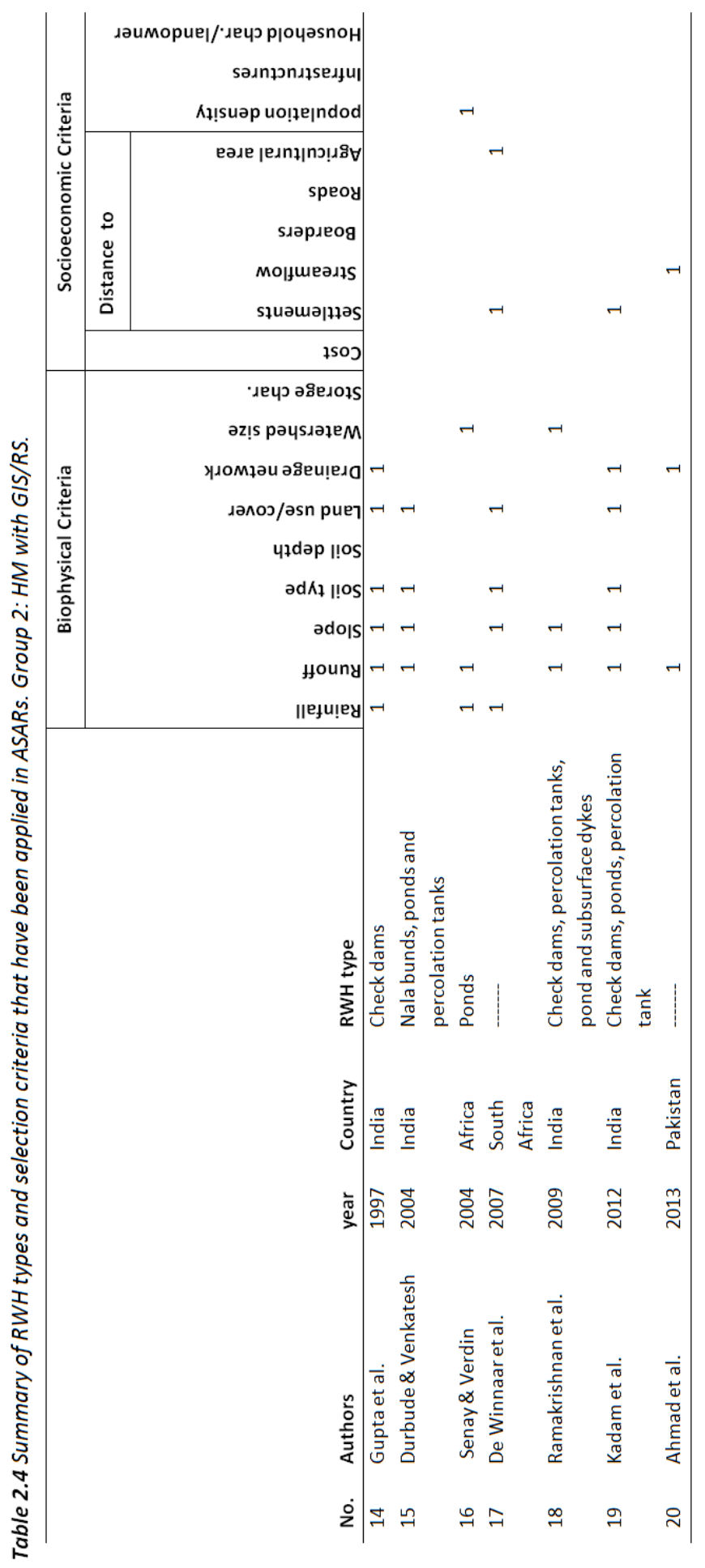


GISs and RS complement each other for selecting suitable sites for RWH structures (Forzieri et al., 2008; Prinz et al., 1998; Ziadat et al., 2006). Table 2.3 presents a summary of the studies, RWH types and criteria that have been applied in ASARs using GIS/RS. GISs and RS offer a data-reviewing capability that supports both quality control and the identification of errors. GISs and RS also provide a good opportunity to gain a better understanding of any patterns, make a query, update criteria and trends, and produce easy-to-read/use information via maps, posters and the internet. The maps can also be converted into pictures to enable access by non-GIS users.

The GIS property of spatial analysis makes it effective for use in different regions with differently sized areas and little data. The application of GIS/RS is cost-effective and rapid compared to the three other methods, but GIS/RS analyses must be preceded by field surveys before the actual implementation of RWH to verify suitable sites. In addition, the accuracy of GIS/RS depends highly on the quality (resolution) and availability of the data. This method will therefore be useful as a preliminary method and can be applied as a first step in identifying suitable sites for RWH in ASARs.

\subsubsection{HM with GIS/RS}

The soil conservation service (SCS) method is the most widely used approach for estimating surface runoff from small catchments after a rainfall event (Gupta et al., 1997). It considers the relationship between land cover and hydrologic soil group, which together make up the curve number (CN) (De Winnaar et al., 2007; Kadam et al., 2012; Ramakrishnan et al., 2009). With this approach, the suitable sites for RWH structures were located in areas with the highest capacity for runoff generation and nearby to existing drainage lines. Number of researchers applied the soil conservation service (SCS) with curve number method, focussing on how much runoff could be generated from a runoff area (e.g. De Winnaar et al., 2007; Gupta et al., 1997; Kadam et al., 2012; Senay and Verdin, 2004). Several hydrological models incorporate the SCS-CN method for estimating storm runoff, including TOPMODEL (Warrach et al., 2002), WMS (HEC-1, HEC-HMS and HEC 2001), KINEROS (Woolhiser et al., 1990), and SWAT (Arnold et al., 1996). Integrating these models/methods with advanced tools such as GIS and RS can enhance the accuracy and precision of runoff prediction, allowing faster and less costly identification of potential RWH locations. Table 2.4 shows the studies that have integrated HM with GIS/RS and applied in ASARs along with the criteria for each RWH technique.

De Winnaar et al. (2007) linked the SCS-CN method with a GIS to identify potential runoffharvesting sites in a small sub-catchment in South Africa. This study provided a detail of the spatially explicit method and presented suitability maps for RWH sites. The GIS was used as a tool to store, analyse and manage spatial data. The input data, including 
biophysical and socioeconomic data, were gathered from available data and from field surveys. A DEM with 20-m resolution was used to extract slope information, digital images and aerial photographs were used in ArcGIS 8.2, and a soil survey provided soil data.

The SCS method has been adapted for southern Africa and has become an accepted and widely used technique (De Winnaar et al., 2007; Senay and Verdin, 2004). The SCS method requires information on soil form to classify the hydrological soil groups ( $A, B, C$ and $D)$. The $\mathrm{CN}$ is an index indicating a catchment's runoff response to rainfall event, and varies from 0 to 100; a higher $\mathrm{CN}$ represents a greater proportion of surface runoff. A CN was calculated for each hydrological soil group, and a CN map was generated based on the hydrological soil groups and land cover. The map layers used for the suitability analysis included the slope, $\mathrm{CN}$ map and socioeconomic criteria such as distance to settlement and distance to crop area. RWH sites were ranked on a scale from most to least suitable for each map based on the criteria of each data set. The final step was to combine different factors to identify the most suitable sites for RWH. Seventeen percent of the catchment had a high potential for generating surface runoff, whereas an analysis of all factors influencing the location of such a system found that $18 \%$ was highly suitable for RWH. Incorporating runoff information is consequently an important step for identifying suitable RWH sites using the SCS-CN method. The SCS method provides a useful strategic-planning tool for managers of water resources and offers some guidelines for large-scale studies. RWH, however, is highly location-specific, and applying the SCS approach needs more detailed data, which means that applying the SCS approach will be difficult for larger areas.

Ahmad (2013) investigated potential RWH sites in Pakistan by studying the runoff pattern using a hydrological model with the GIS/RS approach. The Geospatial Hydrologic Modeling Extension developed by the Hydrologic Engineering Center (HEC-GeoHMS), a publicdomain software package for use with ArcView, was used for the delineation of water channels and drainage lines. The Hydrologic Engineering Center's Hydrologic Modeling System (HEC-HMS) was used to simulate rainfall-runoff and to estimate runoff generation in each outlet of a sub-catchment. A DEM with 90-m resolution was used as a source of elevation data in a catchment to determine flow direction, drainage lines and runoff. The HEC-HMS model has two main processes for simulating flow: parameter optimisation with model calibration and model validation. The results obtained by the HEC-HMS model were comparable to the observed results and found that a considerable amount of generated runoff could be stored at different sites, which represented the suitable sites for RWH. Moreover, $60 \%$ of the study area was potentially suitable for RWH. 
The application of the water-balance equation is a good way to understand the water regime of a specified area. The water-balance equation represents the relative values of inflow, outflow and change in water storage for an area or water body. Durbude and Venkatesh (2004) applied the Thornthwaite and Mather (TM) models with the help of RS and a GIS to identify potential runoff zones and sites suitable for RWH in the Hire watershed in the state of Karnatake in India such as contours terrace, farm ponds, gully plugs and percolation tanks. The TM model is one of the simplest and most widely used methods for calculating the water balance (Durbude and Venkatesh, 2004). Thematic maps of land use, soil texture and slope were created in a GIS, and the average annual runoff for the study area was estimated from the calculation of the water balance. The map of runoff potential was generated and reclassified into areas of no, low, moderate and high runoff potential. All sites suitable for RWH techniques were examined and were found to be close to or on the outflow point. Water availability for these structures could thus be confirmed. The final decision rules for identifying suitable sites for RWH were formalised based on the IMSD, (1995) guidelines. Water balance can be applied to obtain a general estimate of the water balance regime for variously sized areas, from individual fields to small watersheds (Gupta et al., 1997).

HM can generally be applied to simulate runoff in an entire watershed to determine the amount of runoff and to better understand the water regime and the relationship between up- and downstream structures. The validation results of previous studies (Ahmad, 2013; De Winnaar et al., 2007; Durbude and Venkatesh, 2004; Senay and Verdin, 2004) confirmed that HM is reliable, flexible, produces highly accurate results, and, when integrated with GIS, provides a rational means to facilitate decision-making and offers a time-efficient and cost-effective method for the identification of suitable RWH sites. Each $\mathrm{HM}$ has its pros and cons, and the accuracy of the results is highly dependent on the model complexity, users and data availability. The use of some models, however, also requires a purchased license.

\subsubsection{MCA integrated with HM and GIS/RS}

MCA is a commonly used method of analysis that combines data for various criteria. The analytical hierarchy process (AHP) is an MCA tool that has been applied widely to identify potential RWH sites (e.g. Krois and Schulte, 2014; Munyao, 2010; Sekar and Randhir, 2007). One of the main rules of MCA is to estimate a relative weight for each criterion, rather than assuming the same weight for all criteria (Banai-kashani, 1989), and then compare two or more alternatives.

AHP is a multi-criteria decision-making method, providing a structured technique for organising and analysing complex decisions based on mathematics and expert knowledge 


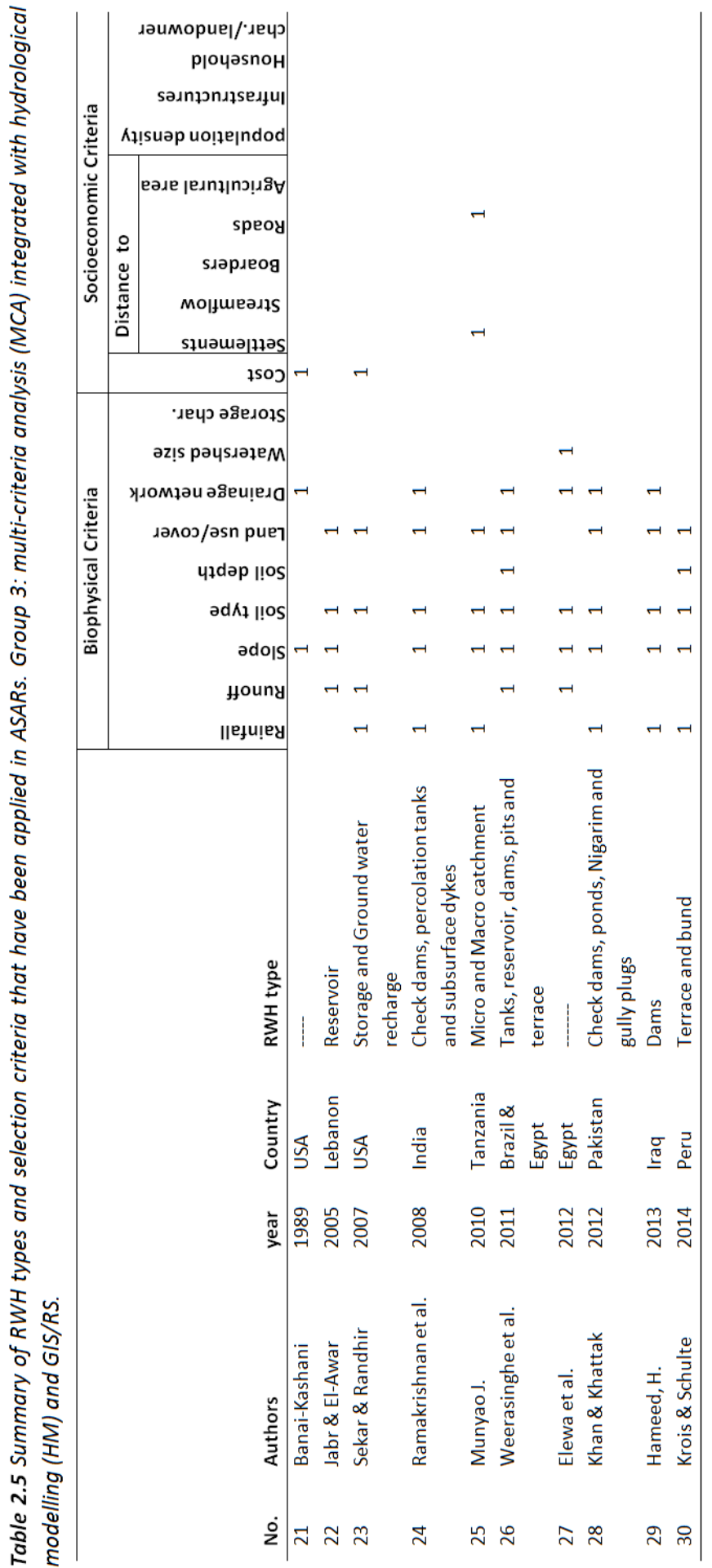


(Saaty, 2008). AHP was developed by Thomas Saaty in the 1970s (Saaty, 1990) and since then has been applied extensively in various disciplines. The essential principle of AHP is to represent the elements of any problem hierarchically to organise the relationships between each level. The uppermost level is the main goal (objective) for resolving a problem, and the lower levels consist of more detailed criteria that influence the main objective. The weights for each criterion are determined by applying a matrix of pairwise comparisons. Pairwise comparisons determine the relative importance of two criteria involved in assessing the suitability for a given objective. Two criteria are compared and rated using a 9-point continuous scale. The odd values 1, 3, 5, 7 and 9 correspond respectively to equally, moderately, strongly, very strongly and extremely important criteria when compared to each other, and the even values 2, 4, 6 and 8 are intermediate values (Saaty, 1990). For example, a rating of 5 between two criteria such as rainfall and slope indicates that the relationship between rainfall and slope is strongly correlated with the main objective.

MCA integrated with HM and GIS is a good tool for identifying suitable sites for RWH and is widely used in ASARs. Several studies have applied this integrated approach, taking advantage of the strengths of MCA together with those of HM and GISs, as shown in Table 2.5 .

Jabr and El-Awar (2005) integrated MCA using AHP with HM, the watershed modelling system (WMS) and a GIS to identify suitable sites for RWH in Lebanon. Firstly, all spatial manipulations, analyses, and representations were performed within a GIS. ArcGIS was used for producing pertinent spatial coverages, including base soil maps, land cover and topography. Secondly, WMS software was used to simulate runoff in watersheds at the sub-watershed level. WMS is a comprehensive HM environment that uses a conceptual model approach. WMS was selected because it supports the HEC-1 rainfall-runoff model. HEC-1 is suitable in regions with insufficient available runoff data, provides tools for all watershed modelling, including geometric and hydrological parameters, and analyses runoff for each outlet (Al-Ansari et al., 2012; Jabr and El-Awar, 2005). HM was used simultaneously with a GIS to estimate the necessary spatial hydrological parameters and to determine the site attributes associated with various decision criteria. Thirdly, a hierarchical decision structure using AHP was developed and implemented using calculated attributes to rank potential RWH sites. The application of the integrated methodology was highly flexible for the number of criteria and confirmed that this methodology was efficient; the results for the study reservoir were actually implemented at the outlet of the watershed with the highest rank. 


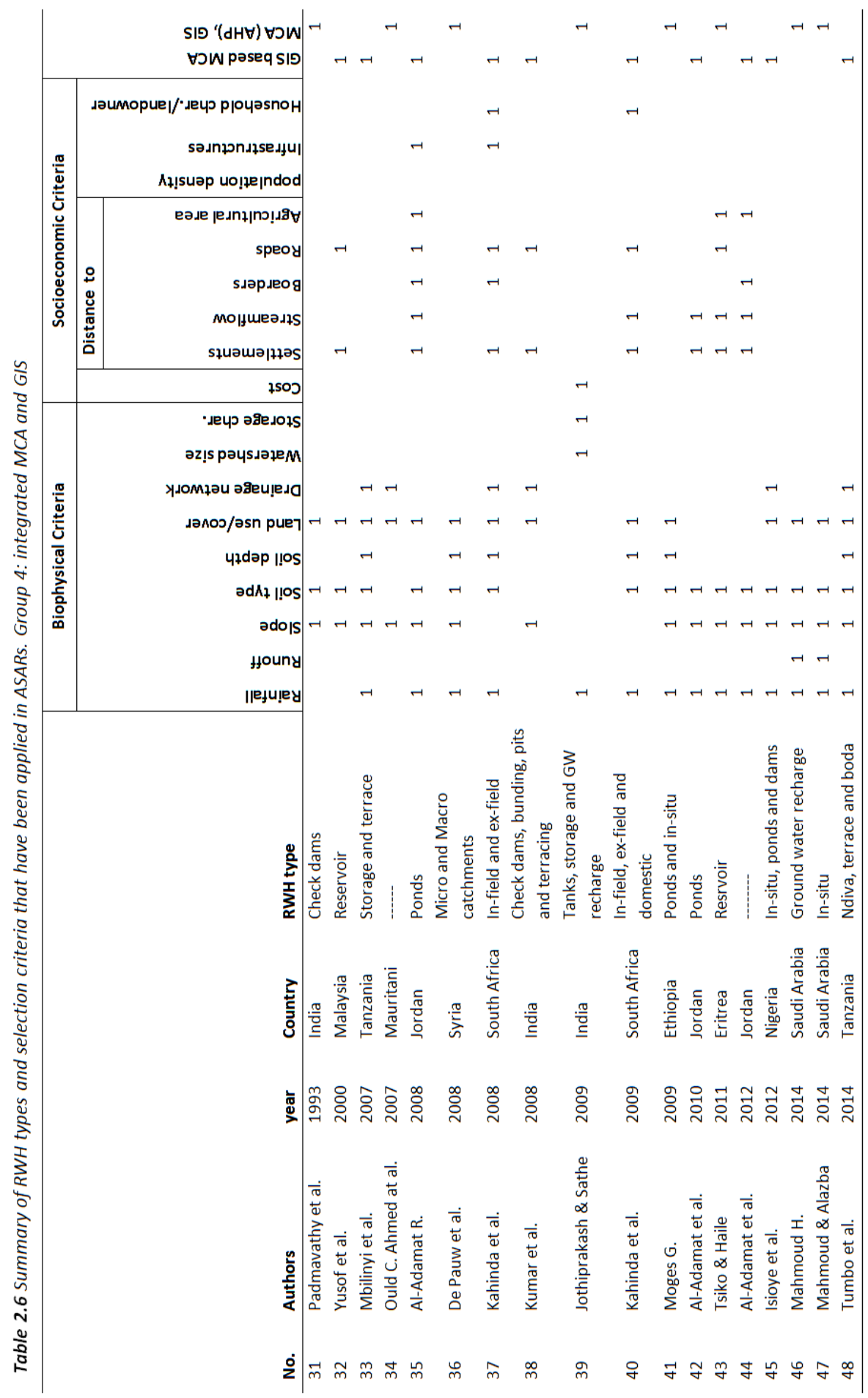


Krois and Schulte (2014) presented a method to identify suitable sites for RWH (terraces and bund systems) in the Ronquillo watershed in Peru by integrating MCA, SCS-CN and a GIS. The site assessment consisted of four steps. Firstly, input data were transferred into vector or grid maps, each of which represented a particular criterion of a RWH technique. Secondly, a GIS procedure created criteria maps by reclassifying the spatial maps based on the suitability level for each RWH technique. Thirdly, pairwise comparison matrix method, AHP, calculated the relative-importance weight of each criterion for each RWH technique. The selection criteria, based on the FAO guidelines, were: rainfall, runoff coefficient, slope, land use, soil texture and soil depth. The assessment of the dominance of one criterion over another was based on the authors' expertise and a literature survey. Fourthly, the weighted overlay process in GIS determined the suitability maps for each RWH technique.

The required data were gathered from a variety of sources. For example, topographic data were provided by a DEM with 30-m resolution, slopes were calculated in an ArcGIS environment, land-use data were generated from Quickbird data, and the SCS-CN model estimated direct runoff in the catchment. The analysis found that the Ronquillo watershed was generally well suited for implementing RWH (terrace and bund systems) and indicated that $44 \%$ of the catchment was highly suited for terracing and that $24 \%$ was highly suited for bund systems. The choice of RWH technique, however, ultimately depended on land use and management practices. A preliminary site assessment should therefore be considered as the first step, which could lead to the adoption of the measure or ultimately to the continued use.

\subsubsection{MCA integrated with GIS}

The adoption of a GIS for combining sets of criteria to select suitable sites for RWH is generally based on using decision rules (Malczewski, 2004). In the present study we adopted two generally applied methods based on the application of MCA and a GIS (Table 2.6): the application of MCA in a GIS environment, and the application of a GIS followed by the definition of weights and scores for the criteria by AHP. In this group (group 4) of methods for selecting suitable sites for RWH, $37 \%$ of the 48 articles integrated MCA with a GIS without using HM, as in group 3.

In the first method, a suitability model was developed in Model Builder of ArcGIS to generate RWH suitability maps (Kahinda et al., 2008) by integrating input criteria maps using the weighted overlay process (WOP), also known as MCA within a GIS environment. WOP allowed the combination of data from several themes by converting cell values to a common scale, assigning weights and aggregating the weighted cell values. MCA can be achieved by using weighted linear combination (WLC) and/or the Boolean operators that are the most often used decision rules in a GIS (Al-Adamat et al., 2010). The WLC method 
provides better site selection because of its flexibility (range of scale) in selecting optimum sites, and the Boolean method, which uses either OR or AND operations, selects RWH sites limited to small separated locations(Malczewski, 2004).

The GIS-based RWH suitability model (RSM) developed by Kahinda et al. (2008) combined, by using MCA, the physical, ecological, socioeconomic and constraint layers for assessing the suitability of RWH sites in South Africa. The RSM model was developed using Model Builder in ArcView 3.3. Suitability values were assigned for different criteria based on a literature review. WOP was applied for a combination of data from several input grid themes to convert the values to a common scale. The model produced three types of RWH maps for in-field and ex-field RWH: physical, potential and suitability maps. The RSM model was applied and tested in two catchments, and the results indicated that about 30 and $25 \%$ of the sites were highly suitable for in-field and ex-field RWH, respectively. The RSM model has a high degree of flexibility to change or update criteria/weights. Moreover, determining the weights is ultimately a political decision, which is the best compromise amongst competing interests (Kahinda et al., 2008).

Al-Adamat et al. (2010) applied both the WLC and the Boolean techniques within a GIS environment to identify suitable locations for RWH (ponds) in northern Jordan. Six WLC criteria, rainfall, slope, soil type, distances to roads, distances to urban centres and distances to wadies, were then given weights and were rated and justified. The Boolean criteria eliminated some sites that had been selected by WCL. Seven Boolean criteria were used in this study: distances to international borders, distances to urban centres, distances to farms, distances to wadis, distances to roads, distances to geological faults and distances to wells. The constraint factors and their justifications based on those used by Al-Adamat (2008) were: distances (metres) to international borders, wadis, roads, urban centres, faults and wells. ArcGIS 9.1 generated both WLC and Boolean maps; $25 \%$ of the total area had high potential for implementing RWH (ponds), $43 \%$ was unsuitable, and $32 \%$ was least suitable.

In the second method, AHP provided a systematic approach to conducting MCA and decision-making. In this group, AHP and a GIS were used as a tool to make decisions based on expert and indigenous knowledge and on comparisons between alternatives. Firstly, a GIS was applied for collecting, analysing and storing thematic maps. MCA was then applied within a GIS environment (as in the first method), with the integration of AHP at the end to identify the weights for each criterion (Moges, 2009), or AHP was applied separately, without applying MCA in a GIS, for various criteria to determine the relative weight of each criterion (Mahmoud and Alazba, 2014; Tsiko and Haile, 2011). Secondly, suitable sites for RWH were identified based on the AHP weights. The relative weights between 
criteria were determined by applying pairwise comparison matrices and assigning the weights to the thematic layers. Pairwise comparison is most likely to reduce bias in the weights, making AHP a more effective MCA technique (Tsiko and Haile, 2011).

Moges (2009) used a GIS with MCA to identify suitable sites for RWH (ponds and in-situ systems) in Ethiopia. Six criteria were selected for the identification of suitable ponds: soil texture, soil depth, rainfall surplus, topography, land cover and groundwater depth. The same criteria except groundwater depth were selected for the identification of suitable insitu systems. WLC was used in the decision rules in the GIS. ArcGIS Model Builder was used to build the suitability model, which generated five suitability classes using WOP: very high, high, moderate, low and very low suitability. AHP was then applied to develop the weight for each criterion based on its relative importance to the other criteria and to the main objective. The criteria were rated based on a literature review, field-survey information and expert opinion. Maps for each criterion and for the overall suitability of sites for RWH were produced. Finally, two suitability maps were produced, one for ponds and another for in-situ systems. Forty-nine percent of the total area was very highly or highly suitable for ponds, and $60 \%$ was highly suitable for in-situ systems. The results from the suitability model were validated using field-survey information, and the validation results indicated that the produced maps have given a reliable map of the spatial distribution of suitable areas. Moreover, the suitability maps provided an easy resource for quickly identifying the most suitable areas.

\subsection{Discussion and conclusions}

The main objective of this study was to define a general method for selecting suitable RWH sites in ASARs based on methods developed throughout the last three decades. The success of RWH systems depends heavily on the identification of suitable sites and on their technical design (Al-Adamat et al., 2012). The 48 articles we reviewed indicated that the way sites are selected has shifted over time, reflected in the three sets of guidelines: IMSD, (1995), Oweis, (1998) and FAO (2003) (see Table 2.2). The main sources of criteria used by most of the 48 studies followed or were derived from one of these three sets.

The selection criteria for suitable RWH sites was the first important change. Studies in the 1990s (e.g. Gupta et al., 1997; Padmavathy et al., 1993; Prinz et al., 1998) focused primarily on biophysical criteria. After 2000, socioeconomic parameters were integrated with the biophysical criteria (e.g. De Winnaar et al., 2007; Senay and Verdin, 2004; Yusof et al., 2000). Studies concluded that socioeconomic criteria were needed to improve the selection of suitable sites following the general trends, such as integrated watershed 
management (Gregersen et al., 2007). in which the development and management of water are linked to economic and social welfare.

The biophysical criteria are similar for all types of RWH, but no consensus has been reached for the social-economic criteria to use for the selection of suitable sites and RWH techniques. The most common criteria applied in ASARs along with the RWH techniques (as a percentage of all studies reviewed) were: slope (83\%), land use/cover (75\%) and soil type (75\%) (Table 2.3 to Table 2.6). Rainfall is a major component in any RWH system, and RWH systems can only function if a catchment receives sufficient rainfall to store, but only $56 \%$ of all studies reviewed included rainfall. Slope was the most common criterion. Slope plays a significant role in the amounts of runoff and sedimentation, the speed of water flow and the amount of material required to construct a dyke (the required height). The most commonly applied socioeconomic criteria were: distance to settlements (25\%), distance to streams $(15 \%)$, distance to roads $(15 \%)$ and cost $(8 \%)$. These technical and socioeconomic criteria are closely linked with each other, but we can distinguish between primary and secondary criteria. For most RWH techniques, rainfall (distribution and rain intensity over the year), soil type (texture and saturated hydraulic conductivity), and slope are the basic criteria that determine the technical suitability of a location. The primary criteria are based on the goals of both RWH and the biophysical conditions and determine the technical suitability of a location and/or RWH system. Primary criteria, however, do not guarantee success. Failure is often due to other reasons associated with socioeconomic parameters. Our results show less consensus about these secondary criteria, which may be case-specific.

Selecting the most relevant socioeconomic criteria requires not only good insight into the local situation and stakeholders involved, but also access to data on costs and benefits and insight into the indirect economic effects and social parameters such as labour availability, land and water rights and risks of flooding. The literature review, however, indicated that insufficient insight into the socioeconomics was one of the main reasons that RWH sites failed to function properly in ASARs. The FAO (2003) guidelines may therefore be the most comprehensive set of instructions for the efficient planning and implementation of new RWH systems. These guidelines contain most of the factors that directly affect the performance of RWH and those directly related to the crop and water requirements, and the FAO has a wide range of suitability values for various factors such as slope, soil texture and rainfall. Moreover, the FAO guidelines include several socioeconomic criteria, e.g. population density, people's priorities, experience with RWH and land tenure, which are important factors to ensure the success of RWH and to increase the adoption of new RWH technology. 
We identified four main methods from the sources of information reviewed that have been used for selecting suitable sites for RWH in ASARs. A GIS supported by RS has been extensively applied either alone or integrated with HM and/or MCA (Tables 2.3-2.6). MCA integrated with GIS (group 4) was used to identify RWH sites in ASARs in $37 \%$ of the 48 studies reviewed, which was the highest percentage amongst the four groups, whereas the group 2 methods were used in about 15\% of the sources, which was the lowest percentage.

Determining the most helpful method for selecting suitable RWH sites is a great challenge. Table 2.7 presents a comparison of the four methods/tools based on the characteristics and requirements of the ASARs, the properties of each method, specific data requirements, applicability to different regions, accuracy and limitations, previous studies and the ability of a method to be applied in different regions.

Each of the four methods has been applied separately in different regions with different criteria, but most sources of information provided little information on the RWH success rate for the selected sites. Field results comparing two or more methods used in the same watershed to identify the main similarities and contrasts are therefore not available. Our analysis of strengths and weaknesses suggests that the integration of MCA and GIS is the most advanced method and provides a rational, objective and unbiased method for identifying suitable sites for RWH. Isioye et al. (2012), Moges (2009) and Al-Adamat et al. (2010) reported similar conclusions. MCA with a GIS has been found to be a robust method that is highly compatible with the indigenous knowledge of the farmers (Tumbo et al., 2014).

The most suitable method for application in a particular case is highly dependent on the main objectives and needs of the project (e.g. flexible, widely applicable, efficient and accurate) and on the quality, availability and reliability of the data. We highly recommend that future studies apply two or more of these four methods in the same region to identify the best method. 


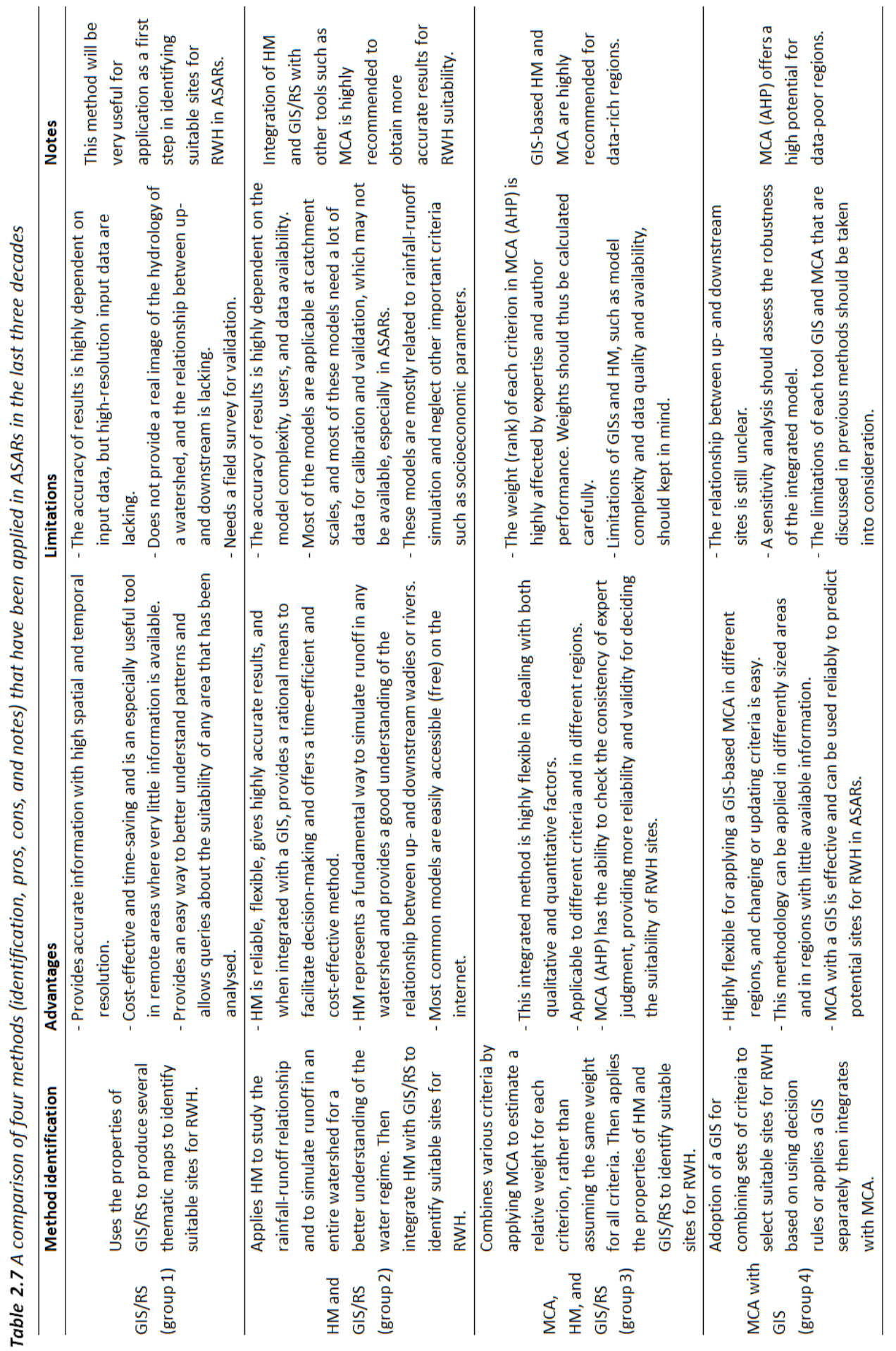




\section{A GIS-Based Approach for Identifying Potential Sites for Harvesting Rainwater in the Western Desert of Iraq}

People living in arid and semi-arid areas with highly variable rainfall and unforeseeable periods of droughts or floods are severely affected by water shortages and often have insecure livelihoods. The construction of dams in wadis to harvest rainwater from small watersheds and to induce artificial groundwater recharge is one of the solutions available to overcome water shortages in the western desert of Iraq. The success of rainwater harvesting (RWH) systems depends heavily on their technical design and on the identification of suitable sites. Our main goal was to identify suitable sites for dams using a suitability model created with Model Builder in ArcGIS 10.2. The model combined various biophysical factors: slope, runoff depth, land use, soil texture and stream order. The suitability map should be useful to hydrologists, decision-makers and planners for quickly identifying areas with the highest potential for harvesting rainwater. The implementation of this method should also support any policy shifts towards the widespread adoption of RWH.

This chapter is submitted as:

Adham A., Khamis, N., Wesseling, J. G., Riksen, M.J.P.M., Abed, R., Ritsema, C.J., et al. (2017); A GIS- based approach for identifying potential sites for harvesting rainwater in the Western Desert of Iraq. Submitted to Journal of Arid Land. 


\subsection{Introduction}

Until the 1970s, Iraq was commonly considered to have rich water resources due to the Tigris and Euphrates Rivers. The construction of dams in these rivers and their tributaries outside the Iraq border, together with the effects of global climate change and the mismanagement of water resources, however, have caused water shortages in Iraq. The growing demand for water in Turkey and Syria could lead to the drying of the Tigris and Euphrates Rivers by 2040 (Al-Ansari et al., 2014). People living in arid areas with highly variable rainfall and unforeseeable periods of droughts or floods, such as Iraq's western desert, are the most affected by climate and scarcity of water and often have insecure livelihoods. The use of non-conventional water resources, e.g. rainwater harvesting (RWH), can overcome the water shortages in Iraq. The database of the World Overview of Conservation Approaches and Technologies (Mekdaschi Studer and Liniger, 2013) defined RWH as: "The collection and management of floodwater or rainwater runoff to increase water availability for domestic and agricultural use as well as ecosystem sustenance". The main role of RWH is to increase the amount of available water by capturing rainwater in one area for local use or for transfer to another area. RWH has been used in Iraq for more than 5000 years (Ben Mechlia and Ouessar, 2004). The construction of dams on wadis in recent decades to harvest water from small watersheds and for inducing artificial groundwater recharge has become an acceptable practice in these regions (Abdulla et al., 2002). The success of RWH systems depends heavily on their technical design and the identification of suitable sites (Adham et al., 2017 and Al-Adamat et al., 2012). More than the financial terms and economic benefits are now considered. Populational and environmental aspects play major roles. Properly planning, designing and implementing dam construction would improve the availability of rainwater for domestic use and agricultural development.

Various methodologies have been developed for the selection of suitable sites and techniques for RWH (Ahmad, 2013). Field surveys are the most common method for small areas. The identification of appropriate sites for the various RWH technologies in large areas is a great challenge (Prinz et al., 1998). Şen and Al-Suba'l (2002) identified and evaluated the factors that could affect dam location in catchments and hence the planning of water resources of proposed reservoirs. These authors studied the effects of sedimentation and flooding on dam location and construction in Saudi Arabia. Forzieri et al. (2008) presented a methodology for assessing the suitability of sites for dams. The selection criteria were defined both qualitatively and quantitatively and were based on a territorial analysis using satellite data in combination with hydrological and climatological information. The methodology is particularly useful in areas where very little territorial information is available, such as most developing countries, and has been applied in the 
region of Kidal in Mali, where 66 sites were assessed, of which only 17 satisfied the proposed selection criteria. The authors selected suitable construction sites from prevalent engineering and technical perspectives and neglected others such as sociopolitical perspectives (Forzieri et al., 2008). Weerasinghe et al. (2011) focused on using a geographic information system (GIS) and remote sensing (RS). They developed an integrated methodology for assessing water management. The model accordingly specifies potential water-harvesting and -storage sites for water storage and soil-moisture conservation on farms (Weerasinghe et al., 2011). Ammar et al. (2016) reviewed the methodologies and the main criteria that have been applied in arid and semi-arid regions (ASARs) during the last three decades. They categorised and compared four main methodologies of site selection, identified three main sets of criteria for selecting RWH locations, and identified the main characteristics of the most common RWH techniques used in ASARs. The methods were diverse, ranging from those based only on biophysical criteria to more integrated approaches, including the use of socioeconomic criteria, especially after 2000. Most studies now select RHW sites using GISs in combination with hydrological models and/or multi-criteria analysis (MCA). The identification of suitable sites for RWH is an important step towards maximising water availability and land productivity in ASARs. Integrated studies of runoff modelling, GISs, and RS have successfully targeted sites suitable for RWH (Adham et al., 2016a,b; De Winnaar et al., 2007; Padmavathy et al., 1993). GISs and RS can meet the challenges of missing data required for the selection of potential sites for $\mathrm{RWH}$, especially in ASARs.

The main objective of the present study was to identify suitable sites and the number of dams required to harvest rainwater in an arid region (wadi Horan, Western desert of Iraq) by integrating runoff modelling and a GIS.

\subsection{Materials and methods}

\subsubsection{The study area}

Wadi Horan is in the western part of Iraq in Al-Anbar province, about $450 \mathrm{~km}$ west of the capital Baghdad (Figure 3.1). The catchment has an area of $13370 \mathrm{~km}^{2}$ and an arid climate with dry summers and cool winters. The mean annual rainfall is very low $(75-150 \mathrm{~mm})$. About $49 \%$ of the rain falls in winter, $36 \%$ in spring, $15 \%$ in autumn, and no rain falls in summer. The mean annual temperature is $21^{\circ} \mathrm{C}$, July is the hottest month, and January is the coldest month (Sayl, 2016). The average annual potential evaporation is $3200 \mathrm{~mm}$, and the monthly average evaporation varies strongly with season (Sayl et al., 2016). The wadi 
is completely dry during most of the year, but short intense floods occur during the rainy season.

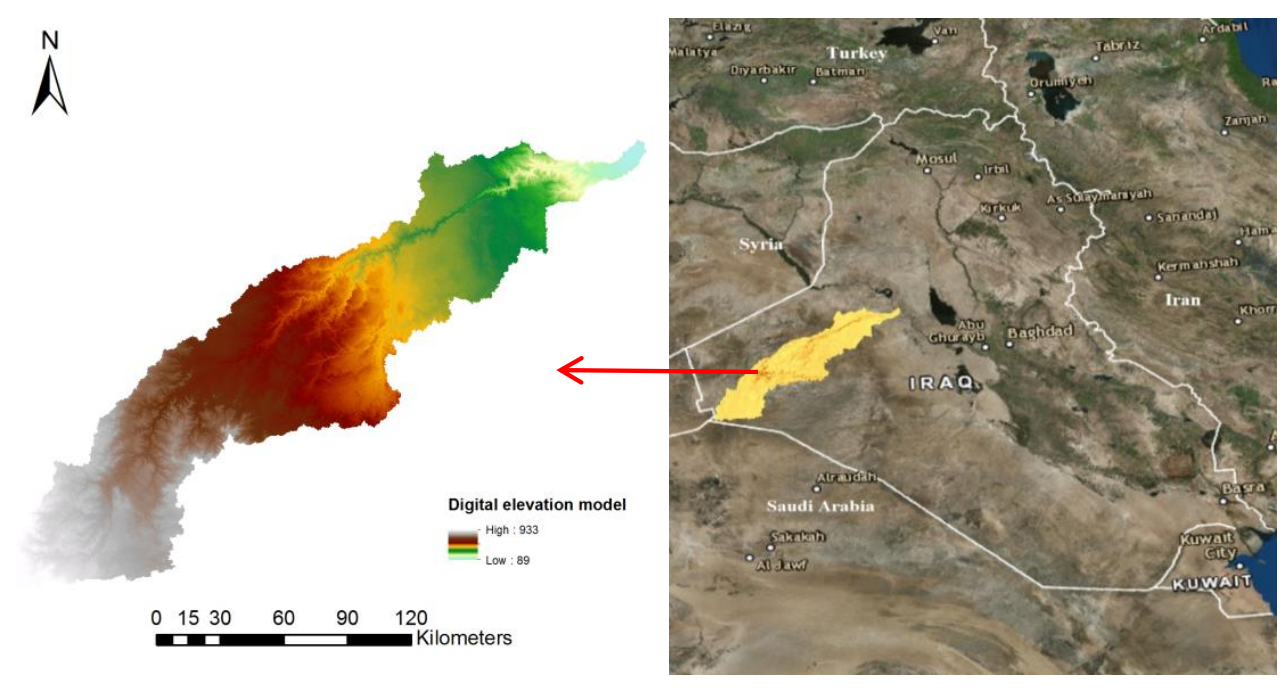

Figure 3.1 Location of the wadi Horan watershed.

Dams are one way to store rainwater in the rainy seasons for use in the dry seasons and are effective structures for the proper use of water in Iraq.

Most of the exposed rocks in the wadi Horan are hard limestone (Alhadithi and Alaraji, 2015). They provide a good base for dams or barriers and can be used to cover the front side of the barrier. The sites of the dams were selected by their drainage area and the availability of a hard, narrow cross-section of the valley with high shoulders to minimise the amount of construction material needed for building the dams, minimise evaporation losses and ensure the required storage.

\subsubsection{General approach}

The identification of suitable sites for RWH consists of four steps:

I. Selection of appropriate criteria;

II. Classification of suitability for each criterion;

III. GIS analysis and generation of suitability maps;

IV. Site identification. 


\subsubsection{Criteria selection}

Food and Agriculture Organization (FAO) lists six key factors for the assessment of sites for soil water conservation: climate, hydrology, topography, agronomy, soils and socioeconomics (Kahinda et al., 2008). Five of these criteria were used to identify potential sites for small dams based on a literature review, expert judgment and most importantly available data. We followed the recommendations of the FAO and used rainfall and runoff as parameters for climate, stream-flow order as a parameter for hydrology, slope as a parameter for topography, land use/cover as a parameter for agronomy and soil texture as a parameter for soils. We did not include socioeconomic criteria.

\section{Slope}

Slope plays an important role in the generation of runoff and thus influences the amount of sedimentation, the speed of water flow, and the amount of material required to construct dams (dyke height) (Adham et al., 2016a). Critchley et al. (1991) did not recommend water harvesting for areas with slopes $\geq 5 \%$, because they are susceptible to high erosion rates due to irregular runoff distribution and because large earthworks are required (Al-Adamat et al., 2010). A digital elevation model (DEM) with 30-m resolution was used to generate a slope map (Figure 3.2a). Sinks and flat areas were removed using ArcGIS 10.2 to maintain the continuity of water flow to the catchment outlet. The slopes were then reclassified to generate the map (Figure 3.2b).

\section{Runoff depth}

Runoff depth is an important criterion for selecting suitable sites of RWH. Runoff depth is used to assess the potential water supply during runoff. The curve number (CN) provided by the soil conservation service was used to estimate the runoff depth. $\mathrm{CN}$ is predictable from the effects of soil and land cover on rainfall/runoff. CN was estimated for each pixel for the study area using the land-cover and soil-texture maps. Runoff depth can be expressed as:

$$
Q=\frac{\left(P-I_{a}\right)^{2}}{\left(P-I_{a}\right)+S}
$$

where $Q$ is runoff depth $(\mathrm{mm}), P$ is precipitation $(\mathrm{mm}), \mathrm{S}$ is potential maximum retention after the onset of runoff $(\mathrm{mm})$ and $\mathrm{I}_{\mathrm{a}}$ is an initial abstraction $(\mathrm{mm})$ that includes all losses before the onset of runoff, infiltration, evaporation and water interception by vegetation. Using $\mathrm{l}_{\mathrm{a}}=0.2 \mathrm{~S}$ determined by analysing the rainfall data for many small agricultural basins (Melesse and Shih, 2002). Eq. 3-1 can therefore be expressed as:

$Q=\frac{(P-0.2 S)^{2}}{(P+0.8 S)}$ 

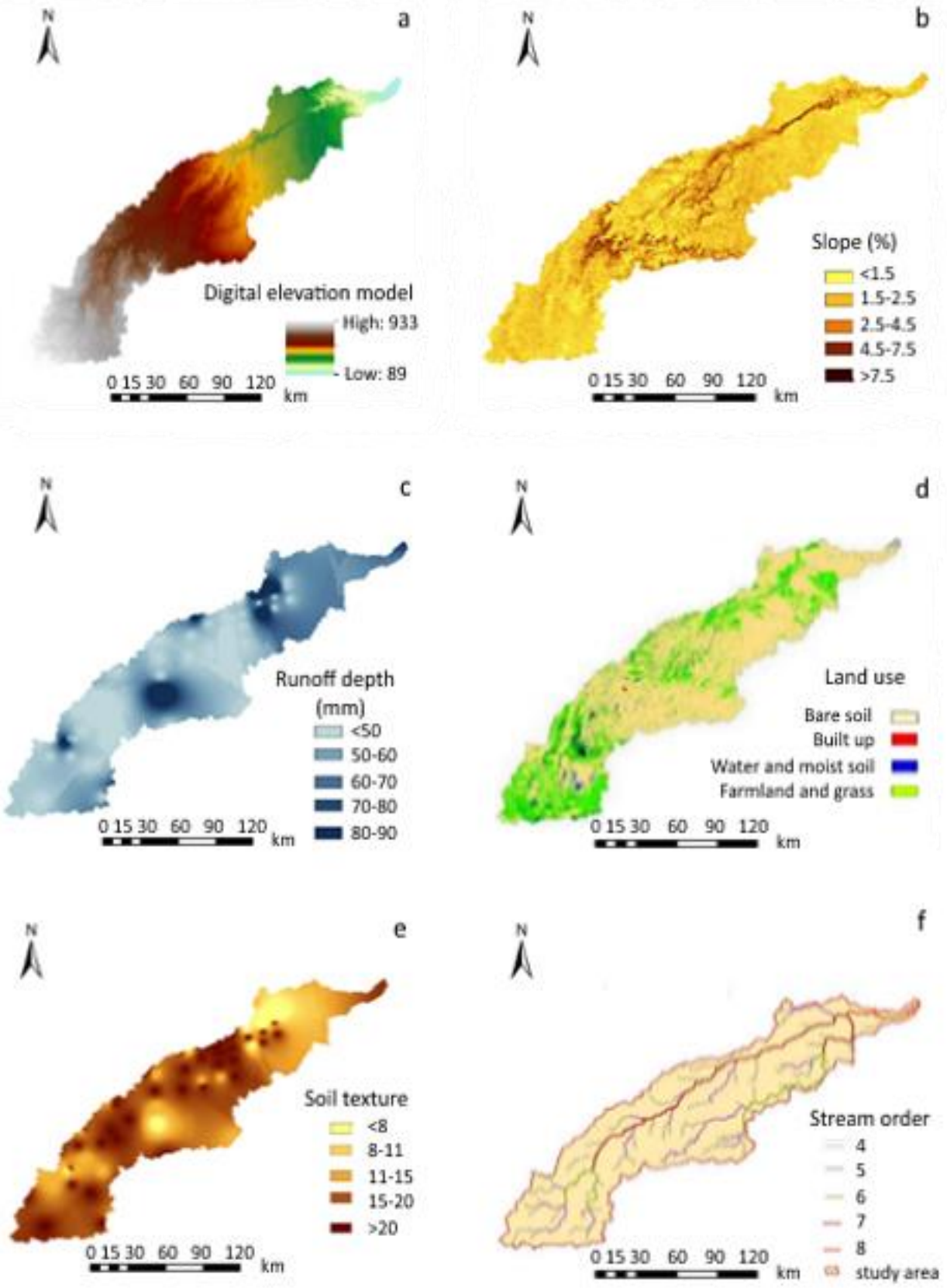

Figure 3.2 Digital elevation model (a) and the spatial analyses for slope (b), runoff depth (c), land use (d), soil texture (e) and stream order (f). 
$\mathrm{S}$ can be calculated using $\mathrm{CN}$ as:

$S=\frac{25400}{C N}-254$

$\mathrm{CN}$ varies from 0 to 100 and represents the runoff response to a given rain. High CNs indicate that a large proportion of the rainfall will become surface runoff (Krois and Schulte, 2014). The downstream area of the watershed had more runoff than the upstream area (Figure 3.2c).

Land cover/use

Land cover is correlated with the runoff produced for each rain in a given area. For example, denser vegetation is correlated with higher rates of interception and infiltration and thus lower runoff (Kahinda et al., 2008). Land cover was obtained from satellite imagery (Landsat 8-2013) with a spatial resolution of $30 \mathrm{~m}$. A maximum-likelihood algorithm was used to classify land cover using the means, variances and covariances from the signature. Four types of land cover were identified: bare soil, built up areas, water and moist soil and farmland and grass (Figure 3.2d).

\section{Soil texture}

Soil texture affects both the rate of infiltration and the surface runoff. The textural class of a soil is determined by the percentages of sand, silt and clay. White (1987) indicated that fine- and medium-textured soils were generally more desirable for RWH because of their higher retention of water. Soils with high water-holding capacities are more suitable for RWH (Adham et al., 2016a). Sites with clay soil are the best for water storage due to the low permeability of clay and its ability to hold the harvested water (Mbilinyi et al., 2007). Soil texture will therefore likely be a critical criterion for selecting a site for a RWH scheme, especially if the purpose is to preserve the water for human, livestock and agricultural purposes (Al-Adamat, 2008). Figure 3.2e shows the variety of soil texture based on clay content.

\section{Stream order}

The wadis in the wadi Horan watershed are the main sources of surface water. The water collected during the winter is used for human needs, watering livestock and other agricultural purposes (Al-Adamat, 2008). The suitability of RWH (dams) depends on wadi density, with highly dense areas as the most suitable. Stream order is based on the connection of tributaries. The order of a stream denotes the hierarchical connection amongst stream segments and permits the categorisation of drainage basins by their size. The analysis of stream order for mapping RWH is important, because lower stream orders have higher permeability and infiltration and vice versa. Moreover, dendritic drainage 
patterns due to the linking of streams have homogeneous soil texture and a lack of structural control. The map of stream order is presented in Figure 3.2f, where potential RWH sites are classified as very low (<4), low (5), moderate (6), high (7) and very high (>7).

\subsubsection{Classification of suitability for each criterion}

Each criterion was first classified due to the variety of measurements and scales for the various criteria. The parameters listed in Table 3.1 were used to classify pixel values from 0 to 10 . The scores reported in Table 3.1 were discussed and adjusted together with technical experts. The most suitable areas were classified as 10 , and the least suitable were classified as 0 .

Table 3.1 Criteria, classification, suitability levels and scores for each criterion for identifying suitable sites of RWH in arid and semi-arid regions.

\begin{tabular}{|c|c|c|c|}
\hline Criterion & Class & Value & Score \\
\hline \multirow[t]{5}{*}{ Runoff depth (mm) } & Very high suitability & $80-90$ & 9 \\
\hline & Medium suitability & $70-80$ & 8 \\
\hline & Suitable & $60-70$ & 4 \\
\hline & Low suitability & $50-60$ & 3 \\
\hline & Very low suitability & $<50$ & 1 \\
\hline \multirow[t]{5}{*}{ Slope (\%) } & Flat & $<1.5$ & 3 \\
\hline & Undulating & $1.5-2.5$ & 9 \\
\hline & Rolling & $2.5-4.5$ & 5 \\
\hline & Hilly & $4.5-7.5$ & 2 \\
\hline & Mountainous & $>7.5$ & 1 \\
\hline \multirow[t]{5}{*}{ Land use/cover } & Farmland and grass & Very high & 9 \\
\hline & Moderately cultivated & High & 7 \\
\hline & Bare soil & Medium & 5 \\
\hline & Mountain & Low & 1 \\
\hline & Water body, urban area & Restricted & Restricted \\
\hline \multirow[t]{5}{*}{ Soil texture } & Very high suitability (clay) & $>20$ & 9 \\
\hline & High suitability (silty clay) & $15-20$ & 7 \\
\hline & Medium suitability (sandy clay) & $11-15$ & 4 \\
\hline & $\begin{array}{l}\text { Low suitability (sandy clayey loam and } \\
\text { sandy loam }\end{array}$ & $8-11$ & 3 \\
\hline & Very low suitability (other) & $<8$ & 1 \\
\hline \multirow[t]{5}{*}{ Stream order } & Very high suitability & $>7$ & 9 \\
\hline & High suitability & 7 & 8 \\
\hline & Medium suitability & 6 & 3 \\
\hline & Low suitability & 5 & 2 \\
\hline & Very low suitability & $<4$ & 1 \\
\hline
\end{tabular}

Scaled maps were produced for each criterion with pixel values ranging from 0 to 10 . An integrated suitability map was produced by combining criterion layers using a raster calculator. Suitability values were then classified into five classes: very high suitability, high suitability, medium suitability, low suitability and very low suitability. Table 3.1 shows the 
assigned scores based on discussions and consultations with experts and on published information.

\subsubsection{GIS analysis and generation of suitability maps}

The GIS database required for identifying potential sites for RWH was developed using ArcGIS with both vector and raster databases. A suitability model was developed using Model Builder in ArcGIS 10.2 to implement all processes for identifying sites suitable for RWH (Figure 3.3). Areas suitable for dams were identified by reclassifying layers of biophysical criteria and combining them using the raster calculator tool in the spatial analyst module of ArcGIS 10.2. Each criterion was clipped to the study area, reclassified to numeric values, and assigned suitability rankings for dams based on Table 3.1

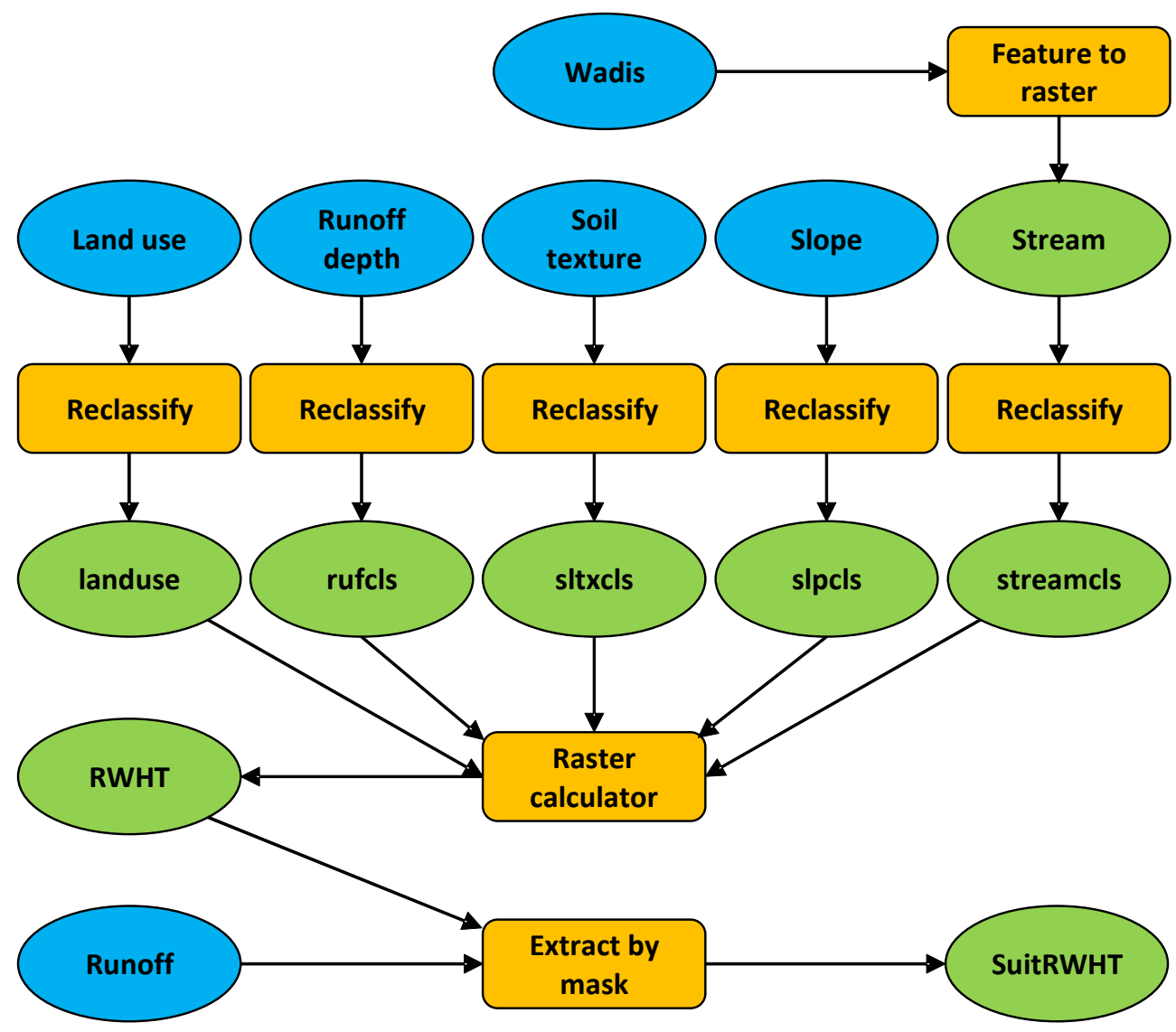

Figure 3.3 Flow chart for the identification of potential RWH sites. 


\subsubsection{Site identification}

The most suitable sites for dams were identified by the visual interpretation of satellite images and analyses of large-scale cartography. The selected sites were then assessed by the other criteria to identify the best sites for RWH (dams). A suitable site for a dam is "a place where a wide valley with high walls leads to a narrow canyon with tenacious walls" (Sayl et al., 2016). Such sites minimise dam dimensions and costs, but steep valley slopes should be given a low priority, because dams at such sites are rarely economical. Narrow valleys are best identified from shuttle radar topography mission (SRTM) data and satellite images (Quickbird satellite images). Valley width is best estimated by visual interpretation elaborated by SRTM in GIS (global mapper 10).

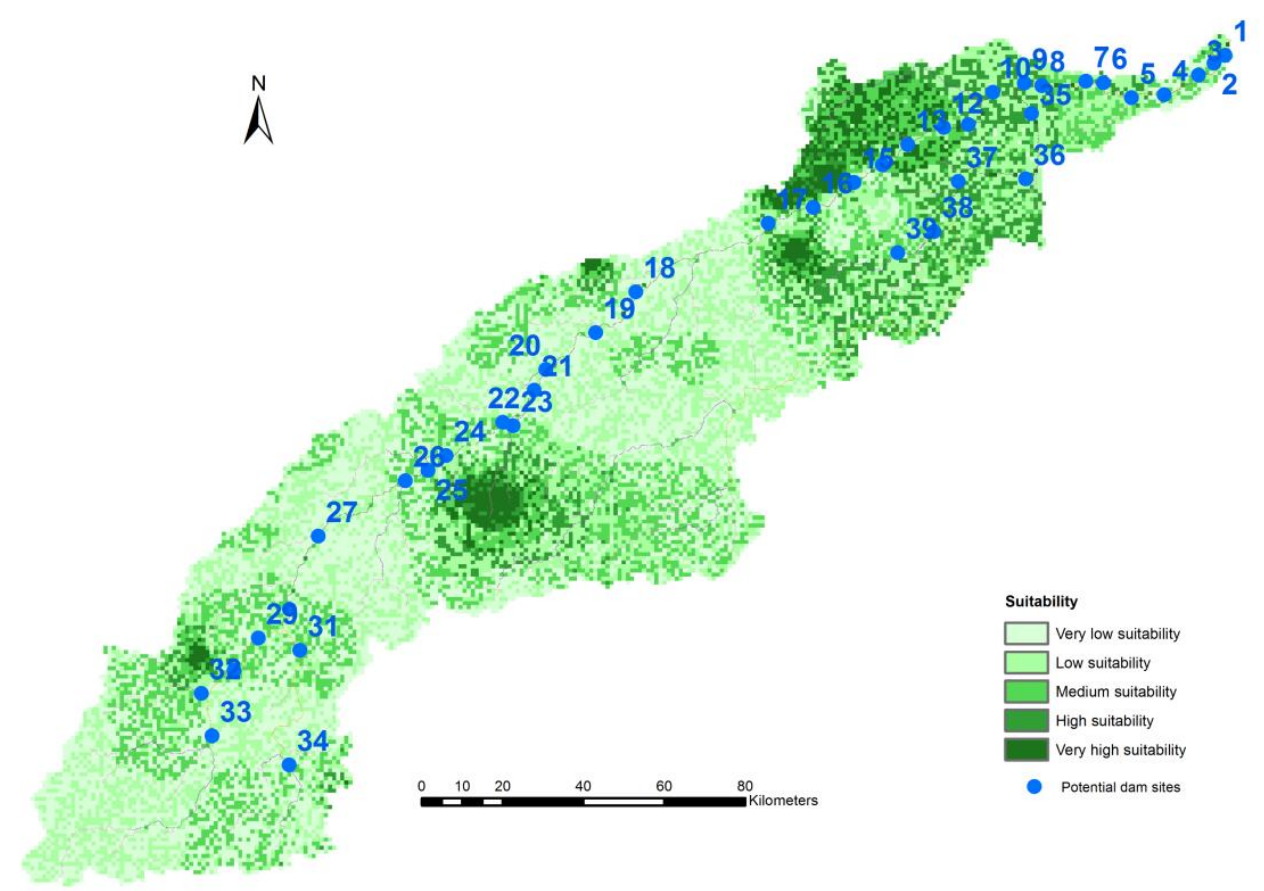

Figure 3.4 Suitability map for the identification of potential dams.

\subsection{Results and discussion}

The first step in the methodology is to prepare all data for the main criteria. The DEM with 30-m resolution was clipped and extracted. From this DEM the slopes of the watershed were extracted. The spatial analysis of the main criteria is shown in Figure 3.2. Slope and runoff were correlated: runoff increased with slope (Figure 3.2b, c). Slopes were clearly steeper in the mountainous area (upstream) and along the main wadi. Runoff depth 
increased towards the downstream area of the watershed. Four land use classes were distinguished, with bare soil covering more than $70 \%$ of the watershed. Urban areas and water bodies occupied only a small percentage of the area (Figure 3.2d).

The five main layers were integrated, but each pixel had a different score based on Table 3.1, when reading them into Model Builder in ArcGIS 10.2. The suitability model generated a map with five classes of RWH suitability: very high suitability, high suitability, medium suitability, low suitability and very low suitability (Figure 3.4).

These results show that most of the downstream area of the watershed was suitable for water harvesting. This area had steeper slopes and dense hydrological networks. The majority of the areas with very high to high suitability had slopes between 1.5 and $4.5 \%$ and were intensively cultivated. The main soil texture in the areas with very high and high suitability were clay and silty clay, and the runoff depth varied between 70 and $90 \mathrm{~mm}$. Runoff depth and slope were the main criteria for identifying areas as ones with low and very low RWH suitability. These results are in agreement with those of Mbilinyi et al. (2005), who indicated that areas having gentle to moderate slopes combined with soils which have a high water-holding capacity, such as clay and silty clay, were suitable for constructing RWH structures.

Dams are the most common and suitable RWH structure in this catchment and are used for a long time. The main characteristic of the dams was that they were in the main wadi stream. The application of our five layers and the multi-criterion option of ArcGIS yielded the suitable locations for these dams (Figure 3.4). Potential dam locations were chosen based on estimates of the available runoff that could be stored behind the dams. We identified 39 potential sites that were compatible with the suitable areas identified in the first step (Figure 3.4) based on the visual interpretation of satellite images and an analysis of large-scale cartography. To assist planners in analysing the match between water supply and water demand, the reservoir capacities must be known to quantify the available water volume at any level. Each potential dam site was further analysed by calculating characteristics such as storage area, required length and height of the dam. Examples of cross-sections are shown in Figure 3.5 (left) for three sites: one in the upstream area (No. 31), the central area (No. 22) and the downstream are (No. 13) of the watershed. The volumes and heights of the dams were calculated from a triangulated irregular network using the tools of ArcGIS. The final thematic maps showed different layers, representing water level at different depths shown in Figure 3.5 (right). This figure shows the surface area for the three reservoirs. Evaporation losses might be extremely high and will increase with an increasing surface area of the stored water. Therefore, the optimal dam heights with maximum storage of water and minimum surface area of 
reservoir are required especially in arid regions with high evaporation losses. In addition, the capacity of the reservoir that can be estimated by computing the surface area and reservoir depth at any level is a vital concern in reservoir operation and management.

No 13
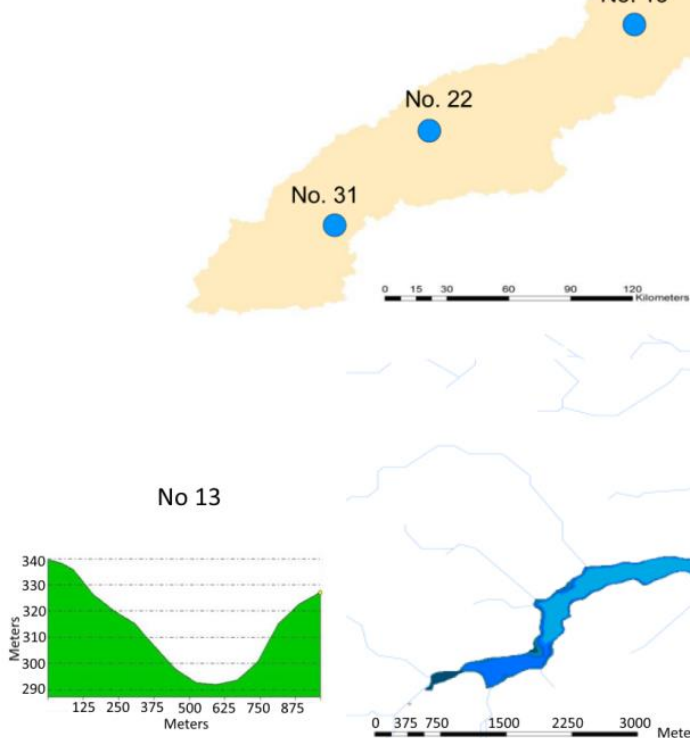

0

No 22
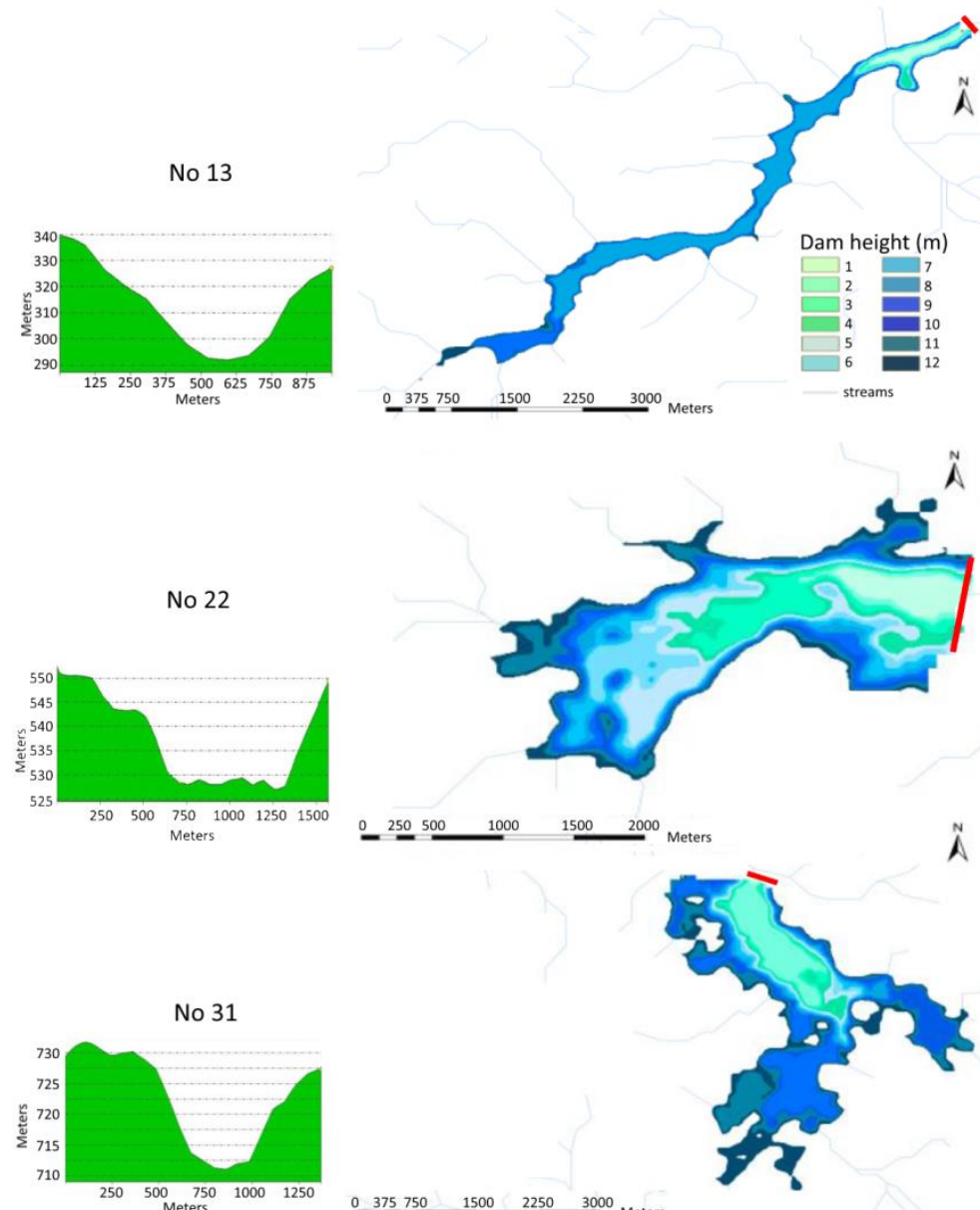

No 31

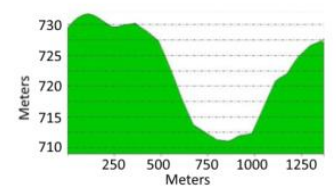

0 $375 \underline{750 \quad 1500 \quad 2250 \quad 3000}$ Meters

$\hat{A}$

Figure 3.5 Study area with three potential dams locations. Cross-sections of the three sites in the upstream (No. 31), central (No. 22), and downstream (No. 13) areas of the watershed (left), and the generated thematic maps for each of three dams that represent the water level at different depths (right). 
To show the relationship between dam height and storage capacity, we considered the three locations presented in Figure 3.5 again. From the area of the reservoir and the depth of water at each point the storage of water was computed (assuming the water level reaches the top of the dam). These results are presented in Figure 3.6. It can be seen there is a nearly linear relationship between storage capacity and dam height for dam 13 . This is in agreement with the results shown in Figure 3.5 where each additional meter in dam height causes about the same increase in storage area. The data for dam 22 show hardly any storage difference until the dam is $7 \mathrm{~m}$ high. If the height exceeds $7 \mathrm{~m}$, a large area will be flooded and storage capacity will increase. This increase is even stronger for dam 31 when it exceeds $8 \mathrm{~m}$. These data are presented as an illustration of the method only, because these dam heights may not be feasible in practice (movement of material, width of dam, cost of labour, etc.).

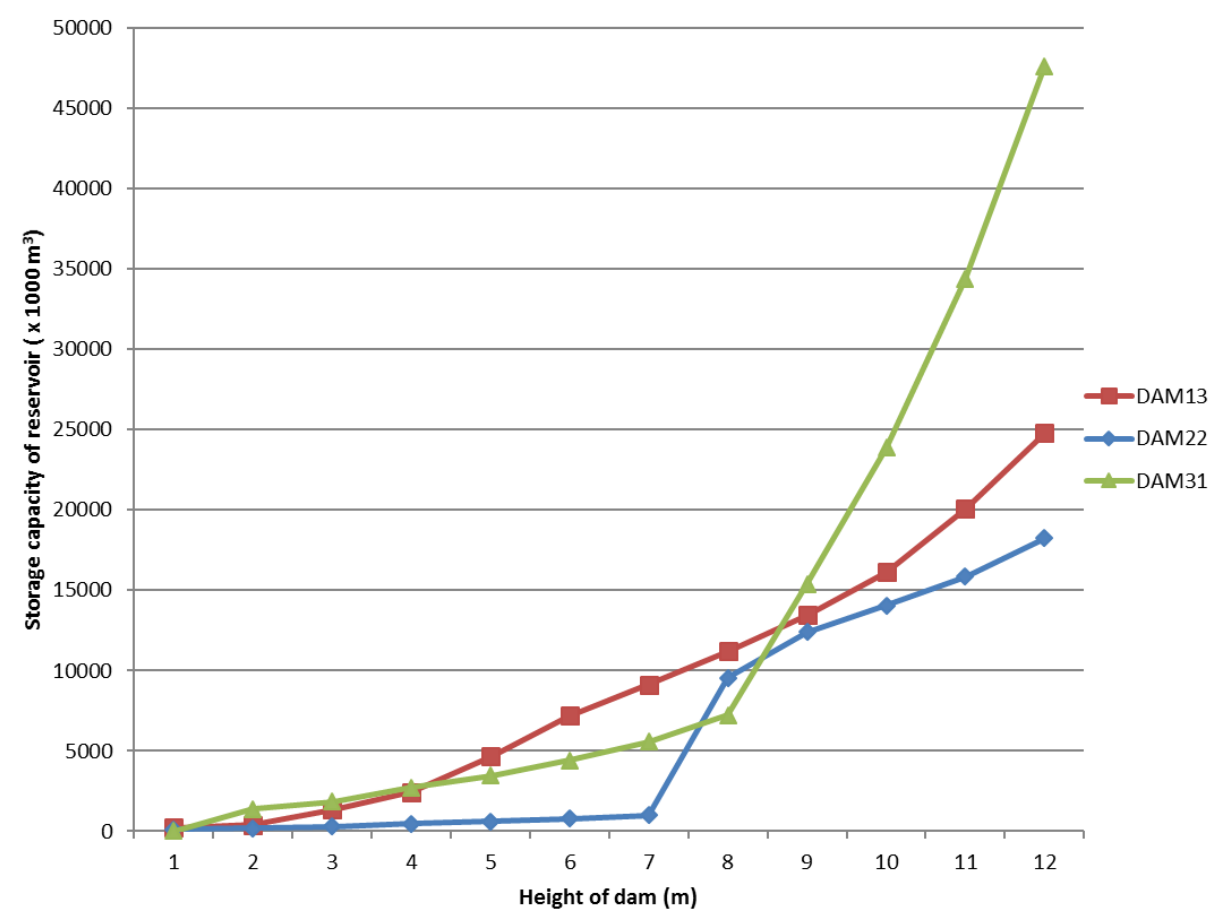

Figure 3.6 The storage capacity of the three reservoirs presented in Figure 3.5 as function of the dam height.

The success of an intervention depends not only on technical aspects, as in this study, but also on how well it fits within the stakeholder's social context and the economic benefit it provides him/her. Several socioeconomic criteria can have an influence, such as ownership, distance to settlements/roads and education, but identifying good indicators associated with the functioning of these RWH systems is much more difficult for 
socioeconomic than for biophysical conditions. The inclusion of socioeconomic criteria is thus very important for obtaining meaningful information for improving the effectiveness of current RWH systems and for planning future structures.

\subsection{Conclusions}

Potential RWH sites were identified using a GIS-based suitability model, created with Model Builder in ArcGIS 10.2. The suitability model combined biophysical factors: slope, runoff depth, land use, soil texture and stream order. The present study found that ArcGIS was a very useful tool for integrating diverse information to find suitable sites for dams for harvesting rainwater. ArcGIS was a flexible, time-saving and cost-effective tool for screening large areas for their suitability of RWH intervention.

The suitability map will be useful to hydrologists, decision-makers and planners for quickly determining areas that have RWH potential. Map quality depended on the quality and accuracy of the data, including how the data were gathered, processed and produced. High-quality data provided the most reliable and efficient output.

Socioeconomic criteria can also be important for water harvesting. Social and economic factors should be studied in more detail and seriously taken into account. Fieldwork should be carried out on the selected sites to ensure that they do not conflict with other land uses in the area that the available GIS data do not identify.

The analysis as presented, however, provides a first valuable screening of large areas and can easily be modified to incorporate other criteria or information with other spatial resolutions. 


\section{A Methodology to Assess and Evaluate Rainwater Harvesting Techniques in (Semi-) Arid Regions}

Arid and semi-arid regions around the world face water scarcity problems due to lack of precipitation and unpredictable rainfall patterns. For thousands of years, rainwater harvesting (RWH) techniques have been applied to cope with water scarcity. Researchers have used many different methodologies for determining suitable sites and techniques for RWH. However, limited attention has been given to the evaluation of RWH structure performance. The aim of this research was to design a scientifically-based, generally applicable methodology to better evaluate the performance of existing RWH techniques in (semi-) arid regions. The methodology integrates engineering, biophysical and socioeconomic criteria using the analytical hierarchy process (AHP) supported by the geographic information system (GIS). Jessour/Tabias are the most traditional RWH techniques in the Oum Zessar watershed in southeastern Tunisia, which were used to test this evaluation tool. Fifty-eight RWH locations (14 jessr and 44 tabia) in three main subcatchments of the watershed were assessed and evaluated. Based on the criteria selected, more than 95\% of the assessed sites received low or moderate suitability scores, with only two sites receiving high suitability scores. This integrated methodology, which is highly flexible, saves time and costs, is easy to adapt to different regions and can support designers and decision makers aiming to improve the performance of existing and new RWH sites.

This chapter is published as:

Adham, A., Riksen, M., Ouessar, M. and Ritsema, C. J. (2016). A methodology to assess and evaluate rainwater harvesting techniques in (semi-) arid regions. Water, 8(5), 198. 


\subsection{Introduction}

Aridity and climate change are the major challenges, especially in arid and semi-arid regions, people are faced with low average annual rainfall and high variability in temporal and spatial distribution. In order to increase the availability of water for domestic use, crop production and cattle grazing, inhabitants of dry areas have constructed and developed several types of rain water harvesting techniques (RWH). RWH is a method for inducing, collecting, storing and conserving local surface runoff in arid and semi-arid regions (Boers and Ben-Asher, 1982). RWH is a likely viable option to increase water productivity at the production system level (Kahinda et al., 2007). RWH and management techniques have a significant potential for improving and sustaining the water availability and rainfed agriculture in the region (Lasage and Verburg, 2015). In fact, a wide variety of micro-catchment, macro-catchment and in situ RWH techniques are available in arid and semi-arid regions. The indigenous techniques, or those modified by the indigenous RWH practices, are more common and widely accepted by smallholder than the others (Biazin et al., 2012). Throughout history, archaeological evidence has revealed RWH sites that were implemented in Jordan, the Al-Negev desert, Syria, Tunisia and Iraq. The earliest signs of RWH are believed to have been constructed over 9000 years ago in the Edom Mountains in southern Jordan (Al-Adamat, 2008; Ammar et al., 2016). The most common RWH techniques in arid and semi-arid regions are dams, terracing, ponds and pans, percolation tanks and nala bunds.

Tunisia is an example of the Mediterranean countries that are facing scarcity of water which will be worsened due to climate change, growing demand for water in agricultural and urban development and an expanding tourism industry (Ouessar et al., 2004). To adapt to this development, Tunisians have developed and implemented several types of water harvesting techniques of which the most common are jessour, tabias, terraces, cisterns, recharge wells, gabion check dams and mescats (Mechlia et al., 2009; Oweis, 2004).

The success of RWH systems depends mainly on the identification of suitable sites and technologies for the particular area. Soil conservation service (SCS) with curve number (CN), geographic information system (GIS), remote sensing (RS) and integrated GIS, RS with multi-criteria analysis (MCA), have all been applied with different biophysical and socioeconomics criteria to identify suitable locations for RWH. Several researchers have presented and applied the SCS with the $\mathrm{CN}$ method to assess how much runoff can be generated from a runoff area like in South Africa (De Winnaar et al., 2007) and India (Kadam et al., 2012; Ramakrishnan et al., 2009). 
Nowadays, geographic ilnformation system and remote sensing data are used to represent the biophysical environment and applied to identify suitable sites for RWH (Kahinda et al., 2008; Mechlia et al., 2009; Ziadat et al., 2006). Other researchers have integrated GIS, RS and Multi-Criteria Analysis to assess the suitability of sites for RWH (Elewa et al., 2012; Mbilinyi et al., 2007).

Ouessar et al. (2009) developed and applied a simple tool to evaluate the structural stability of 12 sites (four jessour, four tabias and four gabion check dams) in southern Tunisia. Through physical inspection, the characteristics of the structures were rated and an overall score was given. The characteristics rated include a cross-section for the water and sediment components of the structure, infiltration potential, vegetation quantity, dyke material and dyke erosion. This study also assessed the hydrological impact of the water harvesting systems by adaptation and evaluation of the soil and water assessment model (SWAT).

Jothiprakash and Mandar V. (2009) applied the analytical hierarchy process to evaluate various RWH techniques (aquifer recharge, surface storage structures and concrete storage structures) in order to identify the most appropriate technique and the required number of structures to meet the daily water demand of a large-scale industrial area.

So far, most attention has been given to the selection of suitable sites and techniques for RWH (Mahmoud, 2014) but little attention has been given to the evaluation of the RWH structure after implementation.

To understand the performance of RWH and to ensure successful implementation of new RWH techniques, engineering (technical), biophysical and socioeconomic criteria need to be integrated into the evaluation tools (Critchley et al., 1991; Mahmoud and Alazba, 2014). In addition, the relation and importance of the various criteria also needs to be taken into consideration.

The overall objective of the study, therefore, was to develop and test a comprehensive methodology to assess and evaluate the performance of existing RWH techniques in arid and semi-arid regions. To achieve this goal, we developed a new RWH evaluation and decision support tool. In this tool, engineering, biophysical and socioeconomic criteria were taken into account to assess the performance of existing RWH techniques, using the analytical hierarchy process supported by GIS. To develop and test this assessment tool, the Oum Zessar watershed in southeastern Tunisia was selected as a case study. Jessour and tabias are the most common RWH techniques in the Oum Zessar watershed and they are used in our methodology. 


\subsection{Materials and methods}

\subsubsection{Case study: wadi Oum Zessar}

To test the RWH evaluation tool we conducted a case study in the wadi Oum Zessar watershed located in Medenine province in the southeastern part of Tunisia (Figure 4.1). The wadi Oum Zessar watershed has an area of $367 \mathrm{~km}^{2}$. The area is characterized by a low arid Mediterranean climate, with an average annual rainfall of $150-230 \mathrm{~mm}$, and average annual temperature of $19-22{ }^{\circ} \mathrm{C}$. Rainfall occurs mainly in winter (40\%), autumn (32\%) and spring (26\%), while summer is almost rainless (Ouessar, 2007).

Several types of RWH exist in the study area to satisfy water requirements for domestic, agriculture and groundwater recharge. The most common RWH systems in the region are jessour and tabias; spreading of flood water and groundwater recharge structures in the wadi beds are applied too (Ouessar et al., 2002).
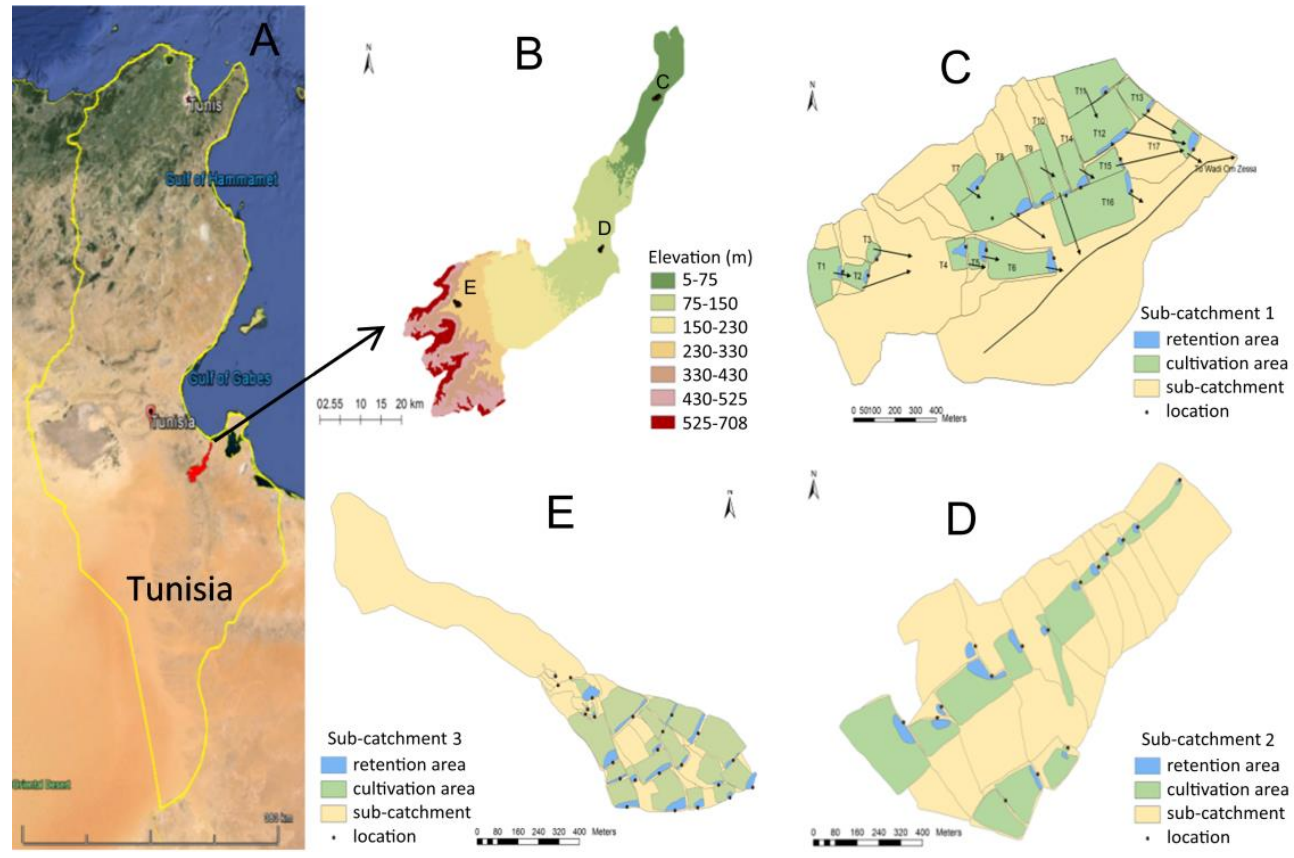

Figure 4.1 Location of Tunisia (A), location of Oum Zessar (B) and test sub-catchments; (C) Sub-catchment $1 ;(D)$ Sub-catchment 2 and (E) Sub-catchment 3. 
To test the RWH evaluation tool, three representative sub-catchments were selected based on four criteria:

i. Representative of the geographic distribution of our watershed; one located in the upstream the another in the midstream and one in the downstream area.

ii. Representative of the different types (jessour and tabias), scale (small and large) and age of RWH systems (new and old).

iii. Source and destination of collected rainwater for each sub-catchment.

iv. Accessibility; easy to access physically and acceptance of the local people.

These three sub-catchments are located in the downstream (sub-catchment 1), middle (sub-catchment 2), and upstream (sub-catchment 3) of the Oum Zessar watershed as shown in Figure 4.1. Each jessr (singular of jessour) or tabia consists of three parts: the impluvium or catchment area providing the runoff water; the terrace or cultivation area where the runoff water is collected and crops or trees are grown; and the dyke, which is a barrier to catch water and sediment. Each dyke has a spillway (menfes if the spillway is located on one or both sides and masref if the spillway is located in the middle of the dyke) to regulate water flow between dykes (see Figure 4.2).
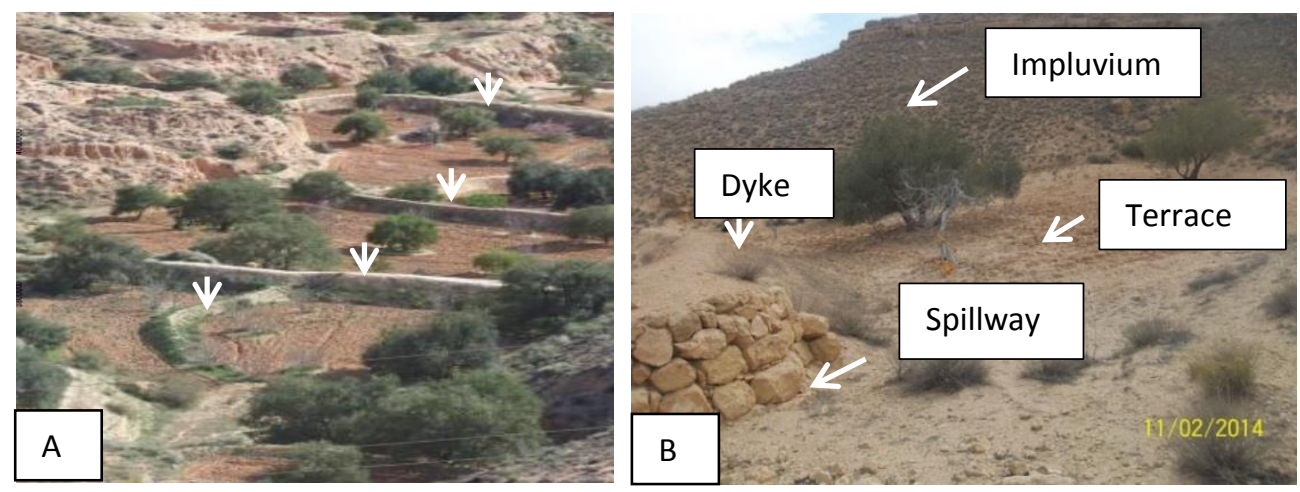

Figure 4.2 (A) An example of jessour (Ouessar, 2007) and (B) properties of jessr

\subsubsection{General description of the RWH evaluation decision support tool}

This research aims to develop a more comprehensive and relevant evaluation tool for RWH structures. To achieve this goal, we developed a simple and robust assessment tool for the evaluation of RWH sites (structures) which is inexpensive, simple to apply, reliable and flexible with different criteria and easy to adapt to various RWH techniques and regions. The analytical hierarchy process (AHP) forms the base for this tool. 
The AHP is a multi-criteria decision making method, providing a structured technique for organizing and analyzing complex decisions, based on mathematics and expert knowledge (Adamcsek, 2008). It was developed by Thomas Saaty in the 1970s and, since then, has been applied extensively in different disciplines. The main principle of AHP is representing the elements of any problem hierarchically to show the relationships between each level. The uppermost level is the main goal (objective) for resolving a problem and the lower levels are made up of the most important criteria that are related to the main objective. Pairwise comparison matrixes are constructed and scaled in preference from 1 to 9 for each level. Then, the consistency of each matrix is checked through the calculation of a consistency ratio (cr). The cr should be smaller or equal to $10 \%$ (Ying et al., 2007). The weight for each criterion and the $\mathrm{cr}$ are determined, then all matrixes are solved.

\subsubsection{Methodology overview}

AHP is particularly useful in multi-index evaluation and consists in our RWH evaluation tool of the following steps:

i. Describe the main objective of the intervention;

ii. Identify the biophysical, engineering (technical) and socio-economical main and sub-criteria;

iii. Develop a decision hierarchy structure;

iv. Collect and process the data for each sub-criteria;

v. Classify the values for each sub-criteria in terms of suitability classes;

vi. Apply the pairwise comparison matrix to identify priorities (weights) for each criterion;

vii. Calculate the RWH performance (suitability);

viii. Check the results with the stakeholders;

ix. Decide based on conclusions and recommendations.

\subsubsection{Description of the main objective of the intervention}

In our case study, the main objective is to collect and store runoff water during the rainy season to mitigate drought spells in arid and semi-arid regions.

\subsubsection{Identification of the main and sub-criteria}

This step formulates the set of criteria for the assessment based on the main objective. All major aspects should be represented, but the set should be as small as possible (simple and flexible). In addition to engineering (technical) aspects, social and economic aspects should also be included. Furthermore, the set of criteria has to be operational (e.g., measurable) and not redundant (the set should not count an aspect more than once). 


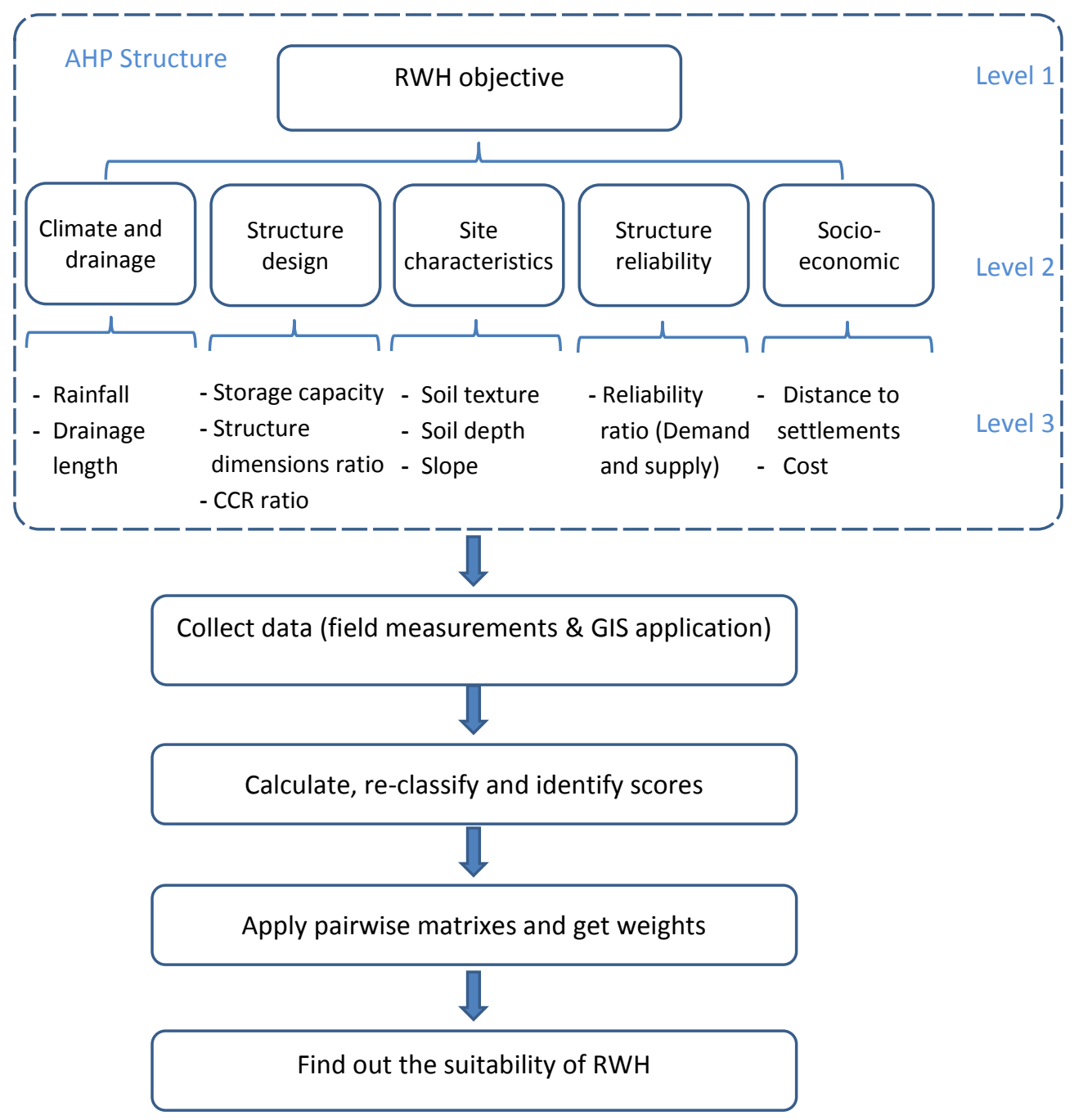

Figure 4.3 The schematic of the RWH suitability model, criteria and hierarchy structure for two methodologies. Method 1 consists of three levels and method two of two levels (Level 1 and Level 3).

In this study, we looked for criteria that represent the key parameters affecting the performance of RWH interventions and which could be applied to different sites and techniques. The parameters we were concerned with were based on the general definition of RWH, i.e., a method for inducing, collecting, storing and conserving local surface runoff in arid and semi-arid regions (Boers and Ben-Asher, 1982), and information found in literature studies. 
The main selected criteria and sub-criteria are shown in Figure 4.3, and reflect the following questions:

i. How suitable is the local climate for RWH (Climate and drainage)?

ii. What is the engineering (technical) performance of the RWH intervention (Structure design)?

iii. How suitable is the location for RWH (Site characteristics)?

iv. How well does the RWH satisfy the water demand (Reliability)?

v. How well does the RWH technique fit in with the social economic context (Socioeconomic criteria)?

Sub-criteria were chosen based on the relation with the main criteria (above), field investigations, expert discussions and literature studies.

\subsubsection{Development of the decision hierarchy structure}

In this step, the main criteria and sub-criteria are arranged in a multilevel hierarchical decision structure. In this study case, the objective of the RWH (jessour and tabias) represents the first level. The second level contains the main criteria for the assessment. These criteria define the aspects by which the intervention is assessed e.g., how it fits within the local conditions (climate, drainage length and landscape), functionality and reliability based on the engineering design and socioeconomic aspects. The sub-criteria used to measure the performance of each main criterion are represented in the third level. Figure 4.3 shows the structure of the applied methodology for our case study.

\subsubsection{Collection and processing of the data for each sub-criteria}

The definition, data collection, field measurements, storage and processing of data, as well as the calculations used for each criterion, are explained in details in section 4.2.4.

\subsubsection{Classification of the values for each sub-criteria in terms of suitability classes}

Due to the variety of measurements and scales for the different criteria, a comparable scale between criteria must be identified before applying AHP tools. For instance, rainfall depth is measured in $\mathrm{mm}$ while soil texture is measured by the percentage of clay content. Therefore, the selected criteria were re-classified into five suitability classes, namely, 5 (very high suitability), 4 (high suitability), 3 (medium suitability), 2 (low suitability) and 1 (very low suitability). For example, suitability Class 3 is considered to have acceptable performance, while suitability Class 1 means that the RWH does not work well and that one or all criteria that caused this insufficient performance need improvement. Table 4.1 shows the scores assigned based on discussions and consultations with experienced people and information found in the literature. 
4.2.3.6 Application of pairwise comparison matrix to identify priorities (weights) for each criteria

After assignment of scores, the weight for each criterion was determined by applying AHP with the pairwise comparison matrix. Pairwise comparison concerns the relative importance of two criteria involved in determining the suitability for a given objective. A pairwise matrix is first made for the main decision criteria being used. Other pairwise matrixes are created for additional criteria levels. The comparison and rating between two criteria are conducted using a 9-point continuous scale, the odd values 1, 3, 5, 7 and 9 correspond respectively to equally, moderately, strongly, very strongly and extremely important criteria when compared to each other. The even values 2, 4, 6 and 8 are intermediate values (Saaty, 2008). During pairwise comparison, criteria were rated based on the literature review, information from the field survey and discussions with stakeholders and experts. The final weight calculation requires the computation of the principal eigenvector of the pairwise comparison matrix to produce a best-fit set of weights. The consistency of each matrix, which shows the degree of consistency that has been achieved by comparing the criteria, was checked through the calculation of consistency ratio (cr). The $\mathrm{cr}$ should be smaller or equal to $10 \%$, otherwise they are judged as not consistent enough to generate weights and, therefore, have to be revised and improved (Ying et al., 2007).

To find out the final weight for each criterion and the $\mathrm{cr}$, we solved the pairwise matrixes mathematically. The results of the main criteria from the pairwise comparison and the final weight are presented in the results section.

In this study, two methods were applied. In the first, the hierarchy structure consists of all three levels; the objective, main criteria ( 5 criteria) and sub-criteria (11 criteria). In the second method, the hierarchy structure consists of just two levels: the objective and the sub-criteria (11 criteria). By applying these two methods, the understanding of the relation between each criterion and its reflection on the main objective becomes much clearer, and they confirm the flexibility of AHP to adopt different criteria on multi-levels. Moreover, this will give an insight into whether there are any mistakes and how they will be distributed or fixed, and gives more reliability and confidence in our methodology for adoption in different regions and/or for different criteria. 
Table 4.1 Classification, suitability levels and scores for each criterion for assessment of existing RWH sites in arid and semi-arid regions. Each value, class and score were rated based on the literature review, information from the field survey and discussions with stakeholders and experts.

\begin{tabular}{|c|c|c|c|c|}
\hline Criteria (Indicator) & Classes & Values & 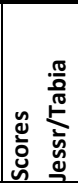 & 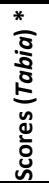 \\
\hline \multirow{5}{*}{$\begin{array}{l}\text { Rainfall }\left(\mathrm{mm} \mathrm{y}^{-1}\right) \text {, more rainfall on } \\
\text { any particular area means higher } \\
\text { possibilities of harvesting part of } \\
\text { it. (Al-Adamat et al., 2010) }\end{array}$} & Very low suitability & $<100$ & 1 & \\
\hline & Low suitability & $100-175$ & 2 & \\
\hline & Medium suitability & $175-250$ & 3 & \\
\hline & High suitability & $250-325$ & 4 & \\
\hline & Very high suitability & $>325$ & 5 & \\
\hline \multirow{5}{*}{$\begin{array}{l}\text { Drainage length }(\mathrm{m}) \text {, the distances } \\
\text { from the water courses to each } \\
\text { dyke (short distance means fewer } \\
\text { losses). (Elewa et al., 2012) }\end{array}$} & Very high suitability & $0-50$ & 5 & \\
\hline & High suitability & $50-125$ & 4 & \\
\hline & Medium suitability & $125-200$ & 3 & \\
\hline & Low suitability & $200-300$ & 2 & \\
\hline & Very low suitability & $>300$ & 1 & \\
\hline \multirow{5}{*}{$\begin{array}{l}\text { Storage capacity ratio }(-) \text {, the ratio } \\
\text { between the total volume of } \\
\text { water inflow and existing storage } \\
\text { capacity. The ratio that is close to } \\
\text { one is ranked as highly suitable. }\end{array}$} & Over requirement (too large a storage capacity area) & $<0.5$ & 2 & \\
\hline & Sufficient & $0.5-1.0$ & 4 & \\
\hline & Optimum requirement & $1.0-2.0$ & 5 & \\
\hline & Critical & $2.0-4.0$ & 3 & \\
\hline & $\begin{array}{l}\text { Very critical requirement (too small a storage capacity } \\
\text { area) }\end{array}$ & $>4.0$ & 1 & \\
\hline \multirow{5}{*}{$\begin{array}{l}\text { Structure dimensions ratio (-), the } \\
\text { ratio between the required design } \\
\text { height and the existing height of } \\
\text { dykes or barriers for each RWH } \\
\text { structure. The ratios that are close } \\
\text { to one are ranked as highly } \\
\text { suitable }\end{array}$} & Over design (existing height is double what is required) & $<0.5$ & 3 & \\
\hline & Suitable & $0.5-0.75$ & 4 & \\
\hline & Optimum & $0.75-1.0$ & 5 & \\
\hline & Under design & $1.1-1.25$ & 2 & \\
\hline & Critical (existing height is lower than required) & $>1.25$ & 1 & \\
\hline \multirow{5}{*}{$\begin{array}{l}\text { Catchment to cropping area } \\
\text { (CCR ratio }(-))\end{array}$} & Medium suitability & $<0.5$ & 2 & \\
\hline & Very high suitability & $0.5-0.75$ & 4 & \\
\hline & Suitable & $0.75-1.25$ & 5 & \\
\hline & Low suitability & $1.25-2.0$ & 3 & \\
\hline & Very low suitability & $>2.0$ & 1 & \\
\hline \multirow{5}{*}{$\begin{array}{l}\text { Soil texture } \\
\text { (Clay content \%) (Tumbo et al., } \\
\text { 2006) }\end{array}$} & Very high suitability (Clay) & $>20$ & 5 & \\
\hline & High suitability (Silty clay) & $15-20$ & 4 & \\
\hline & Medium suitability (Sandy clay) & $11-15$ & 3 & \\
\hline & Low suitability (Sandy clay loam and sandy loam) & $8-11$ & 2 & \\
\hline & Very low suitability (other) & $<8$ & 1 & \\
\hline \multirow{5}{*}{$\begin{array}{l}\text { Soil depth }(m) \text { (Kahinda et al., } \\
\text { 2008) }\end{array}$} & Very deep & $>1.5$ & 5 & \\
\hline & Deep & $0.9-1.5$ & 4 & \\
\hline & Moderately deep & $0.5-0.9$ & 3 & \\
\hline & Shallow & $0.25-0.5$ & 2 & \\
\hline & Very shallow & $<0.25$ & 1 & \\
\hline
\end{tabular}

Table 4.1 to be continued on next page 


\begin{tabular}{|c|c|c|c|c|}
\hline Criteria (Indicator) & Classes & Values & ๗ & 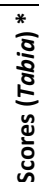 \\
\hline \multirow{5}{*}{$\begin{array}{l}\text { Slope (\%) (De Winnaar et al., } \\
\text { 2007) }\end{array}$} & Flat & $<1.5$ & 1 & $2 *$ \\
\hline & Undulating & $1.5-3$ & 3 & 5 \\
\hline & Rolling & $3-5$ & 4 & 4 \\
\hline & Hilly & $5-10$ & 5 & 3 \\
\hline & Mountainous & $>10$ & 2 & 1 \\
\hline \multirow{5}{*}{$\begin{array}{l}\text { Reliability ratio }(-) \text {, the ratio } \\
\text { between the total demand and } \\
\text { the total supply of water. High } \\
\text { suitability scores for the ratio are } \\
\text { close to one }\end{array}$} & Sufficient (required water is largely less than supply) & $<0.35$ & 2 & \\
\hline & Medium Sufficient & $0.35-0.75$ & 4 & \\
\hline & High Sufficient & $0.75-1.1$ & 5 & \\
\hline & Large deficit & $1.1-1.75$ & 3 & \\
\hline & $\begin{array}{l}\text { Very large deficit (required water is largely higher than } \\
\text { supply) }\end{array}$ & $>1.75$ & 1 & \\
\hline \multirow{5}{*}{$\begin{array}{l}\text { Distance to settlements }(\mathrm{km}) \text {, } \\
\text { highest scorers are ranked to the } \\
\text { closest distance to the settlements } \\
\text { (high suitability). (Al-Adamat, } \\
\text { 2008) }\end{array}$} & Very high suitability (too short a distance) & $<0.5$ & 5 & \\
\hline & High suitability & $0.5-0.75$ & 4 & \\
\hline & Medium suitability & $0.75-1.25$ & 3 & \\
\hline & Low suitability Very low suitability (too far a distance) & $1.25-1.75$ & 2 & \\
\hline & 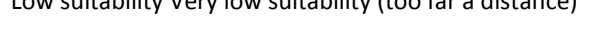 & $>1.75$ & 1 & \\
\hline Cost ( $\$ \mathrm{~m}^{-3}$ of water), low cost & Very high cost (very low suitability) & $>12$ & 1 & \\
\hline indicates high scores (profitable). & High cost & $9-12$ & 2 & \\
\hline Costs are estimated based on the & Medium cost & $6-9$ & 3 & \\
\hline WOCAT database (Mekdaschi & Suitable cost & $3-6$ & 4 & \\
\hline $\begin{array}{l}\text { Studer and Liniger, 2013) and } \\
\text { user interviews }\end{array}$ & Profitable cost (very high suitability) & $<3$ & 5 & \\
\hline
\end{tabular}

* Different suitability classes for slopes between jessour and tabias

\subsubsection{Calculation of the RWH performance (suitability)}

The next step in the assessment methodology is the calculation of the overall suitability for each RWH site. The overall RWH suitability was calculated by applying the following formula:

$\mathrm{S}=\sum_{i=1}^{n} W_{i} X_{i}$

where: $S$ : suitability; $W_{i}$ : weight of criteria $i ; X_{i}$ : score of criteria $i ; n$ : number of criteria.

The overall suitability will be classified also from 1 to 5 , namely, 5 (very high suitability), 4 (high suitability), 3 (medium suitability), 2 (low suitability) and 1 (very low suitability). 


\subsubsection{Discussion of the results with stakeholders}

It is important to check the results with the stakeholders, including the preliminary conclusions and recommendations. If felt that something is missing or has changed, additional measurements or recalculation with different weights might be necessary. Thereafter, results have been presented again to the local stakeholders for discussion and approval.

\subsubsection{Decision making based on conclusions and recommendations}

The main results of the assessment will give insight into if and how a RWH structure can be improved to increase its performance. Once there is general agreement on the results between stakeholders and scientists, a well-founded decision can be made on what structure needs to be improved for better performance of the RWH system.

\subsubsection{Data collection}

Different data sources were used. Meteorological as well as other biophysical data, was collected from the Institute des Régions Arides (IRA) in Tunisia. Field measurements were carried out in the wadi Oum Zessar during the period from December 2013 through March 2014. An open structure interview was made with key stakeholders (41 landowners) and discussions with people working and having experience with RWH (15 experts), particularly the engineers from the Regional Department in Medenine. A pairwise matrix was established and the relative weights for each criterion and suitability rank for classes are assigned as shown in Table 4.1. GIS was also applied to extract data that are needed in our methodology. All collected and measured data were stored and processed using Microsoft Excel software.

\subsubsection{Climate and drainage data}

\section{Rainfall}

Rainfall is one of the major components in any RWH system, with the magnitude of rainfall playing a significant role in assessing the RWH suitability for a given area. In arid and semiarid regions, rainfall varies greatly in time and space. RWH systems can only function if there is sufficient rainfall in the catchment area to be stored somehow. Average monthly rainfall for the period 1979-2004 was collected from IRA for 7 meteorological stations in the wadi Oum Zessar watershed, namely Ben Khedache, Toujan Edkhile, Allamat, Koutine, Sidi Makhlouf, Ksar Hallouf and Ksar Jedid. The rainfall amount in the three test subcatchments was determined by applying the inverse distance weight (IDW) function from ArcGIS 10.0 to interpolate the data from these stations. The rainfall depth data was then 
reclassified and scored as shown in Table 4.1. Areas with high annual rainfall are ranked as highly suitable.

\section{Drainage length}

Since RWH interventions (especially jessour and tabias) are located on the hydrographic network and their location is influenced by topography, the distance from the water course has a significant role in the assessment of RWH performance. In this study, the distance from a RWH site to the drainage networks is used to represent the runoff suitability. By determining the location of the furthest point contributing to runoff (Isioye et al., 2012), the drainage system was classified to each of the RWH sites (short distance means fewer water losses). The distances from the water courses to each dyke were measured using Google earth image and ArcGIS software.

\subsubsection{Structure design}

\section{Storage capacity}

One of the main principles of RWH is storing water to mitigate drought effects in dry seasons. Technically, the volume of water harvested and the amount retained over a reasonable duration of time is one indicator of the performance of $\mathrm{RWH}$.

Potential runoff $\left(V_{1}\right.$ in $\left.\mathrm{m}^{3}\right)$ from a catchment area was calculated by:

$V_{1}=0.001 \times C \times P \times A$

$C$ : The mean annual runoff coefficient (-); equal to 0.18 based on the simulations done by Schiettecatte et al. (2005).

$P$ : The mean annual precipitation $(\mathrm{mm})$

$A$ : The catchment area $\left(\mathrm{m}^{2}\right)$

The total volume of water inflow $\left(V_{i}\right)$ is, therefore:

$V_{i}=V_{1}+V_{2}+V_{3}$

Where $V_{2}\left(\mathrm{~m}^{3}\right)$ is the overflow from upstream dyke(s) and $V_{3}\left(\mathrm{~m}^{3}\right)$ is the volume of rainfall onto the storage area.

During the field measurements, the retention area and maximum potential depth of water (height of spillway) were measured with GPS and measuring tape. Then, the existing storage volumes were calculated (by multiplying the retention area by spillway height). Finally, the ratio between the total volume of water inflow $\left(V_{i}\right)$ and existing storage capacity were calculated and scored. If the ratio, for example, is between 1 and 2, it 
means that the total inflow volume will be similar to the storage capacity or there is excess water that will be an overflow to the downstream. Therefore, the ratios that are close to one are ranked as highly suitable (Table 4.1).

\section{Structure dimensions}

The dimensions of RWH structures are very important for achieving stability, controlling flood hazard and water supply. Furthermore, the primary goal of a structure is to harvest water for irrigation crops; the secondary goal is for flood protection. In this study, we assessed the existing height of dykes or barriers for each RWH structure and then compared this with the theoretical (required) design height.

The existing dyke's height for each site was measured in the field. The total volume of water that could be collected behind each dyke was calculated as noted in the previous section. The effective dyke height was calculated using this information. The free board, the vertical distance between the top of the dam and the full supply level, was calculated using standard dam design principles and added to the effective dyke height to determine the theoretical design height for each site. The ratio between existing and design dyke height was calculated and scored, as shown in Table 4.1.

\section{Catchment to cropping area}

To provide sufficient water to the crops, the terrace area should be not too large and the impluvium area should be enough. Therefore, an optimal ratio between impluvium area and terrace area has to be found. Depending on effective rainfall and runoff rates, the ratio between the catchment (impluvium) and cropping (terrace) area $(\mathrm{Ca} / \mathrm{C})$ can be determined. According to Schiettecatte et al. (2005), the minimum ratio $(\mathrm{Ca} / \mathrm{C})$ "impluvium area/terrace area" (design) can be calculated by:

$\frac{C_{a}}{C}=\frac{W R-P}{C \cdot P}$

Where $W R$ is the annual crop water requirement, $\mathrm{P}$ is the average annual precipitation $(\mathrm{mm})$ for the period 1979-2004, and $\mathrm{C}$ is the average annual runoff coefficient $(0.18)$ of dry soil and wet soil which was measured by Schiettecatte et al., (2005). Catchment area (impluvium) and cropping area were delineated with GPS in the field, and the areas were calculated using ArcGIS. At the end, the CCR ratio between the design and existing "impluvium area/terrace area" were calculated and scored. 


\subsubsection{Site characteristics}

Soil texture

Soil texture is a very important factor in selecting, designing and assessing the performance of RWH. Soil texture affects both the infiltration rate and surface runoff. The textural class of a soil is determined by the percentage of sand, silt and clay. Soil texture also determines the rate at which water drains through a saturated soil; for instance, water moves more freely through sandy soils than it does through clayey soils. High infiltration rates such as with sandy soil are not suitable for RWH structure. Clay soils have a greater water holding capacity than sandy soils, therefore, soil with high water holding capacity are more suitable for RWH. Indeed, Mbilinyi et al. (2005) and others conclude that clay soil is best for water storage due to its low permeability and ability to hold the harvested water.

In this research, the terrace area was sampled at different sites (based on the size of terrace area, 1-3 samples for each site) and at depths up to $1.3 \mathrm{~m}$. The samples were taken to the IRA laboratory and analyzed. The clay contents (\%) were measured, rated and classified into five suitability classes, as shown in Table 4.1.

\section{Soil depth}

Soil should be deep enough to allow excavation to the prescribed depth for RWH, to ensure both adequate rooting development and storage of the harvested water. Critchley et al. (1991) and Kahinda et al. (2008) used soil depth as one criterion for selecting potential sites for RWH. Both soil depth and soil texture determine the total soil water storage capacity, which controls the availability of water for crops during the dry periods (Oweis, 2004). We measured soil depth in the field using a steel bar hammered into the ground until it could go no further and by checking the soil levels between two successive terraces. Then, soil depth data were categorized and classified into five suitability classes, as shown in Table 4.1.

\section{Slope}

Slope is also a major factor in site selection, implementation and assessment of RWH systems. It plays a significant role in runoff and sedimentation quantity, the speed of water flow and in volume of material required to construct the dyke structure (dyke's height). Using DEM (30 m resolution) and ArcGIS 10.0, the slope was extracted for each catchment area and reclassified. Due to the large variety of slope values between jessour and tabias, different suitability classes were used for each type as shown in Table 4.1. 


\subsubsection{Structure reliability}

The relation between the demand and supply of water (reliability) is a good indicator of the performance of a RWH structure. Based on the function (purpose) of each technique, the demand for each RWH site was calculated.

The total demand was calculated by estimating the crop water requirements (evapotranspiration $E T_{c}$ ) plus losses to downward percolation, based on the field measurements by Schiettecatte et al. (2005) in the same watershed.

The total demand $=E T_{c}+$ Downward percolation

Schiettecatte et al., (2005) applied the Penman-Monteith method to calculate potential evapotranspiration (PET) and used data from the meteorological station at Medenine to calculate the average PET values over the period 1985-1995.

The maximum crop evapotranspiration $\left(\mathrm{ET}_{\mathrm{c}}\right)$ was calculated by:

$E T_{c}=P E T \times k_{c}$

Where $k_{c}$ is the crop coefficient. Table 4.2 shows the values for PET, ET ${ }_{c}$ and $k_{c}$.

Table 4.2 Rainfall, potential evapotranspiration (PET), maximum crop evapotranspiration (ET $T_{c}$ and crop coefficient $k_{c}$ results (Schiettecatte et al., 2005), by applying the Penman-Monteith method and using meteorological data from Medenine station.

\begin{tabular}{|c|c|c|c|c|}
\hline Month & $\begin{array}{l}\text { Rainfall } \\
\left(\mathrm{mm} \mathrm{y}^{-1}\right)\end{array}$ & $\begin{array}{r}\text { PET } \\
(\mathrm{mm})\end{array}$ & $\begin{array}{r}\mathrm{ET}_{\mathrm{c}} \\
(\mathrm{mm})\end{array}$ & $\mathrm{k}_{\mathrm{c}}$ \\
\hline January & 37.5 & 69.6 & 27.8 & 0.40 \\
\hline February & 30.6 & 88.6 & 35.4 & 0.40 \\
\hline March & 40.0 & 121.2 & 66.7 & 0.55 \\
\hline April & 16.3 & 159.3 & 79.6 & 0.50 \\
\hline May & 11.2 & 198.4 & 89.3 & 0.45 \\
\hline June & 1.0 & 213.5 & 85.4 & 0.40 \\
\hline July & 0.0 & 234.8 & 82.2 & 0.35 \\
\hline August & 2.0 & 220.9 & 77.3 & 0.35 \\
\hline September & 17.1 & 166.6 & 75.0 & 0.45 \\
\hline October & 23.0 & 126.8 & 63.4 & 0.50 \\
\hline November & 19.9 & 91.1 & 41.0 & 0.45 \\
\hline December & 36.7 & 67.4 & 26.9 & 0.40 \\
\hline
\end{tabular}

The infiltration ratios were used to calculate the downward percolation based on the soil texture results, as shown in Table 4.3 (Oweis et al., 2012). 
Table 4.3 Typical values of final infiltration rate for various soil textures (Oweis et al., 2012)

\begin{tabular}{ll}
\hline Soil Type & $\begin{array}{l}\text { Infiltration Rate } \\
\left(\mathbf{m m ~ h}^{-1}\right)\end{array}$ \\
\hline Coarse sand & $>22$ \\
Fine sand & $>15$ \\
Fine sandy loam & 12 \\
Silt loam & 10 \\
Silty clay loam & 9 \\
Clay loam & 7.5 \\
Silty clay & 5 \\
Clayey soil & 4 \\
\hline
\end{tabular}

From the relation between storage capacity and total runoff volume (Equation (4.2)), the total potential volume of supply water was calculated. Reliability was calculated as the ratio between total demand and the total supply of water for each site.

\subsubsection{Socioeconomic criteria}

The success of an intervention depends not only on technical aspects but also on how well it fits within the stakeholder's social context and the economic benefit it provides him/her. Bamne et al. (2014), Al-Adamat et al. (2010) and Nasr (1999) argued that one of the main reasons we do not use RWH sufficiently in the Middle East and North Africa is insufficient knowledge of the socioeconomic contexts. There are several socioeconomic criteria such as ownership, education etc. To identify good indicators for socioeconomic conditions in relation to the functioning of these RWH systems is much more difficult than the biophysical ones. Based on the literature studies and expert discussion in this case study, we are using distance to the settlements and cost per cubic meter of water as the socioeconomic criteria influencing how suitable the intervention is for the main stakeholders.

\section{Distance to settlements}

Since the local community is targeted in this study, the distance to the settlements is an important parameter in the design, selection and assessment of the RWH suitability (AlAdamat, 2008). We assumed that the distance to their home would influence the way they manage this system. Therefore, it is very logical that the closer the field, the easier are the maintenance operations, particularly in the mountain zones where transportation is difficult. The distance for each site was measured using the image from Googleearth and the ArcGIS program. Thereafter, as with other criteria, the values were reclassified and scored. 
Cost per cubic meter of water

Cost plays a significant role in the design and assessment of RWH sites. In order to assess the cost effectiveness of each structure, the establishment and annual maintenance costs for each site were calculated. The actual costs for each structure were not available; the main problem with the jessour and tabia is that they do not have fixed designs (different shapes and sizes). Therefore, it is difficult to calculate the exact cost for each structure. Thus, the costs have been estimated using the best available resources. The cost for each jessr or tabia was calculated based on the World Overview of Conservation Approaches and Technologies (WOCAT) database (Mekdaschi Studer and Liniger, 2013) and interviews with the local users. The costs for each jessr/tabia include the establishment and maintenance cost per year. The establishment costs consist of dyke construction, spillway construction for jessour and diversion channels and terracing for tabia. The maintenance costs consist of dyke and spillway maintenance, repairs and reconstruction and crop maintenance. The overall costs for jessre per year are 3000 US\$ for establishment and 900 US\$ for maintenance. Whereas, 670 and 200 US\$ for establishment and maintenence for tabia per year, respectively (Mekdaschi Studer and Liniger, 2013). Based on the field measurements, the length for each jessr/tabia was measured and then the cost for each meter length of jessr/tabia was estimated. These costs are similar to the values that were discussed with local users. The volume of collected water in each storage area and maintenance and construction costs of the jessour/tabias were used to calculate the cost per cubic meter of water, which was then classified and scored.

\subsubsection{Application of the assessment tool for different test sub-catchments}

We first tested our methodology on a catchment that has only one type of RWH structure. Sub-catchment one has just 17 tabias and no jessour and a total area of about 20 ha. It is located in the downstream area of the Oum Zessar watershed, as shown in Figure 4.1.

To further validate the methodology and criteria, we applied it on the other two subcatchments, which have different characteristics. The second sub-catchment is located in the middle of wadi Oum Zessar and has 16 RWH structures, 9 tabias followed (downstream) by 7 jessour, and a total area of about 19 ha. Sub-catchment three is located in the upstream part of wadi Oum Zessar, with 8 jessour followed by 17 tabias and a total area of about 45 ha. 


\subsection{Results}

All the collected data for each site were stored and analyzed in Excel. The results for each criterion were then classified according to the five classes as defined in Table 4.1. Figure 4.4 shows the scores percentages ( 5 scores) of each sub-criteria ( 11 criteria) for all 58 sites. The rainfall criterion got a score 3 in all sites since there was no big difference in rainfall pattern nor amount $\left(175-185 \mathrm{~mm} \mathrm{y}^{-1}\right)$ in the three sub-catchments due to the relatively small area. The criteria related to the design structure, like dimensions, storage capacity, CCR, drainage flow and costs got a high percentage of scores of 1 in many sites. More details about suitability and scores for the three sub-catchments are explained in the following sections.

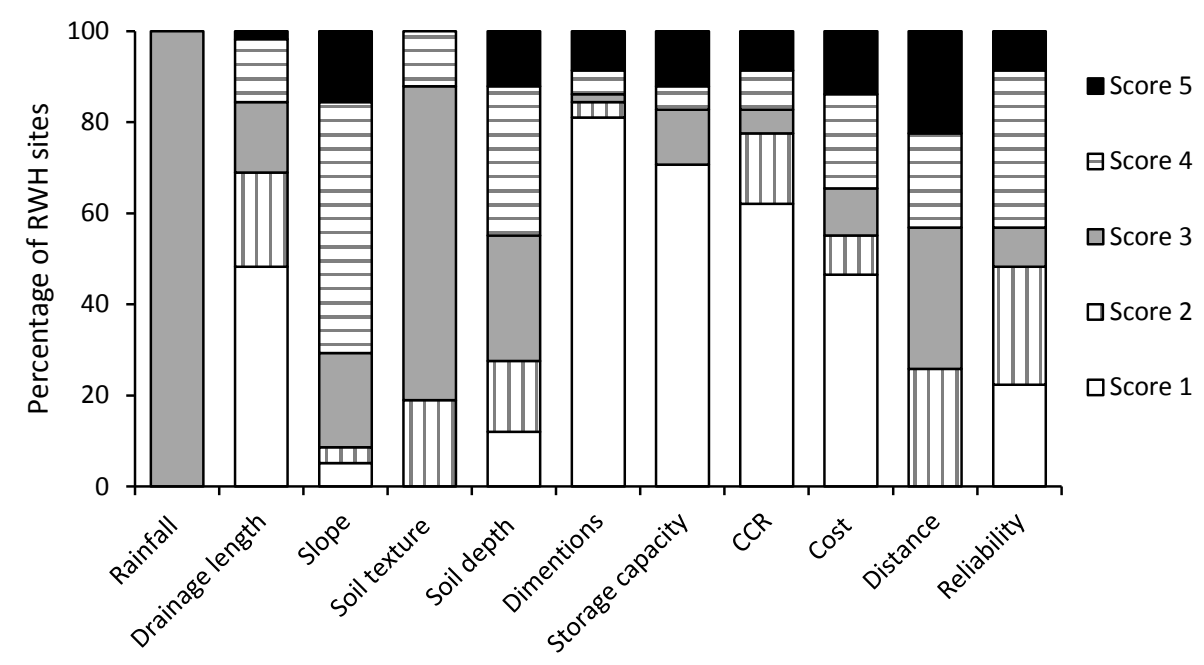

Figure 4.4 The score percentages for each criterion in all RWH sites $(n=58)$, the five scores were determined based on classifications by experts and previous studies.

\subsubsection{AHP and suitability}

During pairwise comparison, criteria were rated based on the literature review, interviews with key stakeholders, field survey information and discussions with people working and having experience with RWH, as shown in Table 4.4 For instance, the reliability and socioeconomic criteria have similar relative importance to the main objective of the RWH system, as shown in this Table 4.4, and each of them has 1 as a relative importance rate.

A pairwise matrix was established and the relative weights for each criterion and suitability rank for classes are assigned as shown in Figure 4.5 and Table 4.1. The climate 
and rainfall criteria received the highest weights in both methods (three levels and two levels AHP). The values for each criterion were calculated and reclassified based on the 5 suitability classes and Equation (4.1) was applied to get the final suitability score for each site.

Table 4.4 The pairwise comparison matrix for the main criteria (Method 1).

\begin{tabular}{|c|c|c|c|c|c|}
\hline & $\begin{array}{c}\text { Climate and } \\
\text { Drainage }\end{array}$ & $\begin{array}{c}\text { Structure } \\
\text { Design }\end{array}$ & $\begin{array}{c}\text { Site } \\
\text { Characteristics }\end{array}$ & Reliability & Socioeconomic \\
\hline Climate and drainage & 1 & 2 & 1 & 3 & 2 \\
\hline Structure design & $1 / 2$ & 1 & 1 & 1 & 2 \\
\hline Site characteristics & 1 & 1 & 1 & 2 & 3 \\
\hline Reliability & $1 / 3$ & 1 & $1 / 2$ & 1 & 1 \\
\hline Socioeconomic & $1 / 2$ & $1 / 2$ & $1 / 3$ & 1 & 1 \\
\hline
\end{tabular}

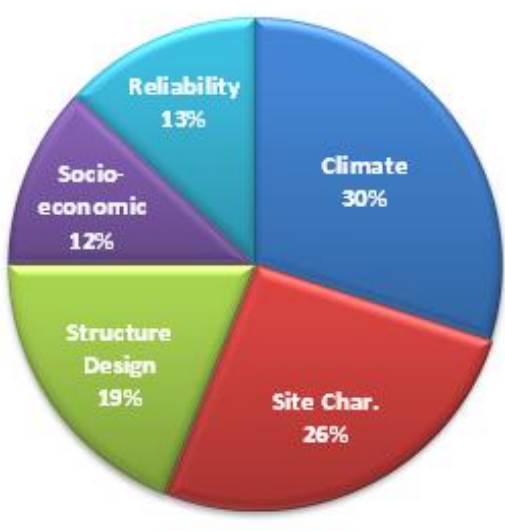

Method 1

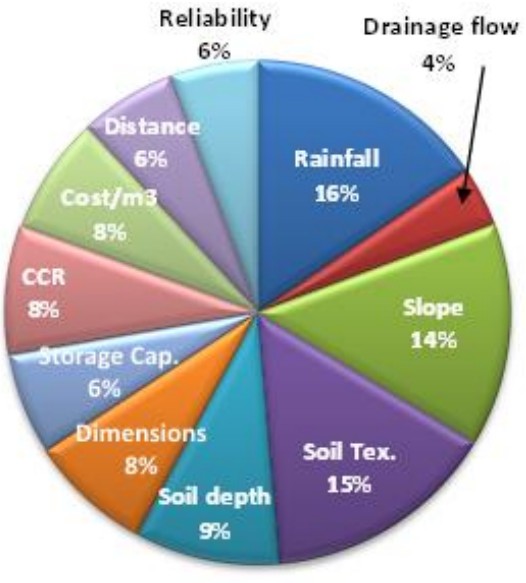

Method 2

Figure 4.5 The weights for main criteria in two methods: Method 1 consists of three levels, the objective in the first level, five main criteria in the second level and 11 sub-main criteria in the third level; while Method 2 has only two levels, the objective in the first level and the 11 indicators (main criteria) on the second level.

\subsubsection{Results for sub-catchment 1}

Table 4.5 shows measurements and scores for each criterion for the tabias receiving the highest (9 and 14) and lowest (10 and 15) suitability scores when AHP Method 1 was applied (before applying Equation (4.1)).

Figure 4.6 (A) shows the overall suitability scores and the suitability score for each criterion based on Method 1 (three levels) after applying Equation (4.1). The highest 
overall score was 3.32 (medium suitability) for tabia 9, whereas the lowest score was 2.04 (low suitability) in tabia 10.

Design criteria (structure dimensions, storage capacity and catchment area to cropping area) are playing a significant (negative) role in the overall RWH suitability for most of the tabias in sub-catchment 1 . These sites scored the lowest on design criteria, resulting in the low overall performance of these RWH sites. This result confirmed the observations of performance in the field.

Table 4.5 The measurements and scores for each criterion (indicator) for the tabias receiving the highest (9 and 14) and lowest (10 and 15) suitability scores in Sub-catchment 1, when AHP Method 1 was applied (before applying Equation (4.1)).

\begin{tabular}{|c|c|c|c|c|c|c|c|c|}
\hline \multirow[b]{4}{*}{ Criteria } & \multicolumn{8}{|c|}{ Sub-catchment 1, Tabia No. } \\
\hline & \multicolumn{4}{|c|}{ high } & \multicolumn{4}{|c|}{ low } \\
\hline & \multicolumn{2}{|c|}{9} & \multicolumn{2}{|l|}{14} & \multicolumn{2}{|c|}{10} & \multicolumn{2}{|c|}{15} \\
\hline & $\mathbf{M}^{*}$ & $\mathrm{~S}^{* *}$ & $\mathbf{M}$ & $\mathbf{S}$ & M & $\mathbf{S}$ & M & $\mathbf{S}$ \\
\hline Rainfall $\left(\mathrm{mm} \mathrm{y}^{-1}\right)$ & 180.00 & 3 & 180.00 & 3 & 180.00 & 3 & 180.00 & 3 \\
\hline Drainage length $(\mathrm{m})$ & 255.00 & 2 & 243.00 & 2 & 257.00 & 2 & 340.00 & 1 \\
\hline Slope (\%) & 3.50 & 4 & 7.90 & 3 & 5.76 & 3 & 4.60 & 4 \\
\hline Soil Texture (clay contents \%) & 14.30 & 3 & 12.60 & 3 & 8.70 & 2 & 11.10 & 3 \\
\hline Soil depth $(\mathrm{m})$ & 0.80 & 3 & 0.95 & 4 & 0.80 & 3 & 0.75 & 3 \\
\hline Structure dimensions ratio (-) & 0.93 & 5 & 1.03 & 5 & 4.88 & 1 & 4.30 & 1 \\
\hline Storage Capacity ratio (-) & 2.49 & 3 & 3.02 & 3 & 34.00 & 1 & 34.50 & 1 \\
\hline CCR ratio (-) & 3.80 & 1 & 4.20 & 1 & 1.30 & 3 & 9.60 & 1 \\
\hline Cost ( $\$ \mathrm{~m}^{-3}$ of water) & 5.90 & 4 & 6.40 & 3 & 48.00 & 1 & 43.00 & 1 \\
\hline Distance to settlements $(\mathrm{km})$ & 1.20 & 3 & 1.24 & 3 & 1.56 & 2 & 1.32 & 2 \\
\hline Reliability ratio (-) & 0.50 & 4 & 0.68 & 4 & 4.46 & 1 & 2.47 & 1 \\
\hline
\end{tabular}

${ }^{*}$ measurements/calculation data; ${ }^{* *}$ scores.
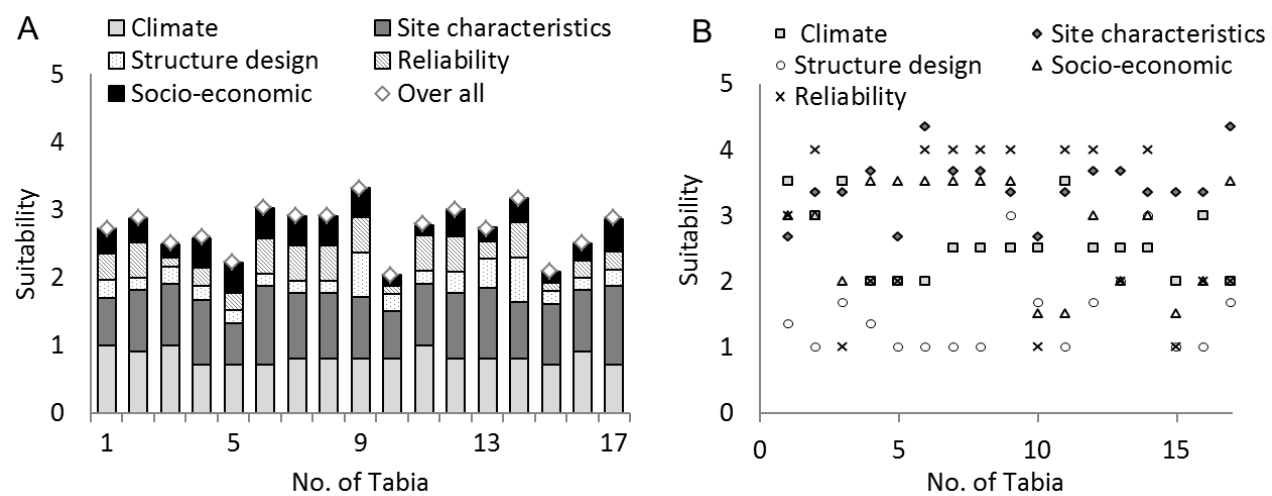

Figure 4.6 The overall suitability and the suitability for each criterion in each site of Sub-catchment 1 (Method 1), the left figure (A) shows the results after applying weights and Equation (4.1), the right figure (B) shows the scores without applying weights to compare weight effecting on the suitability scores for each criteria as shown in the left figure. 
A possible reason for the poor design is the structures built without a proper engineering design. Figure 4.6 (B) shows the suitability scores for each criterion without multiplying by the weights.

Table 4.6. The overall suitability and the suitability for each criterion for the highest ( 9 and 14) and lowest (10 and 15) scoring tabias in Sub-catchment 1, according to Method 2 and after applying Equation (4.1).

\begin{tabular}{|c|c|c|c|c|}
\hline \multirow[b]{3}{*}{ Criteria } & \multicolumn{4}{|c|}{ Sub-Catchment 1, Tabia No. } \\
\hline & \multicolumn{2}{|c|}{ high } & \multicolumn{2}{|c|}{ low } \\
\hline & 9 & 14 & 10 & 15 \\
\hline Rainfall $\left(\mathrm{mm} \mathrm{y}^{-1}\right)$ & 0.465 & 0.465 & 0.465 & 0.465 \\
\hline Drainage length (m) & 0.076 & 0.076 & 0.076 & 0.038 \\
\hline Slope (\%) & 0.572 & 0.429 & 0.429 & 0.572 \\
\hline Soil Texture (clay contents \%) & 0.450 & 0.450 & 0.300 & 0.450 \\
\hline Soil depth $(\mathrm{m})$ & 0.279 & 0.372 & 0.279 & 0.279 \\
\hline Structure dimensions ratio (-) & 0.395 & 0.395 & 0.079 & 0.079 \\
\hline Storage Capacity ratio (-) & 0.195 & 0.195 & 0.065 & 0.065 \\
\hline CCR ratio $(-)$ & 0.083 & 0.083 & 0.249 & 0.083 \\
\hline Cost $\left(\$ \mathrm{~m}^{-3}\right.$ of water $)$ & 0.300 & 0.225 & 0.075 & 0.075 \\
\hline Distance to settlements $(\mathrm{km})$ & 0.186 & 0.186 & 0.124 & 0.124 \\
\hline Reliability ratio (-) & 0.228 & 0.228 & 0.057 & 0.057 \\
\hline Overall score & 3.230 & 3.100 & 2.200 & 2.290 \\
\hline
\end{tabular}
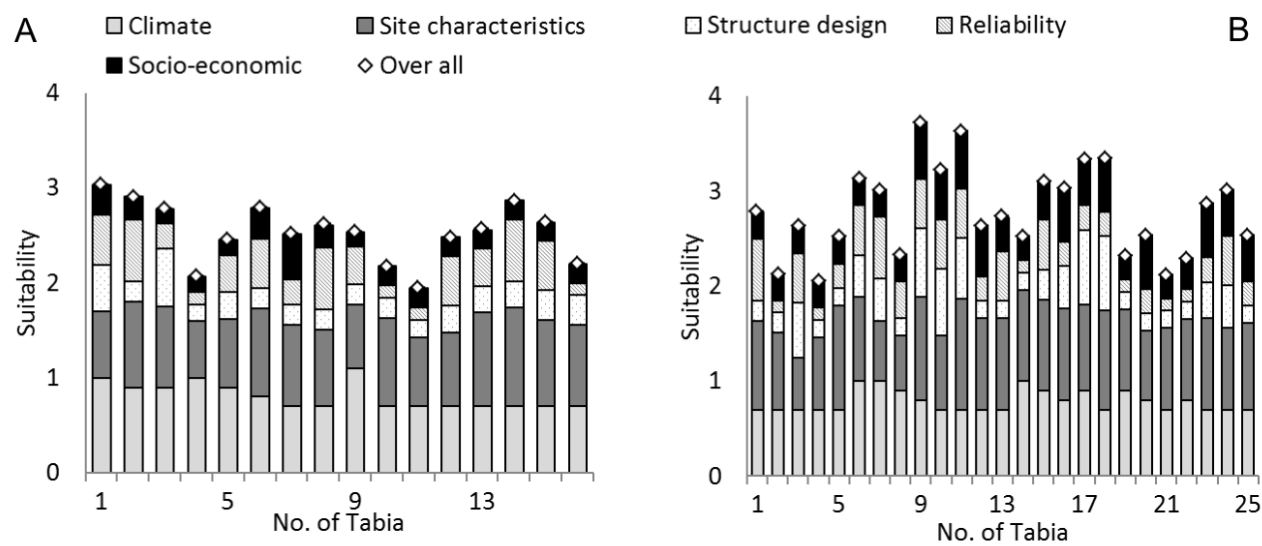

Figure 4.7 The overall suitability and the suitability for each criterion in each site in Sub-catchment 2 (A) and 3 (B) according to Method 1.

In Method two (two levels), the pairwise matrix was applied directly on the sub-criteria. Table 4.6 shows the overall suitability and the suitability for each criterion for the highest (9 and 14) and lowest (10 and 15) scoring tabias using this method. Once again, the design criteria of dimension and storage capacity had a significant negative impact on the 
difference between the high-scoring and low-scoring tabias. However with Method 2, CCR did not stand out as a differentiating factor, but reliability and cost did.

\subsubsection{Test results sub-catchments 2 and 3}

The suitability scores for each criterion and overall from applying Method 1 (three levels) in sub-catchments 2 and 3 are shown in Figure 4.7. The socioeconomic criteria played a significant role in the assessment methodology here, especially for jessour in these subcatchments (8-16 in sub-catchment 2 and 1-8 in sub-catchment 3 ) because of the high cost of implementing and maintaining the RWH compared with the relatively small area and low quantity of water retained behind the dykes. Moreover, these techniques are most common in this region especially in the mountain areas. They seem to be the most suitable techniques to mitigate flood hazard, additionally, the stakeholders consider them to be part of their heritage.

Table 4.7 shows the individual criteria and overall suitability scores for the highest and lowest scoring sites in sub-catchments 2 and 3 after applying Method 2. Catchment to cropping areas ratio (CCR) has a significant effect on overall suitability scores in subcatchment 2, whereas in sub-catchment 3 there was not a difference in CCR between the high and low scoring structures. Moreover, slope played an important role in the overall scores in sub-catchment 3 but not in sub-catchment 2 (Table 4.7).

Table 4.7 The individual criteria and overall suitability scores for the highest and lowest scoring sites in Sub-catchments 2 and 3 after applying Method 2.

Tabia/Jessr No.

\begin{tabular}{lcccc} 
& \multicolumn{2}{c}{ Sub-catchment 2 } & \multicolumn{2}{c}{ Sub-catchment 3 } \\
\cline { 2 - 5 } Criteria & high & low & high & low \\
\cline { 2 - 5 } & $\mathbf{1 4}$ & $\mathbf{1 1}$ & $\mathbf{1 1}$ & $\mathbf{2 1}$ \\
\hline Rainfall $\left(\mathrm{mm} \mathrm{y}^{-1}\right.$ ) & 0.465 & 0.465 & 0.465 & 0.465 \\
Drainage length (m) & 0.038 & 0.038 & 0.038 & 0.038 \\
Slope (\%) & 0.572 & 0.429 & 0.715 & 0.572 \\
Soil Texture (clay contents \%) & 0.600 & 0.450 & 0.600 & 0.450 \\
Soil depth (m) & 0.372 & 0.186 & 0.372 & 0.186 \\
Structure dimensions ratio (-) & 0.079 & 0.079 & 0.316 & 0.079 \\
Storage Capacity ratio (-) & 0.065 & 0.065 & 0.260 & 0.065 \\
CCR ratio (-) & 0.332 & 0.083 & 0.083 & 0.083 \\
Cost (\$ m ${ }^{-3}$ of water) & 0.075 & 0.075 & 0.375 & 0.075 \\
Distance to settlements(km) & 0.186 & 0.186 & 0.310 & 0.248 \\
Reliability ratio (-) & 0.285 & 0.057 & 0.228 & 0.057 \\
Overall suitability & 3.070 & 1.920 & 3.760 & 2.320 \\
\hline
\end{tabular}




\subsubsection{Comparison of methods 1 and 2}

A comparison between the two methods of applying AHP (three and two levels structure) in our methodology is shown in Figure 4.8. Although the results are very similar, Method 2 gives a slightly higher score for the jessour in sub-catchment 2 (jessour 10-16) and subcatchment 3 (jessour 1-8).

The consistency of each matrix was calculated using the consistency ratio (cr). For the main criteria matrix in Method $1 \mathrm{cr}$ was $2.9 \%$ and for the second method $\mathrm{cr}$ was $2.4 \%$.

The principles of AHP call for the $\mathrm{cr}$ to be smaller or equal to $10 \%$, therefore the $\mathrm{cr}$ values were acceptable.

These results suggest that both methods are good and easy to adapt to different criteria, thus researchers can apply either of the two methods.
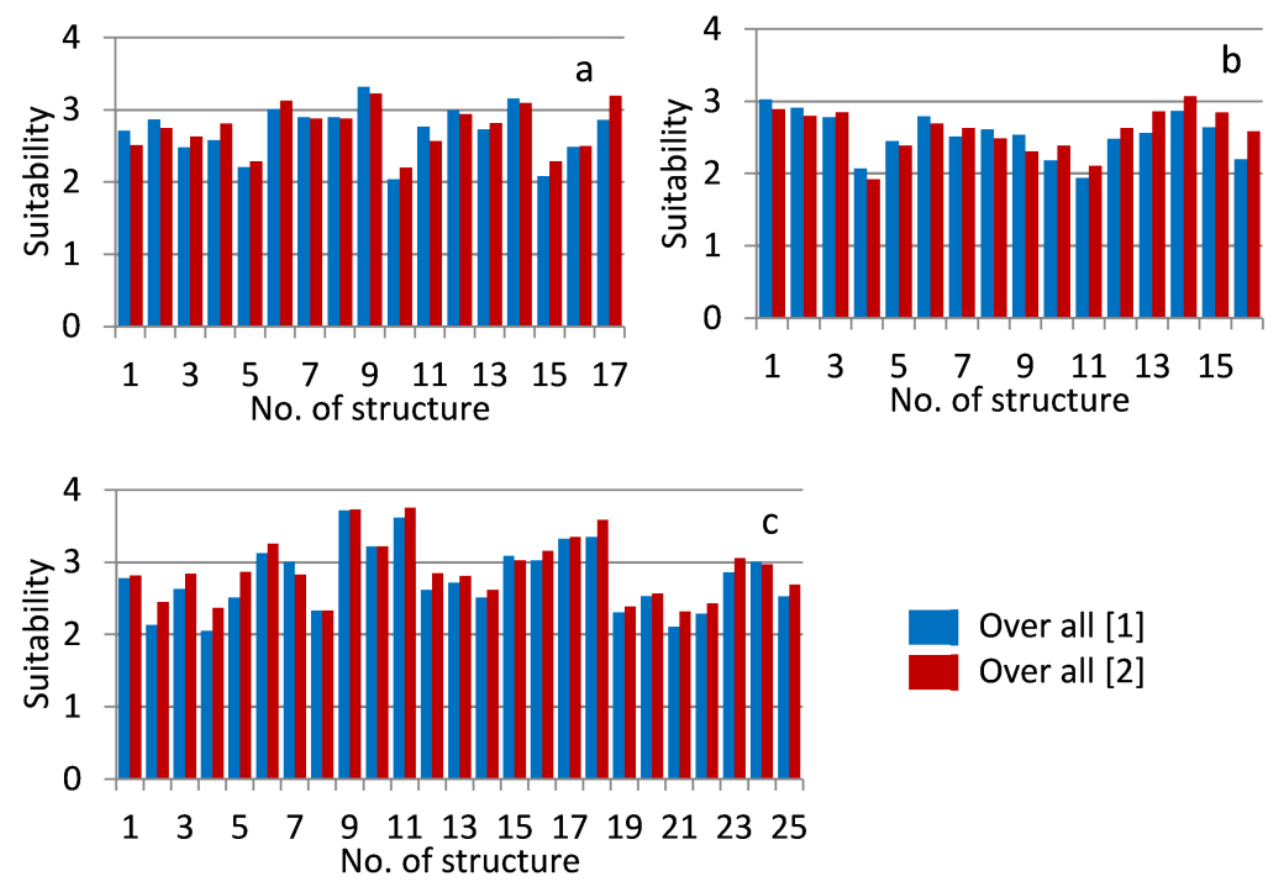

Figure 4.8 The comparison between overall scores for the two methods in the three test sub-catchments (a) Sub-catchment 1, (b) Sub-catchment 2 and (c) Sub-catchment 3. 


\subsubsection{Results validation with the stakeholders}

Based on our discussions with stakeholders and data collection from literature, we assessed the performance of existing RWH with the evaluation tool. Then, the preliminary results were checked with our field observations and discussed with stakeholders and experts. For instance, the RWH sites which scored 2 or lower (low suitability) had been abandoned. Whereas the sites that scored around 3 (medium suitability) showed wellmaintained structures.

\subsection{Discussion}

Fifty-eight RWH sites (44 tabias and 14 jessr) in three sub-catchments were assessed and evaluated on their technical and economic performance as well on social aspects. Using our methodology, $65 \%$ of the assessed sites scored around 3 (medium suitability), $31 \%$ of the RWH sites got scores of about 2 (low suitability), and only 4\%, two sites, scored 4 (high suitability). These results represent the real performance of each site, both overall and at individual criteria levels based on the comparison of our observations and discussion with local users and experts. This suggests that the methodology developed is a valid way to assess the performance of RWH structures.

The percentage of each score for each criterion in all sites was shown in Figure 4.4. Rainfall had the same score (Score 3 ) in all sites because of there was no big difference in rainfall pattern nor amount in the three sub-catchments. This means the rainfall indicator has no significant impact on the overall suitability of the sites in our case study, but it can be very important in the comparison between sites in larger areas (Mahmoud and Alazba, 2014) with a significant difference in rainfall. Moreover, significantly low score percentages were obtained by the design criteria, drainage length and cost, which was Score 1. For example, drainage length scored 1 for $48 \%$ of all sites. That means the distance between watercourses and RWH structures is big and the score would have been higher if these structures were built closer to the watercourse. If the RWH structures were located much closer to the watercourses, the contribution of drainage length to the overall RWH suitability would have been higher for our case study. Therefore, drainage flow has a significant impact on the performance of the RWH, which is not always the case for other types of RWH such as ponds, terraces, etc.

It is interesting to note that although the weight for climate criteria was higher than that for site characteristics criteria, $30 \%$ and $26 \%$ respectively (Figure 4.5 ), the latter received the highest scores in most of the sites in all three sub-catchments (Figure 4.6 and 
Figure 4.7). This indicates that the sites are generally well selected for their purpose, and the site characteristics criteria had more impacts on the performance of RWH than other criteria such as climate, drainage and structure design. These results are similar to other studies, such as Al-Adamat (2008) and Mbilinyi et al. (2007), who concluded that site characteristics are the most important criteria to be considered for design and implementation of RWH techniques.

Where RWH performance (suitability) was low, it was in most cases related to a shortcoming in the engineering design, lack of proper maintenance and the high cost of the water storage. The low performance of these RWH sites was confirmed by getting low scores of these criteria, as shown in Figure 4.4. The evaluation using our methodology clearly shows which criteria should be addressed to improve the performance of, for example, RWH structure design and storage capacity criteria. Due to the small storage area relative to the dyke size, the cost per cubic meter of water, especially in the jessour, was very high-such as jessour 10 and 15 in sub-catchment 1 . These results confirm that water harvesting structures with small storage capacity can ultimately be more expensive than large structures, as shown by Lasage and Verburg (2015). Therefore, if users can improve the dyke design and storage capacity area by following some basic engineering principles such as increasing storage area, constructing a regular spillway and providing periodic maintenance, they will be able to collect more water with less cost and keep the structure working for a longer period of time. Another example is the ratio between catchment size and cultivated area. Where this is not suitable, such as for structures 11 and 21 in sub-catchments 2 and 3, respectively, RWH structure performance can be improved by adapting the cultivated area to the effective area where the water is stored.

In our methodology, two methods were applied (three levels and two levels of AHP hierarchy structure), and the results for both approaches were very similar. The consistency ratio for both methods was also similar and strong. Therefore, both methods are valid and provide reliable results. Both methods are simple to apply and easy to adapt the criteria in case of different RWH techniques and/or regions in order to cater to stakeholders' objectives. While either method can be used, it is recommended to apply Method 1 (three levels). In Method 1, the impact of possible errors in scores (from expert opinion or calculations) will be reduced through the two-step calculation.

In most previous studies, the number of criteria are limited and are aimed primarily at the selection of suitable locations for RWH (Kahinda et al., 2008; Ziadat et al., 2006) and do not consider other factors or performance over time. In addition, many of those studies were mainly desktop studies using GIS and RS, without including stakeholders' objectives and constraints. Our study showed that socioeconomic aspects play an important role in 
RWH suitability and performance. Thus, the inclusion of such criteria as occurs in our methodology is very important to the goal of meaningful information for improving current RWH effectiveness as well as planning for future structures.

A key precondition for the methodology was that it can be widely applied for different RWH techniques in different regions. In this regard, the structure of the methodology allows it to be easily adapted and applied to different RWH techniques and socialeconomic settings by simply changing the criteria selected. In addition, the case study showed that it is very well to select criteria that are easy to assess and still provide accurate results without the need for a complex analysis. This keeps the time investment and costs required within reasonable limits.

While Al-Adamat (2008), Jabr and El-Awar (2005) and Mbilinyi et al. (2005) showed that MCA provides a rational, objective and non-biased method for identifying suitable RWH sites, our study demonstrates that combining MCA and expert opinion in a consistent way allows assessment and evaluation of RWH techniques beyond simply site selection. Site conditions and RWH structure performance are likely to change over time, especially in light of predicted climate change. Therefore, a methodology such as ours, which allows the evaluation of the performance of current and potential RWH projects, and identification of necessary improvements, is of great value.

An important consideration in the application of our methodology that warrants mention is the establishment of the scores/weighting for each criterion. As this depends on expert opinion (Adamcsek, 2008; Al-Adamat et al., 2010), it is essential to use several experts and take into consideration their area of specialty when analyzing and using their inputs.

\subsection{Conclusions}

An evaluation and decision support methodology/tool was developed and tested for assessment of the overall performance of existing RWH systems and criteria affecting that performance. A single-objective AHP supported by GIS was put to the test in the Oum Zessar watershed of southeastern Tunisia to assess the performance of $58 \mathrm{RWH}$ structures (jessour/tabias) in three main sub-catchments. Engineering (Technical), biophysical and socioeconomic criteria were determined, weighted and assessed in this study with input from experts and stakeholders. 
The main conclusions are:

- The methodology provides an accurate evaluation of RWH performance when compared with field investigations.

- The methodology provides a good insight into where in the system improvements are needed for a better performance.

- In the case study, most sites showed low suitability scores for the criteria structure design, drainage flow and cost, which resulted in a low score on the overall performance of RWH.

- Site characteristics criteria (both overall and individual criterion) play a more important role in the overall suitability than other criteria.

In addition, the methodology can be used to pre-evaluate potential new RWH projects, increasing the chances for a good long-term performance. This case study application of our methodology confirmed that it is a highly flexible and applicable tool for the evaluation and improvement of RWH structures. It can employ many different, important and easy to access criteria and indicators in the assessment of different RWH techniques. The time and cost required in using this methodology are also low, making it accessible to the local RWH managers/communities.

To further validate the applicability of the methodology, it needs to be tested in different regions and with different RWH techniques. Moreover, the criteria related to socioeconomic suitability/performance (i.e., ownership, education, etc.) deserve further investigation. These suggestions will increase the reliability and applicability of our methodology so that it can be used for assessing the performance of existing and new planned RWH structures in any region. This new, scientifically-based evaluation and decision support tool provides a basis on which designers and decision makers can build efficient RWH systems to meet the objectives and needs of the communities in waterscarce regions. 


\section{A Microsoft Excel Application to Simulate and Optimise Water Harvesting in a Catchment}

To investigate and optimise the performance of a RWH system under various scenarios of design and management, a simple but generally applicable water harvesting model (WHCatch) has been developed. It is based on the water balance at a sub-catchment level and could be applied with a minimum of data. Initially, it was only intended to compute the water balance of all sub-catchments of a watershed from simple measurements and for a number of events. As all required data was available in Excel, it was chosen to develop the computational section in Visual Basic for Application (VBA) and read the input data directly from the Excel workbook. After working with the basic version for some time, it became clear there were many possible extensions that could be implemented easily. The program was extended with the option to introduce outflow from a sub-catchment into two other sub-catchments instead of only one. More sophisticated graphical presentations were added. After applying the program for some case studies, it seemed to be nice if the program could show graphically what would be the influence of changing the spillway height of a sub-catchment on the waterbalance terms of some downstream sub-catchment. So a module was added that could do so. Another piece of software was developed and added to WHCatch to analyse the measured precipitation data. Though it is very interesting to work with measured precipitation data, a precipitation generator was implemented that can be applied to show the reaction of the rainwater harvesting system on other types of precipitation distributions. This chapter presents the capabilities of the workbook as well as examples of output.

This chapter is submitted as:

Wesseling, J.G., A. Adham, M.J.P.M. Riksen, C.J. Ritsema, K. Oostindie and A.H. Heidema. A Microsoft Excel application to simulate and optimise water harvesting in a catchment. Submitted to Computers and Geosciences. 


\subsection{Introduction}

Worldwide, about $10 \%$ of the freshwater supplies are used for health and sanitation purposes, whereas $70 \%$ and $20 \%$ are used for agriculture and industries, respectively (Machiwal and Jha, 2012). Problems with fresh water mainly occur in the arid and semiarid climate zones. The arid and semi-arid regions (ASARs) cover approximately 50 million $\mathrm{km}^{2}$, representing 35\% of the earth's land surface (Ziadat et al., 2012). ASARs are areas where the rainfall is a problem of amount, distribution and/or unpredictability (Hudson, 1987). Arid regions receive an amount of rainfall of about $150-350 \mathrm{~mm} \mathrm{y} \mathrm{y}^{-1}$ (Ouessar, 2007) and semi-arid regions are receiving little rainfall as well, varying from 350 to $700 \mathrm{~mm} \mathrm{y}^{-1}$ (Oweis et al., 1998). Rainwater harvesting (RWH) is an important way to use surface runoff that was caused by the limited available rainfall. RWH is broadly defined as the collection and concentration of runoff for domestic water supply, productive purposes and livestock in ASARs (Fentaw et al., 2002; Gould, 1999; Stott et al., 2001).

Besides by measurements in the field, the effects of rainwater harvesting can be evaluated by modelling the hydrological characteristics of rainwater harvesting facilities (Ghisi et al., 2007). Fewkes (2000) already addressed the need for a hydrological model for the analysis of rainwater harvesting facilities. A hydrological analysis of water harvesting facilities is rather similar to a long-term rainfall-runoff analysis in a watershed, which generally considers various hydrological circulation components, such as precipitation, evapotranspiration, infiltration, percolation, groundwater and surface runoff (Kim and Yoo, 2009). A number of detailed models, capable of simulating RWH system design and/or performance, have been developed and published (Ward et al., 2010). Dixon (2000) developed DRHM, a mass balance model with stochastic elements for demand profiling, to simulate the quantity, quality and costs of RWH systems. Vaes and Berlamont (2001) developed the Rewaput model, which is a reservoir model with rainfall intensityduration-frequency relationships and triangular distribution. Fewkes (2004) developed the $R C S M$ model which is continuously simulates RWH system with detailed analysis of time interval variation and yield-before/after-spill. Kim and Han (2006) developed the RSR model and applied it in Korea. It optimises the tank size of a RWH system for storm water relations to reduce flooding. An Excel-based balance model (RainCycle) using a yield-afterspill algorithm and a whole life costing approach was developed in 2007 by Roebuck and Ashley (2007).

Water balance models provide the most fundamental information about the hydrological processing of a catchment and may assess the performance of RWH techniques under current and future climate conditions (Chauvin et al., 2011). The water balance model can be used to improve the understanding of the critical processes that influence the 
hydrological cycle and to allow the transfer of field or laboratory experiments results to other sites and climates (Zhang et al., 2005). The water-balance equation presents the values of inflow, outflow and the change in water storage for an area or water body (Tadesse et al., 2010a). In other words, water balance is the application in hydrology of the principle of conservation of mass, often referred to as the continuity equation (Tadesse et al., 2010b).

In this study, the development of a simple RWH model that is based on the water balance equation seemed to be advantageous. It can perform a hydrological analysis regarding rainwater harvesting with only a few parameters that need to be estimated. All examples in this paper are from the application of the model in a study on rainwater harvesting in the Oum Zessar watershed in southeastern Tunisia (Adham et al., 2016b).

\subsection{Theory}

\subsubsection{Catchments and sub-catchments}

This paper deals with the (surface) water flow in a catchment. According to Gregersen et al. (2007), a drainage basin or catchment basin is a large unit of land that drains into a large body of water such as a river, lake, reservoir, estuary, wetland, sea, or ocean. The term watershed or sub-catchment is used to refer to smaller units that contain all lands and waterways that drain to a given common point. In case of rainwater harvesting, each sub-catchment has its own water barrier and reservoir and outlet in the form of a spillway. An example of a catchment and its 25 sub-catchments is presented in Figure $5.1 \mathrm{~A}$.

Initially, it was assumed that the water in a sub-catchment only flows into one other subcatchment (Figure 5-1 B). During the development and testing of the software it appeared to be necessary to have the option of distributing the outflow to two neighboring subcatchments.

\subsubsection{The water balance of a catchment}

Suppose a sub-catchment has an area $A_{c}$. Within this area there is an area $A_{s}$ where the water will be stored. Assuming a rainfall $P$, then the volume of water flowing into the storage area from the non-storage area can be written as: 


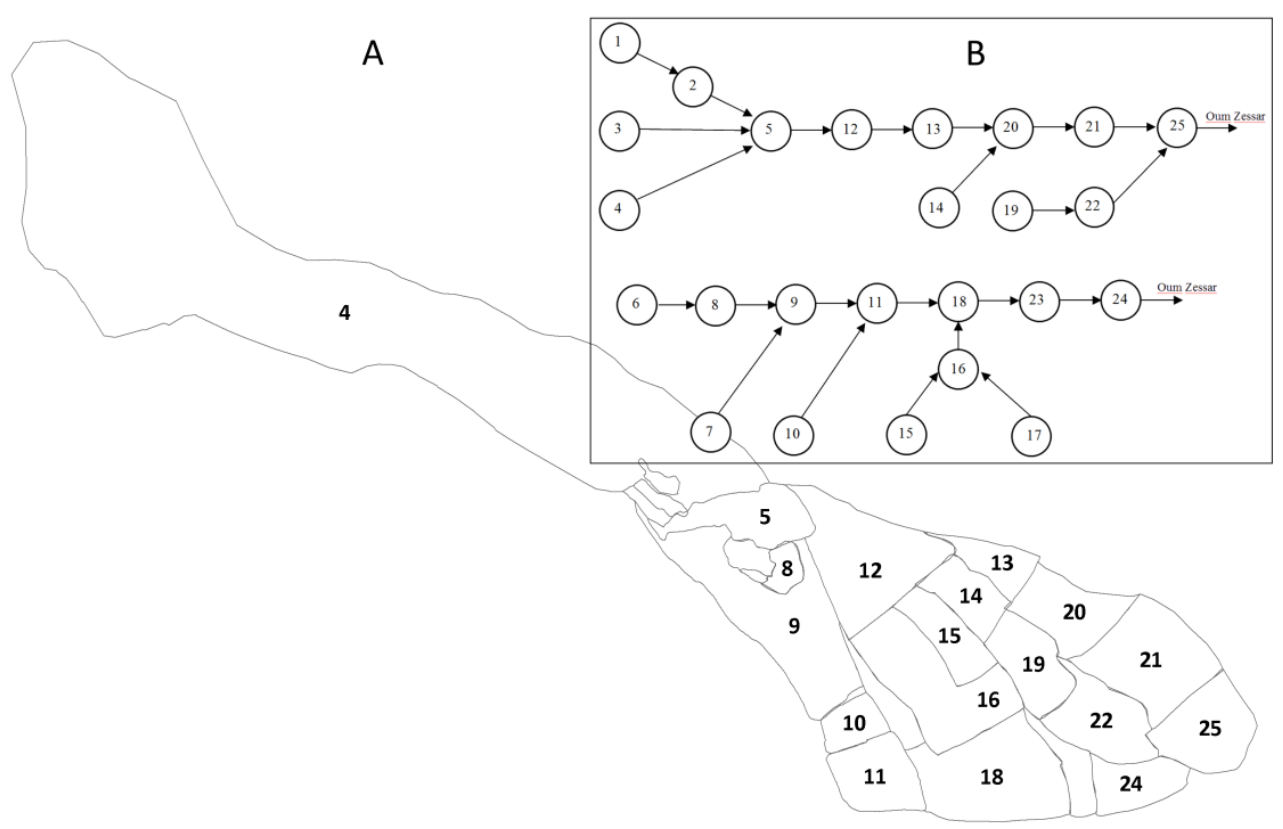

Figure 5.1 (A) The contours of the Oum Zessar watershed in southeastern Tunisia and the distinguished sub-catchments and $(B)$ the flow of water between the sub-catchments.

$V_{\text {in }}=P C\left(A_{c}-A_{s}\right)$

The runoff coefficient $\mathrm{C}$ is a dimensionless coefficient relating the amount of runoff to the amount of precipitation received. It is a larger value for areas with low infiltration and high runoff (pavement, steep gradient), and lower for permeable, well vegetated areas (forest and flat land). According to the California Water Board (http://www.waterboards.ca.gov/water_issues/programs/swamp/docs/cwt/guidance/513 .pdf), it's value varies between 0.1 and 0.95 . The water volume that falls on the storage area is computed from its area and the precipitation rate:

$V_{s}=P A_{s}$

In the storage area infiltration will take place. The volume of infiltration is computed from the infiltration rate and the area:

$V_{I}=I_{r} A_{S} \Delta t$ 
Where $I_{r}$ is the infiltration rate which is usually measured in the field and $\Delta t$ is the average time during which infiltration occurs. Often the infiltration is estimated as a fraction of the total volume of water flowing into the storage area or:

$V_{I}=\alpha_{I} V_{t o t}$

Where $\alpha_{1}$ is the fraction (-) and $V_{\text {tot }}$ is the total volume of water entering the storage area $\left(\mathrm{m}^{3}\right)$. If there is a cultivated area $A_{p}$ as part of the sub-catchment, losses will occur due to evapotranspiration $E_{p}$. The lost volume can be computed from:

$V_{p}=A_{p} E_{p}$

If a volume of water $\left(V_{x}\right)$ is entering from another sub-catchment as well, then the change of the volume of water in the storage area can be computed from:

$\Delta V=V_{\text {in }}+V_{s}-V_{I}+V_{x}-V_{p}$

Adding this volume to the present volume $\left(\mathrm{S}_{\mathrm{i}}\right)$ in the storage area yields the new stored volume:

$S_{i}=S_{i}+\Delta V$

Assuming the maximum height of water storage is $h_{s}$, then the maximum volume of storage is:

$S_{\text {max }}=f_{S} h_{S} A_{S}$

Where $f_{S}$ is a correction factor for the unequal height of the terrain (usually 0.9). This implies that, if $S_{i}>S_{\max }$, there will be an outflow to the next sub-catchment of $V_{x}$, where

$V_{x}=S_{i}-S_{\max }$

With the procedure described above, a global estimate of the possible water harvesting volume can be found as $S_{i}$ when $S_{i}>0$. If, on the other hand, $S_{i}<0$, all water from the catchment will disappear and there may be an insufficient volume of water available ${ }^{1}$.

\footnotetext{
${ }^{1}$ In some cases, one is interested in the 'uncorrected' value of dV. In the program WHCatch this value is called 'bal'.
} 


\subsubsection{Generating rainfall events from distributions}

In arid and semi-arid areas rainfall will usually occur as a limited number of individual showers in a year. Nowadays weather stations are recording precipitation data all over the world, yielding long-year datasets. From our experimental site we have precipitation data of 25 years available. It is assumed the distribution of the values is normal (as most things in nature are distributed normally). A normal distribution can be presented by a bellshaped curve for the probability. In a normal distribution, $68 \%$ of the values are in the range $[\mu-\sigma ; \mu+\sigma]$, and $95 \%$ of the values are in the range $[\mu-2 \sigma ; \mu+2 \sigma]$, where $\mu$ is the mean value and $\sigma$ is the standard deviation (see Figure 5.2).

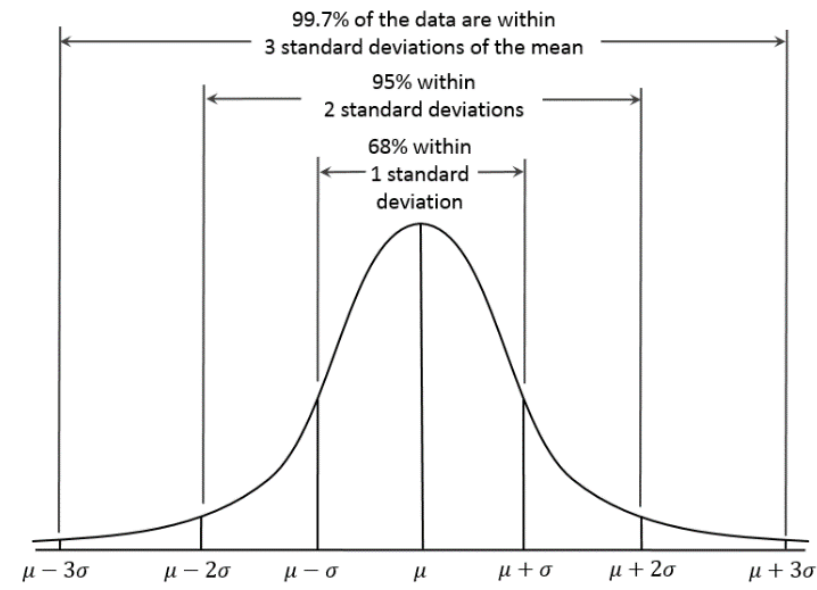

Figure 5.2 The coverage of data with a normal distribution (from Wikipedia).

Table 5.1 The averages and standard deviations of three rainfall characteristics obtained from 25 years of measured precipitation data in the Oum Zessar watershed in Tunisia: the yearly total precipitation, the maximum precipitation value in a year and the size of an event.

\begin{tabular}{lll}
\hline & $\begin{array}{l}\text { Average } \\
(\mathbf{m m})\end{array}$ & $\begin{array}{l}\text { Standard deviation } \\
(\mathbf{m m})\end{array}$ \\
\hline Yearly total & 145.676 & 83.390 \\
Maximum value in year & 39.328 & 23.988 \\
Event size & 11.381 & 13.389 \\
\hline
\end{tabular}

We analyzed the data from our study area, yielding 3 distributions: the yearly amount of precipitation $(\mathrm{N}=25)$, the maximum value of precipitation within a year $(\mathrm{N}=25)$ and the distribution of all rainfall events $(\mathrm{N}=762)$. The averages and standard deviations are presented in Table 5.1. From these values a set of precipitation data for a year can be generated. 


\subsection{The calculation procedure}

\subsubsection{The water balance}

Assuming the considered catchment consists of a known number $\left(\mathrm{N}_{\mathrm{s}}\right)$ of sub-catchments and the relationship between these sub-catchments is known (see e.g. Figure 5-1), a simple computation scheme has been developed:

1. Compute $S_{\max }$ for each sub-catchment;

2. Compute the water volumes $V_{i}, V_{i n}$ and $V_{s}$ for each sub-catchment from the equations presented above;

3. Compute $V_{x}$ for the sub-catchments without inflow $(1,3,4,14,19,6,7,10,15,17$ in the example);

4. Compute $V_{x}$ for those sub-catchments where the upstream sub-catchment(s) is(are) processed;

5. Repeat steps 3 and 4 until all sub-catchments are processed.

It is assumed that there is no interaction between the precipitation events, which implies that all values are initially zero for each event. Calcultations are performed for entire years, the term $v_{p}$ can be added at the end of the computations.

\subsubsection{Generating precipitation events}

In one of the previous sections of this thesis the (normal) distribution of the precipitation data was described. Using these averages and standard deviations, new precipitation data can be generated in the following way':

1. Draw a number from the distribution of the yearly amount of precipitation (say $P_{\text {tot }}$ );

2. Draw a number from the distribution of maximum values (say $P_{\max }$ );

3. If $P_{\max }>P_{\text {tot }}$ (which may happen if there is an overlap between distributions), redo step 2;

4. Draw a number from the distribution of all events $\left(\right.$ say $\left.P_{i}\right)$;

5. If $P_{\mathrm{i}}>P_{\max }$, redo step 4;

6. $P=\Sigma P_{j}, j=1 . . ;$

7. If $P>P_{\text {tot }}$, then $P_{i}=P_{\text {tot }}-P_{i}-P$;

8. If $P<P_{\text {tot }}$ then repeat step 4 .

\footnotetext{
${ }^{2}$ Assuming there is no correlation between the events.
} 
Programmatically the drawing of a number from a normal distribution can be accomplished with the GASDEV procedure described by Press et al. (1986). The generated year of precipitation can be applied as input for the water balance model and the balance term of interest can be read. Repeating this procedure a number of times yields a collection of $\mathrm{N}_{\mathrm{x}}$ values of the water balance term ( $\mathrm{x}$ ). This collection of values can then be analyzed in the following way:

1. Sort the values of $x$;

2. The range $R$ of the values can be computed as $R=x_{N x}-x_{1}$;

3. Divide $\mathrm{R}$ into $\mathrm{N}_{\mathrm{c}}$ equal classes;

4. Distribute $\mathrm{x}$ over the appropriate classes;

5. Count the number of entries in each class;

6. Divide the number by $\mathrm{N}_{\mathrm{x}}$;

7. Now you know the probability that $x$ will be in a specified class.

As an example, we computed the runoff in sub-catchment 4 with different values of $\mathrm{N}_{\mathrm{x}}$ and $\mathrm{N}_{\mathrm{c}}$. From the graphs (Figure 5.3) it can be seen that both the values of $\mathrm{N}_{\mathrm{x}}$ and $\mathrm{N}_{\mathrm{c}}$ have a large influence on the results. It is advised to choose $N_{x} \geq 50 N_{c}$. The bottom figure shows that most runoff values (approx. 6\%) are in the class $7180-7639 \mathrm{~m}^{3}$.
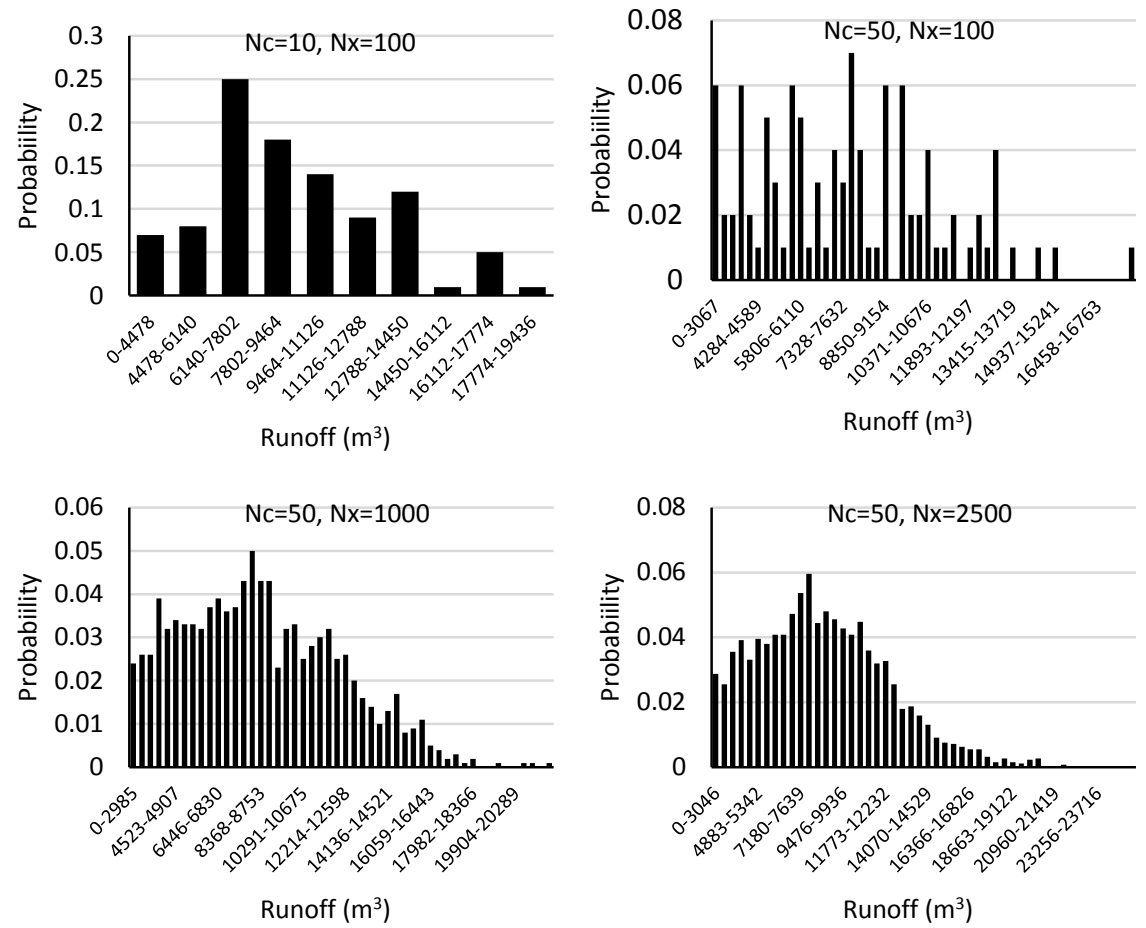

Figure 5.3 The distribution of runoff from sub-catchment 4 computed with precipitation data that was generated with four combinations of $N_{c}$ and $N_{x}$. 
Runoff of subcatchment 19

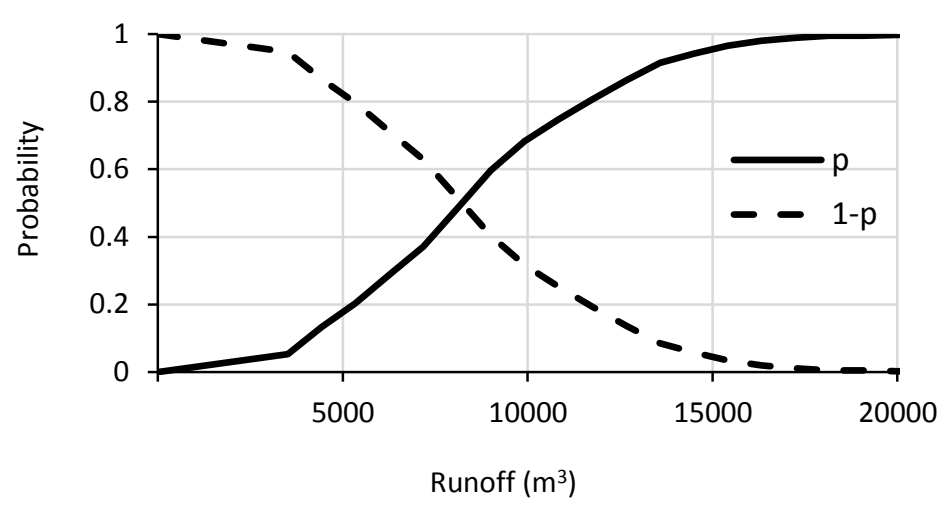

Figure 5.4 The cumulative probability of the runoff values for sub-catchment 19 as obtained from 1000 years with generated rainfall events.

From these values a cumulative probability chart can be created (Figure 5.4).The dotted line indicates the probability that the runoff exceeds a certain value, the continued line shows the probability that the runoff is smaller than the corresponding value. In our case there is a $10 \%$ chance that the value of runoff will exceed $4500 \mathrm{~m}^{3}$. On the other hand, a runoff value of $17500 \mathrm{~m}^{3}$ or higher will occur only once every 100 years.

\subsection{The program of water harvesting at catchment level (WHCatch)}

When we started, all input data was available in Excel already and only simple computations were required. It was decided to write the software as a simple Visual Basic for Applications (VBA) macro in Excel. The advantage was that all output could be stored and visualized in the same Excel workbook as well.

The Excel file consists of several worksheets (Table 5.2) and one VBA macro.

\subsubsection{The worksheets}

\section{Worksheet Control}

The worksheet Control contains the most important control parameters for the computations. It also has the buttons calling the VBA part that performs the required 
calculations (Figure 5-5). Five sections can be distinguished which are surrounded by a colored line, each with its own input data, button and functionality:

- Green: compute all terms of the water balance and store the output on the appropriate sheet.

- Blue: find the requested output data and convert it to a format that is readable by a GIS-application.

- Red: investigate the effects of changing the storage height on a specified term of the water balance of the considered sub-catchment.

- Black: generate a number of precipitation events and analyze the distribution of one of the terms of the water balance.

- Gold: show the distribution of precipitation events in the specified periods.

Table 5.2 The worksheets in the Excel application WHCatch

\begin{tabular}{|c|c|c|}
\hline Name & In/Out & Description \\
\hline Control & In & The settings and options \\
\hline Catchment & In & The sub-catchments and their properties \\
\hline ETp & In & Potential yearly evapotranspiration values \\
\hline Rainfall & In & The rainfall events \\
\hline Help & In & Data used to temporarily assign to in charts ${ }^{*}$ \\
\hline Smax & Out & Maximum volume that can be stored in the reservoir \\
\hline Vin & Out & Volume of water caught in sub-catchment \\
\hline Vs & Out & Volume of water caught in reservoir \\
\hline Vinf & Out & Infiltrated volume \\
\hline $\mathrm{Vx}$ & Out & Volume entered from upstream sub-catchments \\
\hline $\mathrm{dV}$ & Out & Volume stored in reservoir \\
\hline Runoff & Out & Volume leaving the sub-catchment as runoff \\
\hline Bal & Out & Change in water balance \\
\hline Chart1 & Out & Requested term of water balance shown as hi-lo-chart \\
\hline Chart2 & Out & Chart showing influence of storage height on balance term \\
\hline HiLo & Out & Chart showing the requested water balance term for specified years \\
\hline Events & Out & $\begin{array}{l}\text { Chart showing the number of runoff events for each catchment during the entire simulation } \\
\text { period }\end{array}$ \\
\hline GIS & Out & Sheet with data for GIS-processing \\
\hline GenPrecip & In/Out & $\begin{array}{l}\text { Sheet where precipitation events are stored that are generated by the precipitation } \\
\text { generator* }\end{array}$ \\
\hline Distribution & Out & $\begin{array}{l}\text { Shows the distribution of the water balance term of interest as generated with the } \\
\text { precipitation generator }\end{array}$ \\
\hline CumDist & Out & $\begin{array}{l}\text { Cumulative probabilities for the water balance term of interest generated with the } \\
\text { precipitation generator }\end{array}$ \\
\hline Year & Out & Average precipitation for each day of the year during the distinguished periods \\
\hline Month & Out & $\begin{array}{l}\text { Average monthly values of selected water balance term for sub-catchment under } \\
\text { consideration }\end{array}$ \\
\hline Analyze & Out & Distribution of precipitation \\
\hline
\end{tabular}




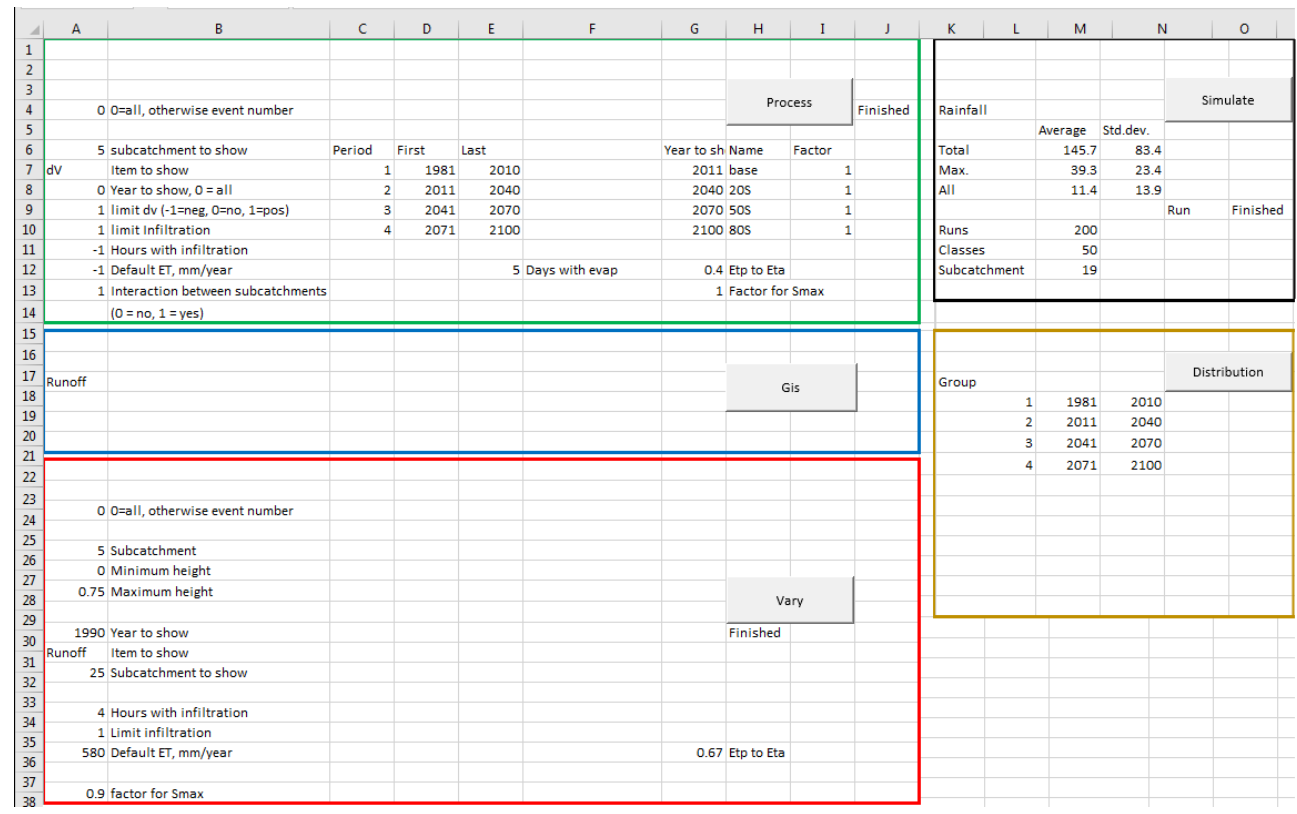

Figure 5.5 The five different sections on worksheet Control, representing the five main options of the program: simulate a simple water balance with measured precipitation (green), create output for a GIS (blue), show the influence of the height of a spillway (red), simulate water balance with artificially generated precipitation data (black), analyse precipitation in specified period (gold).

The program is capable of performing computations for an indefinite number of years. For the sake of presentation, 4 periods can be distinguished. The first and last year of each period can be specified in the 'Control'-sheet. For each period a representative year may be specified, allowing a short description.

The green part is to be used to compute all terms of the water balance. After entering all data, computations can be started by clicking on the button in the green $a^{2} a^{3}$. The message 'Computing' will be shown in cell $\mathrm{J4}{ }^{4}$. The results of the computations will be stored in the appropriate worksheets and shown in the graphs. When all computations are performed correctly, the word 'Finished' will be written to cell J4 and the sheet 'HiLo' will become the active sheet.

When calculations for all sub-catchments are performed as described in the previous section, one often wants to show one of the terms of the water balance using a GIS-

\footnotetext{
${ }^{3}$ Be sure to click on an empty cell first when you changed a value before clicking the button, otherwise Excel may not have stored the changed cell content.

${ }^{4}$ Depending on the speed of the processor, the number of sub-catchments and the number of event, computations may take time varying from a few seconds to several minutes.
} 
application (e.g. ArcGIS). In most cases the shape-file with the layout of the area and the numbers (id's) of the sub-catchment is available. In this case it is possible to make a join between the sub-catchment id in the shape file and the id in the Excel workbook. The joining is simpler when the data in the Excel sheet are organized with one sub-catchment per row and one year per column. This reorganizing of the output data can be performed in the blue section of the 'Control'-sheet. In cell A19 the water balance term to be considered is specified. Clicking on the button in the blue section will start the conversion and the worksheet 'GIS' will appear.

One of the interesting options of WHCatch is its possibility to show the influence of changing the maximum height of water in a storage area (changing the spillway height) on one of the water balance terms of a downstream sub-catchment. The red part of the 'Control'-sheet contains the required parameters of this option have to be specified in the red part of the 'Control'-sheet. After entering all data, computations can be started by clicking on the button in the red area. When finished, sheet 'Chart2' will be shown.

To generate precipitation data from three specified (normal) distributions and find the distribution of one of the terms of the water balance, the black section of the Control sheet has been created. After clicking the 'Simulate' button, the program will generate one year with precipitation from the specified distributions. The value of the water balance term of interest will then be read for the specified sub-catchment and stored in memory. This procedure is repeated 'numberOfSimulations' times. After finishing the simulations, the obtained data will be analyzed and the worksheet 'Distribution' will be shown with the distribution of the requested water balance term.

Analyzing the data on worksheet 'Rainfall' can be performed in the golden section of worksheet 'Control'. The precipitation data can be divided into 4 series of years. Pressing the button 'Distribution' will then start the analysis. Worksheet 'Generated' will then appear, showing three charts: the distribution of amounts of rainfall, the probabilities and the number of events per year and class. All data are averaged over the specified period.

\section{Worksheet Catchment}

The worksheet 'Catchment' contains all properties of every sub-catchment. The first two lines function as a header (see Figure 5.6).

From the third line down (Figure 5.6), the property values (Table 5.3) should be entered for each sub-catchment to be considered. 


\begin{tabular}{|c|c|c|c|c|c|c|c|c|c|c|c|c|}
\hline$\Delta$ & A & B & c & D & $\mathrm{E}$ & $\mathrm{F}$ & G & H & I & J & K & L \\
\hline $\begin{array}{l}1 \\
2\end{array}$ & $\begin{array}{l}\text { Catchmen } \\
\text { number }\end{array}$ & $\begin{array}{l}\text { nArea } \\
\text { m2 }\end{array}$ & $\begin{array}{l}\text { Cultivated } \\
\mathrm{m} 2\end{array}$ & $\begin{array}{l}\text { Storage } \\
\mathrm{m} 2\end{array}$ & $\begin{array}{l}\text { Max. storage } \\
\text { height } m \text {. }\end{array}$ & Runoff coeff. & $\begin{array}{l}\text { f.Infiltration rate } \\
\mathrm{mm} / \mathrm{hr}\end{array}$ & $\begin{array}{c}\text { Infiltration } \\
\%\end{array}$ & $\begin{array}{l}\text { Outflows } \\
\text { to } 1\end{array}$ & $\begin{array}{l}\text { Perc } \\
\%\end{array}$ & $\begin{array}{l}\text { Outflows } \\
\text { to2 }\end{array}$ & $\begin{array}{l}\text { Perc } \\
\%\end{array}$ \\
\hline 3 & 1 & 1240.23 & 20.3 & 15 & 0.6 & 0.21 & $1 \quad 96.00$ & 41 & 2 & 100 & -99 & 0 \\
\hline 4 & 2 & 1411.66 & 16.99 & 17.11 & 0.1 & 0.199 & 101.00 & 43 & 5 & 100 & -99 & 0 \\
\hline 5 & 3 & 1148.03 & 119 & 119.3 & 0.5 & 0.181 & 108.00 & 46 & 4 & 100 & -99 & 0 \\
\hline 6 & 4 & 193248.68 & 17 & 0 & 0 & 0.2668 & 18.00 & 49 & 5 & 100 & -99 & 0 \\
\hline 7 & 5 & 11287.67 & 4110.82 & 2135.84 & 0.55 & 0.299 & 24.00 & 46 & 12 & 100 & -99 & 0 \\
\hline 8 & 6 & 2447.12 & 244.3 & 79.55 & 0.5 & 0.297 & 112.00 & 44 & 8 & 100 & -99 & 0 \\
\hline 9 & 7 & 390.24 & 154.2 & 35.09 & 0.45 & 0.291 & 84.00 & 43 & 9 & 100 & -99 & 0 \\
\hline 10 & 8 & 2755.67 & 1002.21 & 119.88 & 0.35 & 0.263 & 72.00 & 46 & 9 & 100 & -99 & 0 \\
\hline 11 & 9 & 29160.45 & 19616.9 & 2079.38 & 0.8 & 0.356 & 103.00 & 48 & 11 & 100 & -99 & 0 \\
\hline 12 & 10 & 5290.04 & 4107.44 & 520.77 & 0.4 & 0.356 & 103.00 & 42 & 11 & 100 & -99 & 0 \\
\hline 13 & 11 & 10645.76 & 9484.25 & 1600.21 & 0.5 & 0.215 & 108.00 & 43 & 18 & 100 & -99 & 0 \\
\hline 14 & 12 & 22906.3 & 16855.07 & 1323.62 & 0.4 & 0.18 & 111.00 & 45 & 13 & 100 & -99 & 0 \\
\hline 15 & 13 & 5952.82 & 6646.88 & 562.06 & 0.2 & 0.12 & 104.00 & 49 & 20 & 100 & -99 & 0 \\
\hline 16 & 14 & 7389.23 & 4993.37 & 0 & 0 & 0.166 & 102.00 & 46 & 20 & 100 & -99 & 0 \\
\hline 17 & 15 & 8243.31 & 2657.66 & 478.06 & 0.3 & 0.335 & 106.00 & 47 & 16 & 100 & -99 & 0 \\
\hline 18 & 16 & 21633.79 & 9707.59 & 1561.36 & 0.45 & 0.241 & 60.00 & 49 & 18 & 100 & -99 & 0 \\
\hline 19 & 17 & 4431.85 & 1646.06 & 518.04 & 0.4 & 0.18 & 48.00 & 42 & 16 & 100 & -99 & 0 \\
\hline 20 & 18 & 23413.22 & 14812.52 & 2392.02 & 0.7 & 0.118 & 90.00 & 45 & 23 & 100 & -99 & 0 \\
\hline 21 & 19 & 10307.13 & 8553.06 & 0 & 0 & 0.298 & 48.00 & 41 & 22 & 100 & -99 & 0 \\
\hline 22 & 20 & 11650.54 & 12093.84 & 1547.96 & 0.6 & 0.146 & 101.00 & 48 & 21 & 100 & -99 & 0 \\
\hline 23 & 21 & 19392.32 & 20814.62 & 0 & 0 & 0.103 & 108.00 & 43 & 25 & 100 & -99 & 0 \\
\hline 24 & 22 & 12663.6 & 8060.47 & 415.01 & 0.2 & 0.281 & 107.00 & 44 & 25 & 100 & -99 & 0 \\
\hline 25 & 23 & 4842.04 & 4150.92 & 929.45 & 0.6 & 0.204 & 108.00 & 43 & 24 & 100 & -99 & 0 \\
\hline 26 & 24 & 7989.35 & 4223.52 & 316.73 & 0.5 & 0.188 & 100.00 & 43 & -1 & 100 & -99 & 0 \\
\hline 27 & 25 & 13182.81 & 8940.88 & 1272.58 & 0.3 & 0.299 & 110.00 & 46 & -1 & 100 & -99 & 0 \\
\hline
\end{tabular}

Figure 5.6 The properties of each sub-catchment are read from worksheet Catchment.

If the water from a sub-catchment flows into just one other sub-catchment, column J should contain the value 100 , indicating $100 \%$ goes into the specified sub-catchment. In that case column $\mathrm{K}$ should contain -99 and column $\mathrm{L}$ should contain 0 . If a second subcatchment is getting water, then the identification number of this sub-catchment should be entered in column $\mathrm{K}$ and its percentage in column $\mathrm{L}^{5}$. If a positive number is entered in column $\mathrm{H}$, this value will be considered as the percentage of the total volume of water that infiltrates into the soil. If a negative number is entered, then the volume of infiltrated water will be computed from the infiltration rate (column $\mathrm{G}$ ) and the specified number of hours with infiltration (Cell A36 on tabsheet 'Control'). One line of data should be present for each considered sub-catchment.

Table 5.3 Meaning of the columns on worksheet 'Catchment'.

\begin{tabular}{llll}
\hline Column & Name & Units & Remarks \\
\hline $\mathrm{A}$ & Catchment & number & Identification number \\
$\mathrm{B}$ & Area & $\mathrm{m}^{2}$ & Total area \\
$\mathrm{C}$ & Cultivated & $\mathrm{m}^{2}$ & Cultivated area \\
$\mathrm{D}$ & Storage & $\mathrm{m}^{2}$ & Area of storage reservoir \\
$\mathrm{E}$ & Max. storage height & $\mathrm{m}$ & Max. height of water in storage reservoir \\
$\mathrm{F}$ & Runoff coefficient & - & \\
$\mathrm{G}$ & Infiltration rate & $\mathrm{mm} \mathrm{hr}{ }^{-1}$ & Measured infiltration rate \\
$\mathrm{H}$ & Infiltration & $\%$ & Percentage of water that infltrates in the storage area. If this \\
& & & value is not available, put a negative number here. \\
$\mathrm{I}$ & Outflows to 1 & - & Id of first sub-catchment receiving water \\
$\mathrm{J}$ & Percentage1 & $\%$ & Percentage of water flowing to sub-catchment 1 \\
$\mathrm{K}$ & Outflows to 2 & - & Id of second sub-catchment receiving water \\
L & Percentage2 & $\%$ & Percentage of water flowing to sub-catchment 2 \\
\hline
\end{tabular}

\footnotetext{
${ }^{5}$ The sum of the values in column $J$ and $L$ of each row should always add up to 100 .
} 


\section{Worksheet ETp}

In worksheet 'ETp' the yearly potential evapotranspiration can be specified. If the value for the considered year is not available, then the value specified in cell A11 and A38 of the 'Control' worksheet will be used.

\section{Worksheet Rainfall}

As the program does not consider the interaction between rainfall events, it is sufficient to present a list of precipitation ( $\mathrm{mm}$ ) values (Figure 5.7 ). The first column contains the year, the others contain the precipitation for each event. As the number of events may differ per year, the length of the rows is varying as well between the years. We applied the model for two datasets: one with 25 years (1981-2014) and one with 120 years of measured and predicted data (1981-2100).

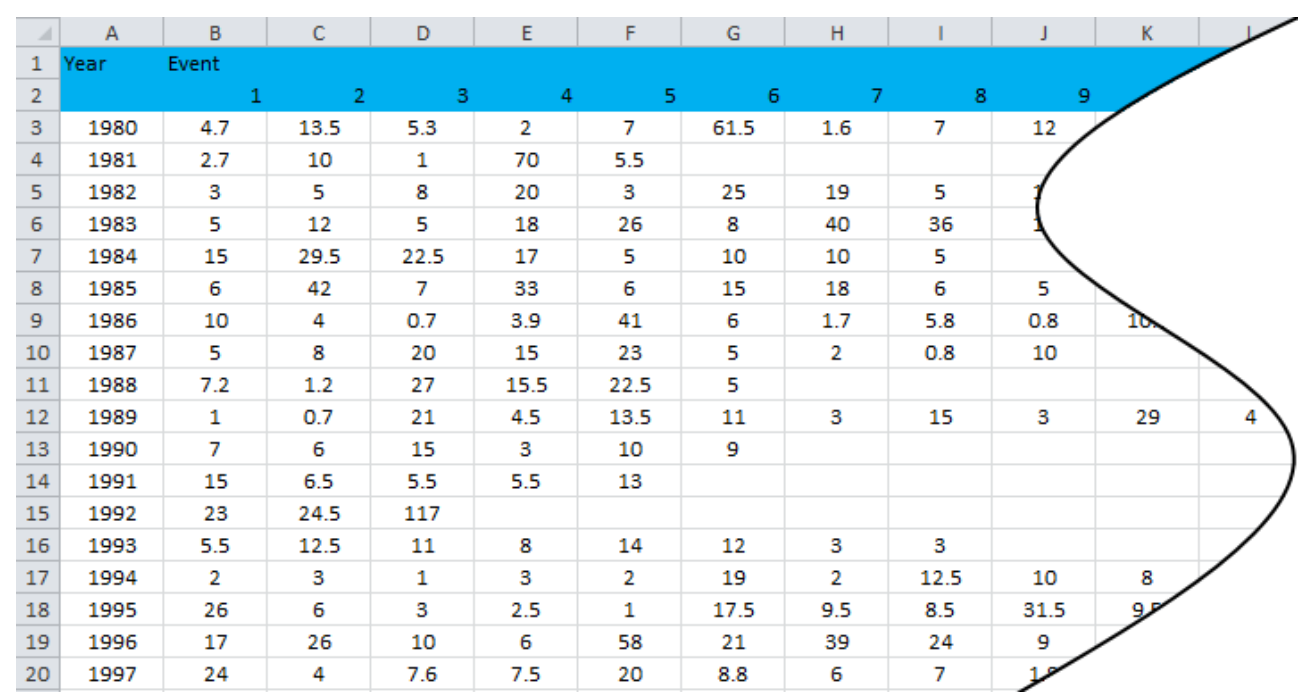

Figure 5.7 Worksheet Rainfall contains the (measured) rainfall data: events are stored in columns, one year per row.

\section{Worksheets Smax, Vin, Vs, Vinf, Vx, $d V$, bal, Runoff}

The data in all of these worksheets is calculated by the program. The values in worksheet 'Smax' represent the maximum volume of water (in $\mathrm{m}^{3}$ ) that can be stored in each subcatchment. Worksheet 'Vin' shows the volume of water (in $\mathrm{m}^{3}$ ) that flows from the nonstorage area into the storage area, ' $V s^{\prime}$ shows the volume of water (in $\mathrm{m}^{3}$ ) that has been fallen in the storage area of each sub-catchment. Worksheet 'Vinf' presents the volume of water (in $\mathrm{m}^{3}$ ) that has been infiltrated into the soil under the storage area of each subcatchment and worksheet ' $V x^{\prime}$ presents the volume of water (in $\mathrm{m}^{3}$ ) that has flows into 
the sub-catchment from other sub-catchment(s) located upstream. Worksheet ' $d V$ ' presents the potential change in volume of water (in $\mathrm{m}^{3}$ ) in the storage area of each subcatchment. Positive values mean that water is stored in the storage area, negative values mean there will be no storage. If you are interested in the potential storage (i.e. the storage when the reservoir walls would be infinitely high) in $\mathrm{m}^{3}$, then you can have a look at the worksheet called 'bal'. Worksheet 'Runoff' presents the runoff volume of water (in $\mathrm{m}^{3}$ ) from the storage area of each sub-catchment.

\section{Worksheet Chart1}

Worksheet 'Chart1' has been developed to present the computed data graphically. The water balance term to be shown is specified in the 'Control' worksheet. At the left hand side of the worksheet, 5 data columns can be seen (see Figure 5-8). In column $A$ the value is stored that should be shown at the x-axis. Column $C$ contains the minimum value, columns $B$ and $E$ contain the average value and column $D$ contains the maximum value to be shown. In this figure the minimum, maximum and averaged runoff from all catchments is shown for all considered years.

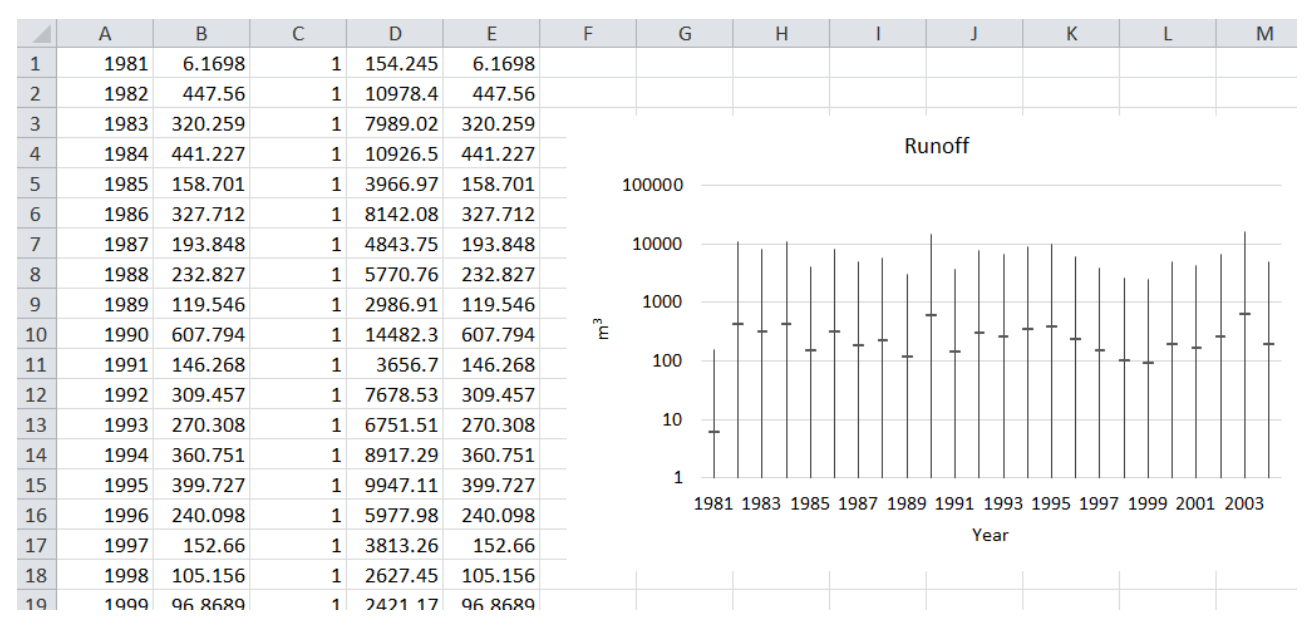

Figure 5.8 If it has been specified that all years have to be considered, the minimum, maximum and average values of a water balance term (in this case runoff) are presented graphically on worksheet Chart1. 


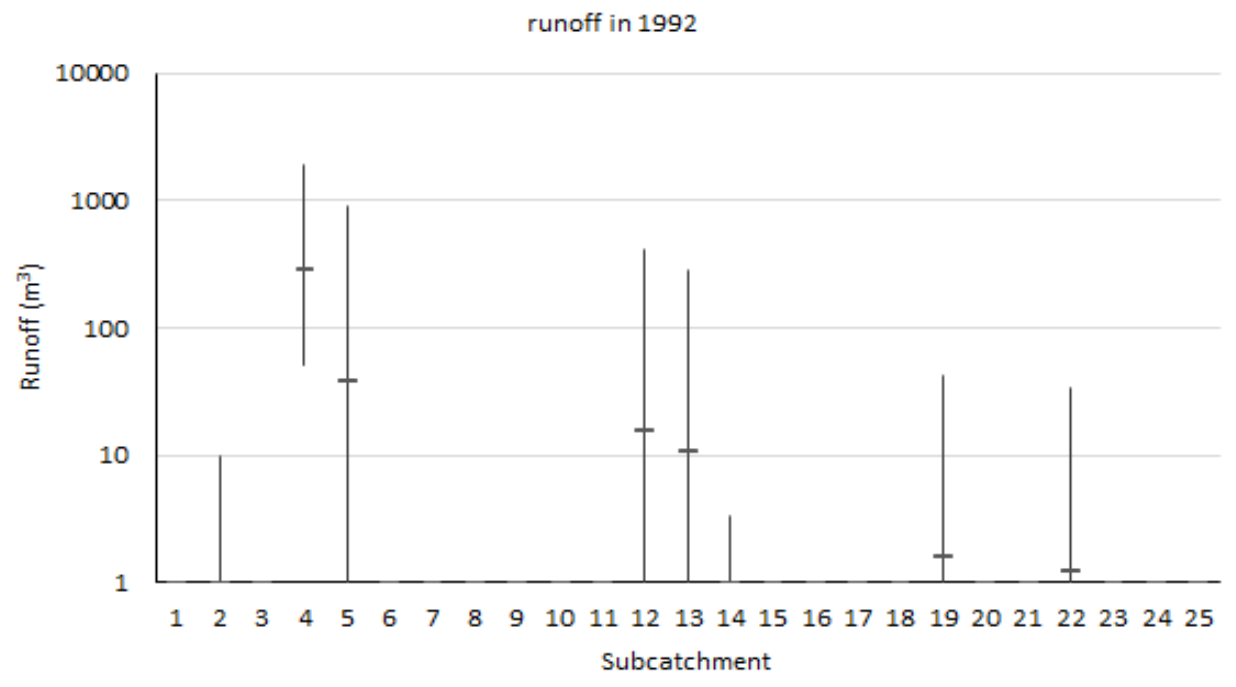

Figure 5.9 If only one year (e.g. 1992) has been specified in the Control sheet, then the minimum, maximum and average values of the requested water balance term (in this case runoff) are taken over all events in the year and presented in the chart of worksheet Chart1.

The minimum value is 0 for all years, indicating there is at least one catchment where no runoff will take place. If the option is chosen to perform computations for all years, then the chart will show the minimum, average and maximum values of all sub-catchments for each year. If calculations had to be performed for a specified year only, then data will be presented as the minimum, average and maximum value of the balance terms of each event for every sub-catchment (Figure 5.9). Runoff is presented for all events in 1992 for all sub-catchments. Here it can be seen there are 4 sub-catchments that always have runoff. These are the sub-catchments where the value of the maximum storage height is set to 0 in worksheet 'Catchment' because the spillway has been broken.

\section{Worksheet Chart2}

In worksheet 'Chart2' the results of varying the maximum storage height of a subcatchment (red part in worksheet 'Control') are visualized (Figure 5-10). If, for example, one wants to know how the storage height of sub-catchment 4 influences the runoff from sub-catchment 25, the corresponding chart is created. Columns A and B of the worksheet 'Chart2' contain the $x$ - and $y$-values to be shown. The titles of the $y$ - and $x$-axis are stored in cells D1 and D2 respectively and cell D3 contains the title of the chart. 


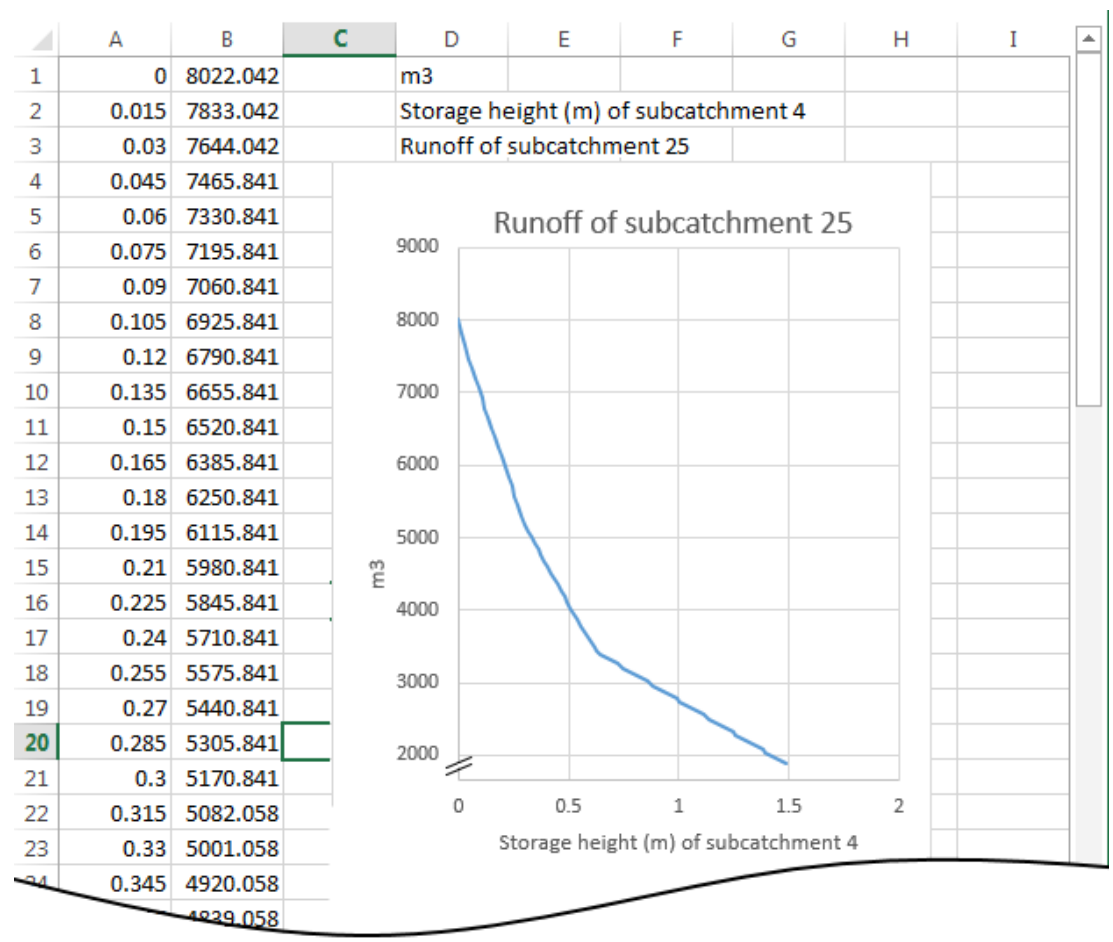

Figure 5.10 Worksheet Chart2 shows the influence of changing the storage height in a sub-catchment (nr. 4 in this example) on one of the waterbalance terms (here: runoff) of another sub-catchment (here: 25$)$.

\section{Worksheet HiLo}

In the description of worksheet 'Control' it was mentioned that four years can be specified as representative years. The results for these years are presented in the chart of worksheet 'HiLo'. The identification number of the sub-catchment is stored in column A. Columns B-F contain the data for the specified years. These values are plotted in a chart. See e.g. Figure 5-11 where the values of $\mathrm{dV}$ are plotted for the four considered years and for every sub-catchment.

\section{Worksheet Events}

One of the most interesting options of the program is presented on worksheet 'Events' (Figure 5.12), showing the number of runoff events for each sub-catchment. This chart indicates which sub-catchment should have a larger storage capacity and where it will take no effect to change the storage capacity. From our example it can be concluded that a lot of runoff can be prevented by changing the storage capacity of the sub-catchments 14, 19 and 21. From the input data it can be seen that these sub-catchments do not have any storage capacity. 
$\mathrm{dV}$, surplus

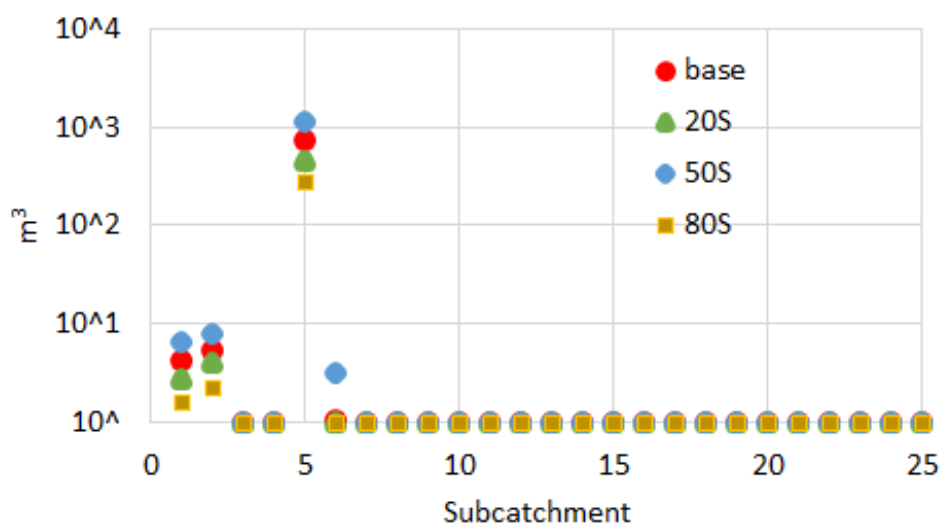

Figure 5.11 On worksheet HiLo a chart is presented with the values of the requested term of the water balance ( $d V$ in the example) for all sub-catchments and for the years specified in the green part of worksheet Control.

\section{Worksheet GIS}

The computed data can be read into a GIS application. The item to be shown can be specified in the blue part of the 'Control'-worksheet. Pressing the button in that area will tell the program to write the data to the worksheet 'GIS' (Figure 5.13 A).

This worksheet can easily be imported into a GIS-application and combined with a shapefile to create maps or movies. An example is presented in Figure 5-13 B showing the runoff values.

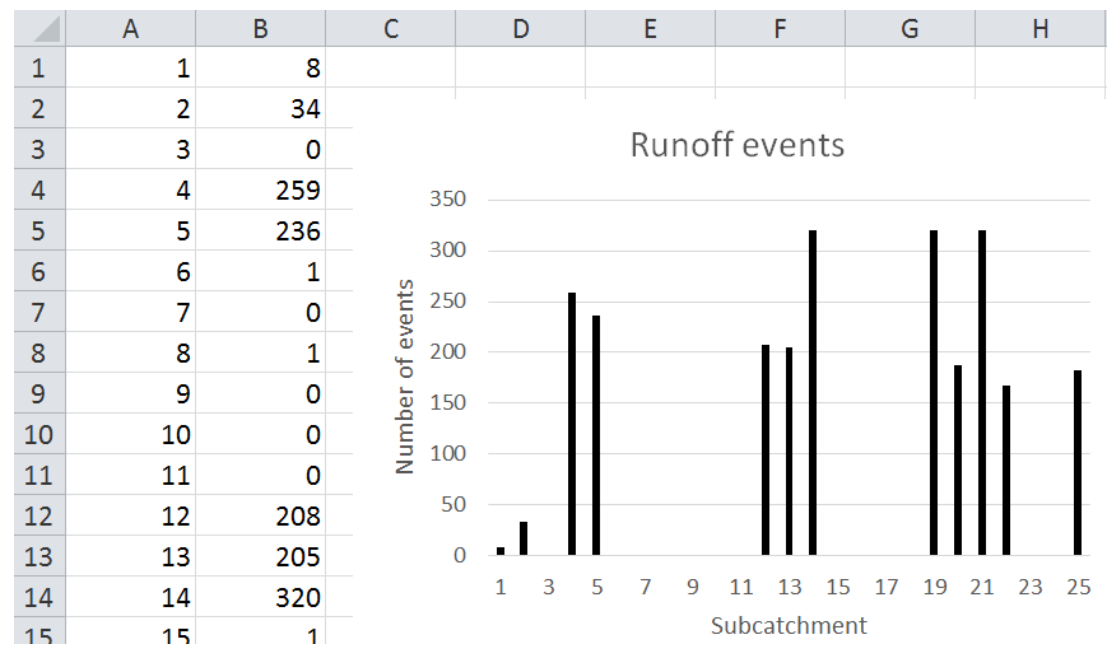

Figure 5.12 The number of runoff events for each sub-catchment is shown on worksheet Events. 


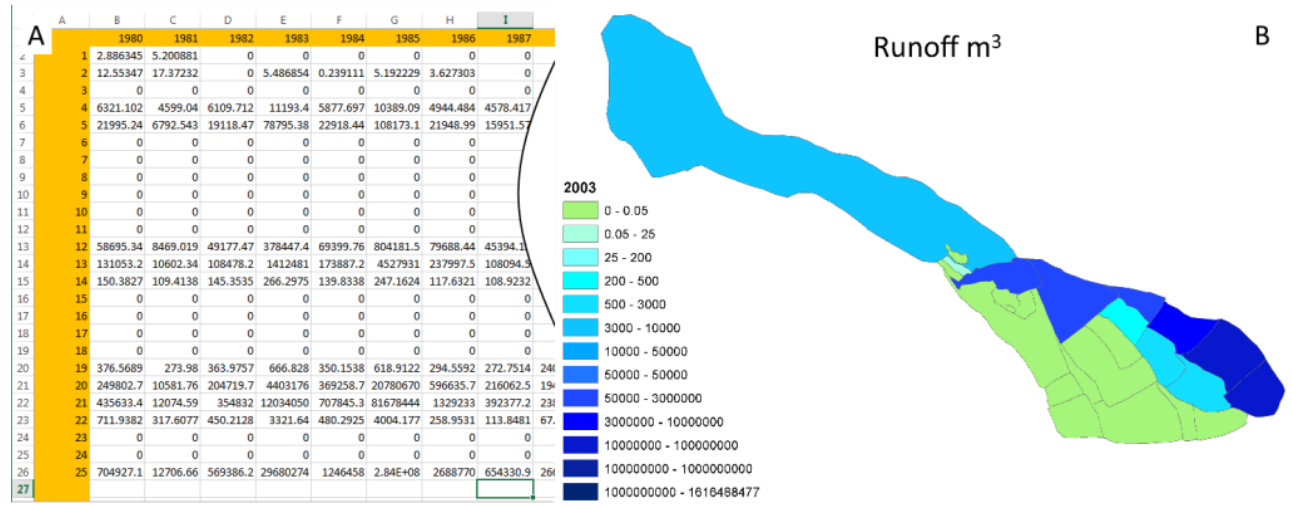

Figure 5.13 An example of the worksheet GIS $(A)$ and the map with runoff values obtained from these data (B).

\section{Worksheet Distribution}

When the simulations with the generated rainfall events are analyzed, the worksheet 'Distribution' will be shown. On this sheet (Figure 5.14), column A contains the lower limit of the classes and column B contains the upper limit. In column $C$ the number of entries in the class can be found and column D shows the probability that a value will be in the class. Finally, column E contains the labels to be shown at the horizontal axis of the chart. As additional information, the average value (cell H2), standard deviation (cell H3) and median value (cell $\mathrm{H} 5$ ) are presented.

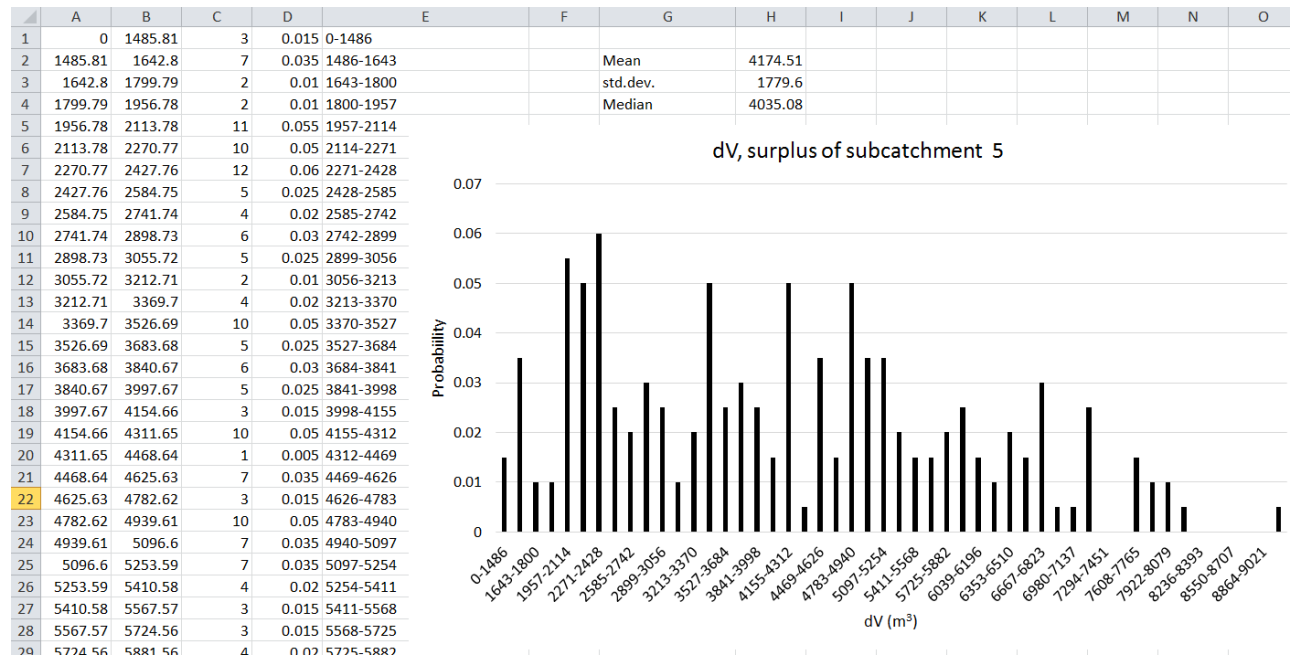

Figure 5.14 The distribution of the selected water balance term (dV) for a specified sub-catchment (5) obtained after computations with generated precipitation events is shown on worksheet Distribution. 


\section{Worksheet CumDist}

When the probability of the distributions is computed (see the previous paragraph), the cumulative distribution is derived and presented on worksheet 'CumDist' (Figure 5-15). Column A contains the value of interest (computed as the middle of the corresponding class), column B contains the probability that a value is smaller than the value in column $A$ and column $C$ presents the probability that a value exceeds the one in column $A$. The dotted and continued lines represent these probabilities. As an example, it can be seen that the $p$-value for 3516 is 0.052 , indicating that the runoff of sub-catchment 19 will be smaller than 3516 during 52 out of 1000 years. On the other hand, the runoff value will exceed 14491 only during 6 years every century.

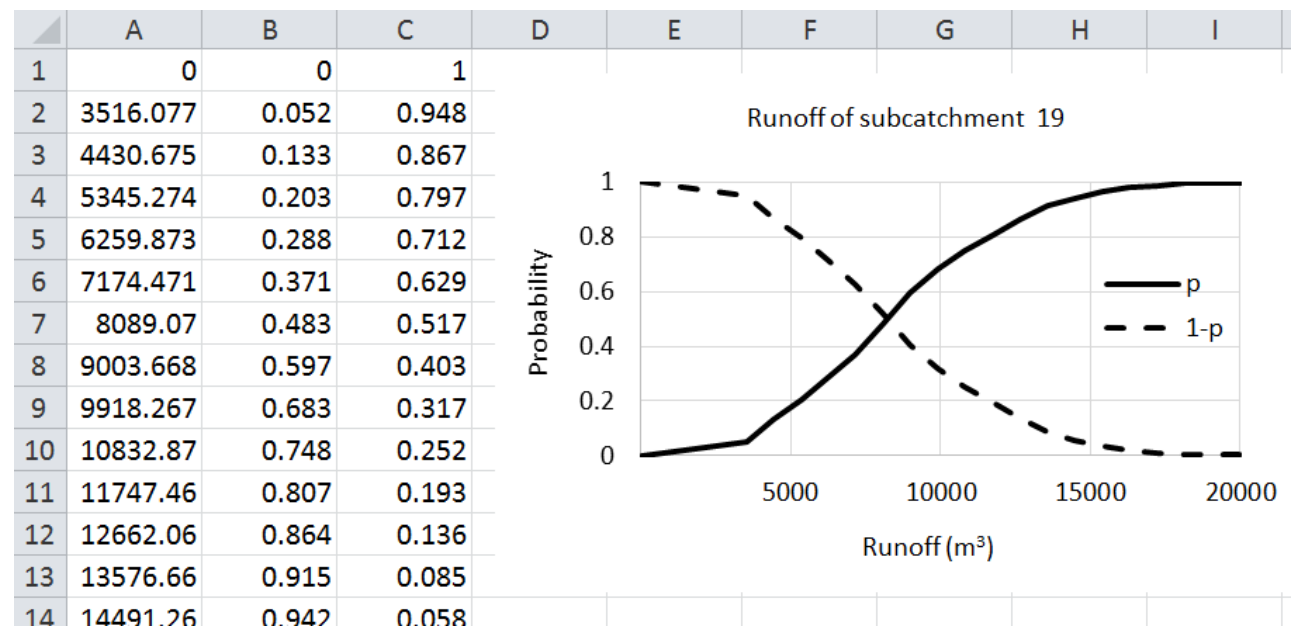

Figure 5.15 Worksheet CumDist shows the cumulative probability of the selected term of the water balance (runoff) in a specified sub-catchment (19).

\section{Worksheet Year}

It is always interesting to see the precipitation in a graph. Therefore, WHCatch will automatically show the daily precipitation of the 4 years of interest in a chart on worksheet 'Year' (see Figure $5.16 \mathrm{~A}$ ) ${ }^{6}$. In this worksheet the first row contains the names of the lines (equal to the name of the special years presented on worksheet 'Control'). The first column presents the day of the year, starting with 1 in row 2 . Columns 2-5 contain the precipitation values, columns 6-9 have the cumulative precipitation values which are shown in the Figure $5.16 \mathrm{~B}$.

\footnotetext{
${ }^{6}$ Take care that in this case the program expects precipitation data for each day of the year in worksheet 'Rainfall'. If you only provide the rainfall events (no zeroes), the charts will not show the real course of rainfall in the considered year.
} 


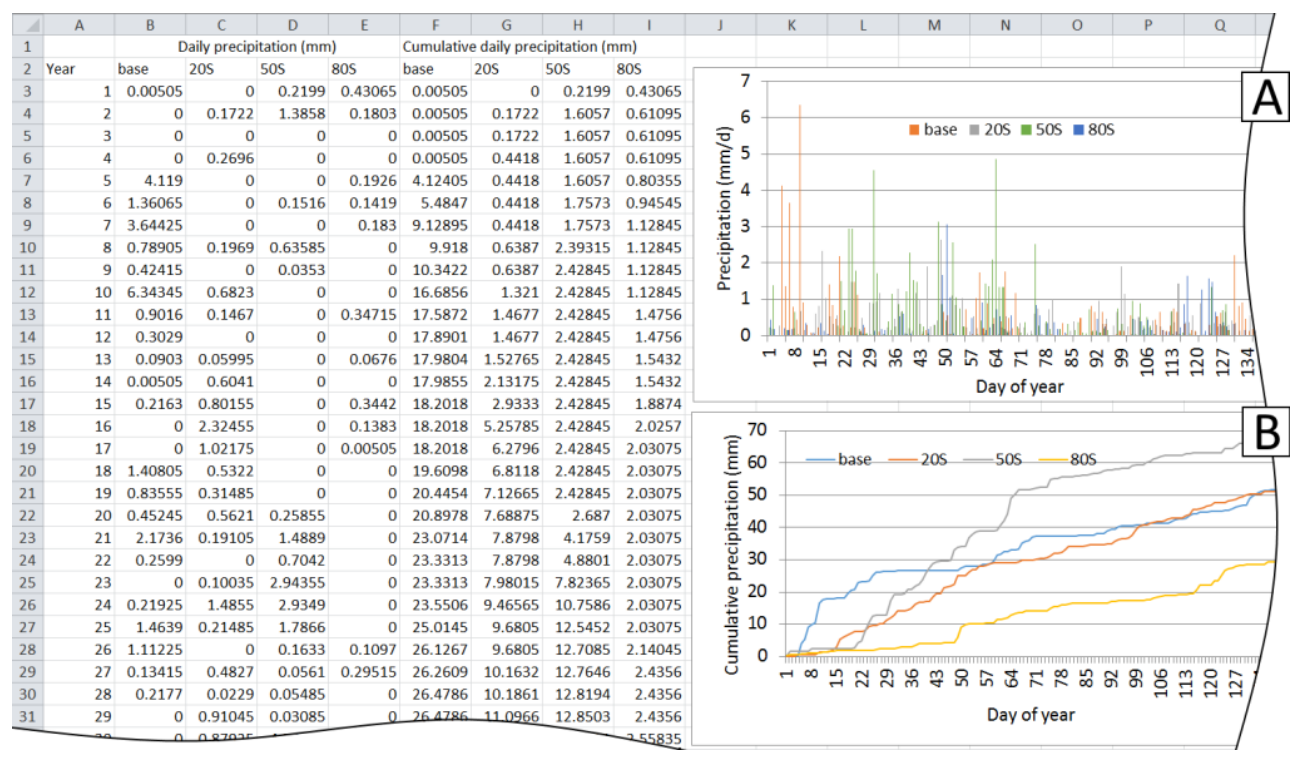

Figure 5.16 The daily precipitation (A) and cumulated values (B) for the 4 years of interest are shown on worksheet Year.

\section{Worksheet Month}

If the data on tabsheet 'Rainfall' is presented on a daily basis, it is possible to generate monthly values of output. The water balance term to show is specified in the black part of the worksheet 'Control'. Monthly values are averaged over the years and presented for the different periods defined before (Figure 5.17).

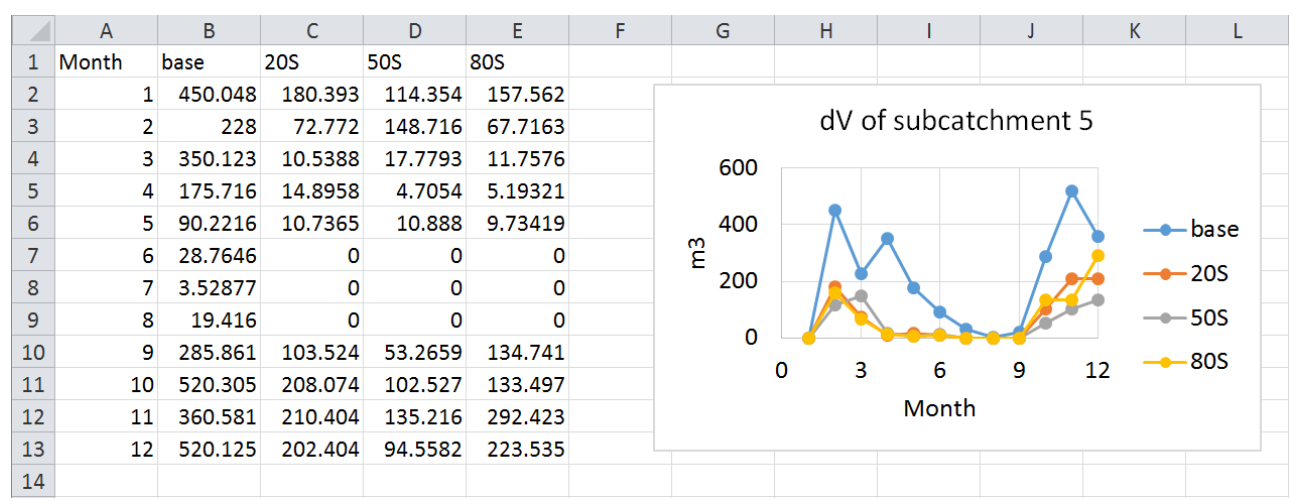

Figure 5.17 The monthly totals for the specified waterbalance term (here: $d V$ ) of the considered subcatchment (here: 5) are shown for the 4 years of interest on worksheet Month. 
A Distribution of precipitation amounts

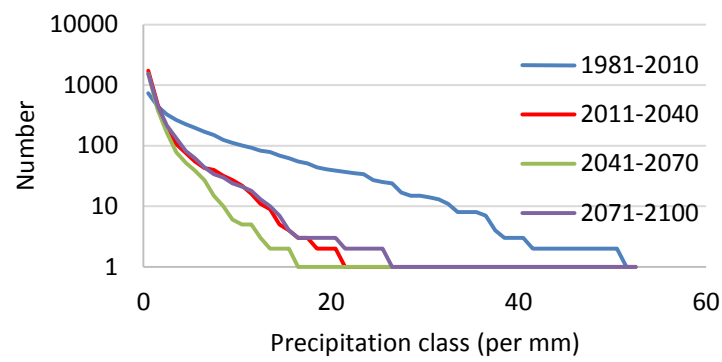

B Precipitation probability

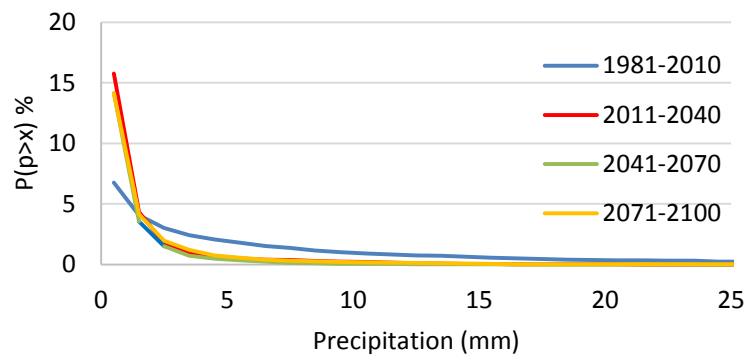

C Number of rainfall events per year

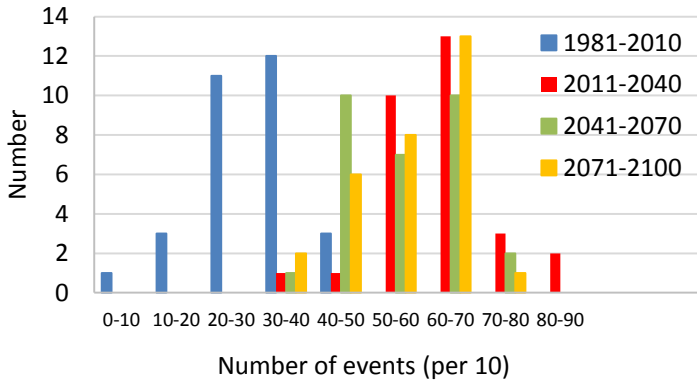

Figure 5.18 The figures showing the results of the analysis of the rainfall data: (A) Distribution of precipitation amounts, (B) Probability of precipitation and (C) Yearly averaged number of occurrences of a rainfall event with specified size.

\section{Worksheet Analyse}

If the button Distribution in the golden part of the 'Control'-sheet is pressed, the rainfall data on worksheet 'Rainfall' will be analyzed and the results will be stored in the worksheet 'Distribution'. Just like in the other options, 4 different periods may be distinguished that will be analyzed separately. Computations start by creating a number of precipitation classes of $1 \mathrm{~mm}$ each and simply counting the number of events in each class. The class-values (middle of the class) and number of events are then stored in 
columns $A-H$. From these values the cumulative probabilities $(P(p>x))$ are computed and stored in columns $U-A B$. Finally, classes of $10 \mathrm{~mm}$ are created and it is checked how many times per year an event correspons to the class. These values are averaged over the number of years in each period and stored in columns J-Q. Starting from column AC three charts are presented to show the results of these computations (see Figure 5.18).

\subsubsection{The VBA part}

To perform the calculations described above and put the results in the correct places, some Visual Basic for Applications (VBA) code was developed: a module WBCatch and a class module SubcatchmentClass. The latter contains all the properties of a sub-catchment and software to perform some basic computations. The module WBCatch consists of a number of private subroutines and only 5 public ones, which correspond to the 5 buttons on the 'Control' worksheet.

As the VBA part is well-documented and the names of the variables explain their function, the VBA part will not be discussed in detail here. Common users of the Excel workbook will not see the VBA part. Only when new functionality is required, it is necessary to enter the code part.

\subsection{Applications}

The program has been tested with 25 sub-catchments and with 258 sub-catchments, both with 120 years of rainfall. See Adham et al. (2016b) for an application of the program.

\subsection{Limitations of the program}

Because we wanted to create a fast and simple program that requires as little data as possible, there are some known limitations:

- There is no interaction between the events, so computations start at the same initial situation, independent of the time between events;

- Infiltration of the soil is considered in a simple way;

- Plant transpiration and soil evaporation are not considered separately;

- Circumstances do not change in time;

- No human actions are incorporated. 


\section{A Water Harvesting Model for Optimising Rainwater Harvesting in the Wadi Oum Zessar Watershed, Tunisia}

Rainwater harvesting (RWH) techniques have been adapted in arid and semi-arid regions to minimise the risk from droughts. The demand for water has increased but water resources have become scarcer, so the assessment and modelling of surface water related to RWH in catchments has become a necessity. An understanding of the hydrological processes at the sub-catchment level is generally lacking, and little attention has been paid to the assessment of RWH after implementation. The objective of this study was to develop a simple but generally applicable water harvesting model and test it at sub-catchment level to evaluate and optimise the performance of RWH under different design and management scenarios. The model was applied to rainfall data for 1980-2004 in 25 sub-catchments of the watershed of wadi Oum Zessar (southeastern Tunisia). The performance and analysis of RWH in three types of years (dry, normal and wet) are presented and discussed. This study emphasises the advantages of simulating long-term water balances at the sub-catchment level for improving our understanding of hydrological processes in the RWH system and provides several solutions for optimising RWH performance in various scenarios. Changing the spillway heights together with the flow directions had a significant impact on the performance of RWH by making $92 \%$ of all sub-catchments supply sufficient water requirements, compared to $44 \%$ of the subcatchments in case of no changes.

This chapter is published as:

Adham, A., Wesseling, J. G., Riksen, M., Ouessar, M. and Ritsema, C. J. (2016). A water harvesting model for optimising rainwater harvesting in the wadi Oum Zessar watershed, Tunisia. Agricultural Water Management, 176, 191-202. 


\subsection{Introduction}

The pressure on water resources is increasing due to climate change and growing demands for water for agricultural and urban development. Aridity and climatic uncertainty are the major challenges in arid and semi-arid regions. These regions have low average annual rainfalls and a highly variable temporal and spatial rainfall distribution. Inhabitants of dry areas have constructed and developed several techniques of rainwater harvesting $(\mathrm{RWH})$ for increasing the availability of water for domestic, crop and cattle production. RWH is a method for inducing, collecting, storing and conserving local surface runoff in arid and semi-arid regions (Gupta et al., 1997). Understanding the performance of RWH, the water yield of a catchment and the flood flows for planning the structures for harvesting rainwater are amongst the most important objectives of hydrological engineers. RWH structures are designed to catch as much of the expected runoff as possible in a specific recurrence interval while satisfying the water requirements (Adham et al., 2016a). RWH must balance water requirements and storage capacity (structure design). Understanding the relationship between rainfall and runoff in catchments is thus necessary. Studying the water balance can provide insights into the hydrological behaviour of catchments and RWH structures and can help to identify the dominant hydrological processes (Uhlenbrook et al., 2008). The water balance equation presents the values of inflow, outflow and the change in water storage for an area or water body (Tadesse et al., 2010a). Thornthwaite (1948) published the first monthly water balance, and the method has since been adapted, modified and used in numerous studies (e.g. Gabos and Gasparri, 1983; Xu and Vandewiele, 1992; Arnell, 1992). Durbude and Venkatesh (2004) applied the Thornthwaite and Mather (TM) models with remote sensing and a geographic information system (GIS) to identify potential zones of runoff and suitable sites for RWH in Africa, such as contours, farm ponds, gully plugs and percolation tanks. Jasrotia et al. (2009) applied the TM models with remote sensing and a GIS to understand the water balance of RWH structures in the Devak-Rui watershed in India.

Budyko (1974) developed an empirical relationship between the ratio of mean annual evaporation, rainfall and dryness index of the catchment to analyse the catchment water balance (Gebrekristos, 2015). Budyko's framework has been widely applied in the catchments around the world (Donohue et al., 2006; Gebrekristos, 2015; Potter and Zhang, 2009; Yang et al., 2009). Yang et al. (2007) analysed the spatiotemporal variability of annual evaporation and runoff for 108 catchments in China and explored both regional and inter-annual variability in annual water balance. Tekleab et al. (2011) applied water balance to analyse twenty catchments in the Upper Blue Nile using top-down modelling based on Budyko's hypotheses for temporal and spatial scales. 
Rainfall is the most important term in the water balance equation, so the interpretation of past records of rainfall and hydrological events in terms of future probabilities of occurrence is one of the challenges for engineers designers and hydrologists. Analysis of maximum rainfall over a catchment area at different frequencies or return periods is a basic tool for safe and economic planning, management of water resources applications and designing of hydraulic structures (Bhakar et al., 2008; Chow et al., 1988; Durbude, 2008). Probability and frequency analysis of rainfall data can be applied to obtain predicted amounts of precipitation for various probabilities (Bhakar et al., 2008). Similar analysis techniques can be applied to predict maximum daily rainfall of future events from the available data (Kumar and Kumar, 1989). Frequency analysis of rainfall is a tool for solving various water management problems (Kumar et al., 2007). Therefore, the probability and frequency of the occurrence of future events of rainfall can be used to minimise flood risks and periods of drought, and for planning and designing of water resources related to engineering such as small dams, reservoirs, culverts, drainage works and rainwater harvesting structures (Dabral et al., 2009).

An understanding of the hydrological processes at the sub-catchment level is generally lacking in practice. Relatively, little attention has been paid to the evaluation of RWH systems after implementation. Few studies have investigated the effectiveness of catching and storing water and the utility of RWH within the existing land use and farm management. The objective of this study was to develop a simple but generally applicable water harvesting model and apply it at sub-catchment level to evaluate and optimise the performance of RWH under different design and management scenarios. The target was to improve water availability for different RWH systems based on water requirements, the rainfall-runoff relationship and the design of RWH structures.

\subsection{Materials and method}

\subsubsection{Study area}

A 50 ha catchment in an upstream area of the wadi Oum Zessar watershed in southeastern Tunisia was selected for the case study. The watershed has a surface area of $367 \mathrm{~km}^{2}$, and the catchment consists of 25 sub-catchments (Figure 6.1). The area has an arid Mediterranean climate, with an average annual rainfall of $150-230 \mathrm{~mm}$, an average annual temperature of $19-22{ }^{\circ} \mathrm{C}$ and an average annual potential evapotranspiration of $1450 \mathrm{~mm}$ (Adham et al., 2016a; Ouessar, 2007). 


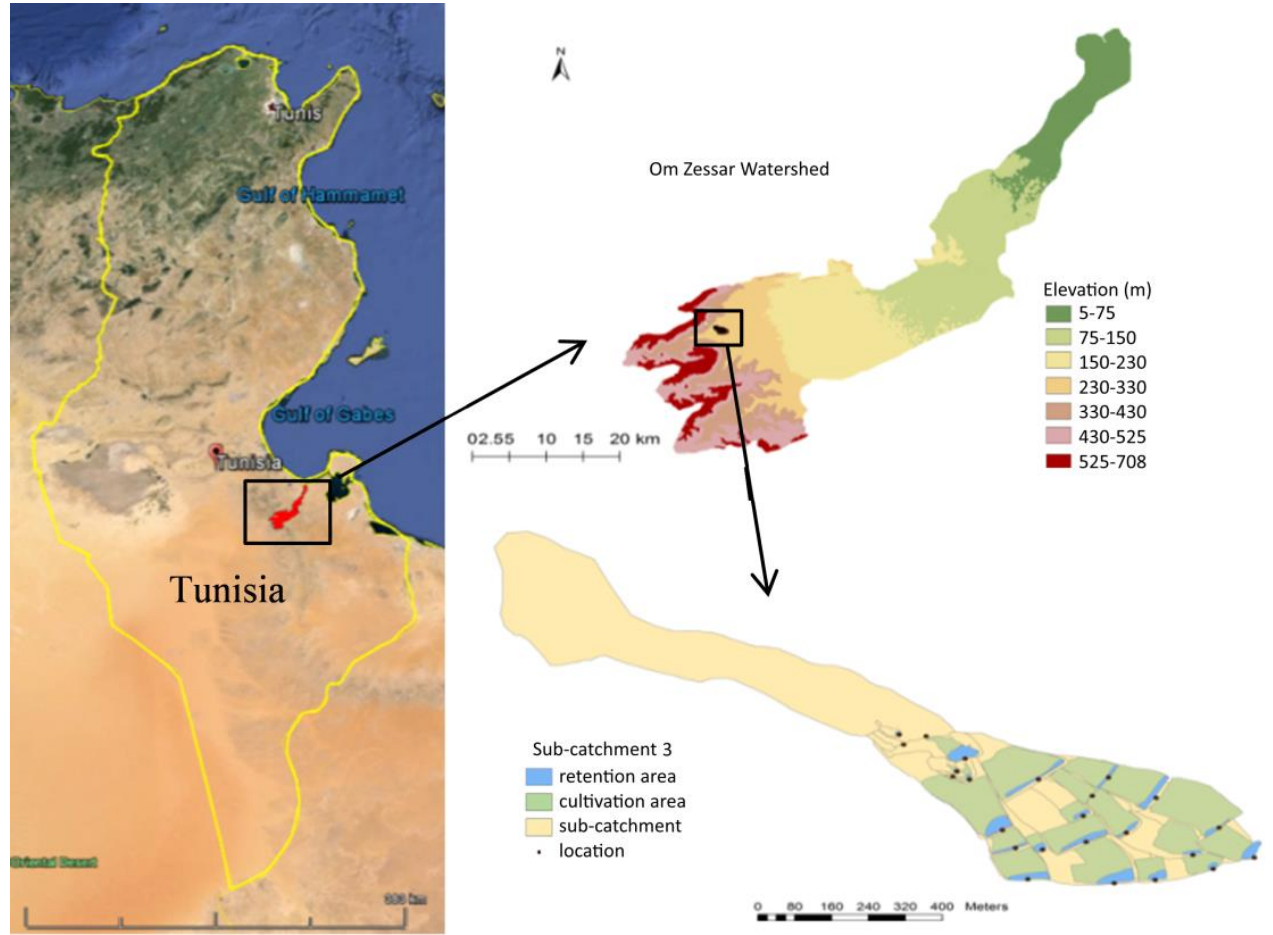

Figure 6.1 Location of wadi Oum Zessar and the test sub-catchment

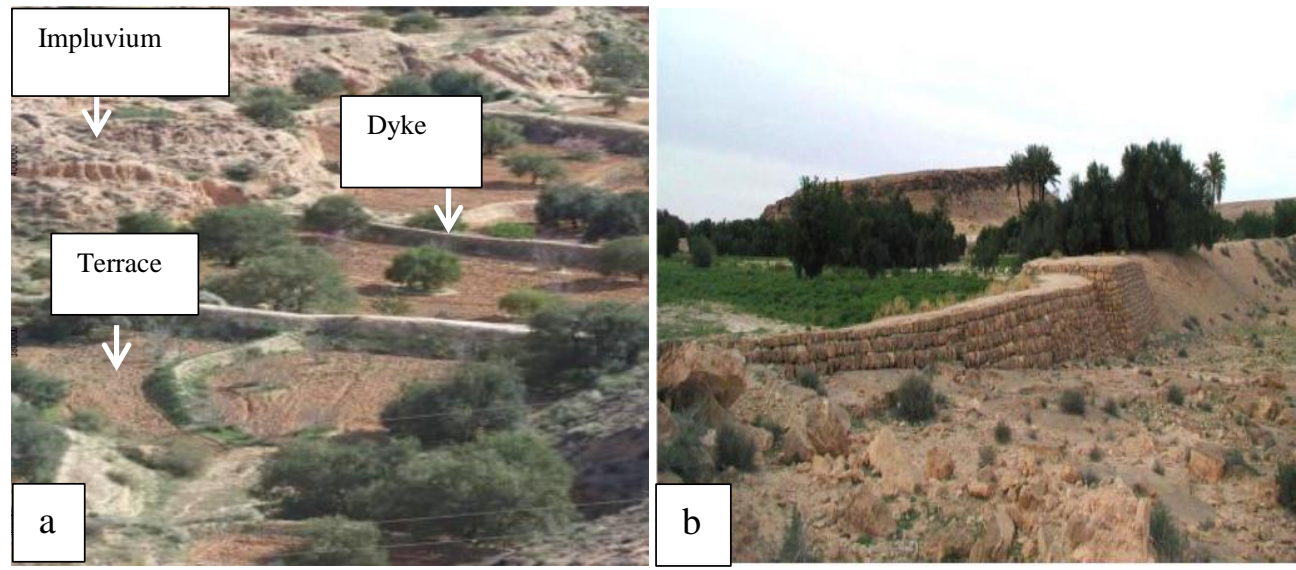

Figure 6.2 a: An example of the jessour (Ouessar, 2007); b: An example of a spillway.

Inhabitants in the study area have built two types of RWH structures to satisfy the water requirements: jessour (in medium to high slopes areas) and tabias (in gently-sloping foothill areas). Each jessr (singular of jessour) or tabia consists of three parts: an 
impluvium or catchment area providing the runoff, a terrace or cultivated area where the runoff is collected, and a dyke to catch the water and sediment. Each dyke has a spillway (menfes if the spillway is on one or both sides and masref if the spillway is in the middle of the dyke) to regulate water flow between dykes (Figure 6.2).

\subsubsection{Data collection}

Time-series of daily rainfall records for a period of 25 years (1980-2004) were collected from the Institute des Régions Arides (IRA) in Tunisia. They concern seven rain gauge stations: Ben Khedache, Toujan Edkhila, Allamat, Koutine, Sidi Makhlouf, Ksar Hallouf and Ksar Jedid. Annual maximum daily rainfall was extracted from these data and using statistical techniques for data analysis. Other data were collected from field measurements in the watershed as explained in the next sections.

\subsubsection{Catchment characteristics}

Physical characteristics (e.g. catchment area, retention area, cropping area and RWH structural dimensions) were measured for each sub-catchment. All areas, dimensions of the RWH structures, and heights of the existing dykes and spillways for each site were measured by measuring tape and the global positioning system (GPS). The total volume of water that could potentially be collected behind each dyke was calculated from these measurements.

To obtain soil textural data from the catchment, each sub-catchment was sampled in different sites ( 1 to 3 samples for each site, based on the size of sub-catchment) and depths up to $1.3 \mathrm{~m}$. The samples were taken to the IRA laboratory and analysed. The slope of each sub-catchment was obtained from the DEM (30 m resolution) using ArcGIS 10.0.

A limitation of this study is that, just like in most arid and semi-arid regions, there are no measured runoff data available. Therefore we drew our conclusions about the model performance from field observations and interviews with local users. Based on these sources, we noticed that some sub-catchments (e.g. 10 and 15) were abandoned, while other sub-catchments are developing (e.g. 20 and 22). The main reasons for that are lack of water and unequal distribution of rainwater between these sites.

Field measurements and observation status of 25 sub-catchments are presented in Table 6.1. In this table a value of one (poor), two (medium) or three (well), was assigned to each sub-catchment, based upon field observations and users interviews. The function status represents the efficient work of each structure (collected and storage rainwater), 
production yield and the relation between up and downstream. Whereas, maintenance is related to the structure such as restoring the spillway height after each storm, keeping the dam in shape and removing the obstacles that block the main waterway.

Table 6.1 Field measurements and observation status of different catchments.

\begin{tabular}{|c|c|c|c|c|c|c|c|c|}
\hline \multirow{3}{*}{$\begin{array}{l}\text { Catch- } \\
\text { ment } \\
\text { No. }\end{array}$} & \multirow[b]{3}{*}{$\begin{array}{r}\text { Catchment } \\
\text { area }\left(\mathrm{m}^{2}\right)\end{array}$} & \multirow[b]{3}{*}{$\begin{array}{l}\text { Retention } \\
\text { area }\left(\mathrm{m}^{2}\right)\end{array}$} & \multirow{3}{*}{$\begin{array}{r}\text { Cultivated } \\
\text { area } \\
\left(\mathrm{m}^{2}\right)\end{array}$} & \multirow{3}{*}{$\begin{array}{r}\text { Spillway } \\
\text { height } \\
(\mathrm{m})\end{array}$} & \multicolumn{3}{|c|}{ Runoff } & \multirow[b]{3}{*}{$\begin{array}{l}\text { Main- } \\
\text { tenance* }\end{array}$} \\
\hline & & & & & Infiltration & & Status & \\
\hline & & & & & $\begin{array}{r}\text { rate } \\
\left(\mathrm{mm} \mathrm{hr}^{-1}\right)\end{array}$ & $\begin{array}{r}\text { ficient } \\
\text { (C) }\end{array}$ & $\begin{array}{l}\text { Func- } \\
\text { tion* }\end{array}$ & \\
\hline 1 & 1240 & 15 & 20 & 0.60 & 96 & 0.21 & 2 & 1 \\
\hline 2 & 1412 & 17 & 17 & 0.10 & 101 & 0.20 & 2 & 2 \\
\hline 3 & 1148 & 119 & 119 & 0.50 & 108 & 0.18 & 2 & 1 \\
\hline 4 & 193249 & 0 & 17 & 0.00 & 18 & 0.37 & 1 & 1 \\
\hline 5 & 11288 & 2136 & 4111 & 0.55 & 24 & 0.30 & 3 & 3 \\
\hline 6 & 2447 & 80 & 244 & 0.50 & 112 & 0.30 & 1 & 1 \\
\hline 7 & 390 & 35 & 154 & 0.45 & 84 & 0.29 & 1 & 1 \\
\hline 8 & 2756 & 120 & 1002 & 0.35 & 72 & 0.26 & 1 & 1 \\
\hline 9 & 29160 & 2079 & 19617 & 0.80 & 103 & 0.36 & 2 & 2 \\
\hline 10 & 5290 & 521 & 4107 & 0.40 & 103 & 0.36 & 1 & 1 \\
\hline 11 & 10646 & 1600 & 9484 & 0.50 & 108 & 0.22 & 2 & 2 \\
\hline 12 & 22906 & 1324 & 16855 & 0.40 & 111 & 0.18 & 3 & 2 \\
\hline 13 & 5953 & 562 & 6647 & 0.20 & 104 & 0.12 & 2 & 2 \\
\hline 14 & 7389 & 0 & 4993 & 0.00 & 102 & 0.17 & 1 & 1 \\
\hline 15 & 8243 & 478 & 2658 & 0.30 & 106 & 0.34 & 1 & 1 \\
\hline 16 & 21634 & 1561 & 9708 & 0.45 & 60 & 0.24 & 1 & 1 \\
\hline 17 & 4432 & 518 & 1646 & 0.40 & 48 & 0.18 & 1 & 1 \\
\hline 18 & 23413 & 2392 & 14812 & 0.70 & 90 & 0.12 & 2 & 2 \\
\hline 19 & 10307 & 0 & 8553 & 0.00 & 48 & 0.30 & 1 & 1 \\
\hline 20 & 11651 & 1548 & 12094 & 0.60 & 101 & 0.15 & 3 & 3 \\
\hline 21 & 19392 & 0 & 20815 & 0.00 & 108 & 0.10 & 2 & 1 \\
\hline 22 & 12664 & 415 & 8060 & 0.20 & 107 & 0.28 & 3 & 3 \\
\hline 23 & 4842 & 929 & 4151 & 0.60 & 108 & 0.20 & 2 & 2 \\
\hline 24 & 7989 & 317 & 4224 & 0.50 & 100 & 0.15 & 3 & 2 \\
\hline 25 & 13183 & 1273 & 8941 & 0.30 & 110 & 0.30 & 3 & 3 \\
\hline
\end{tabular}

\subsubsection{Measurements of infiltration rate}

The infiltration rate was determined using a double-ring infiltrometer (Al-Qinna and AbuAwwad, 1998). Based on previous field measurements conducted by Bosch et al. (2014) in the same region, we used infiltrometers of two sizes: small $(18 / 30 \mathrm{~cm}$ inner-/outer-ring diameter) and large $(32 / 51 \mathrm{~cm})$. Generally, two measurements took place for each site to ensure reliable results. The small infiltrometers were used at least once in each subcatchment, but the large infiltrometers were used in only 11 sub-catchments because the measurements required much more water. The infiltration rates were measured on the retention (terrace) basin in each sub-catchment. The rings were driven $5-10 \mathrm{~cm}$ into the ground carefully because the soil contained rocks that might damage the rings or disturb 
the soil profile. Tap water was used during measurements. The temperature was estimated to vary between 25 and $37^{\circ} \mathrm{C}$. The inner and outer rings were initially filled to a depth of $15 \mathrm{~cm}$. The water level during the test was recorded as a function of time from a scale fixed to the inner ring, and when the level of water in the outer ring dropped below the level in the inner ring, more water was added to maintain equal levels. We continued this procedure until the water level dropped below $5 \mathrm{~cm}$, then the water was replenished for the next repetition. Generally, 1 to 4 repetitions were done to be sure that a constant infiltration rate was reached. A plastic bottle or bag was placed inside the rings to prevent disturbing the soil when pouring the water into the rings. From these measurements, the average infiltration rate for a given time period was estimated for each sub-catchment.

\subsubsection{Rainfall simulation and the runoff coefficient (C)}

A total of 38 rainfall simulations were performed on the impluvium (runoff) areas of the sub-catchments using a Kamphorst's rainfall simulator. Rainfall simulators are devices that imitate the physical characteristics of natural rainfall as close as possible (Aksoy et al., 2012). A Kamphorst simulator is small, easy to transport, economic and has a low water consumption. The device was calibrated as described by Kamphorst (1987). Each test measured water level for three minutes, reading the water level every 30 seconds. Any runoff was collected in a tube, and the volume was recorded. The value of $\mathrm{C}$ (according to the definition of the Food and Agriculture Organization of the United Nations, $C$ is defined as "runoff divided by the corresponding rainfall both expressed as depth over catchment area (mm)" (http://www.fao.org/docrep/u3160e/u3160e05.htm) for an individual rainstorm) was calculated for each sub-catchment at the end of each simulation.

\subsubsection{Rainfall probability}

Probability analysis can predict maximum daily rainfall of future rain events from the available data with the help of statistical methods (Bhakar et al., 2006; Kumar and Kumar, 1989). The probability distributions most commonly used are the log-Pearson Type-III, lognormal, gamma and normal distribution (Kumar et al., 2007; Lee, 2005; Sharma and Singh, 2010). None of the procedures for predicting daily maximum rainfall has been widely accepted (Barkotulla et al., 2009). We analysed the annual maximum daily rainfall data for 1980-2004 to determine the probable maximum daily rainfall for various return periods (T) by a normal distribution function. The RAINBOW programe (Raes et al., 1996) was used for frequency analysis, determining the expected rainfall for various probabilities or $T$ values, evaluating the goodness of fit and testing the homogeneity of the data sets. When dealing with a normal distribution, it is common practice to transform data that are not normally distributed (as in our case) so that the resulting normalized data can be 
presented by the normal curve. The transformation of the data will change the scale of the records. For positively skewed data a transformation was used to reduce higher values by proportionally greater amounts than smaller values. This transformation rescaled the magnitude of the records and the transformed data became closer to the normal distribution than the original data. Operators available in RAINBOW to rescale the data are the square root, the cubical root and the logarithm. RAINBOW is freely available, and an installation file and reference manual can be downloaded from http://www.biw.kuleuven.be/lbh/lsw/iupware/index.htm. The user can select a distribution type (e.g. normal, log-normal or Weibull) and use graphical method s to obtain a probability plot and histogram of the data.

\section{Probability of exceedance and return period $T$}

Let $\mathrm{P}_{\mathrm{e}}$ represent the probability of a rainfall greater than a given value. It can be expressed as a percentage. In our study, $\mathrm{P}_{\mathrm{e}}$ was estimated using the Weibull method (Weibull, 1939):

$P_{e}=\left(\frac{r}{n+1}\right) \times 100$

Where $r$ is a rank number and $n$ is the number of observations.

Assuming T represents the number of years in which the annual observation is expected to return, then:

$T=1 / P_{e}$

Rainfall values for selected values of $\mathrm{P}_{\mathrm{e}}$ and $\mathrm{T}$ were estimated by a frequency analysis using RAINBOW. The probability of future rains can be used to minimise the risks of floods and droughts and for planning and designing structures to optimise the water resources, such as small dams, reservoirs, culverts, drainage channels and RWH structures (Chow et al., 1988; Dabral et al., 2009).

\subsubsection{Water harvesting model}

The water balance of the 25 water harvesting reservoirs (sub-catchments) was analysed based on the water requirements (demand), the rainfall-runoff relationship (supply) and the design of the RWH structures (storage). The change of water storage within the volume was calculated as the difference between total input and output. A catchment generally consists of two main elements: a runoff area and a retention area (reservoir). We analysed the water balance of these two elements and amongst other sub-catchments 
and assessed the performance of RWH in the entire system to improve the yield of the RWH system. We considered two cases. The first case (Case 1) assumed no relationship between the water flows of the sub-catchments, which are stand-alone units, for two main reasons. Firstly, some sub-catchments receive no upstream water. Secondly, assessing each sub-catchment separately will show the user how RWH works. For example, if the amount of water exceeds the storage capacity, the user can improve the storage area or increase the cropping area. The second case (Case 2) considered the interaction between the sub-catchments for analysing the relationship between up- and downstream sub-catchments.

The water-balance equation of an area can be written in units of volume $\left(\mathrm{m}^{3}\right)$ as (Boers et al., 1986):

$\Delta S=I-O$

Where $\Delta S$ is the change in storage during a defined period of time, $I$ is the inflow and $O$ is the outflow, all in $\mathrm{m}^{3}$.

Recognition of the various types of in-and outflow allows a more detailed water balance equation:

$\Delta S=V_{\text {runoff }}+V_{\text {rainfall }}+V_{\text {in }}-V_{\text {out }}-$ Inf $-E T_{c}$

Where $V_{\text {in }}$ is the volume of inflow from upstream catchment(s), $V_{\text {out }}$ is the volume of overflow from the retention basin to the next catchment(s), Inf is the infiltration loss from the retention basin obtained from the measured infiltration rate in each sub-catchment using the double-ring infiltrometer, $E T_{c}$ is the maximum crop evapotranspiration, $V_{\text {runoff }}$ is the volume of runoff into the retention basin from the impluvium (runoff area) calculated as:

$V_{\text {runoff }}=0.001 \cdot C \cdot P \cdot A_{r}$

Where $C$ is the mean annual runoff coefficient (-) measured in the field with the rain simulator. Due to the limited time of our field work, we could not install a gauge station, so no measured runoff-data is available. Therefore we assumed that $\mathrm{C}$ of a rainfall event (average simulated) equals the annual average $\mathrm{C}$. 
$P$ is the annual precipitation $(\mathrm{mm})$ and $A_{r}$ is the impluvium or runoff area $\left(\mathrm{m}^{2}\right)$, and where $V_{\text {rainfall }}$ is the rainfall in the retention basin, calculated as:

$V_{\text {rainfall }}=0.001 \cdot P \cdot A_{b}$

Where $A_{b}$ is the area of the retention basin $\left(\mathrm{m}^{2}\right)$.

$\mathrm{ET}_{\mathrm{c}}$ was derived from the study conducted by Schiettecatte et al. (2005) for the same watershed. These authors used data from the meteorological station at Medenine and applied the Penman-Monteith method to calculate the average yearly potential evapotranspiration (PET) for 1985-1995. The maximum crop evapotranspiration $\left(\mathrm{ET}_{\mathrm{c}}\right.$ ) was calculated based on the PET values and the crop coefficient $k_{c}$. In case the soil moisture content is insufficient to reach $E T_{c}$, the actual evapotranspiration $\left(E T_{a}\right)$ will be lower than $\mathrm{ET}_{\mathrm{c}}$ then $\mathrm{ET}_{\mathrm{a}}$ was estimated for the dominant soil types and applied through the calculation of water balance. To calculate the $\mathrm{ET}_{\mathrm{a}}$, the equation Aboukhaled et al. (1975) was used.

The maximum $\mathrm{ET}_{\mathrm{c}}$ was calculated by:

$E T_{c}=P E T \cdot k_{c}$

The values for $P E T, E T_{c}$ and $k_{c}$ are presented in Table 6.2.

Table 6.2 Rainfall, potential evapotranspiration (PET), maximum crop evapotranspiration (ETC) and crop coefficient $k_{c}$ (after Schiettecatte et al., 2005).

\begin{tabular}{lllll}
\hline Month & $\begin{array}{l}\text { Rainfall } \\
(\mathbf{m m})\end{array}$ & $\begin{array}{l}\text { PET } \\
(\mathbf{m m})\end{array}$ & $\begin{array}{l}\mathbf{E T}_{\mathbf{c}} \\
(\mathbf{m m})\end{array}$ & $\mathbf{k}_{\mathbf{c}}$ \\
\hline Jan & 37.5 & 69.6 & 27.8 & 0.40 \\
Feb & 30.6 & 88.6 & 35.4 & 0.40 \\
Mar & 40.0 & 121.2 & 66.7 & 0.55 \\
Apr & 16.3 & 159.3 & 79.6 & 0.50 \\
May & 11.2 & 198.4 & 89.3 & 0.45 \\
Jun & 1.0 & 213.5 & 85.4 & 0.40 \\
Jul & 0.0 & 234.8 & 82.2 & 0.35 \\
Aug & 2.0 & 220.9 & 77.3 & 0.35 \\
Sep & 17.1 & 166.6 & 75.0 & 0.45 \\
Oct & 23.0 & 126.8 & 63.4 & 0.50 \\
Nov & 19.9 & 91.1 & 41.0 & 0.45 \\
Dec & 36.7 & 67.40 & 26.9 & 0.40 \\
\hline
\end{tabular}


The Water harvesting at Catchment level (WHCatch) model

As all input data were already stored and available in Excel, we developed a simple Visual Basic for Applications (VBA) macro in Excel. This macro performed the calculations described above and stored the resulting values in the corresponding cells. The code consisted of a WHCatch module and a Sub-catchmentClass class module. The latter contained all the properties of a sub-catchment and routines to perform some basic computations. The WHCatch module consisted of some private subroutines and five public subroutines. (for details see Chapter 5 )

\subsection{Results and discussion}

\subsubsection{Infiltration rate and runoff coefficient}

The infiltration rate of each considered sub-catchment is presented in Table 6.1. It can be seen that sub-catchment 6 had the highest infiltration rate $\left(112 \mathrm{~mm} \mathrm{~h}^{-1}\right)$ and subcatchment 4 had the lowest $\left(18 \mathrm{~mm} \mathrm{~h}^{-1}\right)$ and the average rate was $89 \mathrm{~mm} \mathrm{~h}^{-1}$ (Table 6.1).

Soil type is an important factor affecting the infiltration rate. Sandy loam soil has the highest infiltration rates due to the fact that it has a coarse texture and large pores which promote fast infiltration, while sandy clay and loamy clay have a medium to fine texture. Gregory et al. (2005) obtained infiltration rates above $100 \mathrm{~mm} \mathrm{~h}^{-1}$ and less than $50 \mathrm{~mm} \mathrm{~h}^{-1}$ in coarse texture and medium to fine soils, respectively. These infiltration rates are comparable to the ones obtained in the current study where most of the sub-catchments had a sandy loamy soil (as seen from the soil sampling analysis). Moreover, the infiltration rates from our study agreed well with those reported by Makungo and Odiyo (2011), who determined the rates for various soil types in South Africa. Their infiltration rates for sandy loamy soil ranged between 50 and $110 \mathrm{~mm} \mathrm{~h}^{-1}$. Our results, however, differed slightly from those published by Bosch et al. (2014), who used double-ring infiltrometers in southeastern Tunisia throughout a wadi with a rocky bed and obtained an average infiltration rate of $65 \mathrm{~mm} \mathrm{~h}^{-1}$. This difference may have been due to the flatness of the jessour/tabias area, so the soil may have been deeper in our retention areas than in the wadi bed. In addition, sub-catchment 4 with the lowest infiltration rate had a relatively steep slope and so suffered from floods and erosion.

The Kamphorst simulator was used for the simulation of rainfall in each impluvium (runoff area) in each sub-catchment. Only the borders of the delineated experimental area were disturbed during the experimental setup. The results from the Kamphorst simulator would thus correspond well to those obtained under field conditions and so are appropriate for 
RWH calculations for an impluvium. The runoff coefficient $C$ for each subcatchment is shown in the Table 6.1. The maximum value of $C$ was 0.37 , measured in an upstream area of sub-catchment 4 where the slope was relatively steep, and the minimum $C$ of 0.10 was measured in sub-catchment 21 . The average $C$ was 0.24 . The larger values correspond to higher runoff and lower infiltration rates. Moreover, our analysis indicates that the catchment with a large slope usually has a high value of C. Wainwright (2002) and Zhang et al. (2014) indicate that $C$ is proportional to the slope because fast flow occurs in the steep hillslope area where less water remains in the soil or fracture for evapotranspiration. On the other hand, there is a low correlation between $C$ and the size of the catchment area. The runoff measurements agreed well with the above infiltration measurements: sub-catchment 4 had the lowest infiltration rate $\left(18 \mathrm{~mm} \mathrm{~h}^{-1}\right)$ and the highest $C(0.37)$, and sub-catchment 21 had one of the highest infiltration rates $(108 \mathrm{~mm}$ $\mathrm{h}^{-1}$ ) and the lowest $C(0.10)$ (Table 6.1). Total rainfall was not significantly correlated with C. These results are in good agreement with those by Schiettecatte et al. (2005) in the Oum Zessar watershed, where $C$ ranged between 0.002 and 0.841 for initially dry and wet soil conditions.

\subsubsection{Rainfall probability analysis}

Daily rainfall data for $1980-2004$ were analysed to estimate the design rainfall. Most rains are brief but intense. The minimum daily rainfall was $11 \mathrm{~mm}$ in 2002 , the maximum was $117 \mathrm{~mm}$ in 1992, and the average annual maximum daily rainfall was $39.5 \mathrm{~mm}$ (Figure 6.3a).

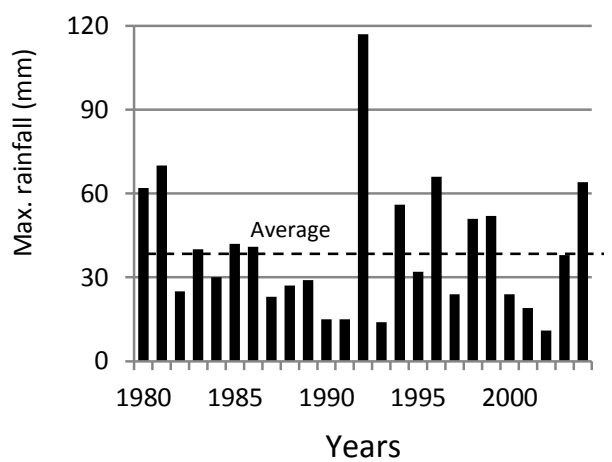

a

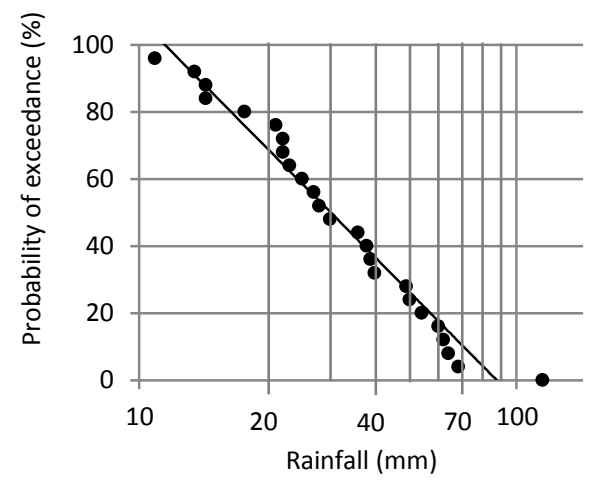

b

Figure 6.3 a: Annual maximum daily rainfall for 25 years (1980-2004), and b: the probability analysis of the rainfall data by RAINBOW, showing the rainfalls in $\mathrm{mm}$ vs the percentage of probability of exceedance. 
The results of the probability analysis using RAINBOW with Weibull's method to calculate the probability is shown in a probability plot (Figure 6.3b). The rainfall values corresponding to various $\mathrm{P}_{\mathrm{e}}$ 's were easily derived from the probability plot by fitting a straight line through the points. A coefficient of determination $\left(R^{2}\right)$ of 0.97 indicated a good fit.

The number of years $(T)$ in which the annual observation is expected to return (also called the recurrence interval) which is the average time between successive years with the specified rainfall was calculated using RAINBOW too. Various interval probabilities $(10,5$, 2 , and $1 \%$ ) can be easily selected in RAINBOW. The estimates of rainfall for the selected probabilities or T's are then obtained from a frequency analysis. The user can also specify a specific rainfall or $T$ and obtain the corresponding $T$ or specific value. For example, if the threshold rainfall is $28.7 \mathrm{~mm}$, then the estimated $T$ will be 1.63 years. The design rainfall will decrease as the probability level increases, and vice versa. For instance, there was $90 \%$ chance of receiving $13 \mathrm{~mm}$ of rainfall (once every year), whilst the chance of receiving $75 \mathrm{~mm}$ was only $10 \%$ (once every 10 years).

\subsubsection{The water harvesting model (WHCatch) results}

The WHCatch model was applied for several rainfall events over 25 years in the 25 subcatchments, then the threshold rainfall was determined which represents which events must be reached to generate stream flow (over flow between sub-catchments). The maximum daily rainfall was $117 \mathrm{~mm}$ in 1992, and the threshold rainfall was $28.7 \mathrm{~mm}$. The T's for the maximum and threshold rainfalls were about 90 and 1.63 years, respectively. Runoff differed greatly amongst the sub-catchments between two rains (Figure 6.4).
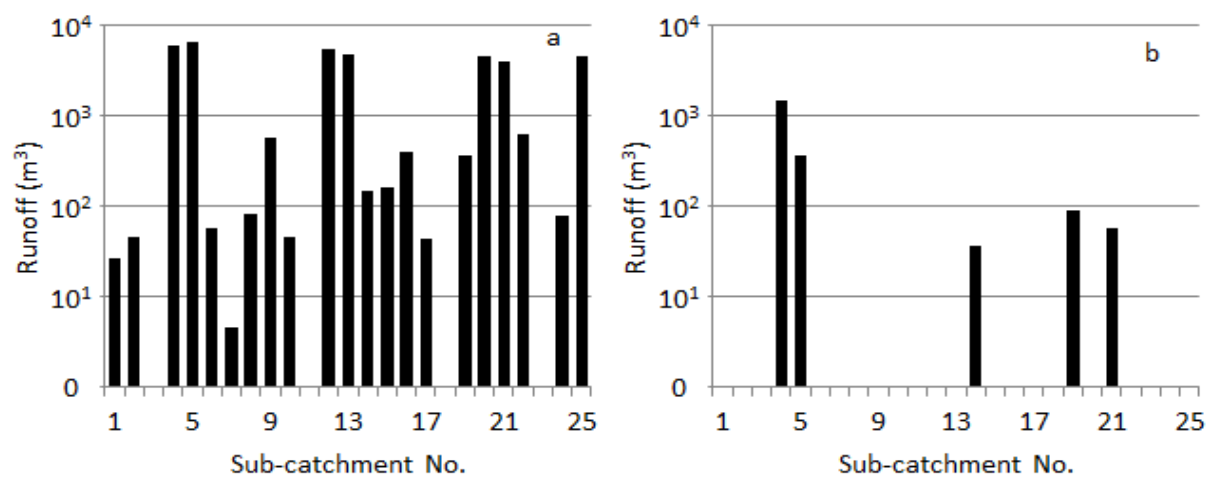

Figure 6.4 Runoff $\left(\mathrm{m}^{3}\right)$ in each sub-catchment calculated using the WHCatch model for a; the maximum daily rainfall, and $b$ : the threshold rainfall. 
The highest rainfall $(117 \mathrm{~mm}$ ) produced a large amount of runoff (Figure 6.4a), but the amount was not considered consequential because this amount of rain may fall only once every 90 years. The threshold rainfall produced no runoff between sub-catchments (Figure 6.4b), except for the broken sub-catchments (4, 14, 19 and 21) and for subcatchment 5 , which was affected by sub-catchment 4 . Moreover, the water requirement had a large deficit. The model was thus applied annually for a long term ( 25 years), and the results for a dry, normal and wet year (minimum, average and maximum annual rainfall) will be presented to illustrate the relationship between different rains and the behaviour of RWH structures.

The results of the water harvesting model (RWH yield) for each RWH structure (storage area) for a dry, normal and wet year are presented in Figure 6.5.

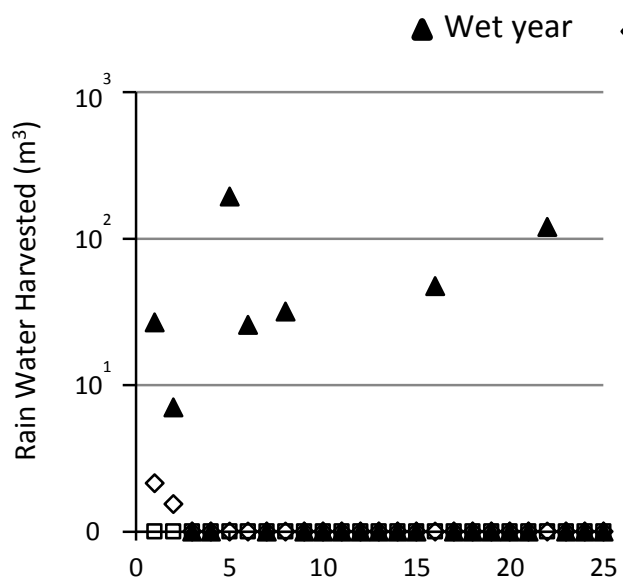

a: Case 1

Sub-catchment No. $\diamond$ Average year $\square$ Dry year

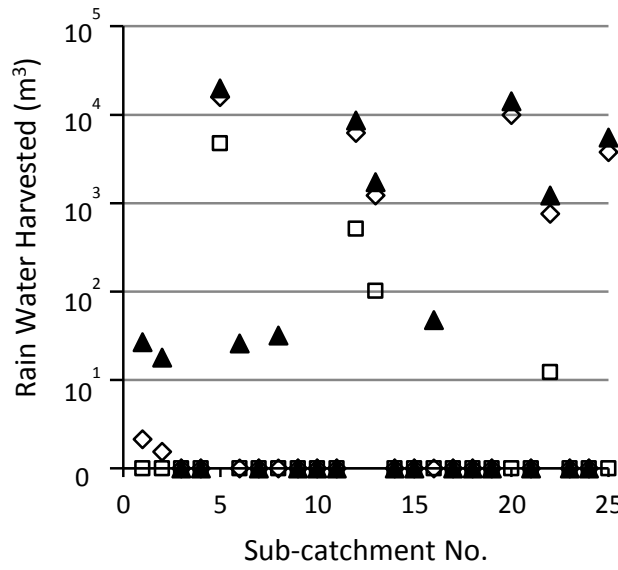

b: Case 2

Figure 6.5 Results of the WHCatch model for a dry, normal and wet year. RWH yield in each subcatchment, a: Case 1 (sub-catchments are independent, left) and b: Case 2 (all sub-catchments potentially interdependent, right).

The volume of water stored in the reservoir depends on the available runoff water and the water demand. When the water flows of the sub-catchments were assumed to be unrelated (Case 1), about 28 (wet year) and 8\% (normal year) of the sub-catchments were able to meet the water requirements (Figure 6.5a). Zero rain water harvested values for sub-catchments, however, indicated the inability of RWH to meet the water requirements. In these low rainfall areas, the water availability is extremely low since most of the rainwater is lost by soil surface evaporation. Therefore, the water productivity is low. These results showed the effectiveness of RWH and illustrated how one could improve the 
performance of RWH by, for example, applying supplemental irrigation to compensate for the deficit in the water requirement. In addition, the performance of the RWH system can be significantly improved, through concentrating the rainwater on part of the land. Case 2 , where all sub-catchments were potentially interdependent, yielded more insight to the hydrological process in the entire catchment. Much more water will flow between subcatchments; therefore about 44,32 and $16 \%$ of all sub-catchments had sufficient water to meet the water requirements in a wet, normal and dry year, respectively (Figure 6.5b). It is observed that runoff has changed over the area according to the land use and flow direction, usually areas with a large slope tend to more runoff generation and lower infiltration rates. From case 2 , it is clear that the estimated runoff volumes are high and a series of connected reservoirs may be more efficient than one large reservoir in the area. These results are in agreement with field observations (Table 6.1). The sub-catchments 10 and 15 for example, have poor function and maintenance values because they have received insufficient rainwater, thus leading to abandonment. On the other hand, the subcatchments 20 and 22 (these have good scores for functioning and maintenance) are developing. This is reflected in the results of our model presented in Figure 6.5b. Zero values of rainwater harvested occurred for reasons such as insufficient storage capacity, suboptimal height of spillway, stream flow direction, siting and type of RWH adoption and socioeconomic aspects not included in this study.

From literature it can be seen that the watershed-runoff relationship in arid and semi-arid areas has long been reported and it turns out that the volume of the harvested runoff is directly proportional to the size and length of the runoff harvesting structure (Ibraimo, 2011; Li et al., 2006; Ndayakunze, 2014). Therefore, to optimise the performance of the RWH structures and to improve the yield (water availability) of the RWH system, three scenarios were applied in Case two as shown in Figure 6.6.

In scenario one, broken jessour (assuming values for the spillway heights of the jessr 14, 19 and 21 based on water requirements) were repaired. To improve the performance and safety of a RWH structure, a spillway with sufficient capacity and at the right location must be provided. Most of the RWH structures built by farmers in arid and semi-arid regions were washed away due to lack of sufficient capacity of spillways (Adham et al., 2016a; Ammar et al., 2016). The WHCatch model was then applied and we analysed the performance of the $25 \mathrm{RWH}$ structures. We found that all sub-catchments had sufficient water to meet the crop water requirements, showing an improvement in water availability of 56,40 and $12 \%$ in a wet, normal and dry year, respectively (Figure 6.6b). As a second scenario we just changed the flow direction because field observations and the analysis of the water balance indicated that most of the runoff flowed in one direction (Figure 6.6a). 
a: Without change in flow directions

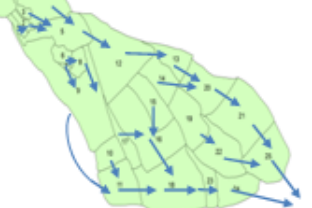

Wadi Oum-Zessat

c. With change in flow directions

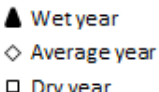

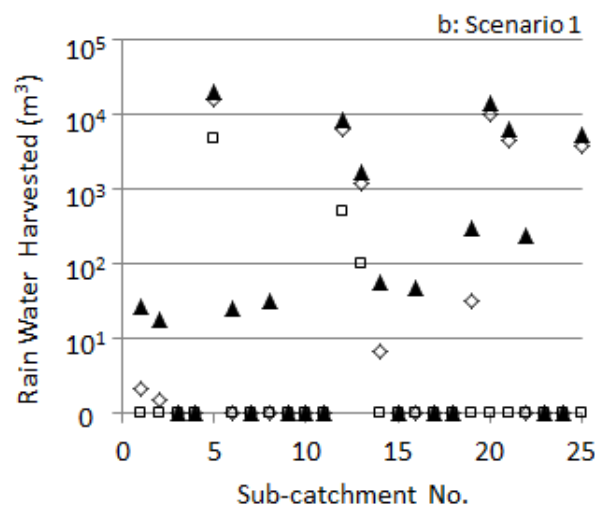
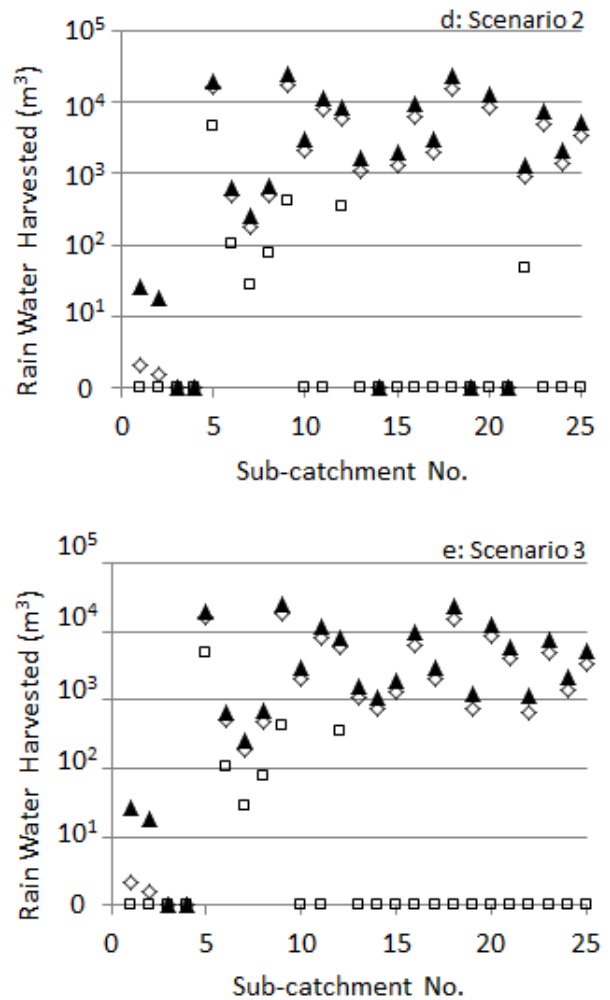

Figure 6.6 The results of the optimising model, the WHCatch model was applied for three scenarios in Case two (all sub-catchments potentially interdependent) for the dry, normal and wet years. Sub-catchment locations with flow directions ( $a$, and c), RWH yield in each sub-catchment; $b$ : scenario one (changing spillway heights), d: scenario two (changing flow directions only) and e: scenario three combined scenarios one and two. 
Therefore, we investigated what would happen when part of the water would flow to one sub-catchment and the remainder to another sub-catchment (Figure 6.6c). Moreover, in this area the structures were built traditionally without any calculation of runoff volume and/or storage capacity. RWH structures were constructed across the flow directions, therefore there is an unequal distribution of water among these structures. The structures close to the water flow can catch more runoff by minimizing the considerable transmission losses. The WHCatch model was thus modified to have the capability to change the directions of stream flow and we analysed the performance of the $25 \mathrm{RWH}$ structures. Flow directions were changed for Case 2, and the water availability nearly doubled for $80 \%$ of the sub-catchments in wet and normal years and in $28 \%$ of the sub-catchments in a dry year (Figure 6.6d) compared to the availabilities for unchanged flow directions (Figure 6.5b). In the third scenario, the scenarios one and two (change spillway heights together with changing flow directions) were combined and the performance of the 25 RWH structures was analysed (Figure 6.6e). In this scenario the performance of RWH was improved increasing the efficiency of water availability in $92 \%$ of all sub-catchments in a wet and normal years compared to $44 \%$ for a wet year in base scenario (without changing spillway heights and flow directions). Scenario three thus had a significant impact on the performance of the RWH structures. Although the scenario's one and two improved the efficiency of the system already, the third scenario had a much higher impact and would be an important recommendation to apply in this region.

It is successfully demonstrated that changing spillway heights together with flow directions significantly enhances rainwater availability in the proposed RWH solutions compared to the results of the traditional design approach. In scenario three the runoff coefficients of the connected catchments are high and the sizes of the reservoirs are adapted to the size of the contributing catchments so that water losses are minimal. In addition, rainwater harvesting systems can catch more runoff by minimizing the considerable transmission losses that take place in the outlet of the catchment (subcatchment 25). The ability to show the frequency of runoff for each sub-catchment is one of the most important options of the WHCatch model. Figure 6.7 indicates which subcatchment should have a larger storage capacity and where changing the storage capacity would have no effect.

A lot of runoff could thus be prevented by changing the storage capacity of subcatchments $4,14,19$, and 21 (Figure 6.7a). The input data shows that this conclusion could be expected because these structures were broken and had no storage capacity. The right hand side of Figure 6.7b shows the times the retention areas overflowed (runoff) after changing flow direction and clearly illustrates the large impact of changing the flow direction on the retention area. Therefore, the performance of a RWH structure could be 
improved by adapting the storage capacity and/or cultivation area to be capable of storing the amount of runoff. Then the ability of RWH to meet the water requirements will be improved. The frequency of runoffs remained unchanged only in sub-catchment 4, because this sub-catchment was considered to be a runoff area, not a storage area.

The WHCatch model can also show the influence of changing the maximum depth of water (spillway height) in a storage area on the terms of the water balance equation for a downstream sub-catchment. An example in Figure 6.8 illustrates the influence of storage height of sub-catchment 5 on the runoff from sub-catchment 25.
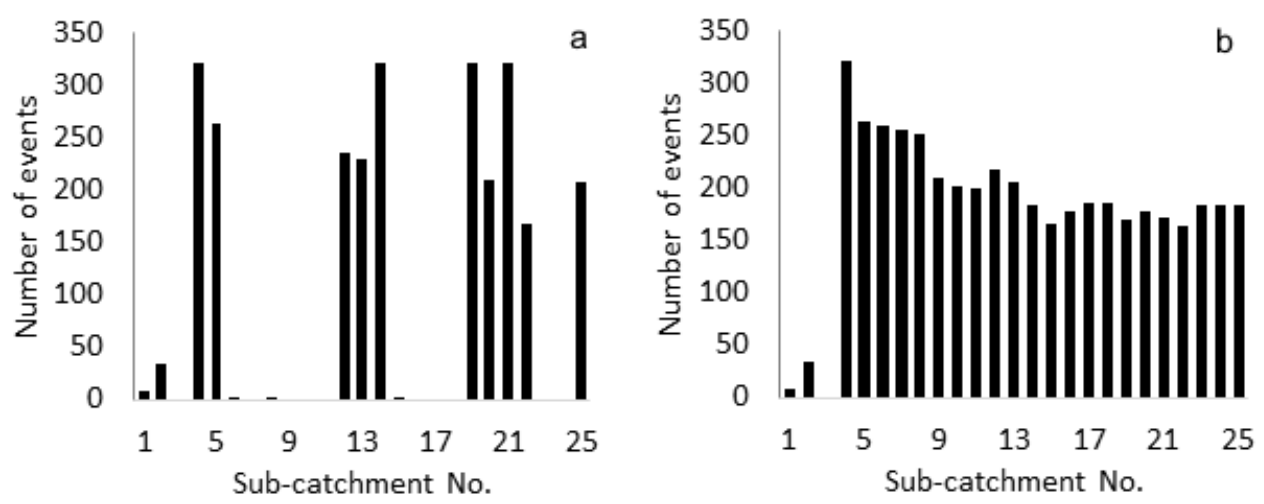

Figure 6.7 Relationship between the frequency of runoff and sub-catchment number over 25 years; a: results without changes in flow direction and $b$ : flow directions were changed.

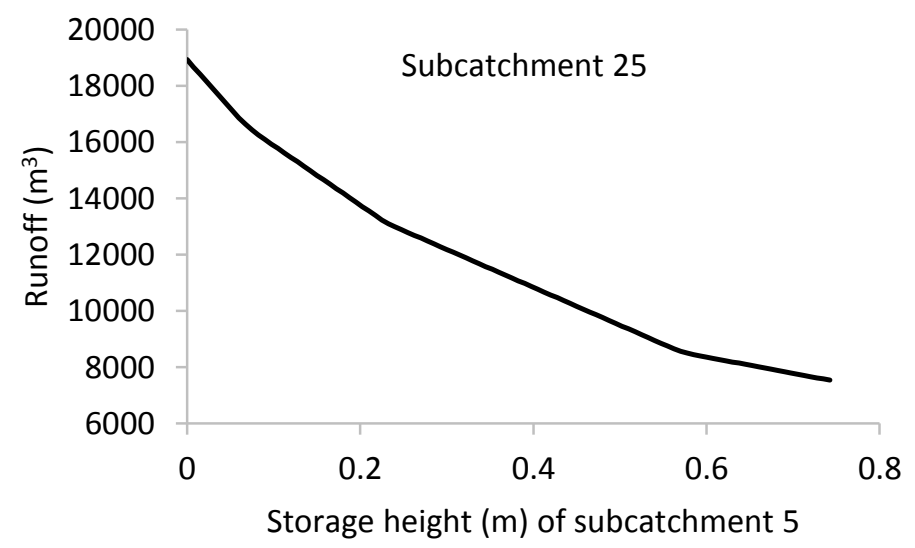

Figure 6.8 An example of the impact of spillway height in a sub-catchment (5) and the runoff volume in the sub- catchments. 


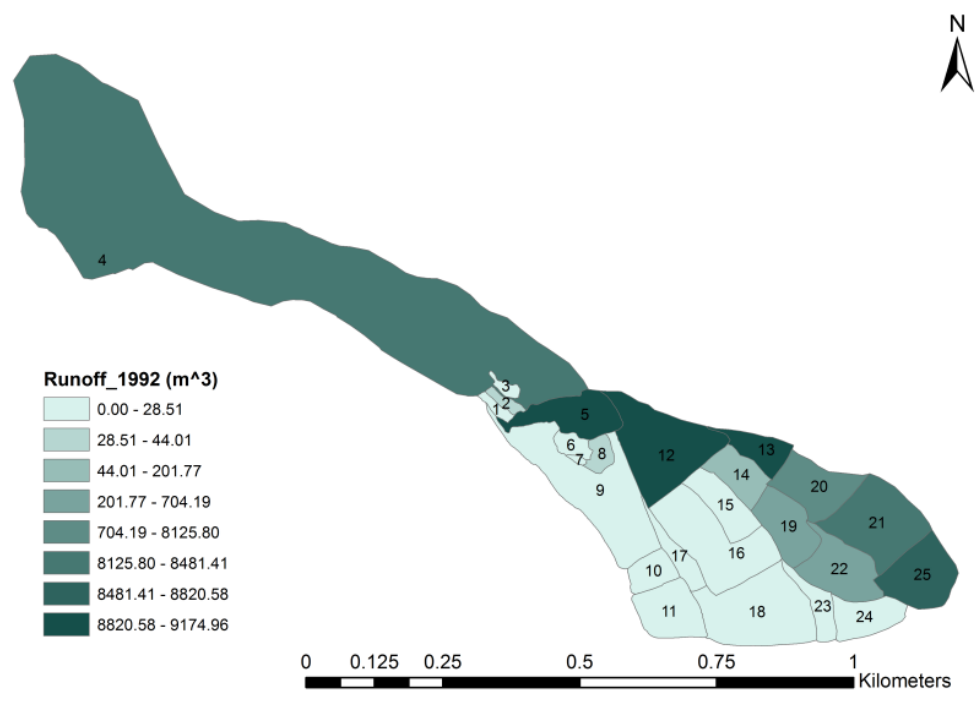

Figure 6.9 An example of the runoff from the catchments for 1992.

The slope of the line changed at a few values of storage height. The storage capacities of some downstream sub-catchments would likely be sufficiently large at these points to hold the upstream water flow. Moreover, the designer of a new RWH structure could use this model to easily estimate the storage capacity required to satisfy the water requirements based on the height of a spillway (Figure 6.8).

The terms of the water balance equation often need to be analysed using a GIS application such as ArcGIS, so the WHCatch model was designed to have the ability to convert the requested output data to a format readable by GIS applications. The output data can easily be imported into a GIS application and combined with a shape-file for creating maps or videos. Figure 6.9 is an example of such a map, where the runoff from the catchments is shown for 1992, which is the year with maximum rainfall $(117 \mathrm{~mm})$.

Another interesting option of the WHCatch application is its built-in generator of precipitation events. Assuming the volumes of daily precipitation are distributed normally, the precipitation generator requires three distributions: the total yearly rainfall, the maximum rainfall in a year and the distribution of all rainfall events. Processing the rainfall data described in this paper, we obtained the following values for averages and standard deviations: 145.7 and 83.4 for the total yearly amount, 39.3 and 23.4 for the maximum value in a year and 11.4 and 13.9 for the individual events. From these distributions, values are drawn at random using the GASDEV procedure as described in (Press et al., 1987). After drawing the values from the distributions, the entire system is computed with 
these precipitation values and the water balance term of interest is read from the results and stored in memory. When all simulations are performed, a number of values are stored in memory. Defining a number of classes, the number of values in these classes can be found and the distribution of output can be drawn. As an example, we generated 1000 datasets and investigated the surface runoff volume of sub-catchment 19 (Figure 6.10a).

A

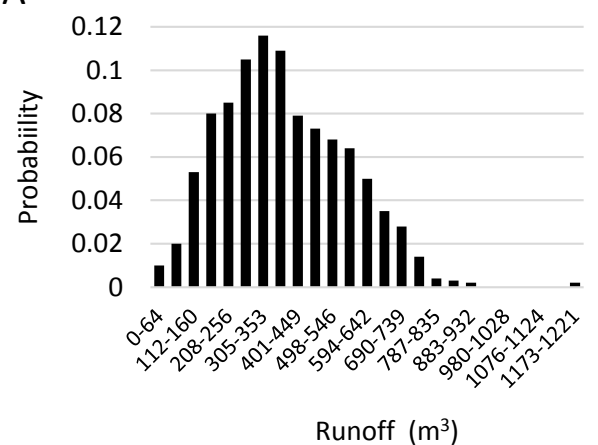

B Runoff of subcatchment 19

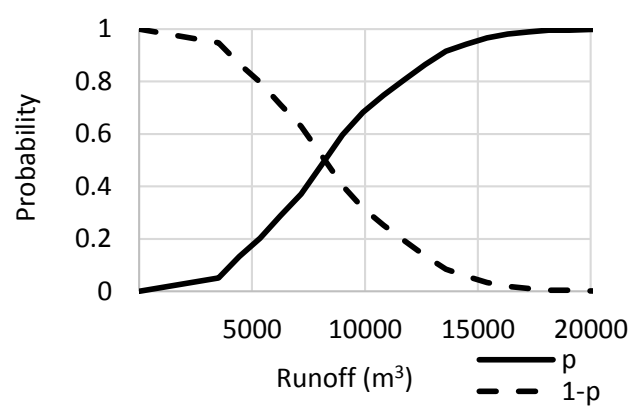

Figure 6.10 A: The distribution of runoff obtained with 1000 years of generated precipitation events, and B: The cumulative distribution of the runoff values for sub-catchment 19, obtained from 1000 years of generated precipitation events. The dotted line indicates the probability that the runoff exceeds a certain value, the continue line is the opposite: the probability that the runoff is smaller than the corresponding value.

From this figure it can be seen that most runoff values (approx. 11\%) are in the classes $305-353$ and $353-401 \mathrm{~m}^{3}$. Only $5 \%$ of the values are lower than $210 \mathrm{~m}^{3}$. From these values the program also produces a cumulative probability chart (Figure 6.10b).

As an example, it can be seen from this figure that there is a $10 \%$ chance that the value of runoff will exceed $4500 \mathrm{~m}^{3}$. On the other hand, a runoff value of $17500 \mathrm{~m}^{3}$ or higher will occur only once every 100 years. This way the simple program WHCatch can be applied for risk analysis as well.

\subsection{Conclusions}

The aim of this study was to develop a simple but generally applicable water harvesting model and test it at sub-catchment level to evaluate and optimise the performance of RWH under different design and management scenarios. A direct approach has been chosen that can be applied with minimum data for the analysis and optimisation of the performance of RWH systems. We developed a simple model, named WHCatch and 
applied it to characterise and quantify the terms of the water balance equation for subcatchments for various cases and temporal scales. The WHCatch model, a simple Excel Visual Basic for Applications macro, was developed and applied to perform all calculations and to present the results of the modelling. The WHCatch model was applied to two cases, and the main conclusions were:

- The water harvesting model results have practical importance, due to the fact that in data scarce regions lower parameterized models are advocated as they require little input data.

- Case 2 (all sub-catchments interdependent) provided an improved understanding of the hydrological processes of the entire catchment. The efficiency of RWH was nearly twice that obtained for Case 1, which assumed sub-catchment independence.

- The combination of changing the flow direction and changing the spillway heights had a significant impact on the performance of the RWH structures. For Case 2, the water availability increased in $92 \%$ of all sub-catchments compared to $44 \%$ where flow directions were not changed.

- The WHCatch model offers several options for improving the understanding of the water balance in an entire catchment, such as presenting the frequency of runoff for each sub-catchment, illustrating the influence of maximum depth of water (spillway height) in a storage area on the terms of the water-balance equation for a downstream sub-catchment, converting the requested output data to a format readable by GIS applications and generation of precipitation events to determine the runoff probability in different sub-catchments.

Overall we can conclude that this approach provides a good overview of an area and is a very useful tool to assist the planning and implementation of a RWH project, especially in arid and semi-arid regions. The scientific prediction of rains, runoff and RWH management may also be an important tool for increasing economic returns.

However the model needs to be calibrated and tested in different regions and with various RWH techniques to validate its applicability. The socioeconomic suitability/performance also need to be investigated and included in the assessment tool. These suggestions will increase the model's reliability and further generalise our methodology. 


\section{Assessing the Impact of Climate Change on Rainwater Harvesting in the Oum Zessar Watershed in Southeastern Tunisia}

Climate change is believed to have a large impact on water resources systems both globally and regionally. It has become a major global issue, especially in developing countries because they are most affected by its impacts. Rainwater harvesting (RWH) techniques offer an alternative source of water and represent specific adaptive strategies to cope with water scarcity within future climate change. Studying the impact of climate change on RWH techniques, however, is difficult, because the general circulation models (GCMs) widely used to simulate scenarios of future climate change operate on a coarse scale. We estimated the impact of climate change on water availability at the watershed level by downscaling precipitation and temperature from the GCMs using a statistical downscaling model. A water harvesting model then assessed the performance of the RWH techniques for the Oum Zessar watershed in southeastern Tunisia under current climatic conditions and scenarios of future climate change. Annual temperature tended to increase and precipitation tended to decrease. These changes of climatic variables were used in the water harvesting model to simulate future water availability. Changing the flow directions combined with changing the spillway heights strongly affected the performance of RWH under the scenarios of future climate, resulting in a sufficient water supply for $92 \%$ of all sub-catchments, compared to $72 \%$ without these changes.

This chapter is submitted as:

Adham A., Wesseling J., Riksen M., Ouessar M, Abed R., Ritsema C.; Assessing the impact of climate change on rainwater harvesting in the Oum Zessar watershed in southeastern Tunisia. CATENA. 


\subsection{Introduction}

Arid and semi-arid regions (ASARs) around the world are facing serious challenges of water availability. It is enlarging the scale of the problems. Climate change is a very serious phenomenon and has become a major global issue in recent years, especially in developing countries strongly affected by its impacts. The United Nations Framework Convention on Climate Change defines climate change as "a change of climate which is attributed directly or indirectly to human activity that alters the composition of the global atmosphere and which is in addition to natural climate variability observed over comparable time periods" (www.unfccc.int). The Intergovernmental Panel on Climate Change (IPCC, 2014b) predicts that the global mean surface temperature will probably increase by $0.3-0.7{ }^{\circ} \mathrm{C}$ during $2016-2035$ and by $2.6-4.8{ }^{\circ} \mathrm{C}$ during $2081-2100$. Higher temperatures lead to higher evaporation rates, to a higher frequency of droughts and to reductions in streamflow (Rind et al., 1990). Tunisia is amongst the lowest water-use countries $\left(450 \mathrm{~m}^{3}\right.$ capita $\left.{ }^{-1} \mathrm{y}^{-1}\right)$ and amongst the most vulnerable to the effects of climate change (MARH, 2011). Climatic projections applied to Tunisia have shown that the average temperature will increase by $1.1{ }^{\circ} \mathrm{C}$ by 2030 and by $2.1{ }^{\circ} \mathrm{C}$ by 2050 . Combining these numbers with a decrease of rainfall, which is predicted to be between $10 \%$ in the north and $30 \%$ in the south during the same period (MARH, 2011), suggests that Tunisia will face a scarcity of water.

Inhabitants of ASARs are adapting rainwater harvesting (RWH) techniques to provide an alternative source of water to meet the increasing demand (Ammar et al., 2016). RWH represents a specific adaptive strategy to cope with water scarcity and future climate change (Mukheibir, 2008). Climatic variables and scenarios of climate change must be developed on a regional or even site-specific scale to ensure the success and sustainability of adapting RWH techniques to the impacts of climate change (Wilby and Wigley, 2000). Projections of climatic variables must be 'downscaled' from the results of general circulation models (GCMs) to provide these values, i.e. translate the climatic projections from coarse-resolution GCMs to finer resolutions using either dynamic or statistical methods (Ipcc-Tgic, 2007).

Different methodologies can assess the impact of climate change on RWH, water availability, runoff and water balance within large catchments (Chiew et al., 1995), but only a few studies have focused on small sub-catchments. Abouabdillah (2010) applied the SWAT2005 model to study the impact to central Tunisia of three scenarios of future climates, generated with the Canadian Global Coupled Model (CGCM 3.1). The data for precipitation and temperature were generated using statistically downscaling of the CGCMs, and the potential impact of climate change on flow, evapotranspiration and soil 
moisture across this catchment was analysed. Al-Ansari et al. (2014) tested the projected validity of RWH techniques in the Iraqi province of Sulaimaniyah using data based on global climatic projections provided by the HadCM3 GCM.

Climatic and hydrological models have not applied adaptive strategies for optimising RWH effectiveness in ASARs. Analysing the performance and efficiency of RWH techniques for the use of the scarce water is therefore necessary. The potential redesign of RWH structures to adapt to future conditions requires more study as well. We developed a tool to assess the performance of existing RWH techniques and to improve the design of the RWH structures (Adham et al., 2016b; Chapter 5).

The main objective of the present study was to investigate the impact of climate change on RWH by assessing the performance of current RWH systems for our case-study area, the Oum Zessar watershed in southeastern Tunisia, under different climatic scenarios. Potential adaptive strategies for optimising RWH effectiveness to mitigate the impact of the predicted climate change were also investigated.

\subsection{Materials and Methods}

\subsubsection{Study area and data used}

The Oum Zessar watershed in the province of Medenine in southeastern Tunisia covers an area of $367 \mathrm{~km}^{2}$. A 50-ha catchment in the upstream area of the watershed was selected for this case study. This catchment consists of 25 sub-catchments (Figure 7.1). The area is characterised by an arid Mediterranean climate with a rainfall of $150-230 \mathrm{~mm} \mathrm{y}^{-1}$, an annual temperature of $19-22{ }^{\circ} \mathrm{C}$ and a potential evapotranspiration of $1450 \mathrm{~mm} \mathrm{y}$ (Adham et al., 2016a).

Local inhabitants have built two main types of RWH structures to cope with water scarcity and to harvest rainfall/runoff for satisfying the water requirements: jessour (in areas with moderate to steep slopes) and tabias (in gently sloping foothills). Each jessr (singular of jessour) or tabia consists of three parts: runoff area, a cultivated area and a dyke to catch the water and sediment. Each dyke has a spillway to regulate water flow between subcatchment(s) (Adham et al., 2016a).

Two types of data were required for our study. The first type was used for downscaling and modelling climate change. Daily precipitation, maximum temperature and minimum temperature data were collected from two nearby meteorological stations, at the Institute 
des Régions Arides (IRA) and Medenine/Tunisia. Daily data for large-scale predictor variables representing current climatic conditions (1961-2005) were derived by reanalysing the data from the National Centres for Environmental Prediction (NCEP) and the National Centre for Atmosphere Research (NCAR). The NCEP data were downloaded from the Canadian Climate Data and Scenarios website http://ccds-dscc.ec.gc.ca/.

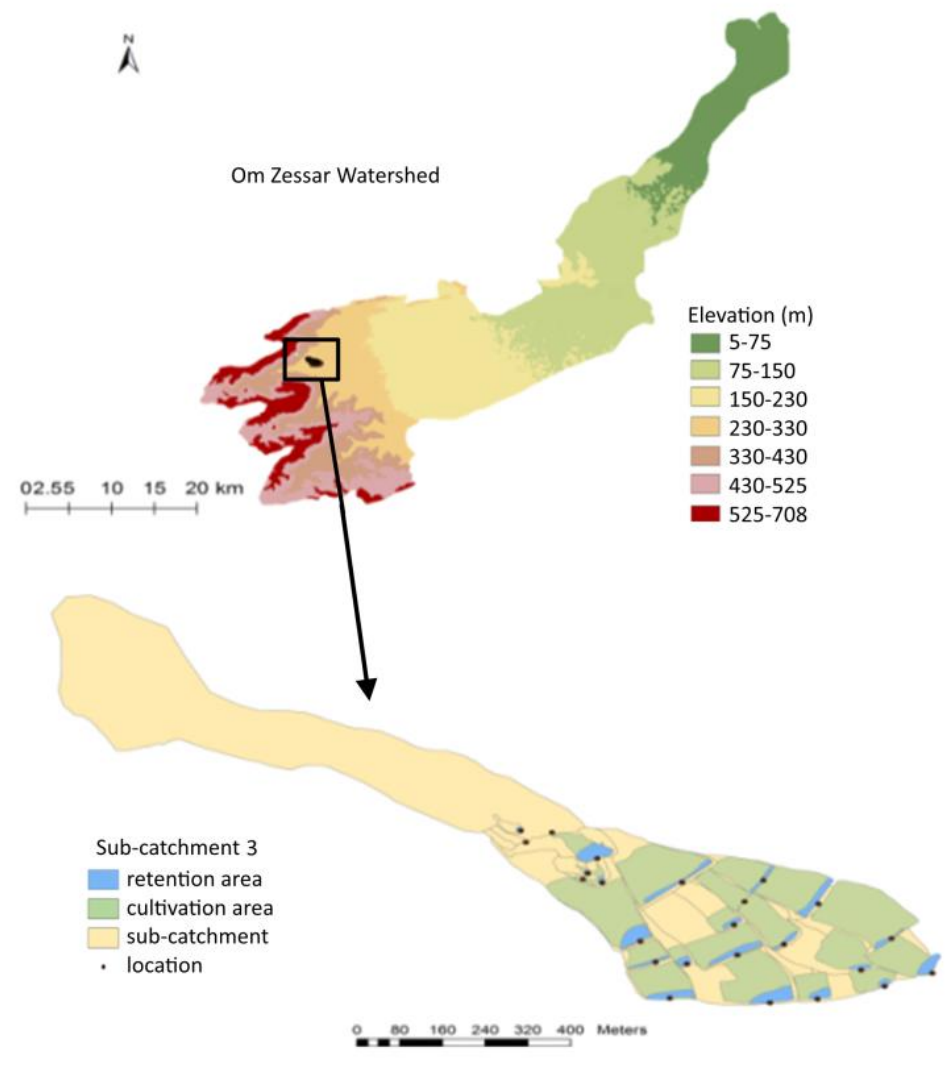

Figure 7.1 Location of wadi Oum Zessar watershed (Tunisia) and the test sub-catchment. The location for each RWH structure with its retention area and cultivation area are presented as well.

The second type of data consisted of the input data for the water harvesting model (WHCatch) (Adham et al., 2016b): physical characteristics of each sub-catchment under consideration were measured. Soil texture was obtained by collecting samples, and the slope of the area was determined using a digital elevation model (DEM) and a geographic information system (GIS) in each sub-catchment. Rates of infiltration were measured in the field using a double-ring infiltrometer and the runoff coefficients were measured using a rainfall simulator in each sub-catchment (Adham et al., 2016b). 


\subsubsection{Methodology overview}

The impacts of climate change on the effects of the RWH techniques were assessed by:

1. Applying GCMs to simulate climatic variables at a large scale and to project scenarios of future global climate;

2. Downscaling the large-scale meteorological variables to local scales;

3. Using the WHCatch model to simulate the effect of climate change on the RWH techniques and to optimise the RWH structures to mitigate the impact of the change.

\subsubsection{GCMs and climate change scenarios}

The fifth phase of the Coupled Model Intercomparison Project (CMIP5) started releasing GCM climate-change data in 2011, encompassing simulations from more than 20 research groups and 50 models (Lebel et al., 2015). GCMs are numerically coupled models representing various earth systems, including the atmosphere, oceans, land surface and sea ice. GCMs are generally used to simulate the present climate and to project future climate with forcing by greenhouse gases and aerosols (Dibike and Coulibaly, 2005). The GCMs were primarily developed in 1956 to simulate average, synoptic-scale patterns of atmospheric circulation, but various other GCMs have been designed and developed since for forecasting the weather, understanding the climate and predicting future climate changes (Xu, 1999). We used only one model, the second-generation Canadian Earth System Model (CanESM2). CanESM2 has been commonly used for various regions. It was developed by the Canadian Centre for Climate Modelling and Analysis (CCCma) of Environment Canada. We used CanESM2 because it is the only model that produces daily predictor variables that can be directly applied to the statistical downscaling model (SDSM). CanESM2 was prepared for CMIP5 basically as the contribution to IPCC's fifth assessment report (AR5) (Taylor et al., 2012). CCCma provided the NCEP/NCAR predictor variables in addition to the large-scale atmospheric variables from CanESM2 for the same period (1961-2005) and also the same variables. Both the NCEP/NCAR and CanESM2 data were downloaded from the Canadian climate data and scenarios website http://ccdsdscc.ec.gc.ca/. The CanESM2 outputs were downloaded for three climatic scenarios, Representative Concentration Pathway (RCP) 2.6, RCP 4.5 and RCP 8.5, which were used in this study. These scenarios were developed and used recently for preparing AR5. The RCP 2.6, was developed by the IMAGE modelling team of the PBL Netherlands Environmental Assessment Agency. The RCP 2.6 representative for scenarios in the literature leading to very low greenhouse gas concentration levels (Van Vuuren et al., 2011). The RCP 4.5 was developed by the GCAM modelling group at the Pacific Northwest National Laboratory's Joint Global Change Research Institute (JGCRI) in the United States. It is a stabilization 
scenario where total radiative forcing is stabilized before 2100 by employment of a range of technologies and strategies for reducing greenhouse gas emissions (Rajesh, 2015). The RCP 8.5 was developed by the MESSAGE modelling team and the Integrated Assessment Framework at the International Institute for Applied System Analysis (IIASA), Austria. The RCP 8.5 is characterized by increasing greenhouse gas emissions over time representative for scenarios in the literature leading to high greenhouse gas concentration levels (Thomson et al., 2011). Climatic scenarios refer to plausible future climates; they are images of the future or an alternative future (Setegn et al., 2011). Climatic scenarios have become an important element in research on climate change, because they allow us to understand the long-term consequences and describe plausible pathways of future climatic conditions (Moss et al., 2010). Daily data for precipitation and maximum and minimum temperature were extracted from CanESM2 to be used in the WHCatch model to assess the impact of climate change on RWH for the three scenarios (RCP 2.6, 4.5 and 8.5).

\subsubsection{Downscaling methods}

GCMs are coarse in resolution and are unable to resolve important sub-grid-scale features such as topography and land use (Grotch and MacCracken, 1991). There is a large gap between the coarse resolution of GCMs and the local watershed processes (Setegn et al., 2011). GCMs were not designed for studying the impact of climate change on a local scale and do not provide direct estimates of hydrological responses to climate change (Dibike and Coulibaly, 2005). A hydrological model is therefore necessary for studying the impacts of climate change on sub-grid scales. Hydrological models need data at similar to sub-grid scales, so the methods used to translate GCM outputs into local meteorological variables required for reliable hydrological modelling are referred to as 'downscaling' techniques (Dibike and Coulibaly, 2005). Dynamic and statistical downscaling are the two main approaches available for downscaling the results of computations by GCMs. The statistical approach used in this study, establishes empirical relationships between local climatic variables (predictands) and large-scale atmospheric variables (predictors). Statistical downscaling is less technically demanding than original modelling, computationally cheaper, and can tailor scenarios for specific localities, scales, and problems (Setegn et al., 2011). The main drawback is the assumption that the statistical relationships developed for the present climate also hold under the different forcing conditions of a possible future climate (Abdo et al., 2009).

Formally, the concept of conditioning the regional climate by the large-scale state may be written as:

$R=F(L)$ 
where $\mathrm{R}$ is the predictand, $\mathrm{L}$ is the predictor (a set of large-scale climatic variables), and $\mathrm{F}$ is a deterministic/stochastic function conditioned by $L$ that must be derived empirically from historical observations or modelled data sets (Dibike and Coulibaly, 2005).

\section{I) Statistical downscaling model (SDSM 4.2)}

SDSM is a statistical downscaling tool widely applied in climatic studies. SDSM is a hybrid model that uses linear regression and a stochastic weather generator (Hassan et al., 2014). It is a decision support tool developed by Wilby et al. (2002) for assessing the impact of local climate change using statistical downscaling. This model was downloaded from the website http://co-public.lboro.ac.uk/cocwd/SDSM/. We used the output of CanESM2 as the predictor, and RCP 2.6, 4.5 and 8.5 were used for the generation of future data. SDSM establishes the empirical relationship function (F) in equation 7.1 between the predictors and predictands. The model has four main parts: identification of the predictands and predictors, model calibration, weather generation and generation of a future series of climatic variables (scenario generation). The quality-control module in SDSM can assess the performance of the predictands (precipitation and temperature) to identify errors, missing data and outliers in the data records. We applied a transformation of the fourth root to account for the skewed nature of the rainfall distribution (Hassan et al., 2014). Some parameters such as threshold event, bias correction and variance inflation were adjusted several times during the calibration of SDSM until the statistical agreement between the observed and simulated outputs was highest for precipitation. The SDSM default values for these parameters were then used for temperature. The unconditional process and the monthly model were applied for temperature, and a conditional process was applied for precipitation. In an unconditional process it is assumed that there is a direct link between predictor and predict and whereas conditional assumes the existence of intermediate processes between regional forcing and local weather.

II) Downscaling daily rainfall and temperature time series

Daily precipitation and maximum and minimum temperature were chosen as the predictand variables for the downscaling experiments. Precipitation and temperature have been measured at the Medenine meteorological station near our study area for 32 years (1978-2010). These data were used for our downscaling experiments. The largescale predictor variables representing the current climatic conditions were derived from the reanalysed NCEP data for 1961-2005. To make a consistent data set of predictand and predictor variables we assumed the data got the period from 1961 to 1978 as missing data and assigned -999 to them to be applicable with the SDSM program. The other climatic variables for the future scenarios were extracted from the CanESM2 location, which is 
closest to the study area. Data were ultimately extracted for three periods (every 30 years from 2011-2100): the 20s (2011-2040), 50s (2041-2070) and 80s (2071-2100).

III) Calibration and validation of SDSM

The first 30 of the 45 years of the current climatic data (1961-1990) were used for calibrating the regression models, and the remaining 15 years of data (1991-2005) were used for SDSM validation. The performance of SDSM was evaluated using the coefficient of determination $\left(R^{2}\right) . R^{2}$ is a comparison of the variance of the modelled data with the total variance of the observed data (Shrestha et al., 2015). The weather-generator module in SDSM was used for the validation. We then used the summary statistics and frequency analysis in SDSM to compare the observed and simulated climatological data for the 15 years (1991-2005).

\subsubsection{The water harvesting model (WHCatch)}

Hydrological models are mathematical formulations that can determine the volume of runoff leaving a watershed from the rainfall received by the watershed (Abdo et al., 2009). We applied the simple model WHCatch (Adham et al., 2016b) for 25 sub-catchments in the Oum Zessar watershed to assess the performance of the RWH techniques based on current and future climatic conditions. The change of water storage within the volume was calculated as the difference between total input and output.

The water balance equation of an area can be written in units of volume $\left(\mathrm{m}^{3}\right)$ as (Boers et al., 1986):

$\Delta S=I-O$

Where $\Delta S$ is the change in storage during a defined period of time, I is the inflow, and $\mathrm{O}$ is the outflow, all in $\mathrm{m}^{3}$.

Recognition of the various types of in- and outflow allows a more detailed water balance equation:

$\Delta S=V_{\text {runoff }}+V_{\text {rainfall }}+V_{\text {in }}-V_{\text {out }}-V_{\text {loss }}$

Where $V_{\text {runoff }}$ is the volume of runoff into the retention basin from the runoff area, $V_{\text {rainfall }}$ is the rainfall in the retention basin, $V_{\text {in }}$ is the volume of inflow from upstream catchment(s), $V_{\text {out }}$ is the volume of overflow from the retention basin to the next catchment(s), and the $V_{\text {loss }}$ consist of infiltration loss from the retention basin and the maximum crop evapotranspiration. 
The Thornthwaite equation was used to estimate the potential evapotranspiration in each sub-catchment as follows (Xu and Singh, 2001):

$E T=16\left(\frac{L}{12}\right)\left(\frac{N}{30}\right)\left(\frac{10 T_{a}}{I}\right)^{\propto}$

Where ET is the potential evapotranspiration $\left(m m m^{-1}\right), T_{a}$ is the average daily temperature $\left({ }^{\circ} \mathrm{C}\right.$, if this is negative use 0$), \mathrm{N}$ is the number of days in the month being calculated, $\mathrm{L}$ is the average day length (hours) of the month being calculated, and $\alpha$ is calculated as (Xu and Singh, 2001):

$\propto=\left(6.75 \times 10^{-7}\right) I^{3}-\left(7.71 \times 10^{-5}\right) I^{2}+\left(1.792 \times 10^{-2}\right) I+0.49239$

With:

$I=\sum_{i=1}^{12}\left(\frac{T_{a i}}{5}\right)^{1.514}$

Where $\mathrm{I}$ is the heat index which depends on the 12 monthly mean temperatures $\mathrm{T}_{\mathrm{ai}}$. The maximum crop evapotranspiration $\left(E T_{c}\right)$ was calculated by:

$\mathrm{ET}_{c}=\mathrm{ET} \cdot \mathrm{K}_{c}$

Where $K_{c}$ is the crop coefficient.

The output of CanESM2 for RCP 2.6, 4.5 and 8.5 were used as inputs and compared with the results for the current climatic variables. The volume of water that could be harvested in each sub-catchment was calculated and presented for the current (baseline) 1981-2010 scenario and the future scenarios, 2011-2040, 2041-2070 and 2071-2100 (similar periods of climatic scenarios).

To achieve the adaptive goal of RWH for the future climatic scenarios, we changed the spillway heights and flow directions to optimise the performance of the RWH structures and to improve the yield (water availability) of the RWH system under the future climatic conditions. 


\subsection{Results and Discussion}

\subsubsection{Statistical downscaling}

SDSM 4.2 was applied to assess the impact of local climate change using a statistical downscaling technique. Four main steps were applied: the predictor variables were selected, the calibration and validation of SDSM were evaluated (second and third steps) and a series of future climatic variables (projection of temperature and precipitation) was generated.

\subsubsection{Selection of predictor variables}

The choice of predictor variables is a major problem in the development of statistical downscaling. The screening option in SDSM assists in choosing the appropriate predictor variables for downscaling. The predictor variables from the reanalysed NCEP/NCAR (19612005) data were chosen to investigate the percentage of variance explained by each predictand-predictor pair. The final set of predictor variables was selected after analysing the significance level $(\mathrm{P})$ and correlation coefficient (partial $r$ ), where each predictor was selected based on the highest correlation and smaller $P$ value with each predictand (Table 7.1).

Table 7.1 Selected set of predictor variables with their description, each predictor was selected based on the highest correlation $(r)$ and smaller $P$ value with each predictand. For all combinations of predictor and predictand the $P$-variable had a value of 0.00 .

\begin{tabular}{lllr}
\hline Predictand & Predictor & Predictor description & Partial r \\
\hline$T_{\max }$ & p500gl & $500 \mathrm{hPa}$ Geopotential & 0.239 \\
& s500gl & $500 \mathrm{hPa}$ Specific humidity & -0.099 \\
& shumgl & $1000 \mathrm{hPa}$ Specific humidity & -0.470 \\
& tempgl & Air temperature at 2 m & 0.841 \\
$\mathrm{~T}_{\min }$ & $\mathrm{p} 500 \mathrm{gl}$ & $500 \mathrm{hPa}$ Geopotential & -0.077 \\
& s500gl & $500 \mathrm{hPa}$ Specific humidity & 0.114 \\
& shumgl & $1000 \mathrm{hPa}$ Specific humidity & 0.252 \\
\multirow{3}{*}{ Precipitation } & tempgl & Air temperature at 2 m & 0.700 \\
& p1_ugl & $1000 \mathrm{hPa}$ Zonal wind component & 0.104 \\
& p8_ugl & $850 \mathrm{hPa}$ Zonal wind component & -0.180 \\
& prcpgl & Total precipitation & 0.199 \\
\hline
\end{tabular}

The procedure for selecting the predictor variables was similar to that used in other studies (Wilby et al., 2002; Dibike and Coulibaly, 2005; Hassan et al., 2014). Air temperature at a height of $2 \mathrm{~m}$ was the dominant predictor variable for both maximum and minimum temperature (Table 7.1). This variable has the highest impact on temperature and is expected to generate a temperature in response to a climatic scenario 
(Hassan et al., 2014). Total precipitation was the dominant predictor variable for precipitation. Some predictor variables (e.g. p1_ugl) were poorly correlated with precipitation $(r=0.104)$ but were selected because combinations of one or more of them were able to describe the conditional process for precipitation. The selection of predictor variables for maximum and minimum temperature was easier than for the rainfall predictor variables, because rainfall is under condition process.
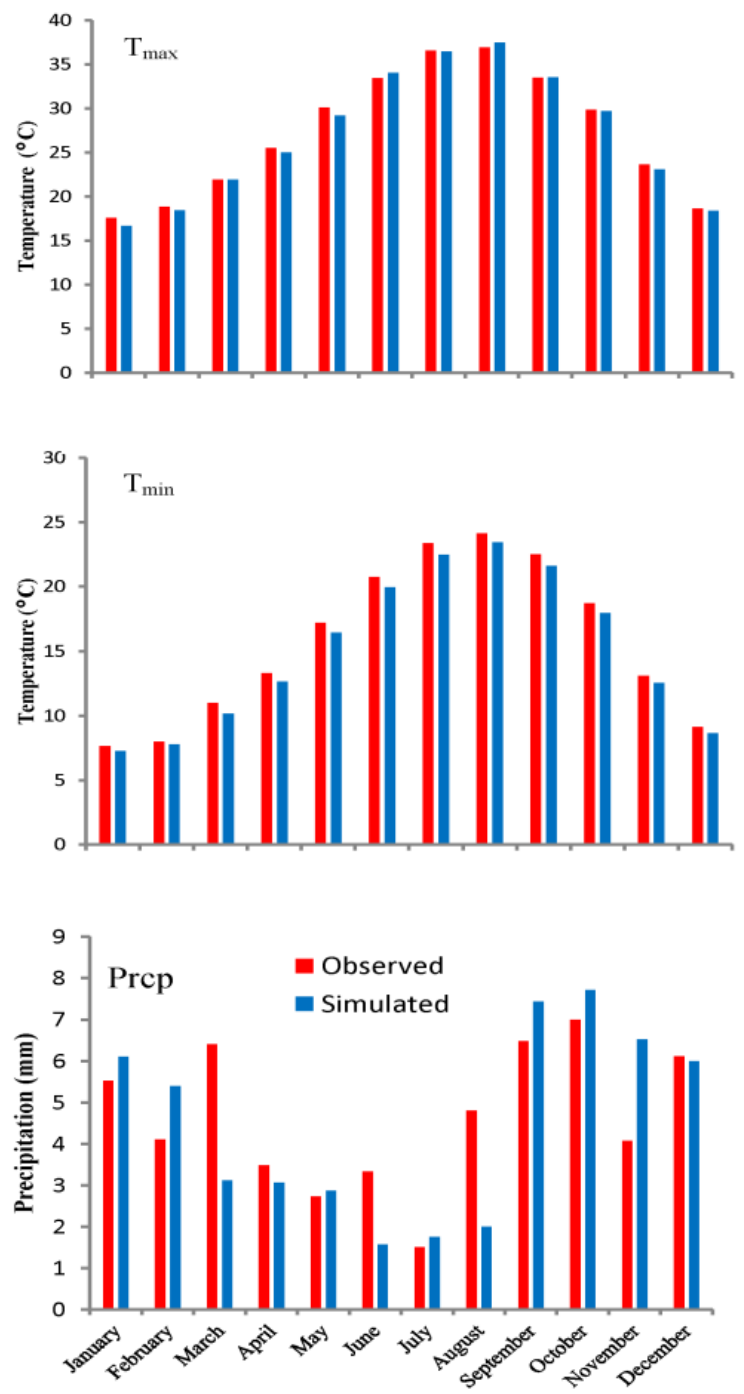

Figure 7.2 Validation of SDSM performance for $T_{\max } T_{\min }$ and precipitation by comparing the monthly means for the observed and simulated data for 1991-2005. 


\subsubsection{SDSM performance}

SDSM performance was evaluated by downscaling the temperature and precipitation for the study area. The calibration module in SDSM was applied automatically to evaluate the performance of SDSM using $R^{2}$ for the first 30 years (1961-1990). The $R^{2}$ values were 0.74, 0.64 and 0.28 for maximum temperature $\left(T_{\max }\right)$, minimum temperature $\left(T_{\min }\right)$ and precipitation (Prcp), respectively. These results indicated that SDSM performed well for downscaling maximum and minimum temperature but not for precipitation, which was more complex than temperature (Fowler et al., 2007). The complexity of downscaling rainfall is due to the conditional process, which is dependent on another intermediate process inside the rainfall process, such as humidity, cloud cover and/or wet days (Hassan et al., 2014).

The weather-generator module in SDSM was used for validation. The observed data and results of the climatic simulation were then compared using summary and frequency analysis in SDSM for 1991-2005 (Figure 7.2). Comparisons of the monthly mean maximum and minimum temperatures and precipitation indicated a good agreement between the observed and simulated outputs for $T_{\max }$ and $T_{\min }$, which were very similar.

The precipitation data, however, differed more, especially in March and August. The $\mathrm{R}^{2}$ values were $0.97,0.95$ and 0.46 for $T_{\max }, T_{\min }$ and Prcp, respectively. These results indicated that SDSM performed well for the validation but not for the calibration of precipitation, perhaps due to missing rainfall data (observed), which negatively affected the performance of SDSM. Overall, the agreement between the observed and simulated monthly $T_{\max }, T_{\min }$ and precipitation was satisfactory.

\subsubsection{Projection of temperature and precipitation}

The next step after validation was to use SDSM 4.2 to downscale the future scenario of climate change simulated by the GCM. As explained above, the output from CanESM2 provided the predictors used in this study. The future climatic variables for RCP 2.6, 4.5 and 8.5 based on the mean of 20 ensembles were analysed for each 30 -year period, i.e. 20s (2011-2040), 50s (2041-2070) and 80s (2071-2100). The data for the baseline period (1981-2010) were compared with the future data. The downscaled maximum and minimum temperatures clearly indicated an increasing trend in the mean monthly temperature for all three scenarios and all future periods (Figure 7.3).

The mean annual maximum temperature under RCP 2.6 increased by 2.33 and $3.32{ }^{\circ} \mathrm{C}$ in the $20 \mathrm{~s}$ and $50 \mathrm{~s}$ periods, respectively. The increase in the mean annual maximum temperature was slightly lower at $3.29{ }^{\circ} \mathrm{C}$ by the end of this century compared with the 50 s period. The mean annual temperature increased in RCP 4.5 in all three periods. The 
increases in the maximum future temperatures were highest in RCP 8.5: $2.61{ }^{\circ} \mathrm{C}$ in $20 \mathrm{~s}$, $5.39{ }^{\circ} \mathrm{C}$ in $50 \mathrm{~s}$, and $8.96{ }^{\circ} \mathrm{C}$ in $80 \mathrm{~s}$ (Table 7.2). RCP 8.5 assumed higher emissions of greenhouse gases than RCP 4.5 (Rajesh, 2015), and RCP 2.6 usually assumed the lowest emission due to mitigate activities (Van Vuuren et al., 2011). The mean annual maximum temperature increased in all months, except in May when the temperature was slightly lower for all scenarios in all periods. Temperature only increased in May in RCP 8.5 for the 80s period (Figure 7.3).
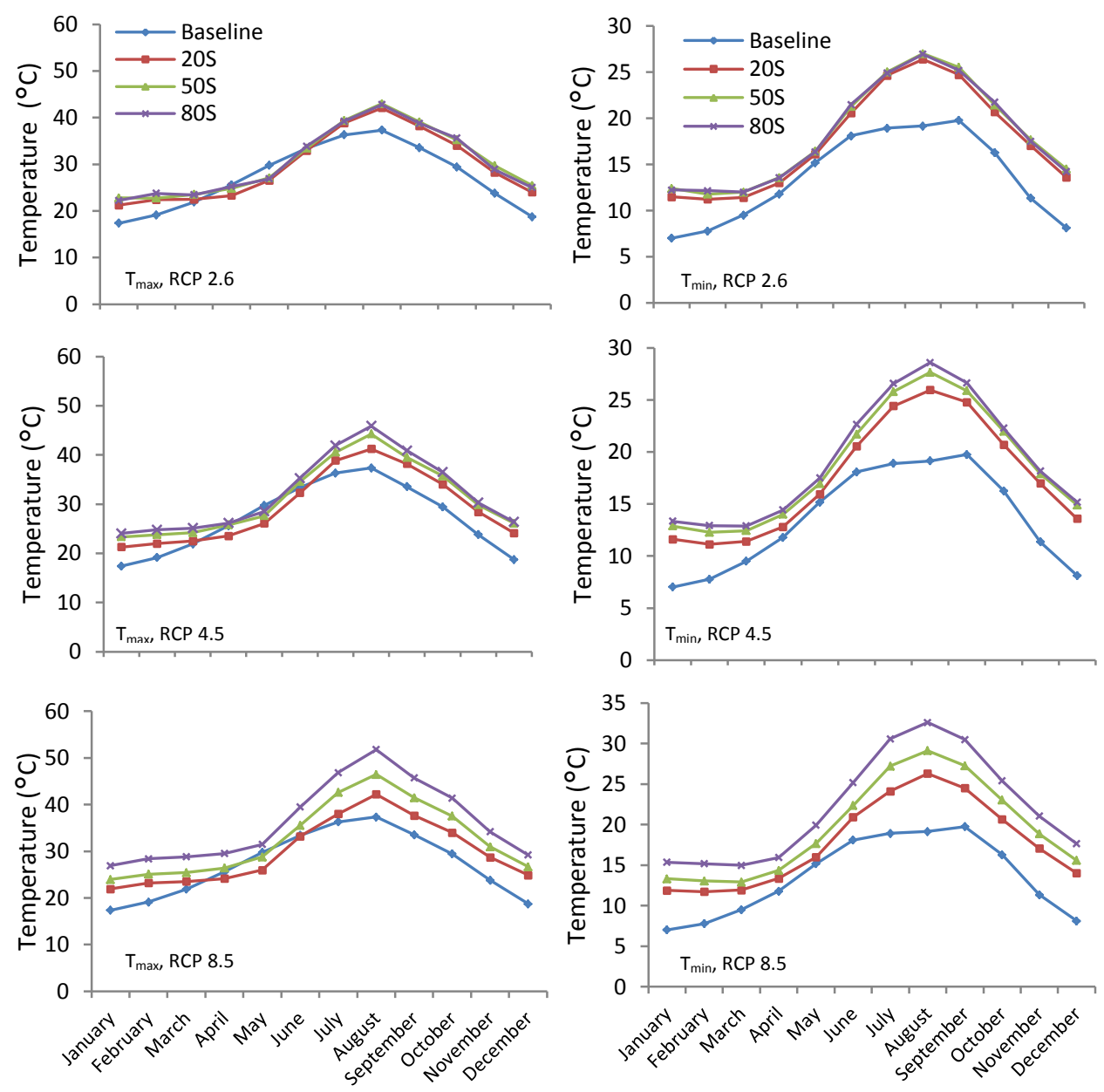

Figure 7.3 Monthly mean maximum and minimum temperature under three scenarios ( $R C P$ 2.6, 4.5 and $8.5)$ in the baseline and the three projected periods (20s, 50s and 80s).

The mean annual minimum temperature also increased in all three scenarios in all periods and months (Table 7.2). The mean annual minimum temperature increased in RCP 2.6 by 
$3.98{ }^{\circ} \mathrm{C}$ in $20 \mathrm{~s}$ and by $4.63{ }^{\circ} \mathrm{C}$ in $50 \mathrm{~s}$, and the increase was slightly lower at $4.61{ }^{\circ} \mathrm{C}$ by the end of this century, as with the maximum temperature. The mean annual minimum temperature increased in RCP 4.5 during all periods. The minimum temperature increased most in RCP 8.5: 4.13, 5.98 and $8.45^{\circ} \mathrm{C}$ in 20s, 50s and 80s, respectively (Table 7.2 and Figure 7.3). Mean annual minimum temperature increased substantially during summer (June-September), especially in RCP 8.5, but increased only slightly in May.

The increases in the mean maximum and minimum temperatures were generally slightly higher than those in earlier studies (MARH, 2011), but our results are consistent with an increasing trend for the $21^{\text {st }}$ century. This study is the first to apply new scenarios based on CMIP5 modelling to this region.

Potential evapotranspiration is projected to increase in the future due to the impact of increasing temperatures (Figure 7.4, A). Monthly ET-values show a similar pattern in all three scenarios, but RCP 8.5 increases more than the other two scenarios, especially during June to September. The annual mean potential ET is likely to increase by $6 \%$ in RCP 2.6 in 20 s to $21 \%$ in RCP 8.5 in 80 s (Table 7.2 ).

Table 7.2 The mean annual $T_{\max }, T_{\min }$, precipitation and evapotranspiration for the three scenarios in the three periods. The maximum, minimum and evapotranspiration tended to increase (+) while precipitation tended to decrease (-) in all scenarios (RCPS) of future emissions of greenhouse gases and in all periods (20s, 50s, and 80s).

\begin{tabular}{lrrrr}
\hline & RCPs & $20 s$ & $50 s$ & $80 \mathrm{~s}$ \\
\hline $\mathrm{T}_{\max }$ & 2.6 & +2.33 & +3.32 & +3.29 \\
& 4.5 & +2.18 & +4.08 & +4.95 \\
& 8.5 & +2.61 & +5.39 & +8.96 \\
\hline $\mathrm{T}_{\min }$ & 2.6 & +3.98 & +4.63 & +4.61 \\
& 4.5 & +3.92 & +5.13 & +5.70 \\
& 8.5 & +4.13 & +5.98 & +8.45 \\
\hline Precipitation (\%) & 2.6 & -27 & -37 & -29 \\
& 4.5 & -30 & -32 & -30 \\
& 8.5 & -36 & +8 & -36 \\
\hline Evapotranspiration (\%) & 2.6 & +6 & +10 & +8 \\
& 4.5 & +6 & +13 & +12 \\
& 8.5 & +7 & +21 \\
\hline
\end{tabular}

The projection for precipitation indicated a decreasing trend in the mean annual daily precipitation for the three scenarios in all periods (Figure $7.4 \mathrm{~B}$ ). The mean annual daily precipitation decreased in RCP 2.6 by $27 \%$ in 20 s, $37 \%$ in 50 s and $29 \%$ in 80 s and in RCP 4.5 by about $30 \%$ in 20 s and 80 s and by $33 \%$ in 50 s. The mean annual daily precipitation decreased most in RCP 8.5 , by $36 \%$ in both 20 s and 80 s and by about $32 \%$ in 50 s (Table 7.2). These changes in precipitation varied monthly. The largest decrease was in March and October in all scenarios and periods. The mean annual daily precipitation 
increased slightly in RCP 2.6 in February 50s, in RCP 4.5 in February 80s and November 80s and 20s, and in RCP 8.5 in May and September 80 s (Figure 7.4 B). The pattern was similar in RCP 2.6 and 4.5 but with some differences, whereas the pattern was much different in RCP 8.5 in September to December in 20s and 80s compared with the base.

These results are generally consistent with the climatic projections in a Tunisian case study, which reported that rainfall would decrease between $10 \%$ in the north and $30 \%$ in the south in the same period (MARH, 2011).

To gain more insight in the predicted precipitation and the expected changes, the generated RCP4.5 dataset was analysed and compared with the baseline precipitation period of 1981-2010. To do so, first the distribution of the daily amounts of precipitation was computed. The cumulative probabilities are shows in Figure 7.5 A.
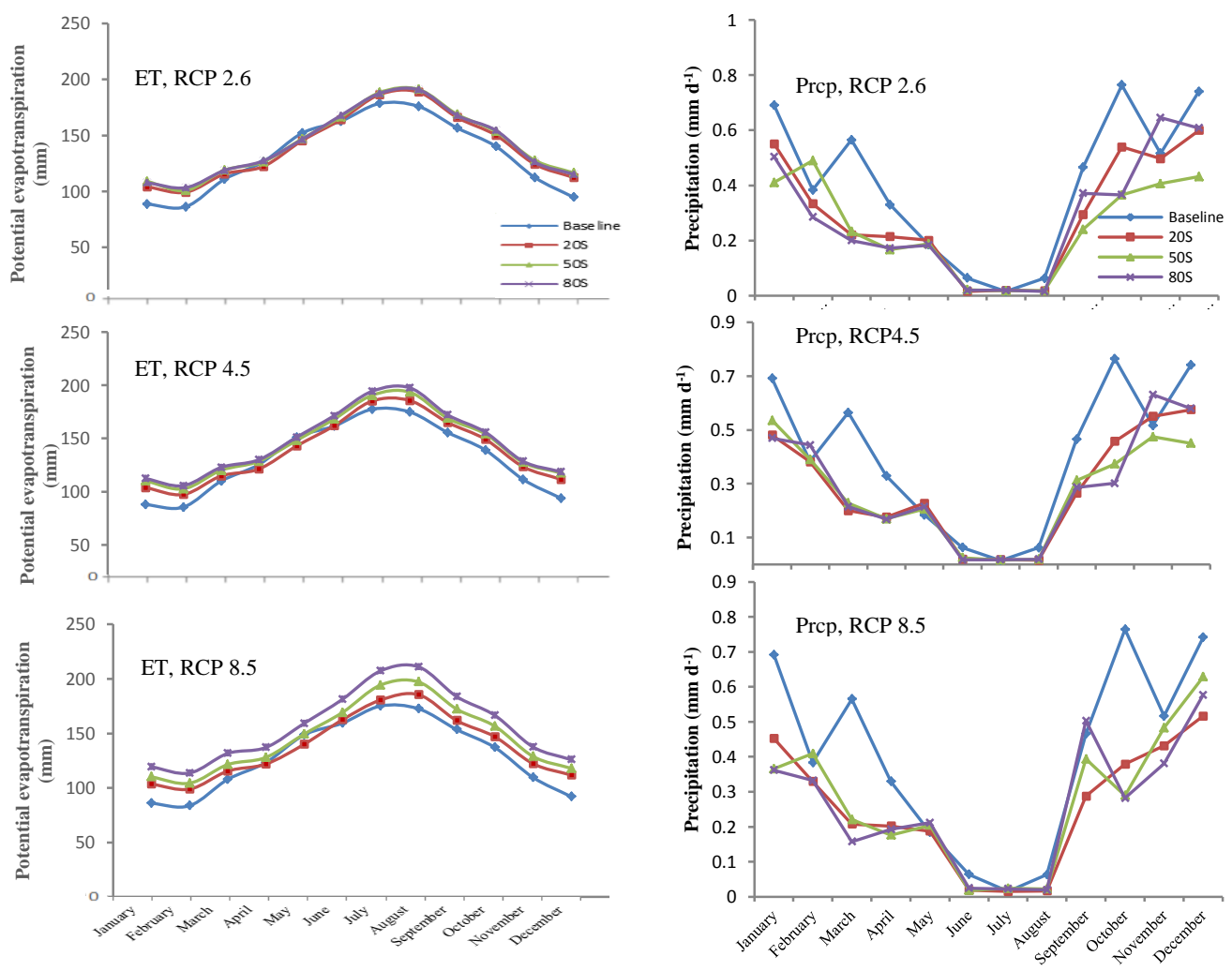

B: Mean daily precipitation per month

A: Average monthly evapotranspiration

Figure 7.4 Monthly mean evapotranspiration (A) and monthly mean precipitation (B) in the three scenarios (RCPS) in the baseline and the three projected periods. 
Figure 7.5 A; shows that the probability of a day with rainfall was only $7 \%$ for the years 1981-2010, while the probability increases to 16,14 and $14 \%$ for the periods $2011-2040$, 2041-2070 and 2071-2100 respectively. The chance of a rainfall event of $2.5 \mathrm{~mm}$ or more is $3,1.8,1.5$ and $1.9 \%$ for the different periods. The larger the amount of precipitation, the smaller the differences between the periods.
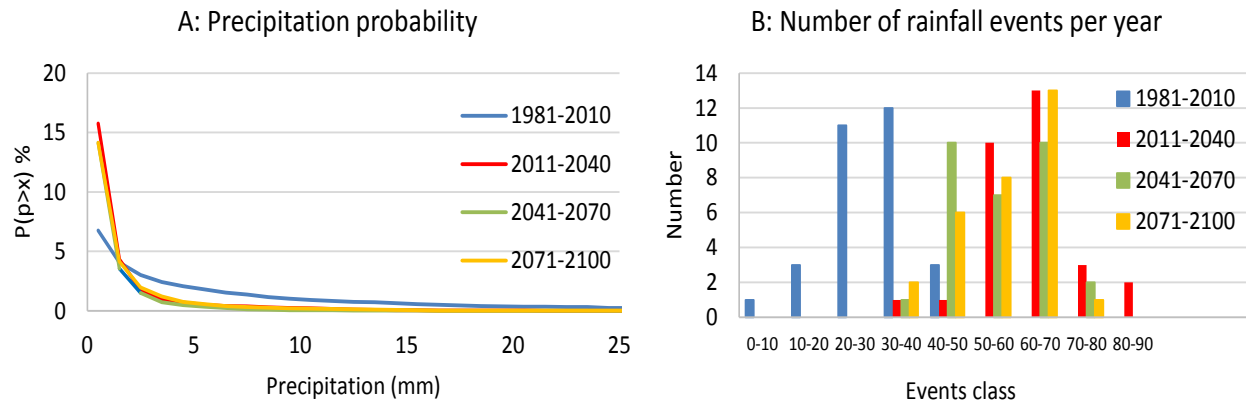

Figure 7.5 The probability of precipitation events in the RCP4.5 scenario (A). The number of years in which a certain number of rainfall events occur (B).

Not only the size of the precipitation events is important, so is the number of them. For every year considered we counted the number of events. Classes of precipitation of 10 $\mathrm{mm}$ were assumed and the number of events was counted for each class during the four periods considered. The results of this simple but effective analysis are shown in Figure 7.5 B. From this figure it can be seen that during the years 1981-2010 the majority of years had between 30-40 precipitation events. During this period there were also years with 0-10 events. In the periods with generated data, there were no years with less than 30 events. During 2041-2070 and 2071-2100 no years occurred with more than 80 events.

The projection results of temperature, evapotranspiration and precipitation were used in the WHCatch model to estimate the future water availability in each sub-catchment. The amount of rainfall and the change in temperature affected directly on calculation of water balance and evapotranspiration amounts as presented in equations 7.3 and 7.4. 


\subsubsection{Water harvesting model (WHCatch)}

WHCatch was used to estimate future water availability for each RWH structure relative to the baseline period. The sub-catchments and flow directions are shown in Figure 7.6.

The amount of water that will be caught by each RWH structure is highly dependent on the amount of precipitation in its sub-catchment and on actual evapotranspiration. Changes in precipitation and temperature will therefore have a direct impact on the availability of water and on the performance of RWH in general. The simulations for each sub-catchment for RCP 2.6, 4.5 and 8.5 for the 20s (2011-2040), 50s (2041-2070) and 80s (2071-2100) are compared with the baseline period (1981-2010) and presented in Figure $7.7 \mathrm{~A}$.

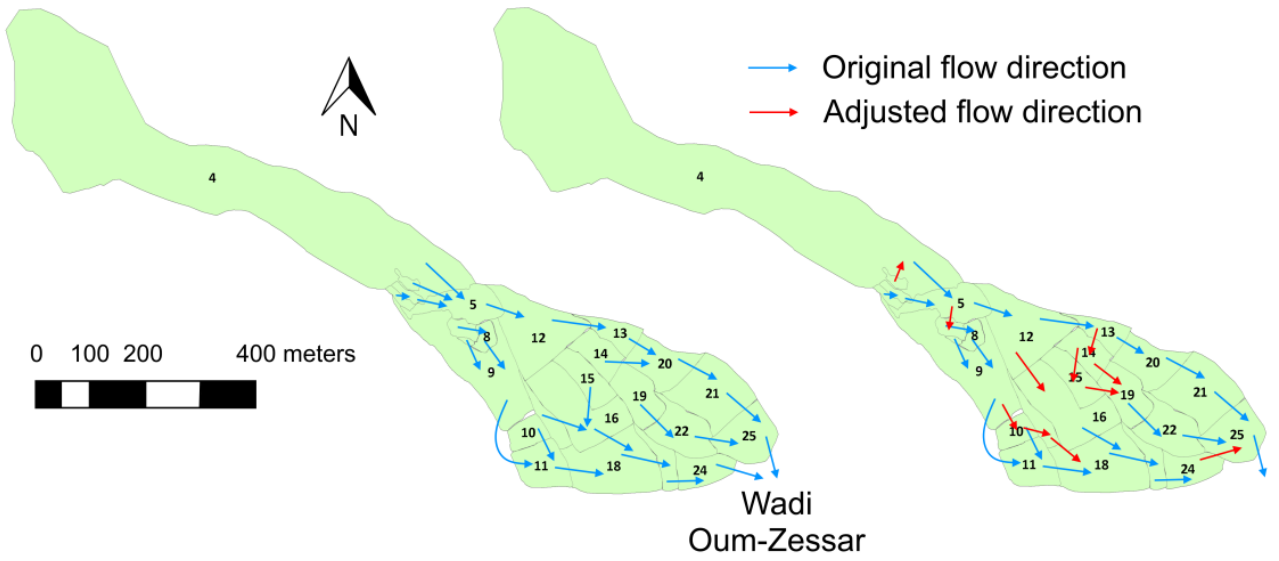
A: without change
B: with change

Figure 7.6 A; Study area with normal flow directions and B: changed flow directions.

The volume of water stored in a reservoir depends on the available runoff and the water demand. The performance of RWH under current conditions was previously assessed and discussed (Adham et al., 2016b). The amount of water stored in each sub-catchment decreased under the future conditions in RCP 2.6, 4.5 and 8.5 (Figure 7.7A). About $72 \%$ of the sub-catchments were able to meet the water requirements in the baseline period. For future scenarios about 30\% in RCP 2.6, 25\% in RCP 4.5 in all periods and 50\% for RCP 8.5 in 20 s and 50 s will be able to meet the water requirements (Figure $7.7 \mathrm{~A}$ ). Whereas, only $25 \%$ of the sub-catchments for $80 \mathrm{~s}$ in the RCP 8.5 was able to meet the water requirements. 
RCP 2.6

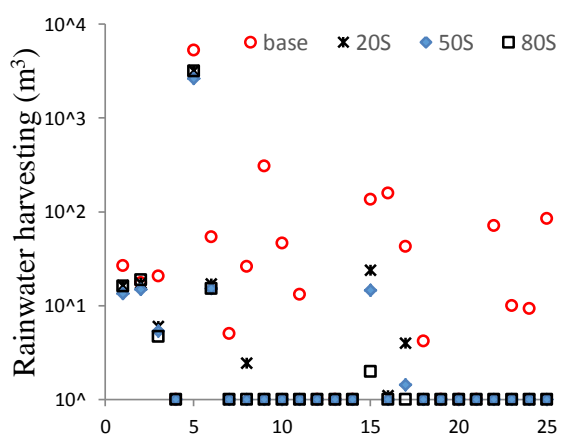

RCP 2.6

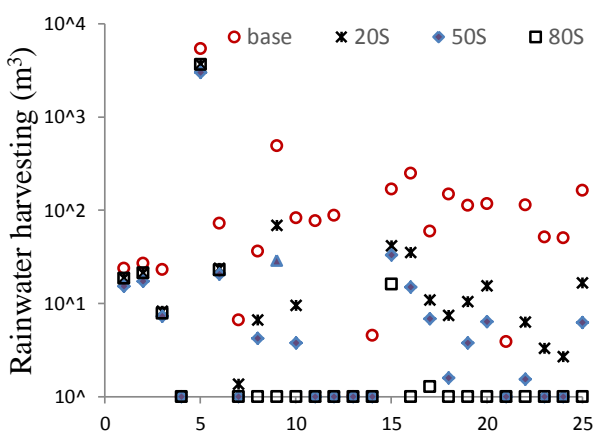

RCP 4.5

RCP 4.5
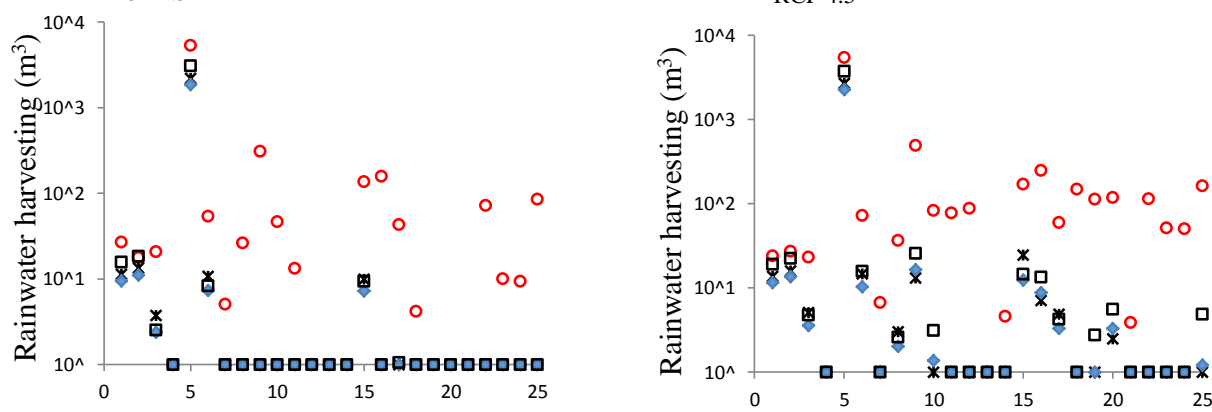

RCP 8.5

RCP 8.5

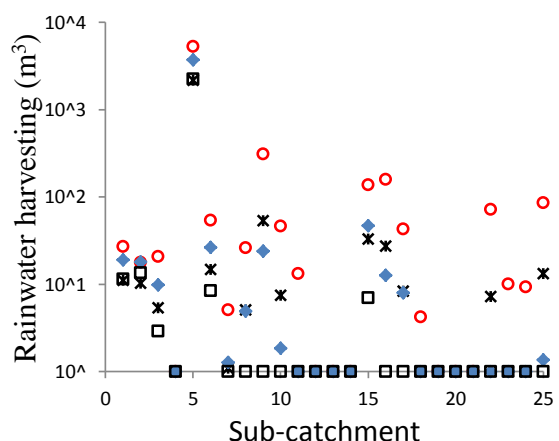

Sub-catchment

A: Current conditions

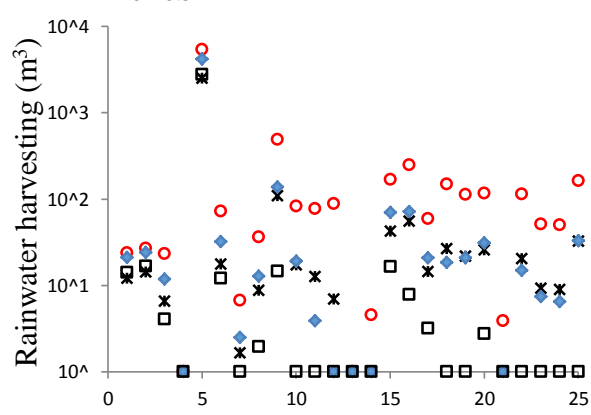

Sub-catchment

B: Adjusted condition

Figure 7.7 Results of water-harvesting modelling. A: the simulation of harvested rainwater in each subcatchment under normal conditions, and B: the results after optimalisation of the RWH system. 
Zero values of harvested rainwater for the sub-catchments, however, indicated the inability of RWH to meet the water requirements. The zero values were due to reasons such as insufficient storage capacity, suboptimal height of the spillway and direction of streamflow (Adham et al., 2016b). The availability of water is extremely low in these areas of low rainfall, because most of the rainwater is lost by evaporation from the soil surface. Therefore, water productivity is low (Adham et al., 2016b).

The watershed-runoff relationship in ASARs has long been reported. The volume of the harvested runoff is directly proportional to the size and length of the runoff-harvesting structure (Adham et al., 2016b). Most of the RWH structures built in ASARs are washed away due to the insufficient capacity of spillways (Adham et al., 2016b). Spillways with sufficient capacity and at the right location must therefore be provided. Field observations and the analysis of the water balance indicated that most of the runoff flowed in one direction (Figure 7.6A). Adham et al., (2016b) reported that changing spillway heights together with flow directions substantially increased rainwater availability under current climatic conditions for the proposed RWH solutions compared to the results for traditional designs. The WHCatch analysis indicated that changing spillway heights together with flow directions (Figure 7.6B) for optimising the performance of the RWH structures and improving the yield (water availability) of the RWH system based on the projected future climatic conditions (Figure 7.7B) substantially increased the performance of RWH, increasing the efficiency of water availability in $92 \%$ of all sub-catchments in the baseline period in all three RCP scenarios compared to $72 \%$ without the changes. The efficiency of water availability will be increased almost double in both scenarios RCP 2.6 and 4.5 in all periods compared to the sub-catchments without changes, whereas the percantage of sub-catchments that could be supply the water demand will be the same for $80 \mathrm{~s}$ in RCP 2.6. Moreover, about $80 \%$ of the sub-catchments in the RCP 8.5 in 20 s and 50 s will be able to meet the water requirements compared to $50 \%$ without the changes (Figure $7.7 \mathrm{~B}$ and Table 7.3).

Table 7.3 The efficiency (\%) of water availability in all sub-catchments in present and future climate scenarios, comparing normal situation and changing spillway hights together with flow direction (optimisation).

\begin{tabular}{|c|c|c|c|c|c|c|}
\hline \multirow[b]{2}{*}{ Baseline } & \multicolumn{3}{|c|}{ Efficiency under current condition (\%) } & \multicolumn{3}{|c|}{ Efficiency under adjusted condition (\%) } \\
\hline & \multicolumn{3}{|c|}{72} & \multicolumn{3}{|c|}{92} \\
\hline & $20 S$ & $50 \mathrm{~S}$ & $80 \mathrm{~S}$ & $20 \mathrm{~S}$ & $50 \mathrm{~S}$ & $80 \mathrm{~S}$ \\
\hline RCP 2.6 & 36 & 28 & 24 & 76 & 64 & 28 \\
\hline RCP 4.5 & 24 & 24 & 24 & 44 & 52 & 56 \\
\hline RCP 8.5 & 56 & 52 & 24 & 84 & 80 & 44 \\
\hline
\end{tabular}


Figure 7.7B shows, that the first four RWH structures (sub-catchments) do not have a significant change with this scenario. These results are due to a relatively small runoff area in the first three structures, whereas the structure was broken in the fourth site and we considered it works as a runoff area. Harvested rainwater increased in all three RCPs (Table 7.3). Table 7.3 confirmed that the increasing of the water supply in most subcatchments are more depend on the water management and structure design than climate change scenarios itself.

\subsection{Conclusions}

This study demonstrated the feasibility of rainwater harvesting (RWH) as an adaptive strategy to mitigate water scarcity and to improve water availability now and under changing climatic conditions. Both the minimum and maximum temperatures tended to increase and precipitation tended to decrease in all scenarios of future emissions of greenhouse gases in most periods (20s, $50 \mathrm{~s}$ and $80 \mathrm{~s})$. The increase in temperature yields an increase in potential evapotranspiration as well. Changing the flow directions combined with increasing the heights of spillways had a large impact on the performance of the RWH structures. Water availability increased in $92 \%$ of the sub-catchments compared to $72 \%$ without these adaptive measures in all the scenarios of climate change. Therefore, at sub-catchments level, water management and structure design play more important role in the performance of RWH rather than climate change itself.

The results could be important for designers, decision-makers and farmers for adapting to the forthcoming climatic conditions and/or for mitigating the adverse impacts of a changing climate on water resources. Further research, however, is required to include multiple GCMs and downscaling models under CMIP5 and to consider changes in land use/cover in simulation models to better understand the impact of climate change on water availability. 
8. Synthesis 


\subsection{Introduction}

Pressure on water resources is increasing around the world, and water stress is aggravated due to climate change and growing demands for water for agricultural and urban development. A conducive social structure, financial capacity and/or technical expertise in modern approaches to managing water are usually lacking in developing countries (Ouessar, 2007). Between 75 and 250 million people in Africa are predicted to become exposed to increased water stress by 2020 (Field et al., 2014). The United Nations Environment Programme estimates that $>2 \times 10^{9}$ people will live under conditions of high water stress by 2050 , which would be a limiting factor for development in many countries around the world (Sekar and Randhir, 2007).

Arid and semi-arid regions (ASARs) around the world are already regularly facing problems of water scarcity, so aridity and climatic uncertainty are the main challenges faced by people in these regions. ASARs represent $40 \%$ of the Earth's land surface, covering about 50 million $\mathrm{km}^{2}$ (Mekdaschi Studer and Liniger, 2013). ASARs face low average annual rainfall and variable temporal and spatial rainfall distributions. ASAR inhabitants are adapting to fulfil the increasing demand for water by developing several techniques of rainwater harvesting (RWH) for supplying an alternative source of water (Jackson et al., 2001). Climate change has become a major global issue, especially in developing countries, because they are most affected by its impacts. Climate change will likely have a large impact on systems of water resources, both globally and regionally. RWH is a specific adaptive strategy to cope with the water scarcity that will occur due to future changes in climate (Kahinda et al., 2010; Mukheibir, 2008; Pandey et al., 2003). RWH is broadly defined as the collection and concentration of runoff for domestic water supply, productive purposes and livestock in ASARs (Fentaw et al., 2002; Gould, 1999; Stott et al., 2001). Inhabitants of ASARs have endeavoured to increase water availability for domestic use, crop production and livestock grazing using a range of traditional RWH techniques, but methods to quantitatively determine RWH efficiency and replacement strategies are lacking. Moreover, little is known about the quantitative impact of RWH techniques on hydrological processes and their efficiency in storing and conserving water. How RWH techniques and structures will perform under a changed climatological regime, and whether redesigns of RWH systems will be required to adapt to future conditions, are also unknown.

The main objective of this study was to develop a scientifically based and generally applicable methodology to evaluate and optimise the performance of RWH techniques under current and future climatic conditions in ASARs. To achieve this objective, we first compiled an inventory of the main methods and criteria for selecting suitable RWH sites in 
ASARs. A general method for selecting suitable RWH sites in ASARs was identified, and the most common RWH techniques used in ASARs and the main parameters of the design and efficiency of each technique were defined (Chapter 2). Secondly, potential RWH sites in the western desert of Iraq were identified using a suitability model based on a geographic information system (GIS), created with ArcGIS 10.2 Model Builder. The suitability model combined biophysical factors: slope, runoff depth, land use, soil texture and stream order (Chapter 3). Thirdly, a method of assessment was developed to improve the evaluation of the performance of existing RWH techniques in (semi-)arid regions. This methodology integrated engineering, biophysical and socioeconomic criteria using the analytical hierarchy process (AHP) supported by a GIS. Field experiments and interviews with experts were combined with the development of the assessed methodology, which was applied to a case in Tunisia (Chapter 4). Fourthly, a direct approach was developed based on the water balance at a catchment level that could be applied with minimum data for the analysis and optimisation of the performance of RWH systems. This approach yielded a simple but generally applicable water harvesting model (WHCatch) (Chapter 5). Fifthly, the water harvesting model was tested on data from the Oum Zessar watershed in southeastern Tunisia to understand the hydrology at the sub-catchment level for each RWH structure. The output from this model was combined with field measurements and meteorological data to evaluate and optimise the performance of the RWH system under different scenarios of design and management (Chapter 6). Sixthly, parameters of future climate were downscaled and projected at the sub-catchment level, and the water harvesting model was used to assess the performance of RWH techniques in the Oum Zessar watershed for scenarios of climate change (Chapter 7).

The main findings of Chapters 2-7 and their scientific insights and developmental implications are further discussed in the present chapter.

\subsection{Answering the research questions: summary and general discussion}

\section{I) What are the common methodologies and criteria that have been applied to identify the suitable sites of RWH systems in ASARs?}

The success of RWH systems depends heavily on the identification of suitable sites and on RWH technical design (Al-Adamat et al., 2012). Determining the best method or guidelines for site selection, however, is difficult. Field surveys are most commonly used for selecting suitable sites and RWH techniques for small areas. The selection of appropriate sites for the various RWH technologies in larger areas is a great challenge, because the necessary hydrological and soil data are often lacking (Prinz et al., 1998). 
The main methods, criteria and guidelines that have been used for selecting suitable RWH sites in ASARs in the last three decades are presented and compared in Chapter 2. Fortyeight studies were reviewed, and four main groups of methodologies for site selection were categorised and compared. These four groups were diverse, with methodologies ranging from those based only on biophysical (technical) criteria to the more integrated approaches that include socioeconomic criteria, which were applied after 2000. GISs supported by remote sensing have been extensively applied either alone or integrated with a hydrological model and/or an multi criteria analysis (MCA). An MCA integrated with a GIS (group 4) was used to identify RWH sites in ASARs in $37 \%$ of the 48 studies reviewed, which was the highest percentage amongst the four groups.

The 48 studies we reviewed indicated that the selection of sites shifted over time, demonstrated by the three sets of guidelines: IMSD (1995), Oweis (1998) and FAO (2003). The main criteria used by most of the 48 studies followed or were derived from one of these three sets. This study indicated that the FAO (2003) guidelines may therefore be the most comprehensive set of instructions for the efficient planning and implementation of new RWH systems. The FAO guidelines address most of the factors that directly affect the performance of RWH and those directly related to the crop and water requirements. These guidelines cover a wide range of suitabilities for various factors, such as slope, soil texture and rainfall. They also include several socioeconomic criteria, e.g. population density, people's priorities, experience with RWH and land tenure, which are important for ensuring the success of RWH and for increasing the adoption of new RWH technologies by local users.

This study found that slope, soil type and rainfall were the basic technical criteria for most RWH techniques but reached no consensus on the socioeconomic criteria for selecting suitable sites and RWH techniques. The most common biophysical criteria used in ASARs to identify suitable sites for RWH were (as a percentage of all studies reviewed) slope (83\%), soil type and land use (75\%) and rainfall (56\%). The distance to settlements $(25 \%)$, distance to streams/roads (15\%) and cost (8\%) were the most commonly applied socioeconomic criteria. We concluded that insufficient insight into socioeconomics was one of the main reasons why RWH sites failed to function properly in ASARs. Selecting the most relevant socioeconomic criteria therefore requires not only good insight into the local situation and stakeholders involved, but also necessitates access to data on costs and benefits and insight into the indirect economic effects and social parameters, such as labour availability, land and water rights and risks of flooding.

The comparison of the four methodologies was based on the characteristics and requirements of the ASARs, the properties of each method, specific data requirements, 
applicability to different regions, accuracy and limitations and previous studies. Each of the four categorised groups of methodologies has been applied separately in different regions with different criteria, which implies that two or more methods have not been used for the same watershed to identify the main similarities and contrasts. We therefore highly recommend that future studies apply two or more of these four methods in the same region to identify the most applicable method for selecting suitable RWH sites.

Our analysis of strengths and weaknesses indicated that the integration of an MCA and a GIS was the most advanced method for data-poor regions and provided a rational, objective and unbiased method for identifying suitable sites for RWH in different regions and differently sized areas. This methodology simplifies changing or updating criteria. AlAdamat et al. (2010), Isioye et al. (2012) and Moges (2009) reported similar conclusions. The most important limitations of integrating an MCA and a GIS are i) this methodology does not provide a real image of the hydrology of a watershed and ii) the relationship between up- and downstream is lacking. Moreover, the weight (rank) of each criterion in an MCA (AHP) is highly affected by expertise and author performance. Weights should thus be calculated carefully.

GIS-based hydrological modelling is recommended for data-rich regions. Hydrological modelling can fundamentally simulate runoff in any watershed and can provide a good understanding of the relationship between up- and downstream wadis or rivers. This integrated method is also highly flexible in dealing with both qualitative and quantitative factors. The main limitations of this method are i) most of the hydrological models are applicable at catchment scales only and ii) the accuracy of the results is highly dependent on the model complexity, users and data availability. Data availability may be a major problem, especially in ASARs. These models mostly simulate rainfall/runoff and neglect other important criteria such as socioeconomic parameters.

\section{II) What are the potential RWH sites in the wadi Horan watershed in the western desert of Iraq?}

Potential RWH sites in wadi Horan in the western desert of Iraq were identified using a GIS-based suitability model, created with Model Builder in ArcGIS 10.2 (Chapter 3). The suitability model combines biophysical criteria: slope, runoff depth, land use, soil texture and stream order. Various data were used to find the best sites for constructing RWH structures. The slopes of the soil surfaces were extracted from a digital elevation model (DEM) of the area, which had a resolution of $30 \mathrm{~m}$. The runoff model was based on the soil conservation service-curve number (SCS-CN) method (Chow et al., 1988). The main purpose of this method is to estimate direct runoff depth from the rainfall of individual storms. Land cover was obtained from satellite imagery (Landsat 8-2013), also at a spatial resolution of $30 \mathrm{~m}$. A maximum-likelihood algorithm was applied to classify land cover 
using the means, variances and covariances from the signature. The textural class of a soil is determined by the percentages of sand, silt and clay. A map of stream order was created using the ArcGIS 10.2 analytical options. The order of a stream denotes the hierarchical connection amongst stream segments and permits the categorisation of drainage basins by their size. Scaled maps were produced for each criterion, with pixel values ranging from 0 (unsuitable) to 10 (most suitable). Areas suitable for dams were identified by reclassifying layers of biophysical criteria and combining them using the raster calculator tool in the spatial analyst module of ArcGIS 10.2. Each criterion was clipped to the study area, reclassified to numeric values and assigned suitability rankings for dams.

After identifying the areas suitable for dams following the procedure described in the previous paragraph, the most suitable sites for dams were identified by visually interpreting satellite images and analyses of large-scale cartography. The selected sites were then assessed by the other criteria to identify the best sites for RWH structures (dams). A suitable site for a dam is "a place where a wide valley with high walls leads to a narrow canyon with tenacious walls" (Sayl, 2016). Such sites minimise dam dimensions and costs, but steep valley slopes should be given a low priority, because dams at such sites are rarely economical. Valley width is best estimated by visual interpretation elaborated by SRTM in the GIS (Global Mapper 10). The suitability model generated a map for RWH with five suitability classes: very high suitability, high suitability, medium suitability, low suitability and very low suitability.

We identified 39 potential sites that were compatible with the suitable areas identified in the first step based on the visual interpretation of satellite images and an analysis of largescale cartography. Each potential dam site was further analysed by calculating characteristics such as the available storage area and the required length and height of the dam.

The results of this study agreed well with those of Critchley et al. (1991), who did not recommend harvesting water in areas with slopes $\geq 5 \%$, because they are susceptible to high erosion rates due to irregular runoff distribution and because large earthworks are required. The majority of the areas with high to very high suitabilities thus had slopes between 1.5 and $4.5 \%$. In addition, clay and silty clay were the main soil textures in the areas with very high and high suitabilities, which supports the findings of Mbilinyi et al. (2005), who indicated that areas with gentle to moderate slopes and with soils with high water-holding capacities, such as clay and silty clay, were suitable for constructing RWH structures. 
The present study found that ArcGIS was a very useful tool for integrating diverse information to find sites suitable for dams for harvesting rainwater. ArcGIS was a flexible, time-saving and cost-effective tool for screening large areas for their suitability of RWH intervention.

Socioeconomic criteria, however, can also be important for water harvesting. Social and economic factors should be studied in more detail and seriously taken into account. Moreover, fieldwork should be carried out on the selected sites to ensure that they do not conflict with other land uses in the area that are not identified by the available GIS data. The analysis as presented, however, provides a valuable first screening of large areas and can easily be modified to incorporate other criteria or information with different spatial resolutions.

III) What is the most appropriate approach that includes engineering, biophysical and socioeconomic criteria for assessing the performance of RWH designs?

A methodology/tool for evaluation and decision support was developed and tested in Chapter 4 for assessing the overall performance of existing RWH systems and the criteria affecting that performance. A single-objective MCA supported by a GIS was tested in the Oum Zessar watershed in southeastern Tunisia to assess the performance of $58 \mathrm{RWH}$ structures in three main sub-catchments. Engineering (technical), biophysical and socioeconomic criteria were selected, weighted and assessed in this study, with input from experts and stakeholders. The decision to choose and further develop this method was based on the literature review and our recommendations in Chapter 2. The main principle of AHP is to represent the elements of any problem hierarchically to identify the relationships between each level. The highest level is the main goal (objective) for resolving a problem, and the lower levels contain the most important criteria associated with the main objective. The main criteria were chosen to address the following questions. i) How suitable is the local climate for RWH (climate and drainage)? ii) What is the engineering (technical) performance of the RWH intervention (structural design)? iii) How suitable is the location for RWH (site characteristics)? iv) How well does the RWH satisfy the water demand (reliability)? v) How well does the RWH technique suit the socioeconomic context (socioeconomic criteria)?

The different criteria used a variety of measurements and scales, so a scale for comparing criteria was created with five suitability classes, from 1 (very low suitability) to 5 (very high suitability). The results for overall suitability indicated that $65 \%$ of the assessed sites scored near 3, 31\% of the RWH sites had scores near 2 and only $4 \%$, two sites, scored 4 . The low suitabilities for RWH were due to shortcomings in the engineering design, lack of proper maintenance and the high cost of water storage. These results agree with the real 
performance at each site, both overall and at individual criterion levels based on the comparison of our observations and discussions with local users and experts.

The criteria assessments indicated that rainfall had the same score (3) at all sites, because rainfall and its patterns differed little between the three sub-catchments. Rainfall thus did not have a large impact on the overall suitability between sites in our case study but can be very important in comparisons between sites in larger areas with large differences in rainfall. Moreover, the evaluation using our methodology clearly identified the criteria that should be addressed to improve the performance of, for example, RWH structural design and storage capacity. The cost per cubic meter of water, especially in the jessour, was very high due to the small storage area relative to the dyke size. These results indicate that structures for harvesting water with small storage capacities can ultimately be more expensive than large structures, as shown by Lasage and Verburg (2015).

Weights were higher for climatic criteria than for site characteristics (soil texture/depth and slope), 30 and 26\%, respectively, but the site characteristics received the highest scores at most of the sites in all three sub-catchments. The site characteristics thus had a larger impact on the performance of RWH than other criteria such as climate, drainage and structural design. These results are similar to our analysis in Chapter 2 and those in other studies, such as Al-Adamat (2008) and Mbilinyi et al. (2007). Our study also found that socioeconomic factors could play an important role in RWH suitability and performance. The evaluation tool therefore supported our recommendation in Chapter 2 to include socioeconomic factors, because they are very important for obtaining meaningful information for improving current RWH effectiveness and for planning future structures.

A key precondition for the methodology was that it should be widely applicable to different RWH techniques in different regions. The structure of the methodology allows it to be easily adapted and applied to various RWH techniques and socioeconomic settings by simply selecting different criteria. The case study also found that selecting easily assessable criteria but still providing accurate results without the need for complex analysis was not difficult, which keeps the investment of time and money within reasonable limits.

An important consideration in the application of our methodology that should be mentioned is the evaluation of the scores/weighting for each criterion. Scores and weighting depend on expert opinion, so using the advice from experts in different fields of expertise as inputs is essential. 
The methodology should be tested in different regions and with different RWH techniques to further validate its applicability. Moreover, the criteria for socioeconomic suitability/performance (e.g. ownership and education) deserve further investigation. These suggestions will increase the reliability and applicability of our methodology for assessing the performance of existing and newly planned RWH structures in any region.

\section{IV) How can the performance of an RWH system under various scenarios of design and management be evaluated and optimised?}

The effects of RWH can be evaluated by modelling the hydrological characteristics of RWH facilities (Ghisi et al., 2007). A hydrological analysis of facilities for harvesting water is similar to an analysis of long-term rainfall/runoff in a watershed, which generally contains various components of hydrological circulation, such as precipitation, evapotranspiration, infiltration and surface runoff (Kim and Yoo, 2009).

A direct approach was developed in Chapter 5 that was based on the water balance at a catchment level and that could be applied with minimum data for the analysis and optimisation of the performance of RWH systems. This approach yielded a simple but generally applicable water harvesting model (WHCatch) that was tested at the subcatchment level in Chapter 6. WHCatch was developed as a Visual Basic for Applications macro in a Microsoft Excel workbook and can be applied to all calculations and to present the results of the modelling. The performances of RWH systems were thus evaluated and optimised under different scenarios of design and management (Chapter 6).

The change in water storage of 25 sub-catchments in three types of years (dry, normal and wet) was calculated as the difference between total input and output. Two cases were considered. Case 1 assumed no relationship between the water flows of the subcatchments, implying that these sub-catchments were independent units. Case 2 considered the interaction between the sub-catchments for analysing the relationship between up- and downstream sub-catchments. In case 1, about $28 \%$ (wet year) and $8 \%$ (normal year) of the sub-catchments were able to meet the water requirements. Zero values of harvested rainwater for sub-catchments, however, indicated the inability of $\mathrm{RWH}$ to meet the water requirements. This inability was due to shortcomings in the engineering design, lack of proper maintenance, poor site selection and inappropriate type of RWH adoption (Chapter 4). Moreover, the availability of water is extremely low in these areas, because most of the rainwater is lost by evaporation from the soil surface. Water productivity is therefore low. In case 2 , about 44,32 and $16 \%$ of all sub-catchments had sufficient water to meet the water requirements in a wet, normal and dry year, respectively. The estimated runoff volumes were therefore clearly high, so a series of connected reservoirs may be more efficient than several unconnected reservoirs in the area. 
Three scenarios were applied in case 2 to optimise the performance of the RWH structures and to improve the availability of water from the RWH system. Broken structures were first repaired (scenario 1), flow directions were changed (scenario 2), and scenarios 1 and 2 were combined in scenario 3. The WHCatch model was modified to enable changing the directions of stream flow and was applied to analyse the performance of the $25 \mathrm{RWH}$ structures. Scenario 3, changing both the spillway heights and the flow directions, had a large impact on the performance of the RWH systems. Ninety-two percent of all subcatchments supplied sufficient water to meet the requirements when scenario 3 was applied to a wet year, compared to $44 \%$ of the sub-catchments without changes.

The ability to determine the frequency of runoff for each sub-catchment is one of the most important options of WHCatch. WHCatch is therefore a good tool for identifying subcatchments that should have a larger storage capacity and those where changing the storage capacity would have no effect. The performance of RWH structures could consequently improve by adapting the storage capacity and/or cultivation area to be capable of storing the amount of water lost by runoff. The ability of the RWH system to meet the water requirements would then be improved.

WHCatch can show how changing the maximum depth of water (spillway height) in a storage area influences the terms of the water-balance equation for a downstream subcatchment. The storage capacities of some downstream sub-catchments would have to be sufficiently large at these points to hold the upstream water flow. Moreover, the designer of a new RWH structure could use this model to easily estimate the storage capacity required to satisfy the water requirements based on the height of a spillway.

The evaluation results demonstrated the effectiveness of RWH systems and how users could improve the performance of a RWH system by, for example, applying supplemental irrigation to compensate for a deficit in the water requirements. The performance of an RWH system could also be substantially improved by concentrating the rainwater on part of the land. WHCatch results have practical importance, because WHCatch requires little input data, and lower parameterised models are advocated for data-poor regions.

The lack of runoff data for the Oum Zessar watershed, as with most ASARs, was a limitation of this study. We therefore drew our conclusions for model performance from field observations and interviews with local people. The model also needs to be calibrated and tested in different regions and with various RWH techniques to validate its applicability. The impacts of sedimentation on a storage area that could change the storage capacity over time was not considered in this model, because no empirical data were available. The impacts of sedimentation therefore need to be investigated and included in the assessment tool for future studies. These suggestions will increase the model's reliability and further generalise our methodology. 


\section{V) What is the impact of climate change on the performance of RWH systems?}

RWH techniques represent a specific adaptive strategy for coping with water scarcity predicted for future climate change (Kahinda et al., 2010). Climatic variables and scenarios of climate change must be developed on a regional or even site-specific scale to ensure the success and sustainability of RWH techniques to adapt to the impacts of climate change (Wilby and Wigley, 2000). Precipitation and temperature were downscaled in our study from the general circulation models (GCMs) using a statistical downscaling model (SDSM) to estimate the impacts of climate change on RWH at the sub-catchment level (Chapter 7). SDSM is less technically demanding than original modelling, computationally cheaper and able to tailor scenarios for specific localities, scales and problems (Setegn et al., 2011). The main drawback is the assumption that the statistical relationships developed for the present climate also hold under the different forcing conditions of a possible future climate (Abdo et al., 2009). Three climatic scenarios, Representative Concentration Pathway (RCP) 2.6, RCP 4.5 and RCP 8.5, based on 20 ensembles used in this study were analysed for each 30-year period, i.e. 2011-2040, 2041-2070 and 20712100. These pathways are used for modelling climate and describe possible climatic changes, all of which are possible depending on the level of emission of greenhouse gases in the years to come. The data for the baseline period (1981-2010) were compared with predicted future data.

The downscaled maximum and minimum temperatures clearly indicated an increasing trend in the mean monthly temperature for all three scenarios and all future periods. The mean annual maximum temperature increased by $2.33^{\circ} \mathrm{C}$ under RCP 2.6 for 2011-2040 to $8.96{ }^{\circ} \mathrm{C}$ for $2071-2100$ under RCP 8.5. The mean annual minimum temperature also increased in all three scenarios in all periods, by $3.98{ }^{\circ} \mathrm{C}$ for $2011-2040$ under RCP 2.6 to $8.45{ }^{\circ} \mathrm{C}$ for $2071-2100$ under RCP 8.5. The increases in the mean maximum and minimum temperatures in this study were generally slightly higher than those in earlier studies (e.g. $\mathrm{MARH}, 2011$ ) but were comparable to those in earlier studies predicting increasing trends in the $21^{\text {st }}$ century.

Potential evapotranspiration is expected to increase in the future due to the impact of increasing temperatures. Monthly evapotranspiration had a similar pattern in all three scenarios, but increased more for RCP 8.5 than for the other two scenarios. The annual mean potential evapotranspiration is likely to increase by 6\% in RCP 2.6 for 2011-2040 to $21 \%$ in RCP 8.5 for 2071-2100.

Mean annual daily precipitation tended to decrease for the three scenarios in all periods. Decreases varied from $27 \%$ for 2011-2040 under RCP 2.6 to 36\% for 2071-2100 under RCP 8.5. These results are generally consistent with the climatic projections in a Tunisian case 
study, which reported that rainfall would decrease by between $10 \%$ in the north and $30 \%$ in the south in the same periods (MARH, 2011). RCP 2.6 thus projected a smaller increase in the mean annual temperature and a smaller decrease in the mean annual precipitation compared to the other two scenarios. Changes were largest for RCP 8.5 compared to the baseline data.

The projected results for temperature, evapotranspiration and precipitation were used in WHCatch to estimate the future availability of water in each sub-catchment of the Oum Zessar watershed under current climatic conditions and scenarios of future climate change. The amount of water stored in each sub-catchment decreased under the future conditions in all RCPs. About $72 \%$ of the sub-catchments were able to meet the water requirements in the baseline period, whereas only about $30 \%$ of the sub-catchments were able to meet the requirements for all RCP scenarios.

Spillway heights and flow directions were changed to optimise the performance of the RWH structures and to improve the yield (water availability) of the RWH system under the future climatic conditions for achieving the adaptive goal of RWH for the future climatic scenarios. WHCatch was then applied, which indicated that the availability of water would increase in $92 \%$ of all sub-catchments in the baseline period in all three RCP scenarios, compared to $72 \%$ without the changes. The efficiency of water availability would increase almost two-fold in both RCP 2.6 and 4.5 in all periods, compared to the sub-catchments without the changes. Moreover, about $80 \%$ of the sub-catchments in RCP 8.5 for 2011 2040 and 2041-2070 would be able to meet the water requirements, compared to about $50 \%$ without the changes. Water management and structural design at the sub-catchment level therefore play more important roles than climate change in the performance of RWH.

This study demonstrated the feasibility of RWH as an adaptive strategy to mitigate water scarcity and to improve water availability now and under changing climatic conditions. The results could be important for designers, decision-makers and farmers for adapting to the forthcoming climatic conditions and/or for mitigating the adverse impacts of a changing climate on water resources. Further research, however, should include multiple GCMs and downscaling models under CMIP5 and should consider changes in land use/cover in simulation models to improve our understanding of the impact of climate change on water availability. 


\subsection{General conclusions}

A methodology has been developed in this thesis for assessing and optimising the performance of existing RWH systems under current and future climatic conditions. The following are the main conclusions:

- The most suitable method for selecting suitable RWH sites in ASARs is strongly dependent on the main objectives and needs of the project (e.g. flexible, widely applicable, efficient and accurate) and on the quality, availability and reliability of the data. An MCA integrated with a GIS offers the best selection method for datapoor regions. Selection methods using GIS-based hydrological modelling in combination with an MCA is always recommended for data-rich regions.

- A GIS-based approach found that ArcGIS was a very useful tool for integrating various types of information to find suitable sites for dams to harvest the rainwater. ArcGIS was a flexible, time-saving and cost-effective tool for screening large areas for their suitability of RWH intervention. Map quality depended on the quality and accuracy of the data, including how the data were gathered, processed and produced. High-quality data provided the most reliable and efficient output, as expected. The analysis as presented provides a first valuable screening of large areas and can easily be modified to incorporate other criteria or information with other spatial resolutions. Fieldwork at the selected sites is highly recommended to ensure that the identified locations do not conflict with other land uses in the area that the available GIS data did not identify, despite the accuracy of the results.

- A methodology for evaluation and decision support, which was developed and tested for the assessment of the overall performance of existing RWH systems, can be used to pre-evaluate potential new RWH projects, increasing the chances for good long-term performance. Tests of our methodology indicated that it is a highly flexible and applicable tool for the evaluation and improvement of RWH structures and can use many different, important and easily assessed criteria and indicators for assessing different RWH techniques. The time and cost required using this methodology are also low, making it accessible to the local RWH managers/communities.

- A simple but generally applicable water harvesting model (WHCatch) was developed and applied with minimal data to evaluate and optimise the performance of RWH systems under different scenarios of design and management. WHCatch indicated that the combination of changing the flow direction and changing the spillway height had a large impact on the performance of the RWH structures in our study area; $92 \%$ of all sub-catchments supplied sufficient water to fulfil the requirements, compared to $44 \%$ of the sub- 
catchments without the changes. WHCatch offers several options for improving our understanding of the water balance in an entire catchment, such as determining the frequency of runoff for each sub-catchment, illustrating the influence of maximum depth of water (spillway height) in a storage area on the terms of the water-balance equation for a downstream sub-catchment, converting the requested output data to a format readable by GIS applications and generating simulated precipitation to determine the probability of runoff in different sub-catchments.

- The investigation of the impacts of climate change on the performance of RWH systems at a sub-catchment level demonstrated the feasibility of RWH as an adaptive strategy for mitigating water scarcity and improving the availability of water now and under changing climatic conditions. Both the minimum and maximum temperatures tended to increase and precipitation tended to decrease in all scenarios of future emissions of greenhouse gases in most periods (20112040, 2041-2070 and 2071-2100). Computations with WHCatch indicated that the amount of water stored in each sub-catchment would decrease under future conditions for three scenarios (RCPs 2.6, 4.5 and 8.5) in all three periods, especially by the end of this century. Changing the flow directions combined with changing the heights of spillways would provide a sufficient water supply for $92 \%$ of all sub-catchments, compared to $72 \%$ without these changes, for all scenarios of climate change. Water management and structural design at the subcatchment level therefore play a more important role than climate change in the performance of RWH.

\subsection{Implications}

\subsubsection{Scientific contribution}

The results of this study contribute to solving problems of water scarcity and the impacts of climate change, not only in ASARs but also in other climatic zones, by creating accurate images and quality data sets for increasing RWH efficiency. These data sets are based on field data and can be used to i) identify potential sites for RWH, ii) determine the suitability of existing RWH technologies, iii) evaluate and optimise the performance of existing RWH systems and iv) incorporate the impact of climate change on future designs of RWH structures. The identification of a suitable methodology that has been used to select suitable sites of RWH (Chapter 2), a GIS-based approach for identifying potential RWH sites (Chapter 3 ) and a methodology for evaluating the effectiveness of existing RWH 
designs (Chapter 4) provide new tools that can lead to the development of RWH methodologies that better meet future needs.

This study developed a new water harvesting model based on the water balance of subcatchments (Chapter 5), then applied this model to evaluate and optimise the performance of existing RWH systems (Chapter 6). The water harvesting model incorporates most of the hydrological processes relevant to $\mathrm{RWH}$, contributes to our understanding of the water balance feedbacks associated with $\mathrm{RWH}$, and determines the data inputs required. This model is also less complex and requires less data than other water balance models. This model is therefore a good tool for application in regions where little information is available, such as most ASARs. It is also applicable in other regions.

The general innovation of this research lies in the development of a new procedure for incorporating the effects of climate change into the design of RWH systems. The procedure uses a climatic and hydrological model to forecast future potential adaptive strategies for optimising RWH effectiveness in a region (Chapter 7). The performance and efficiency of RWH techniques for using scarce water was analysed and optimised. This study is the first in this region where new scenarios of climate change are applied that are based on CMIP 5 modelling. This study also further highlights local-scale impacts of RWH and the hydrological processes associated with RWH and increases the body of knowledge about RWH and the impact of climate change on RWH. This study will provide a scientifically based tool for studying the impact of climate change on water resources.

The results derived from this research contribute to the current scientific database of the WAHARA project (the European Union's Seventh Framework Programme, FP7/20072013). These results could also be included in the WOCAT database for implementation in other regions with similar characteristics.

\subsubsection{Societal significance}

The demand for water in agricultural and urban development will unavoidably increase as populations continue to grow and as climate changes. These factors, together with the expanding tourism industry, have already intensified the pressure on the limited water resources in ASARs and have thus aggravated water stress in the regions. Poor planning and management of RWH systems have forced people to abandon these sites and migrate to large cities (such as in Iraq and Tunisia in our case study). Most RWH systems are implemented based on local experience and traditional design rather than on objective criteria, thus decreasing water availability. The research presented in this thesis will contribute to addressing this problem by developing a methodology to incorporate 
climate change and socioeconomic impacts in the evaluation and design of regional RWH systems (Chapters 4-7). The methodology will enable the generation of scientifically based recommendations for government for investing in new or existing RWH systems. More effective RWH systems will help reduce the pressure of migration to urban areas by enabling people to better survive in rural areas, which is expected to lead to improved economic and environmental conditions by increasing the effectiveness of water use, agricultural productivity, food security and improved livelihoods.

\subsection{Limitations and recommendations}

Despite the contribution of this research to solving problems of water scarcity and optimising the performance of RWH systems under current and future climatic conditions, a number of challenges need to be addressed to fully understand the hydrological processes at a sub-catchment level and their effects on RWH. The main challenges and recommendations are:

- The lack of data is a major limitation in most ASARs. We developed an assessment methodology and a water harvesting model that require few data, but more data is needed, especially for discharge at the outlets of subcatchments, for calibrating and validating the model.

- The short period of field study was one of the largest limitations of this research. More time should therefore be devoted to future projects on RWH for installing new equipment for measuring rainfall and runoff.

- The output of the model was comparable to more complex models if the data requirements were met. Our model can also continue to be developed to address the cost-benefit questions associated with RWH development.

- The impacts of climate change on RWH were based on a single GCM (CanESM2), one downscaling model (SDSM), and three emission scenarios (RCPs). Applying multiple GCMs is often recommended for studying the hydrological impacts of climate change to enhance the reliability of the results.

- The simulation model used in this study only considered future scenarios of climate change. Other changes, such as changes in land use and land cover, were not taken into account. We therefore recommend that future studies include multiple GCMs and downscaling models under CMIP5 and consider land use/cover changes in simulation models to provide a better understanding of the impacts of climate change on water availability. 


\section{References}

Abdo, K.S., Fiseha, B.M., Rientjes, T.H.M. 2009. Assessment of climate change impacts on the hydrology of Gilgel Abay catchment in Lake Tana basin, Ethiopia. Hydrological Processes, 23, 3661-3669. DOI: 10.1002/hyp.7363.

Abdo, G.M., Eldaw, A.K. 2004. Water harvesting experience in the Arab world, regional workshop on management of aquifer recharge and water harvesting in arid and semiarid regions of Asia, Yazd, Iran, 79-99.

Abdulla, F.A., Amayreh, J.A., Hossain, A.H. 2002. Single event watershed model for simulating runoff hydrograph in desert regions. Water resources management, 16(3), 221-238.

Abouabdillah, A. 2010. Hydrological modeling in a data-poor Mediterranean catchment (Merguellil, Tunisia). Assessing scenarios of land management and climate change. PhD Thesis, Tuscia University Of Viterbo, Italy, 148 pp.

Aboukhaled, A., Arar, A., Balba, A.M., Bishay, B.G., Kadry, L.T., Rijtema, P.E., Taher, A. 1975. Research on crop water use, salt affected soils and drainage in the Arab Republic of Egypt. A review with recommendations, $92 \mathrm{pp}$.

Adamcsek, E. 2008. The analytic hierarchy process and its generalizations. Budapest: Eotvos Lorand University. 43 pp.

Adham, A., Riksen, M., Ouessar, M., Ritsema, C.J. 2016a. A Methodology to assess and evaluate rainwater harvesting techniques in (semi-) arid regions. Water, 8(5), p. 198.

Adham, A., Wesseling, J.G., Riksen, M., Ouessar, M., Ritsema, C.J. 2016b. A water harvesting model for optimising rainwater harvesting in the wadi Oum Zessar watershed, Tunisia. Agricultural Water Management, 176, 191-202. DOI: 10.1016/j.agwat.2016.06.003.

Adham, A., Riksen, M., Ouessar, M., Abed, R., Ritsema, C. (2017). Development of Methodology for Existing Rainwater Harvesting Assessment in (semi-) Arid Regions. In Water and Land Security in Drylands (pp. 171-184). Springer International Publishing.

Adil Al-Khafaji, 2004. Indigenous Water harvesting systems in Iraq. chapter 7 in Oweis, Theib; Ahmed Hachum and Adriana Bruggeman. (eds). 2004. Indigenous water harvesting systems in west Asia and north Africa. ICARDA, Aleppo, Syria, 173 pp.

Ahmad, I. 2013. Investigating of potential water harvesting sites at Potohar using modeling approach. Pak. J. Agri. Sci,50(4), 723-729.

Aksoy, H., Unal, N.E., Cokgor, S., Gedikli, A., Yoon, J., Koca, K., Inci, S.B., Eris, E. 2012. A rainfall simulator for laboratory-scale assessment of rainfall-runoff-sediment transport processes over a two-dimensional flume. Catena 98, 63-72. DOI: 10.1016/j.catena.2012.06.009. 
Al-Adamat, R. 2008. GIS as a decision support system for siting water harvesting ponds in the Basalt Aquifer/NE Jordan. Journal of Environmental Assessment Policy and Management, 10(02), 189-206.

Al-Adamat, R., Al-Ayyash, S., Al-Amoush, H., Al-Meshan, O., Rawajfih, Z., Shdeifat, A., AlHarahsheh, A., Al-Farajat, M. 2012. The combination of indigenous knowledge and geo-informatics for water harvesting sitting in the Jordanian Badia. Journal of Geographic Information System, 4, 366-376. DOI: 10.4236/jgis.2012.44042.

Al-Adamat, R., Diabat, A., Shatnawi, G. 2010. Combining GIS with multicriteria decision making for siting water harvesting ponds in Northern Jordan. Journal of Arid Environments, 74(11), 1471-1477. DOI: 10.1016/j.jaridenv.2010.07.001.

Al-Ansari, N., Abdellatif, M., Ali, S.S., Knutsson, S. 2014. Long term effect of climate change on rainfall in northwest Iraq. Central European Journal of Engineering 4, 1-14. DOI: 10.2478/s13531-013-0151-4.

Al-Ansari, N., Ezz-Aldeen, M., Knutsson, S., Zakaria, S. 2012. Water harvesting and reservoir optimization in selected areas of south Sinjar mountain, Iraq. Journal of Hydrologic Engineering 18(12), 1607-1616.

Al-Daghastani, 2010. Water harvesting search in Ninevah government using remote sensing data. Iraqi Journal of Desert Studies, 2(1), 1-15.

Alhadithi, A.A., Alaraji, A. A. 2015. Rainwater harvesting of Hauran valley, west of Iraq. Iraqi Journal of Science, 57(1B), 465-468.

Al-khateeb, M. 2013. The challenges of water sustainability in Iraq. Engineering and Technology Journal, 31(5), 828-840.

Al-Qinna, M.I., Abu-Awwad, A.M. 1998. Infiltration rate measurements in arid soils with surface crust. Irrigation Science 18, 83-89. DOI: 10.1007/s002710050048.

Al-Shamiri, A., Ziadat, F.M. 2012. Soil-landscape modeling and land suitability evaluation: the case of rainwater harvesting in a dry rangeland environment. International Journal of Applied Earth Observation and Geoinformation, 18, 157-164.

Ammar, A., Riksen, M., Ouessar, M., Ritsema, C.J. 2016. Identification of suitable sites for rainwater harvesting structures in arid and semi-arid regions: A review. International Soil and Water Conservation Research, 4(2), 108-120. DOI: 10.1016/j.iswcr.2016.03.001.

Arnell, N.W. 1992. Factors controlling the effects of climate change on river flow regimes in a humid temperate environment. Journal of Hydrology, 132, 321-342. DOI: 10.1016/0022-1694(92)90184-W.

Arnold, J.G., Williams, J.R., Srinivasan, R., King, K.W. 1996. The soil and water assessment tool (SWAT) User's Manual. Temple, TX.

Arunima, D., Dhinwa, P.S., Rajawat, A.S. 2015. Monitoring implementation of desertification combating plan using geomatics -A case study, districts Dhar and Jhabua, Madhya Pradesh. Journal of Earth System Science, 124, 87-99. 
Bakir, M., Xingnan, Z. 2008. GIS and remote sensing applications for rainwater harvesting in the Syrian desert (Al-Badia). In proceedings of twelfth international water technology conference, IWTC12. Alexandria, Egypt, 73-82.

Bamatraf, M.A. 1994. Water harvesting and conservation systems in Yemen. FAO proceedings of the expert consultation about water harvesting for improved agricultural production, Water Report 3, $67 \mathrm{pp}$.

Bamne, Y., Patil, A., Vikhe, D. 2014. Selection of appropriate sites for structures of water harvesting in a watershed using remote sensing and geographical information system. International Journal of Emerging Technology and Advanced Engineering, 4(11), 270275.

Banai-Kashani, R. 1989. A new method for site suitability analysis: the analytic hierarchy process. Environmental management, 13(6), 685-693.

Barkotulla, M.A., Rahman, M.S., Rahman, M.M. 2009. Characterization and frequency analysis of consecutive days maximum rainfall at Boalia, Rajshahi and Bangladesh. Journal of Development and Agricultural Economics 1, 121-126.

Ben Khlil, K. 1983. Technique de construction des Illeskats du Sahel de Sousse. Centre de Recherche en Genie Rural (CRGR), Tunis, Tunisia.

Ben Mechlia, N., Oweis T., Masmoudi M., Khatteli H., Ouessar M., Sghaier N., Anane M., Sghaier, M. 2009. Assessment of supplemental irrigation and water harvesting potential: methodologies and case studies from Tunisia. ICARDA, Aleppo, Syria. 36 pp.

Ben Mechlia, N., Ouessar, M. 2004. Water harvesting systems in Tunisia. Indigenous water harvesting systems in west Asia and north Africa. International Center for Agricultural Research in the Dry Areas (ICARDA), Aleppo, Syria, 19-41.

Bhakar, S.R., Bansal, A.K., Chhajed, N. 2008. Frequency analysis of consecutive days of maximum rainfall at Udaipur. Journal of the Institution of Engineers (India): Agricultural Engineering Division 89, 14-16.

Biazin, B., Sterk, G., Temesgen, M., Abdulkedir, A., Stroosnijder, L. 2012. Rainwater harvesting and management in rainfed agricultural systems in sub-Saharan Africa--a review. Physics and Chemistry of the Earth, Parts A/B/C, 47, 139-151.

Boers, T.M., Ben-Asher, J. 1982. A review of rainwater harvesting. Agricultural Water Management 5, 145-158. DOI: 10.1016/0378-3774(82)90003-8.

Boers, T.M., Zondervan, K., Ben-Asher, J. 1986. Micro-catchment-water-harvesting (MCWH) for arid zone development. Agricultural Water Management, 12, 21-39. DOI: 10.1016/0378-3774(86)90003-X.

Bosch, van den, S., Hessel, R., Ouessar, M., Zerrim, A., Ritsema, C.J. 2014. Determining the saturated vertical hydraulic conductivity of retention basins in the Oum Zessar watershed, Southern Tunisia. Report/WAHARA , (22).

Bulcock, L.M., Jewitt, G.P.W. 2013. Key physical characteristics used to assess water harvesting suitability. Physics and Chemistry of the Earth, Parts A/B/C, 66, 89-100. 
Chauvin, G.M., Flerchinger, G.N., Link, T.E., Marks, D., Winstral, A.H., Seyfried, M.S. 2011. Long-term water balance and conceptual model of a semi-arid mountainous catchment. Journal of Hydrology, 400(1), 133-143. DOI: 10.1016/j.jhydrol.2011.01.031.

Chiew, F.H.S., Whetton, P.H., McMahon, T., Pittock, B. 1995. Simulation of the impacts of climate change on runoff and soil moisture in Australian catchments. Journal of Hydrology, 167, 121-147. DOI: 10.1016/0022-1694(94)02649-V.

Chow, V.T., Maidment, D.R., Mays, L.W. 1988. Applied hydrology. McGraw-Hill Series in Water Resources and Environmental Engineering . McGraw-Hill: New York. ISBN 0-07010810-2. xiii, 572 pp.

Critchley, W., Siegert, K., Chapman, C. 1991. Water harvesting, a manual guide for the design and construction of water harvesting schemes for plant production. Found at: FAO, Rome www.fao.org/docrep/u3160e/u3160e07.htm.

Dabral, P.P., Pal, M., Singh, R.P. 2009. Probability analysis for one day to seven consecutive days annual maximum rainfall for Doimukh (Itanagar), Arunachal Pradesh. Journal of Indian Water Resources, 2, 9-15.

Dai, A. 2013. Increasing drought under global warming in observations and models. Nature Climate Change, 3, 52-58.

De Pauw, Oweis, T., Youssef, J. 2008. Integrating expert knowledge in GIS to locate biophysical potential for water harvesting: Methodology and a case study for Syria. ICARDA, Aleppo, Syria. 59 pp.

De Winnaar, G., Jewitt, G.P.W, Horan, M. 2007. A GIS-based approach for identifying potential runoff harvesting sites in the Thukela River basin, South Africa. Physics and Chemistry of the Earth, Parts A/B/C, 32(15), 1058-1067.

Dibike, Y.B., Coulibaly, P. 2005. Hydrologic impact of climate change in the Saguenay watershed: Comparison of downscaling methods and hydrologic models. Journal of Hydrology, 307, 145-163. DOI: 10.1016/j.jhydrol.2004.10.012.

Dixon, A.M. 2000. Simulation of domestic water re-use systems: greywater and rainwater in combination. Imperial College London (Doctoral thesis, University of London).

Donohue, R.J., Roderick, M.L., McVicar, T.R. 2006. On the importance of including vegetation dynamics in Budyko's hydrological model. Hydrology and Earth System Sciences Discussions 3, 1517-1551. DOI: 10.5194/hessd-3-1517-2006.

Durbude, D.G. 2008. Estimation of probable maximum precipitation for planning of soil and water conservation structures. Journal of Soil and Water Conservation 7 (3), 3135.

Durbude, D.G., Venkatesh, B. 2004. Site suitability analysis for soil and water conservation structures. Journal of the Indian Society of Remote Sensing, 32, 399-405. DOI: 10.1007/BF03030865. 
Elewa, H.H., Qaddah, A.A., El-Feel, A.A. 2012. Determining potential sites for runoff water harvesting using remote sensing and geographic information systems-based modeling in Sinai. American Journal of Environmental Sciences, 8, 42-55.

FAO, 2003. Land and water digital media series, 26. Training Course on RWH (CDROM). Planning of water harvesting schemes, Unit 22. Food and Agriculture Organization of the United Nations, Rome, FAO.

Fardous, N., Taimeh, A., Jitan, M., Oweis, T., Hachuma, A., Bruggeman, A. 2004. Indigenous water-harvesting systems in Jordan. Indigenous Water-Harvesting Systems in West Asia and North Africa (Book), 42-60.

Fentaw, B., Alamerew, E., Ali, S. 2002. Traditional rainwater harvesting systems for food production: the case of Kobo Wereda, northern Ethiopia. GHARP case study report. Greater Horn of Africa Rainwater Partnership (GHARP), Kenya Rainwater Association, Nairobi, Kenya. 28 pp.

Fewkes, A. 2000. Modelling the performance of rainwater collection systems: towards a generalised approach. Urban water, 1, 323-333.

Fewkes, A. 2004. The modelling and testing of a rainwater catchment system in the UK. (Doctoral thesis, Nottingham Trent University).

Field, C.B., Barros, V.R., Dokken, D.J., Mach, K.J., Mastrandrea, M.D., Bilir, T.E., White, L.L. 2014. IPCC, 2014: Climate change 2014: Impacts, adaptation, and vulnerability. Part A: Global and sectoral aspects. Contribution of working group II to the fifth assessment report of the intergovernmental panel on climate change. Cambridge University Press, Cambridge, United Kingdom and New York, NY, USA, 1132 pp.

Forzieri, G., Gardenti, M., Caparrini, F., Castelli, F. 2008. A methodology for the preselection of suitable sites for surface and underground small dams in arid areas: $A$ case study in the region of Kidal, Mali. Physics and Chemistry of the Earth, Parts A/B/C, 33(1), 74-85.

Fowler, H., Kilsby, C., Stunell, J. 2007. Modelling the impacts of projected future climate change onwater resources in north-west England. Hydrol Earth Syst Sci, 11, 11151126.

Gabos, A., Gasparri, L. 1983. Monthly runoff model for regional planning. Water International, 8, 42-45.

Gebrekristos, S.T. 2015. Understanding catchment processes and hydrological modelling in the Abay/Upper Blue Nile Basin, Ethiopia (Doctoral dissertation, TU Delft, Delft University of Technology), $189 \mathrm{pp}$.

Ghisi, E., Bressan, D.L., Martini, M. 2007. Rainwater tank capacity and potential for potable water savings by using rainwater in the residential sector of southeastern Brazil. Building and Environment, 42(4), 1654-1666.

Ghosh, S., Misra, C. 2010. Assessing hydrological impacts of climate change: Modeling techniques and challenges. The Open Hydrology Journal, 4, 115-121. 
Ghule, S.B., Pawar, S.N., Yadhav, S.B., Ramteke, R.T., Bhuibhar, B.W. 2010. Performance evaluation of nala bund. Karnataka Journal of Agricultural Sciences 19 (1), 90-96.

Gould, J. 1999. Assessment of water supply options contributions relating to rainwater harvesting. Contribution to the World Commission on Dams, Thematic Review IV, 3.

Gowing, J.W., Mahoo, H.F., Mzirai, O.B., Hatibu, N. 2015. Review of rainwater harvesting techniques and evidence for their use in semi-arid Tanzania. Tanzania Journal of Agricultural Sciences 2(2), 171-180.

Gregory, J.H., Dukes, M.D., Miller, G.L., Jones, P.H. 2005. Analysis of double-ring infiltration techniques and development of a simple automatic water delivery system. Applied Turfgrass Science, 2(1), 7 pp. DOI: 10.1094/ATS-2005-0531-01-MG.

Grotch, S.L., MacCracken, M.C. 1991., The use of general circulation models to predict regional climatic change. Journal of Climate, 4, 286-303. DOI: 10.1175/15200442(1991)004<0286:TUOGCM>2.0.CO;2.

Gupta, K.K., Deelstra, J., Sharma, K.D. 1997. Estimation of water harvesting potential for a semiarid area using GIS and remote sensing. IAHS Publications-Series of Proceedings and Reports-Intern Assoc Hydrological Sciences, 242(63), 63 pp.

Hameed, H. 2013. Water harvesting in Erbil Governorate, Kurdistan region, Iraq: detection of suitable sites using geographic information system and remote sensing. MSc. thesis, Lund University, Sweden, 68 pp.

Hassan, Z. Shamsudin, S., Harun, S. 2014. Application of SDSM and LARS-WG for simulating and downscaling of rainfall and temperature. Theoretical and Applied Climatology, 116, 243-257. DOI: 10.1007/s00704-013-0951-8.

HEC-1, Hydrologic Engineering Center 2001 Hydrologic Modeling System, HEC-HMS: Differences Between HEC-HMS and HEC-1; US Army Corps of Engineers, CPD-74B, Mississippi, USA.

Hudson, N. 1987. Soil and water conservation in semi-arid areas (No.57). Food and Agriculture Org, Rome, $172 \mathrm{pp}$.

Ibraimo, N.A. 2011. Rainwater harvesting: Management strategies in semi-arid areas. Doctoral dissertation, University of Pretoria, $265 \mathrm{pp}$.

IMSD, 1995. Integrated Mission for Sustainable Development: Technical Guidelines, NRSA, Hyderabad, India, $127 \mathrm{pp}$.

IPCC, 2014b. Climate change 2014:Impacts, adaptation and vulnerability. Contribution of working group II to the fifth assessment report of the intergovernmental panel on climate change. In: C.B.F., Barros, V.R., Dokken, D.J., Mach, K.J., Mastrandrea, M.D., Bilir, T.E., Chatterjee, M., EBI, K.L., Estrada, Y.O., Genova, R.C., Girma, B., Kissel, E.S., Levy, A.N., Maccracken, S., Mastrandrea, P.R., White, L.L. (eds.). Cambridge, United Kingdom and New York, NY, USA.

IPCC, 2013a., Climate change 2013: the physical science basis. Contribution of working group I to the fifth assessment report of the intergovernmental panel on climate 
change. Tignor, K., Allen, M., Boschung, S.K., Nauels, J., Xia, A., Bex, Y., Midgley, P.M. Cambridge University Press Cambridge, United Kingdom and New York, NY, USA.

Ipcc-Tgic, A. 2007. General guidelines on the use of scenario data for climate impact and adaptation assessment. Version 2. From http://www.ipccdata.org/guidelines/TGICA_guidance_sdciaa_v2_final.pdf.

Isioye, O.A., Shebe, M.W., Momoh, U.O., Bako, C.N. 2012. A Multi criteria decision support system (MDSS) for identifying rainwater harvesting site(s) in Zaria, Kaduna state, Nigeria. International Journal of Advanced Scientific Engineering and Technological Research, 1(1), 53-71.

Jabr, W.M., El-Awar, F.A. 2005. GIS and analytic hierarchy process for siting water harvesting reservoirs, Beirut, Lebanon. Journal of Environmental Engineering, 122 (6), 515-523.

Jackson, R.B., Carpenter, S.R., Dahm, C.N., McKnight, D.M., Naiman, R.J., Postel, S.L., Running, S.W. 2001. Water in a changing world. Ecological applications, 11(4), $1027-$ 1045.

Jasrotia, A.S., Majhi, A., Singh, S. 2009. Water balance approach for rainwater harvesting using remote sensing and GIS techniques, Jammu Himalaya, India. Water Resources Management 23, 3035-3055. DOI: 10.1007/s11269-009-9422-5.

Johnson, K., Renwick, H. 1979. Rain and storm water harvesting for additional water supply in rural areas: Component Review on North America. United Nations Environment Programme, $28 \mathrm{pp}$.

Jothiprakash, V., Sathe, M.V. 2009. Evaluation of rainwater harvesting methods and structures using analytical hierarchy process for a large scale industrial area. Journal of Water Resource and Protection, 1(6), 427-438.

Kadam, A.K., Kale, S.S., Pawar, N.J., Sankhua, R.N., Pawar, N.J. 2012. Identifying potential rainwater harvesting sites of a semi-arid, basaltic region of Western India, Using SCSCN method. Water Resource Management, 26(9), 2537-2554.

Kahinda, J.M., Rockström, J., Taigbenu, A.E., Dimes, J. 2007. Rainwater harvesting to enhance water productivity of rainfed agriculture in the semi-arid Zimbabwe. Phys. Chem. Earth, Parts A/B/C, 32, 1068-1073.

Kahinda, J.M., Taigbenu, A.E., Sejamoholo, B.B.P., Lillie, E.S.B., Boroto, R.J. 2009. A GISbased decision support system for rainwater harvesting (RHADESS). Physics and Chemistry of the Earth, Parts A/B/C, 34(13), 767-775.

Kahinda, J., Taigbenu, A.E., Boroto, R.J. 2010. Domestic rainwater harvesting as an adaptation measure to climate change in South Africa. Physics and Chemistry of the Earth, 35(13-14), 742-751. DOI: 10.1016/j.pce.2010.07.004.

Kahinda, J.M., Lillie, E.S.B., Taigbenu, A.E., Taute, M., Boroto, R.J. 2008. Developing suitability maps for rainwater harvesting in South Africa. Physics and Chemistry of the Earth, Parts A/B/C 33, 788-799. DOI: 10.1016/j.pce.2008.06.047. 
Kamel, A., Ahmed, S. 2010. Determination of water harvesting regions in Iraqi western desert using GIS system. Iraqi Journal of Desert Studies, 2(2), 33-42.

Kamphorst, A., 1987. A small rainfall simulator for the determination of soil erodibility. Netherlands Journal of Agricultural Science, 35, 407-415.

Khan, M.D., Khattak, M. 2012. Sitting of rainwater harvesting locations in District Haripur using geographic information techniques. Journal of Himalayan Earth Sciences, 45(2), p. 82.

Kim, K., Yoo, C. 2009. Hydrological modeling and evaluation of rainwater harvesting facilities: case study on several rainwater harvesting facilities in Korea. Journal of Hydrologic Engineering, 14(6), 545-561.

Kim, Y., Han, M. 2006, September. A Rainfall-Storage-Runoff (RSR) model for the design of a rainwater tank effective for flow control in urban drainage pipes. In Proceedings of the 2nd IWA international rainwater harvesting workshop, $10 \mathrm{pp}$.

Krois, J., Schulte, A. 2014. GIS-based multi-criteria evaluation to identify potential sites for soil and water conservation techniques in the Ronquillo watershed, northern Peru. Applied Geography, 51, 131-142.

Kumar, A., Kaushal, K.K., Singh, R.D. 2007. Prediction of annual maximum daily rainfall of Almora based on probability analysis. Indian Journal of Soil Conservation 35, 82-83.

Kumar, D., Kumar, S. 1989. Rainfall distribution pattern using frequency analysis. J. Agril. Engg. 26, 33-38.

Kumar, M.G., Agarwal, A.K., Bali, R. 2008. Delineation of potential sites for water harvesting structures using remote sensing and GIS. Journal of the Indian Society of Remote Sensing, 36(4), 323-334.

Lasage, R., Verburg, P.H. 2015. Evaluation of small scale water harvesting techniques for semi-arid environments. Journal of Arid Environments, 118, 48-57.

Lebel, S., Fleskens, L., Forster, P.M. 2015. Evaluation of in situ rainwater harvesting as an adaptation strategy to climate change for maize production in rainfed Africa. Water Resources Management 29, 4803-4816. DOI: 10.1007/s11269-015-1091-y.

Lee, C.Y. 2005. Application of rainfall frequency analysis on studying rainfall distribution characteristics of Chia-Nan plain area in Southern Taiwan. Crop, Environment and Bioinformaticsl', 2, 31-38.

Li, X.Y., Shi, P.J., Sun, Y.L., Tang, J., Yang, Z.P. 2006. Influence of various in situ rainwater harvesting methods on soil moisture and growth of Tamarix ramosissima in the semiarid loess region of China. Forest ecology and management, 233, 143-148.

Machiwal, D., Jha, M.K. 2012. Hydrologic time series analysis: theory and practice. Springer Science and Business Media, 316 pp.

Mahmoud, S.H. 2014. Delineation of potential sites for groundwater recharge using a GISbased decision support system. Environmental earth sciences, 72(9), 3429-3442. 
Mahmoud, S.H., Alazba, A.A. 2014. The potential of in situ rainwater harvesting in arid regions: developing a methodology to identify suitable areas using GIS-based decision support system. Arabian Journal of Geosciences, 8(7), 5167-5179.

Makungo, R., Odiyo, J.O. 2011. Determination of steady state infiltration rates for different soil types in selected areas of Thulamela Municipality, South Africa.

Malczewski, J. 2004. GIS-based land-use suitability analysis: a critical overview. Progress in planning, 62(1), 3-65.

MARH, G. 2011. Stratégie nationale d' adaptation de I' agriculture tunisienne et des écosystèmes aux changements climatiques. Ministry of Infrastructure and Environment, Tunisia. 148p.

Mati, B., De Bock, T., Malesu, M., Khaka, E., Oduor, A., Nyabenge, M., Oduor, V. 2006. Mapping the potential of rainwater harvesting technologies in Africa. A GIS overview on development domains for the continent and ten selected countries. Technical Manual, (6), $126 \mathrm{pp}$.

Mbilinyi, B.P., Tumbo, S.D., Mahoo, H., Mkiramwinyi, F.O. 2007. GIS-based decision support system for identifying potential sites for rainwater harvesting. Physics and Chemistry of the Earth, Parts A/B/C, 32(15), 1074-1081.

Mbilinyi, B.P., Tumbo, S.D., Mahoo, H.F., Senkondo, E.M., Hatibu, N. 2005. Indigenous knowledge as decision support tool in rainwater harvesting. Physics and Chemistry of the Earth, Parts A/B/C 30, 792-798. DOI: 10.1016/j.pce.2005.08.022.

Mechlia, N.B., Oweis, T., Masmoudi, M., Khatteli, H., Ouessar, M., Sghaier, N., Anane, M. Sghaier, M. 2009. Assessment of supplemental irrigation and water harvesting potential: Methodologies and case studies from Tunisia. ICARDA, $36 \mathrm{pp}$.

Mekdaschi, S., Liniger, H. 2013. Water Harvesting: Guidelines to Good Practice. Centre for Development and Environment (CDE), Bern; Rainwater Harvesting Implementation Network (RAIN), Amsterdam; MetaMeta, Wageningen; The International Fund for Agricultural Development (IFAD), Rome, $210 \mathrm{pp}$.

Melesse, A.M., Shih, S.F. 2002. Spatially distributed storm runoff depth estimation using Landsat images and GIS. Computers and Electronics in Agriculture, 37(1-3), 173-183.

Min, S.K., Zhang, X., Zwiers, F.W., Hegerl, G.C. 2011. Human contribution to more-intense precipitation extremes. Nature 470, 378-381.

Moges, G. 2009. Identification of potential rainwater harvesting areas in the central Rift Valley of Ethiopia using a GIS based approach (Doctoral dissertation) Wageningen University, the Netherlands, $83 \mathrm{pp}$.

Mohammed, Y. 2009. Climate change impact assessment on soil water availability and crop yield in Anjeni Watershed Blue Nile Basin. 2009. 123f. Thesis (Master of Science in Meteorology)-Arba Minch University, Arba Minch, 140 pp. 
Moss, R.H., Edmonds, J.A., Hibbard, K.A. 2010. The next generation of scenarios for climate change research and assessment. Nature, 463, 747-756. DOI: $10.1038 /$ nature08823.

Mukheibir, P. 2008. Water resources management strategies for adaptation to climateinduced impacts in South Africa. Water Resources Management, 22(9), 1259-1276. DIO: 10.1007/s11269-007-9224-6.

Munyao, J.N. 2010. Use of satellite products to assess water harvesting potential in remote areas of Africa: A case study of Unguja Island, Zanizbar. (Doctoral dissertation, MSc Thesis) Faculty of Geoinformation Science and Earth Observation in Water Resources and Environmental management, ITC, Enschede, The Netherlands, 80 pp.

Myers, L.E. 1975. Water harvesting 2000 B.C. to 1974 A.D. ARS W Agric Res Serv US Dep Agric.

Nasr, M. 1999. Assessing desertification and water harvesting in the Middle East and North Africa: Policy implications. Universitaet Bonn, Zentrum fuer Entwicklungsforschung -ZEF-, Bonn (Germany), 59 pp.

Nasri, M., Soleimani Sardoo, F., Katani, M. 2011. Simulation of the rainfall-runoff process using of HEC-HMS hydrological model (A case study of Sheikh Bahaei dam basin). World Academy of Science, Engineering and Technology, 78, 20 pp.

Ndayakunze, A. 2014. Optimising rainfall utilisation in dryland crop production: A case of shallow-rooted crops. (Doctoral thesis, University of Pretoria), $292 \mathrm{pp}$.

Ouessar, M. 2007. Hydrological impacts of rainwater harvesting in wadi Oum Zessar watershed (Southern Tunisia). (Doctoral thesis, Ghent University, Belgium), 172 pp.

Ouessar, M., Bruggeman, A., Mohtar, R., Ouerchefani, D., Abdelli, F., Boufelgha, M., 2009. Future of drylands - an overview of evaluation and impact assessment tools for water harvesting. In the Future Drylands, 255-267.

Ouessar, M., Sghaier, M., Mahdhi, N., Abdelli, F., De Graaff, J., Chaieb, H., Yahyaoui, H., Gabriels, D. 2004. An integrated approach for impact assessment of water harvesting techniques in dry areas: the case of oued Oum Zessar watershed (Tunisia). Environmental monitoring and assessment, 99, 127-40. DOI: 10.1007/s10661-0044013-7.

Ouessar, M., Zerrim, A., Boufelgha, M., Chniter, M. 2002. Water harvesting in southeastern Tunisia: state of knowledge and challenges. In Water Harvesting in Mediterranean Zones: An Impact Assessment and Economic Evaluation. Proceedings from EU Wahia Project Final Seminar in Lanzarote. The Netherlands, Wageningen University, Tropical Resource Management Papers (40), 13-24.

Ould Cherif Ahmed, A., Nagasawa, R., Hattori, K., Chongo, D., Perveen, M.F. 2007. Analytical hierarchic process in conjunction with GIS for identification of suitable sites for water harvesting in the oasis areas: Case study of the oasis zone of Adrar, northern Mauritania. Journal of Applied Sciences, 7, 2911-2917. 
Oweis, T.Y., Prinz, D., Hachum, A.Y. 2012. Rainwater harvesting for agriculture in the dry areas. CRC press London, UK, $262 \mathrm{pp}$.

Oweis, T., Oberle, A., Prinz, D. 1998. Determination of potential sites and methods for water harvesting in central Syria. Advances in GeoEcology, 31, 83-88.

Oweis, T.Y. 2004. Rainwater harvesting for alleviating water scarcity in the Drier environments of West Asia and North Africa, in: International Workshop on Water Harvesting and Sustainable Agriculture Moscow, Russia. 182 pp.

Padmavathy, A.S., Raj, K.G., Yogarajan, N., Thangavel, P., Chandrasekhar, M.G. 1993. Checkdam site selection using GIS approach. Advances in Space Research, 13(11), 123 127.

Pandey, D.N., Gupta, A.K., Anderson, D.M. 2003. Rainwater harvesting as an adaptation to climate change. Current Science, 85(1), 46-59.

Potter, N.J., Zhang, L. 2009. Interannual variability of catchment water balance in Australia. Journal of Hydrology, 369, 120-129. DOI: 10.1016/j.jhydrol.2009.02.005.

Press, W.H., Flannery, B.P., Teukolsky, S.A., Vetterling, W.T., Chipperfield, J.R. 1987. Numerical recipes: the art of scientific computing, $949 \mathrm{pp}$.

Prinz, D., Singh, A., 2000. Technological potential for improvements of water harvesting. Gutachten für die World Commission on Dams, technical papers, $126 \mathrm{pp}$.

Prinz, D. 1996. Water harvesting-history, techniques, trends. Z. f. Bewaesserungswirtschaft, 31(1), 64-105.

Prinz, D., Oweis, T., Oberle, A. 1998. Rainwater harvesting for dry land agricultureDeveloping a methodology based on remote sensing and GIS. In Proceedings of XIII international congress agricultural engineering, ANAFD, Rabat, Morocco, $12 \mathrm{pp}$.

Pun, S. 2013. A case study on the rainwater harvesting schemes of RWSSP-WN in Kyakmi Vdc, Syangja district and Swargadwari Khal Vdc, Pyuthan district in the context of climate change impacts and community vulnerabilites.

Raes, D., Mallants, D., Song, Z. 1996. RAINBOW: a software package for analysing hydrologic data. Hydraulic Engineering Software VI. Computational Mechanics Publications, Southampton, Boston 525-534.

Rajesh, S. 2015. Potential Impacts of Climate Change on Hydrology of Western Siberian Lowland Catchments. Master's thesis, Erasmus Mundus Master of Science in Ecohydrology, Kiel University, Germany, 135 pp.

Ramakrishnan, D., Bandyopadhyay, A., Kusuma, K.N. 2009. SCS-CN and GIS-based approach for identifying potential water harvesting sites in the Kali Watershed, Mahi River Basin, India. Journal of earth system science, 118(4), 355-368.

Ramakrishnan, D., Durga Rao, K.H.V., Tiwari, K.C. 2008. Delineation of potential sites for water harvesting structures through remote sensing and GIS techniques: a case study of Kali watershed, Gujarat, India. Geocarto International, 23(2), 95-108. 
Rind, D., Goldberg, R., Hansen J. 1990. Potential evapotranspiration and the likelihood of future drought. Journal of Geophysical Research, 95, 9983-10004. DOI: 10.1029/JD095iD07p09983.

Roebuck, R.M., Ashley, R.M. 2007. Predicting the hydraulic and life-cycle cost performance of rainwater harvesting systems using a computer based modelling tool. Water Practice and Technology, 2, 8. DOI: 10.2166/WPT.2007046.

Saaty, T.L. 1990. How to make a decision: the analytic hierarchy process. European journal of operational research, 48(1), 9-26.

Saaty, T.L. 2008. Decision making with the analytic hierarchy process. International journal of services sciences, 1(1), 83-98.

Salas, J.C., König, K.W., Lo, A. 2009. Rainwater harvesting providing adaptation opportunities to climate change. Rainwater Harvesting: A Lifeline for Human Wellbeing. A Report Prepared for UNEP by Stockholm Environment Institute. Stockholm, Sweden: Stockholm Resilience Centre, 56-63.

Salih, S.A., Al-Tarif, A.S.M. 2012. Using of GIS spatial analyses to study the selected location for dam reservoir on wadi Al-Jirnaf, west of Shirqat area, Iraq. Journal of Geographic Information System, 4, 117 pp.

Sayl, K.N. 2016. GIS based for Pre-selection of suitable site for Water Harvesting in arid areas case study in the West of Iraq. ZANCO Journal of Pure and Applied Sciences, 28(2).

Sayl, K.N., Muhammad, N.S., Yaseen, Z.M., El-shafie, A. 2016. Estimation the physical variables of rainwater harvesting system using integrated GIS-based remote sensing approach. Water Resources Management, 30(9), 3299-3313.

Schiettecatte, W., Ouessar, M., Gabriels, D., Tanghe, S., Heirman, S., Abdelli, F. 2005. Impact of water harvesting techniques on soil and water conservation: a case study on a micro catchment in southeastern Tunisia. Journal of Arid Environments, 61, 297313. DOI: 10.1016/j.jaridenv.2004.09.022.

Sekar, I., Randhir, T.O. 2007. Spatial assessment of conjunctive water harvesting potential in watershed systems. Journal of Hydrology, 334(1-2), 39-52. DOI: 10.1016/j.jhydrol.2006.09.024.

Şen, Z., Al-Suba'l, K. 2002. Hydrological considerations for dam siting in arid regions: a Saudi Arabian study. Hydrological Sciences Journal, 47(2), 173-186.

Senay, G.B., Verdin, J.P. 2004. Developing index maps of water-harvest potential in Africa. Applied Engineering in Agriculture, 20(6), 789-799.

Setegn, S.G., Rayner, D., Melesse, A.M., Dargahi, B., Srinivasan, R., Wörman, A. 2011. Climate change impact on agricultural water resources variability in the Northern Highlands of Ethiopia. In Nile River Basin, Springer Science+Business Media B.V, 241265. DOI: 10.1007/978-94-007-0689-7_12. 
Sharma, M.A., Singh, J.B. 2010. Use of probability distribution in rainfall analysis. New York Science Journal 3, 40-49.

Shrestha, S., Anal, A.K., Salam, P.A., der Valk, M. 2015. Managing water resources under climate uncertainty. 438 pp. DOI: 10.1007/987-3-319-10467-6.

Stott, D.E., Mohtar, R.H., Steinhardt, G.C. 2001. Water conservation, harvesting and management (WCHM)-Kenyan experience. Sustaining the Global Farm, 1139-1143.

Tadesse, N., Tadios, S., Tesfaye, M. 2010a. The Water balance of May Nugus catchment, Tigray, northern Ethiopia. Agricultural Engineering XII, 1-29.

Tadesse, N., Tadios, S., Tesfaye, M. 2010b. The water balance of may nugus catchment, Tigray, Northern Ethiopia. International Journal of Earth Sciences and Engineering 3, 609-625.

Taylor, K.E., Stouffer, R.J., Meehl, G.A. 2012. An overview of CMIP5 and the experiment design. Bulletin of the American Meteorological Society 93, 485-498. DOI: 10.1175/BAMS-D-11-00094.1.

Tekleab, S., Uhlenbrook, S., Mohamed, Y., Savenije, H.H.G., Temesgen, M., Wenninger, J. 2011. Water balance modeling of Upper Blue Nile catchments using a top-down approach. Hydrology and Earth System Sciences, 15, 2179-2193. DOI: 10.5194/hess15-2179-2011.

Thomson, A.M., Calvin, K.V., Smith, S.J., Kyle, G.P., Volke, A., Patel, P., Delgado-Arias, S., Bond-Lamberty, B., Wise, M.A., Clarke, L.E. Edmonds, J.A. 2011. RCP4.5: A pathway for stabilization of radiative forcing by 2100. Climatic Change, 109 (1), 77-94. DOI: 10.1007/s10584-011-0151-4.

Thornthwaite, C.W. 1948. An approach toward a rational classification of climate. Geographical review, 38(1), 55-94.

Tsiko, R.G., Haile, T.S. 2011. Integrating geographical information systems, Fuzzy logic and analytical hierarchy process in modelling optimum sites for locating water reservoirs. A case study of the Debub district in Eritrea. Water, 3(1), 254-290.

Tumbo, S.D., Mbilinyi, B.P., Mahoo, H.F., Mkilamwinyi, F.O. 2014. Identification of suitable indices for identification of potential sites for rainwater harvesting. Tanzania Journal of Agricultural Sciences, 12(2), 35-46.

Tumbo, S.D., Mbilinyi, B.P., Mahoo, H.F., Mkiramwinyi, F.O. 2006. Determination of suitability levels for important factors for identification of potential sites for rainwater harvesting. In proceeding of the 7th WaterNet-WARFSA-GWP-SA symposium, Lilongwe, Malawi, 1-3.

Uhlenbrook, S., Didszun, J., Wenninger, J. 2008. Source areas and mixing of runoff components at the hillslope scale-a multi-technical approach. Hydrological Sciences Journal, 53, 741-753. DOI: 10.1623/hysj.53.4.741. 
United Nations, Department of Economic and Social Affairs, Population Division 2015. World Population Prospects: The 2015 Revision, Key Findings and Advance Tables. Working Paper No. ESA/P/WP.241. 66 pp.

Vaes, G., Berlamont, J.M. 2001. The effect of rainwater storage tanks on design storms. Urban Water 3, 303-307.

Van Vuuren, D.P., Edmonds, J.A., Kainuma, M., Riahi, K., Weyant, J. 2011. A special issue on the RCPs. Climatic Change, 109, 1-4. DOI: 10.1007/s10584-011-0157-y.

Wainwright, J. 2002. The effect of temporal variations in rainfall on scale dependency in runoff coefficients. Water Resources Research, 38 (12). DOI: 10.1029/2000WR000188.

Ward, S., Memon, F.A., Butler, D. 2010. Rainwater harvesting: model-based design evaluation. Water Science and Technology, 61(1), 85-96.

Warrach, K., Stieglitz, M., Mengelkamp, H.T., Raschke, E. 2002. Advantages of a topographically controlled runoff simulation in a soil-vegetation-atmosphere transfer model. Journal of Hydrometeorology, 3(2), 131-148.

Weerasinghe, H., Schneider, U.A., Löw, A. 2011. Water harvest-and storage-location assessment model using GIS and remote sensing. Hydrology and Earth System Sciences Discussions, 8(2), 3353-3381.

Wilby, R.L., Wigley, T.M.L. 2000. Precipitation predictors for downscaling: observed and general circulation model relationships. International Journal of Climatology, 20(6), 641-661.

Wilby, R.L., Dawson, C.W., Barrow, E.M. 2002. SDSM-a decision support tool for the assessment of regional climate change impacts. Environmental Modelling and Software, 17(2), 145-157.

Woolhiser, D.A., Smith, R.E., Goodrich, D.C. 1990 KINEROS: a kinematic runoff and erosion model: documentation and user manual. US Department of Agriculture, Agricultural Research Service, $38 \mathrm{pp}$.

$\mathrm{Xu}, \mathrm{C} .1999$. Climate change and hydrologic models: A review of existing gaps and recent research developments. Water Resources Management, 13, 369-382. DOI: 10.1023/A:1008190900459.

Xu, C.Y., Singh, V.P. 2001. Evaluation and generalization of temperature based methods for calculating evaporation. Hydrological processes, 15(2), 305-319. DOI: 10.1002/hyp.119.

Xu, C.Y., Vandewiele, G.L. 1992. Reliability of calibration of a conceptual water balance model: the humid case, in: The 9 Th International Conference on Computational Methods in Water Resources, Denver, CO, USA, 06/92. 773-780.

Yang, D., Shao, W., Yeh, P.J.F., Yang, H., Kanae, S., Oki, T. 2009. Impact of vegetation coverage on regional water balance in the nonhumid regions of China. Water Resources Research, 45, W00A14. DOI: 10.1029/2008WR006948. 
Yang, D., Sun, F., Liu, Z., Cong, Z., Ni, G., Lei, Z. 2007. Analyzing spatial and temporal variability of annual water-energy balance in nonhumid regions of China using the Budyko hypothesis. Water Resources Research, 43(4), 12 pp. DOI:10.1029/2006WR005224.

Ying, X., Zeng, G.M., Chen, G.Q., Tang, L., Wang, K.L., Huang, D.Y. 2007. Combining AHP with GIS in synthetic evaluation of eco-environment quality-A case study of Hunan Province, China. Ecol. Modell. 209, 97-109.

Yusof, K.W., Serwan, M., Baban, J. 2000. Identifying optimum sites for locating reservoirs employing remotely sensed data and geographical information systems. In Proceedings of the 21st Asian conference on remote sensing, 1, 35-40.

Zhang, L., Hickel, K., Shao, Q. 2005. Water balance modelling over variable time scales. Modsim 2005: International Congress on Modelling and Simulation: Advances and Applications for Management and Decision Making, 2988-2994.

Zhang, Z., Chen, X., Huang, Y., Zhang, Y. 2014. Effect of catchment properties on runoff coefficient in a karst area of southwest China. Hydrological Processes, 28, 3691-3702. DOI: 10.1002/hyp.9920.

Ziadat, F., Bruggeman, A., Oweis, T., Haddad, N., Mazahreh, S., Sartawi, W., Syuof, M. 2012. A Participatory GIS approach for assessing land suitability for rainwater harvesting in an arid rangeland environment. Arid Land Research and Management, 26(4), 297-311. DOI: 10.1080/15324982.2012.709214.

Ziadat, F., Oweis, T., Mazahreh, S., Bruggeman, A., Haddad, N., Karablieh, E., Benli, B., Zanat, M.A., Al-Bakri, J., Ali, A. 2006. Selection and characterization of badia watershed research sites. Int. Cent. Agric. Res. Dry Areas (ICARDA), Aleppo, Syria. 111 pp. 


\section{English summary}

Rainwater harvesting (RWH) is an ancient traditional technology practiced in many parts of the world, especially in arid and semi-arid regions (ASARs). ASARs represent $40 \%$ of the earth's land surface and are characterised by low average annual rainfall and uneven temporal and spatial distributions of that rainfall. These climatic characteristics indicate that using the limited amount of rainfall available as efficiently as possible is important. One method for doing this is to collect and use surface runoff (water harvesting). The inhabitants of ASARs have developed several RWH techniques for increasing the availability of water and thereby coping with water shortages. Over the past century, access to water for agriculture and domestic use has become worse because of increasing population, higher levels of human activity and the impacts of climate change. Climate change is a very serious problem and has become a major global issue, especially in developing countries which are severely affected by its impacts. RWH is seen as an important mitigation strategy to the impact of climate change on water availability in ASARs. A robust methodology is therefore needed to assess the potential for rainwater harvesting and identify areas that are suitable for these techniques. Also further knowledge regarding the impact of climate change on the functioning of RWH in the future is needed to assess their ability to meet future water requirements.

A general overview of the history of RWH techniques, a review of the literature concerning these techniques and brief descriptions of the available models are presented in Chapter 1 . The motivation for using the results of general circulation models (GCM) in the design of RWH structures is also given.

An inventory of the main methods and criteria developed in ASARs during the last three decades and a general method for selecting suitable RWH sites in ASARs are presented in Chapter 2. Four main methodologies of site selection were categorised based on 48 studies published in scientific journals, reports of international organisations, or sources of information obtained from practitioners. The most suitable method for application in a particular case was highly dependent on the main objectives and needs of the project (e.g. flexible, widely applicable, efficient and accurate) and on the quality, availability and reliability of the data. The methods were diverse, ranging from those based only on biophysical criteria to more integrated approaches that include socioeconomic criteria, especially after 2000. Three main sets of criteria for selecting RWH locations were 
identified, and the main characteristics of the most common RWH techniques used in ASARs are presented. This study identified slope, land use/cover, soil type, rainfall, distance to settlements/streams and cost as the most important biophysical and socioeconomic criteria for the selection of suitable sites for RWH in ASARs. The most common techniques developed and used in ASARs were also identified: ponds, check dams, terracing, percolation tanks and nala bunds.

Our analysis of the strengths and weaknesses of RWH assessment methodologies suggests that the integration of multi-criteria analysis (MCA) with a geographic information system (GIS) is the most advanced approach and provides a rational, objective and unbiased method for identifying suitable sites for RWH. MCA integrated with GIS offers high potential in data-poor regions; GIS-based hydrological modelling is always recommended for data-rich regions.

The research project started with a case study on the potential for RWH in Iraq (Chapter 3). For safety reasons, the method for selection of suitable RWH locations was restricted to factors for which GIS data were available. Potential RWH sites in wadi Horan, located in the western desert of Iraq, were identified using a GIS-based suitability model. The suitability model combined different biophysical criteria: slope, runoff depth, land use, soil texture and stream order. Areas suitable for dams were identified by reclassifying these layers and combining them using the raster calculator tool in the spatial analyst module of ArcGIS 10.2. Each criterion was clipped to the study area, reclassified to numeric values and assigned suitability rankings for dams. The selected sites were then assessed by the other criteria to identify the best sites for RWH structures (dams). A suitable site for a dam is a place where a wide valley with high walls leads to a narrow canyon with tenacious walls. Such sites minimise dam dimensions and costs, but steep valley slopes should be given a low priority, because dams at such sites are rarely economical. 39 potential sites were identified based on the visual interpretation of satellite images and an analysis of large-scale cartography. Each potential dam site was further analysed by calculating characteristics such as the available storage area and the required length and height of the dam.

The present study found that ArcGIS was a very useful tool for integrating diverse information to find suitable sites for RWH. ArcGIS is a flexible, time-saving and costeffective tool for screening large areas for their suitability to be used for RWH intervention. Fieldwork should be carried out on the selected sites to ensure that they do not conflict with other land uses in the area that are not identified with the available GIS data. The analysis as presented, however, provides a valuable first screening of large areas 
and can be easily modified to incorporate other criteria or information with different spatial resolutions.

The method for selecting suitable sites for RWH was then further developed into an evaluation and decision support tool (Chapter 4 ) for assessing the overall performance of existing RWH techniques and the criteria affecting that performance in ASARs. The support tool developed is robust, inexpensive, simple to apply, reliable and easily adaptable to a variety of criteria, RWH techniques and regions. Based on our suggestions in Chapter 2, this methodology integrates engineering, biophysical and socioeconomic criteria using MCA supported by GIS. A comparable scale between criteria was identified before applying the MCA tools due to the variety of measurements and scales for the criteria. The selected criteria were re-classified into five suitability classes, from 1 (very low suitability) to 5 (very high suitability), for assigning scores to the criteria based on discussion and consultation with experienced people and published information.

This methodology was tested in the wadi Oum Zessar in southeastern Tunisia by evaluating $58 \mathrm{RWH}$ locations in three main sub-catchments of the watershed. Based on the criteria selected, $65 \%$ of the assessed sites scored near 3 (medium suitability), 31\% scored near 2 (low suitability) and only 4\%, two sites, scored 4 (high suitability). This study indicated that RWH with low suitability was associated with poor engineering design, lack of proper maintenance and the high cost of water storage. The criteria assessments indicated that rainfall had no substantial impact on the overall suitability between sites in our case study but could be very important for comparisons between sites in larger areas with large differences in rainfall. Our study also found that socioeconomics played an important role in RWH performance and was a very important criterion for improving current RWH effectiveness and planning future structures. Our methodology clearly identified the criteria that should be addressed to improve the performance of, for example, RWH structural design and storage capacity.

Based upon the comparison between our observations and the views of local people and experts, our results effectively represented the real performance of each site-both at an overall level and at the level of individual criteria. This confirms that the methodology developed in this project is a good way to assess the performance of RWH structures.

To further investigate and optimise the performance of the RWH systems described in Chapter 4 under various scenarios of design and management, a simple but generally applicable water harvesting model (WHCatch) was developed and is presented in Chapter 5. The model is based on the water balance at a catchment level and can be applied with minimum data. WHCatch was developed as a Visual Basic for Applications 
macro in a Microsoft Excel workbook and can be used to make all necessary calculations as well as to present the results of the modelling.

Using WHCatch the performance of RWH systems in wadi Oum Zessar were evaluated and optimised under different scenarios of design and management (Chapter 6). The changes in the water storage of 25 sub-catchments in three types of years (dry, normal and wet) were calculated from the water balances of the sub-catchments. Two cases were considered for the scenarios. In case 1 , no relationship between the water flow of the subcatchments was assumed. In case 2 , interaction between the sub-catchments was considered. In case 1 , about $28 \%$ (wet year) and $8 \%$ (normal year) of the sub-catchments were able to meet the water requirements. The complete absence of harvested rainwater (zero) for some sub-catchments, however, indicated the inability of RWH to meet the water requirements due to shortcomings in the engineering design, lack of proper maintenance, site selection, or type of RWH adopted, as shown in Chapter 4 . In case 2, about 44,32 and $16 \%$ of all sub-catchments had sufficient water to meet the water requirements in a wet, normal and dry year, respectively. The estimated runoff volumes in case 2 were clearly higher compared to case 1 , indicating that a series of connected reservoirs can be more efficient than several unconnected reservoirs in the area.

With this information three management scenarios were applied under case 2 conditions to improve the performance of the RWH system and water availability. Broken structures were repaired in management scenario 1, flow directions were changed in scenario 2 and scenarios 1 and 2 were combined in scenario 3. Scenario 3 , changing the spillway heights together with the flow directions, had a large impact on the performance of the RWH structures: $92 \%$ of all sub-catchments supplied sufficient water, compared to just $44 \%$ of the sub-catchments before the changes. This study emphasises the advantages of simulating long-term water balances at the sub-catchment level for improving our understanding of hydrological processes in a RWH system, and provides several solutions for optimising RWH performance in various scenarios.

The impact of climate change on existing RWH systems in the Oum Zessar watershed under current and future scenarios of climate was also investigated (Chapter 7). Potential adaptive strategies for optimising RWH effectiveness were estimated based on the predicted climate change. To estimate the impact of climate change on the RWH at the sub-catchment level, precipitation and temperature data were downscaled from general circulation models using a statistical downscaling model (SDSM). Three climatic scenarios, representative concentration pathway (RCP) 2.6, RCP 4.5 and RCP 8.5, were analysed for each 30-year period, i.e. 2011-2040, 2041-2070 and 2071-2100. The downscaled maximum and minimum temperatures clearly indicated an increasing trend in the mean 
monthly temperature for all three scenarios and all future periods. The generated precipitation tended to decrease the mean annual daily precipitation for the three scenarios in all periods.

The application of WHCatch demonstrated that water availability in each sub-catchment would decrease under future conditions for all three scenarios (RCPs 2.6, 4.5 and 8.5) and periods, especially at the end of this century. It also indicated that while about $72 \%$ of the sub-catchments were able to meet the water requirements of the baseline period, only about $30 \%$ would be able to meet the water requirements under any of the future RCP climate scenarios. Here too, the combination of changing both flow direction and the spillway height had a large impact on the performance of the RWH systems. With these changes, the sub-catchments able to meet the baseline water requirements increased to $92 \%$ and those able to meet the water requirements in future scenarios increased to $50 \%$. Water management and structural design at the sub-catchment level therefore played a more important role than climate change in the performance of RWH.

Chapter 8 presents a synthesis of the major findings of this study and the possible contributions to the scientific efforts for improving the performance of RWH designs under current and future climatic conditions. The implications and recommendations of this study are also presented. 


\section{Nederlandse samenvatting}

Het opvangen van regenwater (engels: rainwater harvesting, RHW) is een traditionele technologie die in grote delen van de wereld wordt toegepast, vooral in aride en semiaride gebieden (ASARs). ASARs beslaan 40\% van het aardoppervlak en worden gekarakteriseerd door een kleine hoeveelheid jaarlijkse neerslag en een ongelijke temporele en ruimtelijke verdeling daarvan. Deze klimaateigenschappen geven al aan hoe belangrijk het is om de beperkte hoeveelheid neerslag die valt zo efficient mogelijk te gebruiken. Een van de methoden hiervoor is om het regenwater dat oppervlakkig afstroomt op te vangen en te gebruiken ('water harvesting'). De inwoners van ASARs hebben dan ook verschillende RWH technieken ontwikkeld om de beschikbaarheid van water te vergroten en daarmee de tekorten tegen te gaan. In de voorbije eeuw is de beschikbaarheid van water voor landbouw en huishoudelijk gebruik sterk afgenomen door de groei van de bevolking, toegenomen aktiviteiten en de gevolgen van klimaatsverandering. Dit laatste is een zeer ernstig probleem en is uitgegroeid tot een wereldwijde kwestie gedurerende de laatste jaren, vooral in ontwikkelingslanden die ernstig bedreigd worden door de gevolgen ervan. RWH wordt gezien als een methode om de gevolgen van klimaatsverandering voor de beschikbaarheid van water in ASARs te beperken. Daarom is het nodig om een robuuste methode te ontwikkelen om de potentiele mogelijkheden van RWH te onderkennen en om de gebieden te identificeren die geschikt zijn voor deze technieken. Ook is meer kennis vereist over de effekten van klimaatsverandering op het fuctioneren van RWH systemen in de toekomst om op deze manier te beoordelen of zij geschikt zijn om aan de te verwachten vraag naar water te voldoen.

Een algemene beschrijving van de geschiedenis van RWH technieken, een overzicht van de literatuur betreffende deze technieken en korte beschrijvingen van de beschikbare modellen worden gegeven in Hoofdstuk 1. De motivatie om globale circulatie modellen te gebruiken bij het ontwerpen van RWH constructies kan hier ook worden gevonden.

Een inventarisatie van de voornaamste methodes en criteria die gedurende de voorbije drie decades in ASARs zijn ontwikkeld wordt gegeven in Hoofdstuk 2, samen met een algemene methode voor het selecteren van geschikte RWH lokaties in ASARs. De vier voornaamste methodologieen voor het kiezen van geschikte lokaties zijn gecategoriseerd. De basis hiervoor bestond uit 48 onderzoeken die zijn gepubliceerd in wetenschappelijke 
tijdschriften, rapporten van internationale organisaties of informatiebronnen uit de praktijk. Welke methode in een bepaald geval het beste toepasbaar is hangt sterk af van de doelen en behoeften van het uit te voeren project (b.v. flexibel, breed inzetbaar, efficient of nauwkeurig) en van de beschikbaarheid, kwaliteit en betrouwbaarheid van de benodigde gegevens. De methodes waren geheel verschillend, varierend van methodes die alleen gebaseerd zijn op bio-fysische criteria tot de meer geintegreerde benaderingen die ook sociaal-economische criteria beschouwen. Deze laatste zijn vooral na 2000 toegepast. Drie hoofdgroepen met criteria voor het kiezen van RWH locaties konden worden onderscheiden en de voornaamste eigenschappen van de meestgebruikte RWH technieken in ASARs worden beschreven. Dit onderzoek toont aan dat helling, landgebruik, bodemtype, neerslag, afstand tot nederzetting en kosten de belangrijkste bio-fysische en sociaal-economische criteria zijn voor het kiezen van een geschikte RWHlokatie. De meest voorkomende technieken die in ASARs zijn ontwikkeld en gebruikt zijn: waterreservoirs, strekdammen, terrasvorming, percolatietanks en nala bunds.

Onze analyse van sterke en zwakke punten van de verschillende bepalingsmethoden van geschikte RWH locaties toont aan dat de integratie van muli-criteria analyse (MCA) met een geografisch informatie systeem (GIS) de meest geavanceerde methode is. Het biedt een rationele, objectieve en zuivere methode voor het bepalen van geschikte RWH locaties. De combinatie van MCA en GIS is potentieel heel aantrekkelijk in gebieden met weinig beschikbare gegevens. Op GIS gebaseerd hydrologisch modelleren is altijd aan te bevelen voor gebieden waarvan veel gegevens beschikbaar zijn.

Het veldonderzoek begon met een case-study naar de potentiele geschikheid van lokaties voor RWH in Iraq (Hoofdstuk 3). Om veiligheidsredenen bleef de methode voor het kiezen van geschikte lokaties beperkt tot die methodes die alleen gegevens gebruikten waarvan GIS bestanden aanwezig waren. Potentiele RWH locaties in de wadi Horan, gelegen in de westelijke woestijn van Iraq, werden bepaald met behulp van een op GIS gebaseerd geschikheidsmodel. Het geschiktheidsmodel combineerde meerdere bio-physische criteria: helling, oppervlakkige afvoer, landgebruik, bodemtextuur en stromingsgegevens. Locaties die geschikt zijn om een dam te bouwen zijn bepaald door deze waarden te klassificeren en vervolgens te combineren met behulp van de raster calculator tool in de spatial analyst module van ArcGIS 10.2. De gegevens van elk criterium werden beperkt tot het studiegebied en opnieuw geklassificeerd tot numerieke waarden. Vervolgens zijn er geschiktheidsgraden voor dambouw aan toegekend. Hieruit zijn de meest geschikte locaties voor RWH constructies (dammen) gehaald. Een geschikte plek voor een dam is een plaats waar een brede vallei met hoge wanden overgaat in een nauwe kloof met steile wanden. Zulke locaties minimaliseren de afmetingen en kosten van dammen. Gebieden met steile hellingen in de vallei moeten een lage geschiktheid krijgen want dammen op 
zulke plaatsen zijn zelden economisch aantrekkelijk. Met behulp van visuele interpretatie van satellietbeelden en een analyse van een kartografie op grote schaal zijn 39 potentieel geschikte locaties geselecteerd. Elke potentiele lokatie is verder geanalyseerd aan de hand van berekenende eigenschappen zoals het beschikbare bergingsoppervlak en de vereiste lengte en hoogte van de dam.

De huidige studie toont aan dat ArcGIS een goed bruikbaar hulpmiddel is bij het integreren van verschillende soorten informatie om geschikte locaties voor dammen te vinden voor RWH. ArcGIS is een flexibel, tijdbesparend en kosten-effectief hulpmiddel om de geschiktheid van grote gebieden te bepalen voor RWH. Op de gekozen locaties moet nog wel veldwerk worden gedaan om er zeker van te zijn dat er geen conflicten met ander landgebruik ontstaan die niet met behulp van de beschikbare GIS-gegevens konden worden gevonden. De hier gepresenteerde analysemethode biedt een waardevolle eerste schifting van grote gebieden en kan gemakkelijk worden aangepast voor andere criteria of informatie die op verschillende schalen aanwezig is.

Vervolgens is de methode voor het kiezen van geschikte RWH lokaties verder ontwikkeld tot een evaluatie- en beslis gereedschap dat is bedoeld om de algehele werking van bestaande RWH-technieken in te kunnen schatten en de criteria die deze werking bepalen in ASARs (Hoofdstuk 4). Het is een robuust, goedkoop, eenvoudig toepasbaar en betrouwbaar stuk gereedschap dat gemakkelijk is aan te passen voor een grote hoeveelheid criteria, RWH-technieken en gebieden. Zoals aanbevolen in Hoofdstuk 2 worden technische, bio-fysische en sociaal-economische criteria gecombineerd met MCA dat wordt ondersteund door GIS. Vanwege de grote verscheidenheid aan metingen van criteria en schalen waarop deze zijn toegepast, is eerst een vergelijkbare schaal ontwikkeld voor de criteria. Voor ieder gebied is een geschiktheidsklasse ontwikkeld voor ieder criterium. ledere klasse heeft een nummer, varierend van 1 (zeer lage geschiktheid) tot 5 (zeer grote geschiktheid) gebaseerd op gesprekken met ervaringsdeskundigen en op basis van gepubliceerde gegevens.

De ontwikkelde methode is getest voor de wadi Oum Zessar in zuid-oost Tunesie door 58 $\mathrm{RWH}$ locaties te onderzoeken in de drie grootste deelgebieden van het stroomgebied. Gebaseerd op de gekozen criteria, scoorde $65 \%$ van de locaties een 3 (gemiddelde geschikheid), 31\% scoorde een 2 (lage geschiktheid) en slechts $4 \%$ ( 2 locaties) scoorde een 4 (grote geschiktheid). Deze studie toont aan dat de lage geschiktheid voornamelijk te danken was aan een slecht technisch ontwerp, gebrek aan onderhoud en de hoge kosten van waterberging. Uit verdere analyse bleek dat de neerslag geen substantiele invloed had op de geschiktheid van sites in ons studiegebied maar van groot belang kan zijn als locaties worden vergeleken in een groter gebied met ruimtelijke variatie in de neerslag. 
Ook bleek dat sociaal-economische aspecten een grote rol spelen bij de goede werking van RWH. Dit was dan ook een belangrijk criterium bij het verbeteren van de doeltreffendheid van de huidige RWH constructies en bij het plannen van toekomstige locaties. Toepassen van de door ons ontwikkelde methode gaf een duidelijk beeld van die criteria die moeten worden aangepakt voor het verkrijgen van bijvoorbeeld een verbeterde werking van ontwerpen van RHW constructies of een vergrootte waterbergingscapaciteit.

De aldus verkregen resultaten gaven een goed beeld van de werking van het RWHsyateem op iedere locatie, zowel als geheel als op het niveau van de individuele criteria. Dit kan worden gezien als een bevestiging dat het toepassen van de in dit project ontwikkelde methode een goede manier is om inzichteliijk te maken hoe goed de werking van $\mathrm{RWH}$-constructies is.

Om de werking van de in Hoofdstuk 4 beschreven RWH systemen verder te onderzoeken en te optimaliseren voor verschillende vormen van ontwerp en beheer is een eenvoudig maar algemeen toepasbaar RWH model (WHCatch) ontwikkeld dat is gebaseerd op de waterbalans van een deelgebied en dat met een minimum aan gegevens kan worden toegepast (Hoofdstuk 5). WHCatch is ontwikkeld als een Visual Basic for Applications macro in een Microsoft Excel werkboek dat kan worden gebruikt voor alle berekeningen en om de uitkomsten mee te visualiseren.

Op deze wijze is in Hoofdstuk 6 de werking van RWH systemen in de wadi Oum Zessar geevalueerd en geoptimaliseerd. Hiertoe zijn een aantal scenario's doorgerekend waarna de verandering van de waterberging van 25 deelgebieden is bepaald voor drie soorten jaren: droog, normaal en nat. Er zijn twee gevallen onderscheiden. In geval 1 is aangenomen dat er geen water van het ene deelgebied naar het andere stroomt. In geval 2 is de interaktie tussen de deelgebieden meegenomen. In geval 1 kon ongeveer $25 \%$ en $8 \%$ (resp. voor een nat jaar en een droog jaar) van de deelgebieden aan de waterbehoefte voldoen. Er waren ook subgebieden waar geen water werd opgeslagen, hetgeen was veroorzaakt door tekortkomingen in het ontwerp, slecht onderhoud, verkeerde locatie of een verkeerd toegepaste RWH methode, zoals aangetoond in Hoofdstuk 4. In geval 2 kon resp. 44\% (nat jaar), 32\% (gewoon jaar) en 16\% (droog jaar) van de subgebieden aan de vraag naar water voldoen. De berekende hoeveelheden oppervlakkige afvoer waren in geval 2 duidelijk hoger dan in geval 1, hetgeen aantoont dat een reeks verbonden reservoirs in het beschouwde gebied efficienter kan werken dan een aantal losse reservoirs. 
Met de opgedane kennis zijn voor geval 2 drie verschillende scenario's doorgerekend om te kijken of de werking van de RWH-systemen kon worden verbeterd en de hoeveelheid beschikbaar water kon worden vergroot. In scenario 1 werden de defecte dammen weer gerepareerd. In scenario 2 zijn andere verbindingen tussen de deelgebieden gelegd voor de stroming van overtollig water en scenario 3 is een combinatie van de andere twee scenario's. Scenario 3 liet een grote verbetering van de werking van het RWH systeem zien: in een nat jaar kon $92 \%$ van de deelgebieden aan de vraag naar water voldoen tegen $44 \%$ zonder aanpassingen. Deze resultaten benadrukken het belang van het simuleren van langjarige waterbalansen op het niveau van deelgebieden om de werking van RWH systemen onder diverse omstandigheden te optimaliseren.

De invloed van klimaatsverandering op bestaande RWH systemen in het Oum Zessar stroomgebied in Tunesie onder huidige en toekomstige klimaatscenario's is onderzocht in Hoofdstuk 7. Mogelijke aanpassings- strategieen voor het optimaliseren van de effectiviteit van RWH zijn onderzocht aan de hand van de voorspelde klimaatsveradering. Neerslag en temperatuur zijn neergeschaald uit resultaten van algemene circulatie modellen door gebruik te maken van een statistisch neerschalingsprogramma. Drie klimaatscenario's, weergegeven als RCP (Representative Concentration Pathway) 2.6, RCP 4.5 en RCP 8.5 zijn geanalyseerd voor drie periodes van elk 30 jaar, n.I. 2011-2040, 20412070 en 2071-2100. De neergeschaalde maximum en minimum temperaturen per dag vertoonden een duidelijke trend in de maandelijkse gemiddelden voor alle scenario's en alle periodes. De gegenereerde neerslag nam af voor alle periodes in de drie scenario's.

Toepassen van WHCatch toonde aan dat de beschikbaarheid van water in elk deelgebied zou afnemen onder toekomstige meteorologische omstandigheden voor de drie scenario's (RCP 2.6, 4.5 en 8.5) en de drie beschouwde periodes, vooral aan het einde van deze eeuw. Ongeveer $72 \%$ van de deelgebieden kon in de basisperiode aan de watervraag voldoen, terwijl slechts $30 \%$ hiertoe in staat was onder toekomstige omstandigheden. Ook hier had het veranderen van stroomrichting in combinatie met het verhogen van de overlaat een grote invloed op de werking van de RWH-systemen. Het percentage deelgebieden dat aan de vraag naar water kon voldoen steeg naar $92 \%$ gedurende de basisperiode en naar $50 \%$ voor de toekomstige omstandigheden. Waterbeheer en struktureel ontwerpen op de deelgebiedschaal speelden een belangrijker rol in de effekten van RWH systemen dan de klimaatsverandering.

In Hoofdstuk 8 wordt een synthese van de voornaamste resultaten van dit onderzoek gegeven, samen met de mogelijke bijdragen voor het verbeteren van de werking van RWH ontwerpen onder huidige en toekomstige klimatologische omstandigheden. Ook worden de gevolgen van deze studie gegeven, evenals de daaruit voortvloeiende aanbevelingen. 


\section{Arabic summary}

حصاد مياه الأمطار (RWH) عبارة عن تقنية تقليدية قديمة كانت وماتز ال تمارس في أجزاء عديده

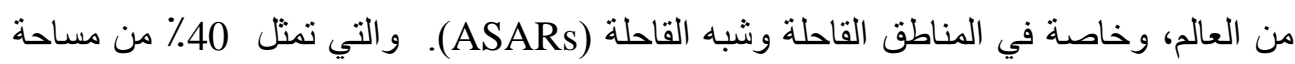

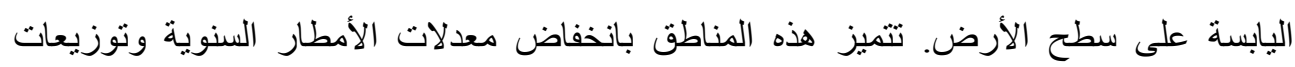
متفاوتة من الأمطار الزمانية والمكانية. واظهرت هذه الخصائص المناخية للمناطق (شبه) القاحلة الهية الحاجة إلى استخدام الكمية المحدودة من الأمطار المتاحة بأكبر قدر من الكفاءة. واحدى الهى

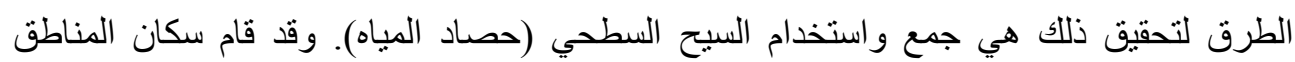

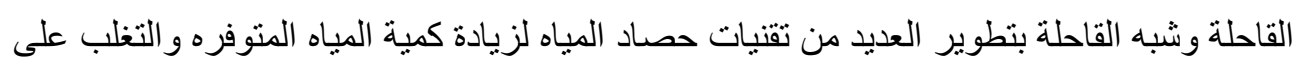

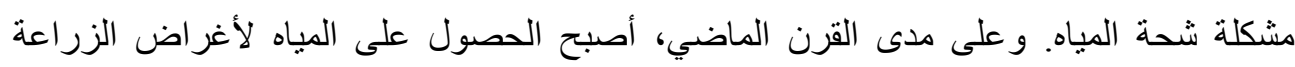
و الاستخدام المنزلي اكثر سوءا بسبب تز ايد عدد السكان، وارتفاع مستوى النشاط البشري، وآثار

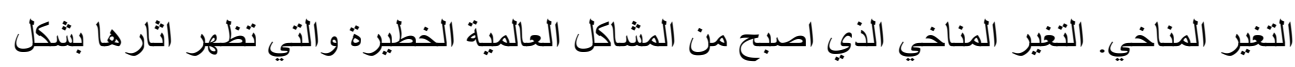

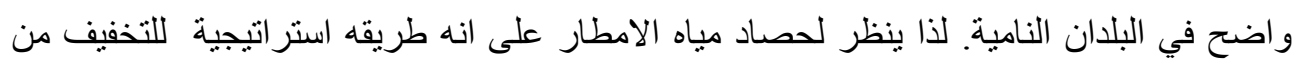

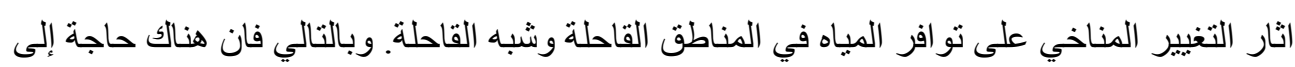
منهجية قوية لتقييم إمكانية تجميع مياه الأمطار وتحديد المناطق المناسبة لهذه التقنيات. كذللك هناك حاجة إلى مزيد من المعرفة حول أثر التغير المناخي على عمل RWH في المستقبل لتقبيم قدرتها على تلبية الاحتياجات المائية المستقبلية. لتكوين نظرة عامة عن تاريخ تقنيات حصاد مياه الأمطار، تم استطلاع البحوث و الدر اسات السابقة

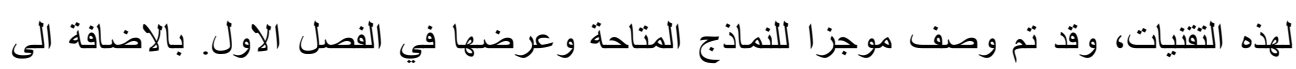

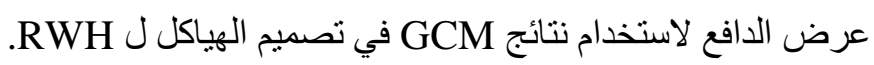

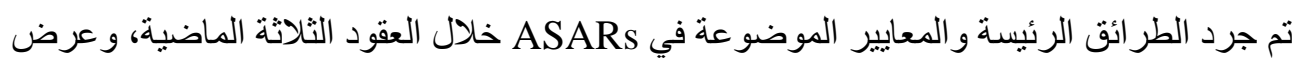
الطريقة العامة لاختيار مواقع مناسبة RWH في ASARs في الفصل الثاني. ونتيجة لذللك كان في النيان

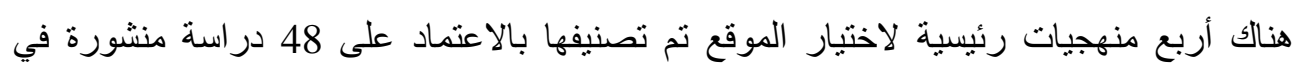

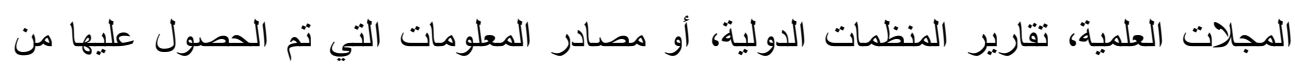
الباحثين. وكان الأسلوب الأكثر ملاءمة للنطبيق في حالة معينة يعتمد إلى حد كبير على الأهداف 
و الاحتياجات الرئيسية لهذا المشروع (مثل المرونة، القابلية للتطبيق على نطاق و اسع وفعال، و الدقة) و على نوعية توافر وموثوقية البيانات. الطرائق كانت منتوعه، بدءا من تلك القائمة على المعايير الفيزيائية الحيوية فقط يليها تحديد نهج أكثر تكاملا والتي تشمل المعايير الاجتماعية والاقتصادية، وخاصة بعد عام 2000. تم تحديد ثلاث مجموعات رئيسية من المعايير لاختيار مواقع RWH، و عرض الخصائص الرئيسية لتقنيات حصاد مياه الأمطار الأكثر شيو عا المستخدمة في ASARs. هذه الدر اسة حددت الميل، واستخدام الأراضي/الغطاء، ونوع التربة، وهطول الأمطار، المسافة إلى المناطق السكنية/مجاري المياه، والكلفة ,هي المعايير الفيزيائية الحيوية والاجتماعية والاقتصادية الأكثر أهمية لاختيار المواقع المناسبة لحصاد مياه الأمطار في المناطق القاحلة وشبه القاحلة. وقد تم تحديد التقنيات الأكثر شيو عا واستخداما في ASARs أيضا: البرك و السدود، المصاطب، وخز انات

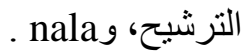

تقترح نتائج التحليل لنقاط القوة والضعف في منهيات التقييم RWH إلى أن دمج التحليل متعدد المعايير (MCA) مع نظام المعلومات الجغرافية (GIS) هو الأسلوب الأكثر تقدما واكثر عقلانية وموضوعية، وهو أسلوب غير متحييز لتحديد المو اقع المناسبة لحصاد مياه الأمطار. يوفر MCA مع نظم المعلومات الجغرافية إمكانيات عالية في المناطق التي تفتقر إلى البيانات. ولكن يوصى بتطبيق نظم المعلومات الجغر افية مع النمذجة الهيدرولوجية دائما في المناطق الغنية بالبيانات. الفصل الثالث بدأ بدراسة إمكانية انشاء مشروع بحث عن احتمالية RWH في العراق. ولأسباب السلامة، حيث ان طريقة تحديد المواقع المناسبة لنظم حصاد المياه كانت مقيده بتلك المعلومات المتوفره عن بيانات نظم المعلومات الجغر افية. مواقع RWH المحتملة في وادي حوران، الذي يقع في الصحر اء الغربية من العراق، تم تحديدها باستخدام نموذج الملاعمة القائم على نظم المعلومات الجغر افية. والنموذج جمع بين مختلف المعايير الفيزيائية الحيوية مثل: الميل، وعمق الجريان السطحي، واستخدام الأراضي، وقوام التربة، و رقم المجرى. وتم تحديد المناطق المناسبة للسدود من خلال إعادة تصنيف هذه الطبقات والجمع بينهما باستخدام حسابات الر استر(Raster) في وحدة التحليل المكاني للنظام .ArcGIS 10.2. حيث تم تحديد كل معيار لمنطقة الدر اسة، اعادة تصنيفها إلى القيم الرقية، وتعبين الترنيب الملائم للسدود. ثم تم تقييم المواقع المختارة من قبل معايير اخرى لتحديد أفضل المو اقع لهياكل حصاد مياه الامطار (السدود). ان الموقع المناسب لإنشاء سد هو المكان الذي يوجد فيه وادي واسع تحيط به أسوار عالية يؤدي إلى و ادي ضيق مع جدران صلبه. مثل هذه المو اقع تعمل على تقليل أبعاد السد والتكاليف، ولكن ينبغي أن تعطى اولولية منخفظة للوديان ذات 
الميل العالي، لان السدود في مثل هذه المو اقع نادر ا ما تكون اقتصادية. ولقد تم تحديد نسع وثلاثين

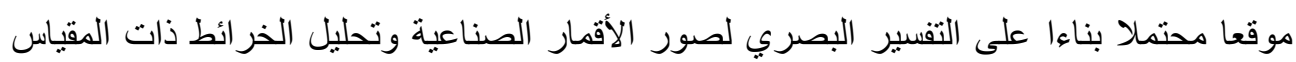
العالي. لكل موقع سد محتمل تم اجراء مزيد من التحليل عن طريق حساب الخصائص مثل منطقة الخداء التخزين المتاحة و الطول المطلوب وارتفاع السد.

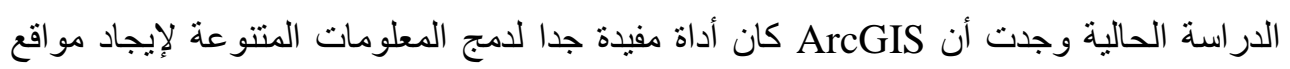
مناسبة للسدود لتجميع مياه الأمطار.حيث ان نظام ArcGIS مرن، يوفر الوقت، وأداة فعالة من حيث التكلفة لفحص مناطق شاسعة لتحديد مدى ملاءمتها لاستخدامها في حصاد مياه الامطار.

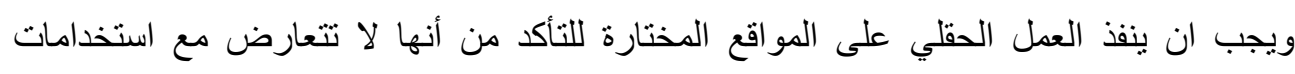

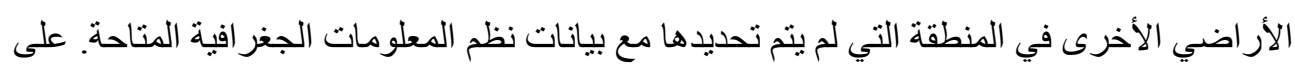
اية حال, ان التحليل على النحو المبين يوفر فحص اولي للمناطق الثاسعة والتي يمكن تعديلها بسهولة كدمج معايير أو غير ها من المعلومات ذات الدقة المكانية المختلفة. لاحقا تم تطوير طريقة تحديد المواقع المناسبة لحصاد مياه الأمطار إلى أداة دعم التقييم والقرار

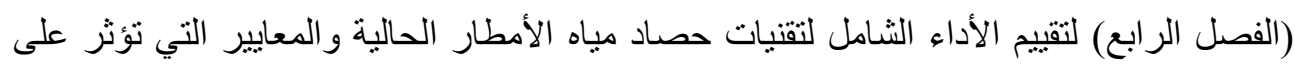
هذا الأداء في المناطق القاحلة وشبه القاحلة. الطريقة المطوره هي طريقه قوية وغير مكلفة وسهلة التطبيق وموثوق بها، كما انها قابلة للتكيف بسهولة لمختلف المجاميع المتنوعة من معايير

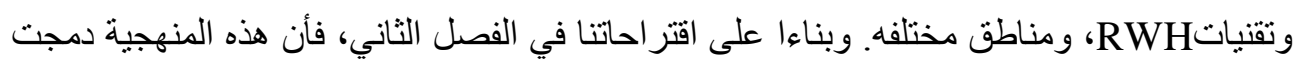

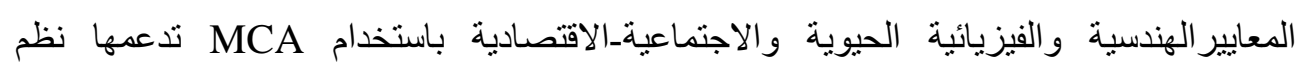

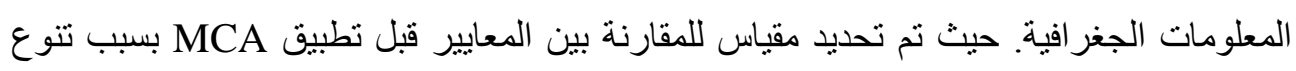

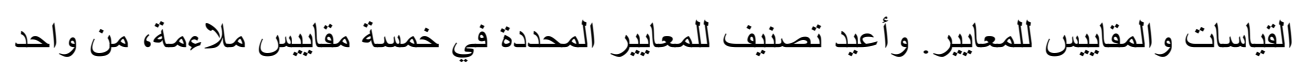

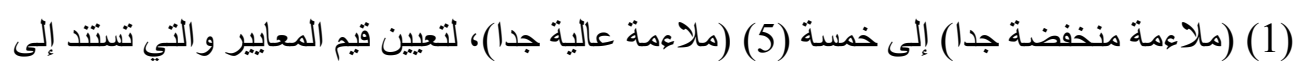
المناقتة و التشاور مع ذوي الخبرة و البيانات في الدر اسات المنشورة.

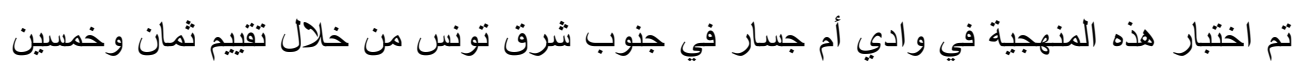

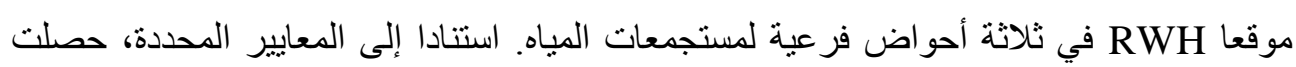

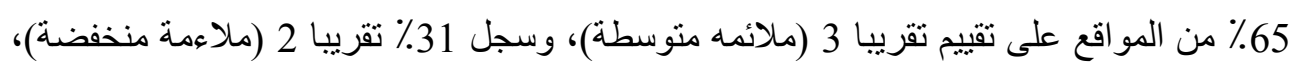

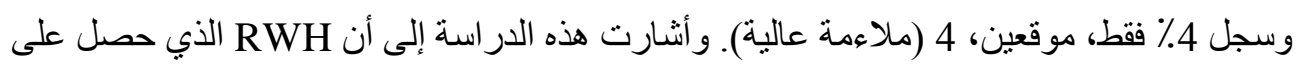

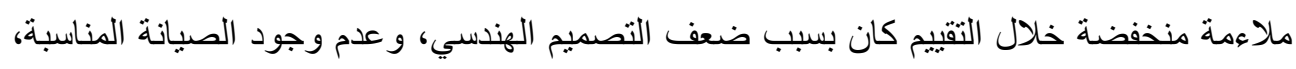

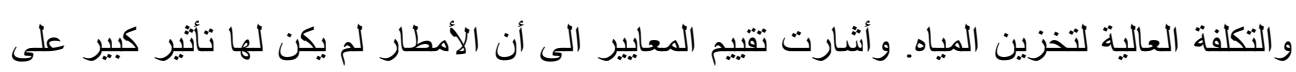


مدى الملائمة الثاملة بين المو اقع في در استتا الحالية ولكن قد تكون مهمة جدا لإجراء مقارنات بين المو اقع في مناطق أوسع مع وجود اختلافات كبيرة في معدلات سقوط الأمطار. وان در استتا وجدت أيضا أن المعايير الاقتصادية والاجتماعية لعبت دور ا مهما في أداء RWH وكانت معيار ا مهما جدا لتحسين فعالية RWH الحالية والتخطيط للهياكل المستقبليه. ومنهجيتنا حددت بوضوح المعايير التي ينبغي معالجتها لتحسين الأداء، على سبيل المثنال، تصميم هيكل حصاد مياه الامطار وسعة التخزين. تمثل هذه النتائج الأداء الحقيقي لكل موقع على حد سواء او على المستوى الكلي وعلى مستوى المعايير الفردية بناءا على المقارنة بين ملاحظاتتا ومناقشتها مع الخبر اء. هذا يؤكد أن المنهجية التي

وضعت في هذا المشروع هي وسيلة جيدة لتقييم أداء الهياكل RWH. لمزيد من التحقيق وتحسين أداء نظام RWH التي تم وصفها في الفصل الرابع تحت سيناريوهات مختلفة من التصميم والإدارة، تم تطوير نموذج حصاد المياه بسيط ولكنه يطبق بشكل عام بناءا على مبدأ التوازن المائي على مستوى مستجمعات المياه والتي يمكن تطبيقها (WHCatch) مع الحد الأدنى من البيانات (الفصل الخامس). تم تطوير WHCatch كما Visual Basic للتطبيقات الماكرو في مصنف Microsoft Excel ويمكن تطبيقها على جميع الحسابات الضروريه و تقديم نتائج النمذجة. اما في الفصل السادس فإن أداء أنظمة RWH في وادي ام جسار تم تقييمها وتحسينها في ظل سيناريوهات مختلفة من التصميم والإدارة. احتسبت التغييرات في تخزين المياه في الاحواض الفرعية ل خمس و عثرين موقع في ثناثة أنواع من السنوات (الجافة، العادية، و الرطبة) من تطبيق الموازنه المائيه في المستجمعات الفرعية. وتم اعتماد حالتين.ففي الحاله الاولى، افترضت عدم وجود علاقة بين تدفق المياه من الأحواض الفرعية. اما في الحالة الثانية، اعتبر وجود تفاعل بين المستجمعات الفرعية. وكانت حوالي 28٪ (سنة رطبه) و 8\% (سنة عادية) من المستجمعات الفرعية في الحالة الاولى قادرة على تلبية الاحتياجات المائية.عدم وجود حصاد لمياه الأمطار (صفر) لمستجمعات المياه الفرعية، ومع ذلك, أشاره الى عجز RWH لتلبية الاحتياجات المائية بسبب عيوب في التصميم الهندسي، والافتقار إلى الصيانة المناسبة، واختيار الموقع، أواختيار نوع RWH المستجمعات الفرعية لديها ما يكفي من المياه لتلبية الاحتياجات المائية في السنوات الرطبة، العادية، و الجافه على التوالي. يظهر بوضوح ان حجم المياه السطحي المحسوب في الحاله الثانية اعلى من 
الحاله الاولى, مشير ا إلى أن سلسلة من الخزانات المنصلة يمكن أن تكون أكثر فعالية من عدة خزانات غير متر ابطة في المنطقة.

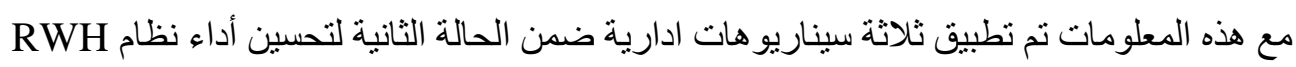
وبالتالي تحسين نوفير المياه وهي كالتالي: في السيناريو الاول نم اعادة تاهيل الهياكل الككسورة ،

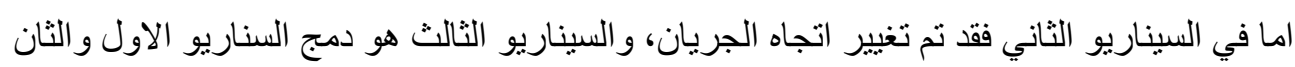
معا ـ فيما يخص نتائج نطبيق السناريو الثالث، فان تغيير ارتفاعات المفيض جنبا إلى جنب مع تغيير

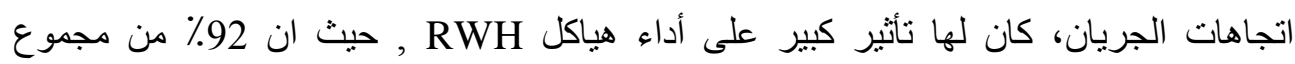
مستجمعات المياه الفرعية زودت ما يكفي من المياه، يقابلها 44٪ من مجموع المستجمعات الفيات الفرعية

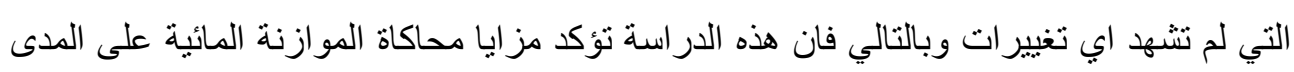

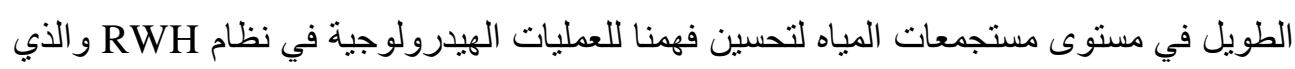
يوفر العديد من الحلول لتحسين الأداء RWH وفق سيناريو هات مختلفة.

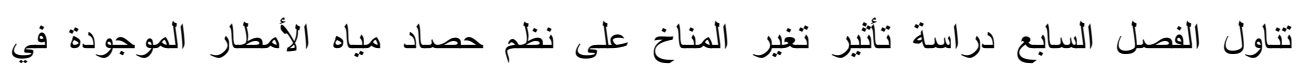
مستجمعات المياه في أم جسار تحت السيناريوهات الحالية والمستقبلية للمناخ. وتم ايضاح استر اتيجيات التكيف الممكنة لتحسين فعالية RWH على أساس التغير المناخي المتوقع. تم تسقيط الامطار ودرجات الحرارة من GCM باستخدام نموذج SDSM لتقدير آثار تغير (downscale) المناخ على RWH على مستوى مستجمعات المياه. وفق ثلاثة سيناريو هات مناخية مختلفة وهي: دُ تحل تم تحليلها لكل ثلاثين عاما، أي 2011-2040، 2041-2070، و 2071-2100. التنبؤ المستقبلي

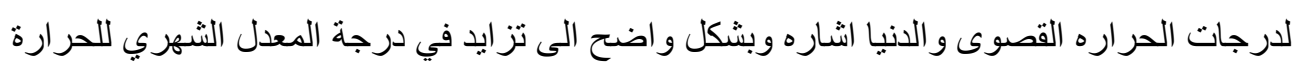

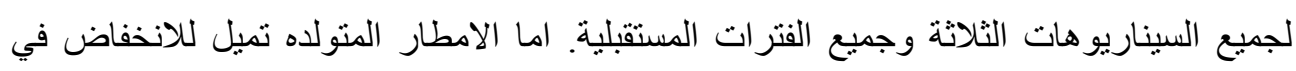
متوسط هطول الأمطار السنوي اليومي للسيناريو هات الثلاثة في كل الفترات. ان تطبيق WHCatch اوضح أن المياه المتوفره في كل مستجمع فرعي من شأنه أن يقل في ظل

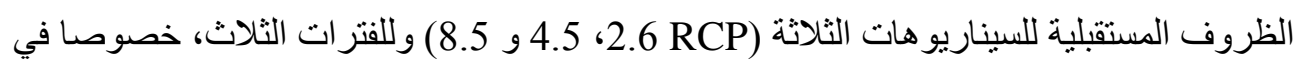
نهاية هذا القرن. وكانت حو الي 72٪ من مجموع المستجمعات الفرعية قادرة على تلبية الاحتياجات المائية في فترة الأساس، في حين أن حوالي 30٪ من جميع RCPs سيكون قادرا على تلبية

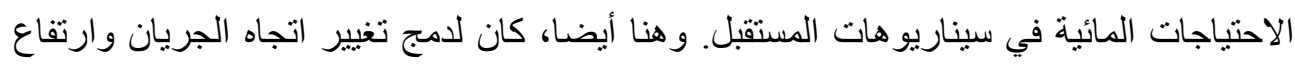
المفيض تأثير كبير على أداء نظم حصاد مياه الأمطار. ارتفعت نسبة المستجمعات الفرعية القادرة 
على تلبية الاحتياجات المائية الأساسية إلى 92٪ وز ادت المستجمعات الفرعية القادرة على تلبية الاحتياجات المائية في سيناريوهات المستقبل إلى 50٪. لذلك لعبت إدارة المياه والتصميم الهيكلي على مستوى المستجمعات الفرعيه دورا أكثر أهمية من تغير المناخ على أداء RWH. ويعرض الفصل 8 توليفة من النتائج الرئيسة لهذه الدراسة والمساهمات التي يمكن تقديمها إلى الجهود العلمية لتحسين أداء التصاميم RWH تحت الظروف المناخية الحالية والمستقبلية. وتعرض أيضـا الآثار و التوصيات لهذه الدر اسة. 


\section{Acknowledgements}

This study has been conducted within the framework of the cooperation between the Higher Committee for Education Development in Iraq (HCED) and Wageningen University (The Netherlands). I am deeply grateful to HCED for providing financial support and logistical assistance. I also want to knowledge the scientific and financial support provided by the Soil Physics and Land Management Group of Wageningen University, The Netherlands.

This PhD thesis is one of the most important achievements in my life. In my long academic journey to achieve it, I experienced enormous challenges, difficulties and obstacles. At the end of this long journey, I would like to express my deepest gratitude and appreciation to all the people who contributed to the success of this thesis. In this text, if by chance I fail to mention their name, it is not deliberate, and they will always deserve my sincere thanks.

First, I am sincerely grateful to my promoter Prof. Coen J. Ritsema for giving me the opportunity to pursue my PhD. From the thesis proposal to the final draft, his comments, constructive discussions, technical guidance and encouragement have been invaluable. Unlike the Dutch cultural practice of adhering to appointments, I did not need to make any appointments to drop into his office anytime I needed help. My deepest gratitude to my daily supervisor, Dr. ir. Michel Riksen, for his guidance and constructive and critical comments on all chapters in this thesis. Michel's office was always open any time I wanted his assistance. My sincere thanks also to my external co-promoter Dr. Mohamed Ouessar, starting with his agreement for doing my field work in Tunisia and the invaluable contribution to the change in my proposal. Oueseer contributed with his comments and suggestions on the thesis, his support and supervision of the field work. I would also like to thank Dr. Jan G. Wesseling for the precious assistance in developing a water harvesting model to be used in this thesis. Jan you encouraged me a lot, and realising this thesis would not have been easy without your contribution. 
The field work was carried out in collaboration with the Institut des Régions Arides (IRA) in Tunisia. A grateful thanks to Dr. Mohamed Mousa for his technical assistance, and special thanks are due to Ammar Zerrim, Abdeladhim Mohamed Arbi, Inas Al-Gasimi, Messaoud Guied and Monji Ben Zaid for their technical assistance and help with the field measurements.

My sincere thanks also to Dr. Usama Karim, University of Twente, for his assistance, encouragement and support. Many thanks also to my colleagues and friends Mustafa, Karrar and Hayder for their support, encouragement and enjoyable moments spent together.

To my colleagues and friends in Iraq, special thanks to Dr. Isam Al-Hadithy and Dr. Ammar Hatem for their comments and suggestions on the thesis proposal. Grateful thanks also go to Dr. Adel Nuheir, Eng. Adnan Dawood, and all my colleagues in the Civil Engineering department, Engineering College at the University of Anbar, for their assistance and encouragement.

Special thanks to the SLM group staff: Sjoerd van der Zee, Jantiene Baartman, Violette Geissen, Luuk Fleskens, Aad Kessler, Saskia Visser, Jos van Dam, Martine van der Ploeg, Klaas Metselaar, Jerry Maroulis, Piet Peters, Hennie Gertsen and Harm Gooren. Also to Klaas Oostindie for helping with some figures and for assembling and formatting the thesis. Many thanks are due to the secretarial section of SLM group, Marnella van der Tol, Annelies Bunte, Anita Kok, Esther van den Brug, Henny van den Berg, Geert Belgers and Siawash Tajdini, who handled administrative and financial issues smoothly throughout my study. Dr. Demie Moore is gratefully acknowledged for her humble and unreserved assistance for editing the language of my articles.

I thank my colleagues and friends at Wageningen University, particularly Nádia, Celia, Akalu, Innocent, Xiaomei, Isaurinda, Vera, Ate, Joep, Mulatie, Berhane, Walle, Alemayehu, Corjan, Samuele, Samuel, Carlos, Govinda, Ricardo, Kaveh, Sija, Renee Salm and many others for their friendship, sharing of ideas, and enjoyable moments spent together. I thank the members of the "Atlas gang" for their friendship within the group.

I would like to express my deepest appreciation to my father and mother for supporting me and helping me get to where I am today. I would not be here without you! I am so proud to be your son. Grateful thanks to my dear sisters and brothers for their endless love and moral support. Their love and encouragement have been fundamental for keeping me strong and successful throughout my life. 
Last, but not least, I express my most profound gratitude to my loving wife for your understanding and encouragement during my study, for carrying the huge responsibility of raising Haneen and Mustafa and for handling the social and economic affairs of our family during my study. Haneen and Mustafa, thank you for your patience and for the funny pictures that you draw and occasionally show me. I hope that I can now stay with you to compensate for what you missed when I was away. 


\section{Acknowledgements of financial support}

The research described in this thesis was financially supported by the Higher Committee for Education Development in Iraq (HCED). 


\section{About the author}

Ammar Adham Ali was born on August 22, 1978 in Anah city, Anbar, Iraq.

Ammar received a bachelor's degree (BSc.) in civil engineering from the University of Anbar (Iraq 2000). After another year of study he received a Higher diploma from the University of Technology (Baghdad, 2001), where he also graduated with a master degree (MSc.) in 2008.

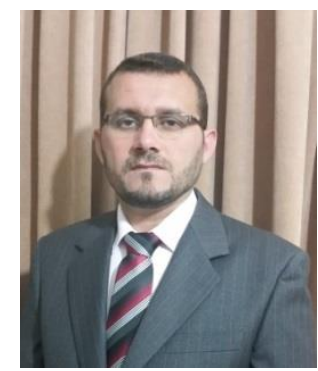

Ammar starting working with the engineering consultant bureau in the University of Anbar (2000-2002), supervising, planning and designing several projects. He then worked with the Mayoralty of Baghdad (2002-2003). After 2003, he returned to the University of Anbar as a lecturer in the civil engineering department of the engineering college on hydrology and water resources engineering.

Ammar was awarded a scholarship from Iraqi government under the Higher Committee for Education Development in Iraq (HCED) for doing his PhD. During his PhD. he developed experience in working with various modelling approaches such as water balance modelling and climate change modelling. This experience was used in developing a new model for investigating and optimising the performance of rainwater harvesting structures.

Ammar has participated in and presented his work at several international events, including the 2015 General Assembly of the European Geosciences Union (EGU) in Vienna, Austria; and Integrated land and water resources management in the dry areas under climate change, Tunisia 2015.

Ammar is married and has two children: an eight year old daughter and a seven year old son.

Email: engammar2000@gmail.com; engammar2000@yahoo.com 


\section{Publications}

\section{Peer reviewed papers}

Adham, A., Wesseling, J. G., Riksen, M.J.P.M., Ouessar, M., and Ritsema, C. J. (2016). A water harvesting model for optimising rainwater harvesting in the wadi Oum Zessar watershed, Tunisia. Agricultural Water Management, 176, 191-202.

Adham, A., Riksen, M.J.P.M., Ouessar, M., and Ritsema, C. J. (2016). A methodology to assess and evaluate rainwater harvesting techniques in (semi-) arid regions. Water, 8(5), 198.

Ammar, A., Riksen, M.J.P.M., Ouessar, M., and Ritsema, C. (2016). Identification of suitable sites for rainwater harvesting structures in arid and semi-arid regions: $A$ review. International Soil and Water Conservation Research, 4(2), 108-120.

Adham, A., Riksen, M., Ouessar, M., Abed, R., and Ritsema, C. (2017). Development of Methodology for Existing Rainwater Harvesting Assessment in (semi-) Arid Regions. In Water and Land Security in Drylands (pp. 171-184). Springer International Publishing.

Adham, A., Wesseling, J. G., Riksen, M.J.P.M., Ouessar, M., Abed R. and Ritsema, C. J. (submitted). Assessing the Impact of Climate Change on Rainwater Harvesting in the Oum Zessar Watershed in southeastern Tunisia. CATENA.

Adham A., Khamis, N., Wesseling, J. G., Riksen, M.J.P.M., Abed, R., Ritsema, C.J., et al. (2017) (submitted); A GIS- based approach for identifying potential sites for harvesting rainwater in the Western Desert of Iraq. Submitted to Journal of Arid Land.

Wesseling, J.G., A. Adham, M.J.P.M. Riksen, C.J. Ritsema and A.H. Heidema (submitted). A Microsoft Excel application to simulate and optimise water harvesting in a catchment. Submitted to Computers and Geosciences.

\section{Poster presentations}

Adham, A., Riksen, M.J.P.M., Ouessar, M., and Ritsema, C.J. (2015). A Methodology to Assess and Evaluate Rainwater Harvesting Techniques in (Semi-)Arid Regions. EGU General Assembly, Vienna, Austria.

Adham, A., Riksen, M.J.P.M., Ouessar, M., and Ritsema, C.J. (2015). Development of methodology for existing rainwater harvesting assessment in (semi)-arid regions. Integrated land and water resources management in the dry areas under climate change; Tunisia.

Adham, A., Riksen, M.J.P.M., Ouessar, M., and Ritsema, C.J. (2015). Identifying Suitable Sites for Implementing of Rainwater Harvesting Structures in (Semi-) Arid Regions: A review. International symposium in the Netherlands.

\section{Proceedings and Master thesis}

Adham A. 2009. Optimization of Water Supply Network by Using Computer. Master thesis, University of Technology.

Adham A. 2001. Analysis and Design Water Distribution Network by Computer. Higher diploma thesis, University of Technology. 
